
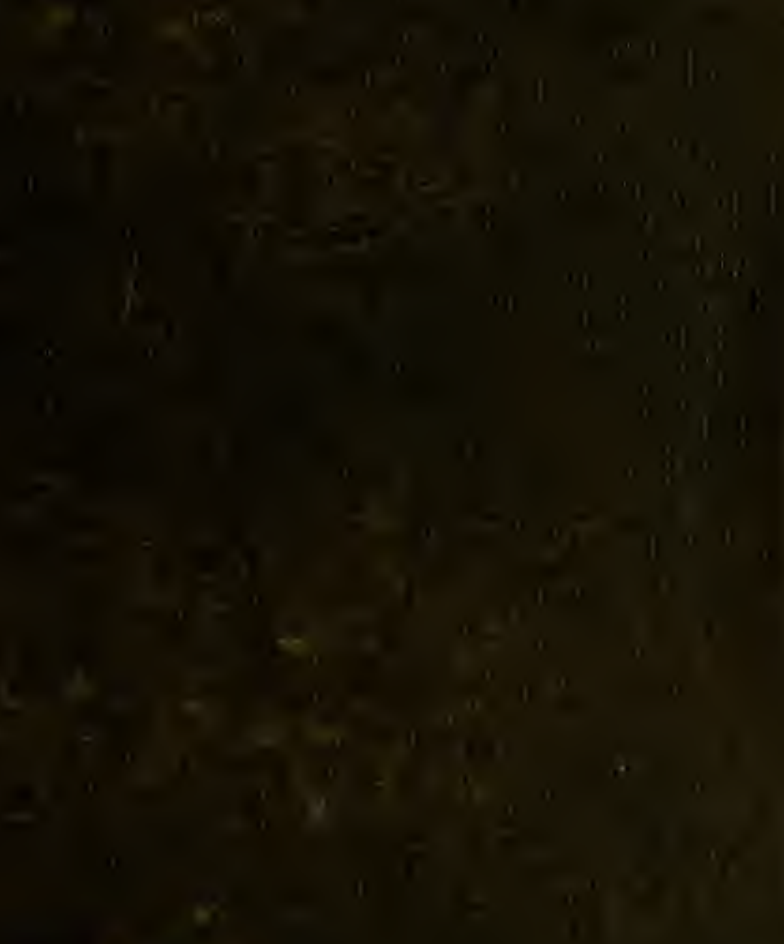


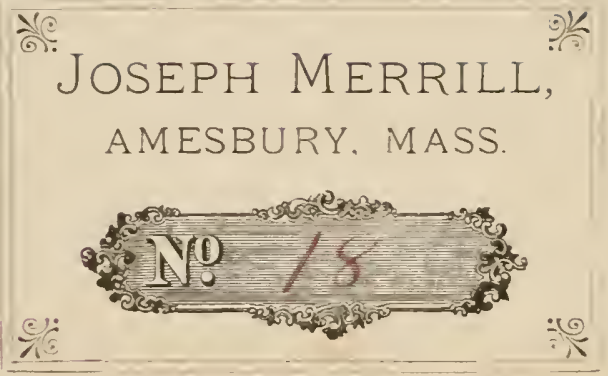




$$
2137
$$


Digitized by the Internet Archive in 2010 with funding from NCSU Libraries 
THE

\title{
PRINCIPLES OF SCIENCE
}

\author{
APRLIED TO
}

\section{THE DOMESTIC AND MECHANIC ARTS,}

\author{
A.T TO
}

\section{MANUFACTURES AND AGRICULTURE :}

$$
\text { TITI }
$$

REFLECTIONS ON THE PROGRESS OF TIIE ARTS, AND TIEIR I.NFLUEX⿻E ON NATIONAL, WELFARE.

\section{BY ALONZO POTTER, D. D.}

PROFESSOR OF MORAL PHLOSOPHT AND RHETORIC IN TNION COLLEGE. SCHENECTADY, NEW YORK.

\section{REYISED EDITION.}

$$
\text { NE T YO R IV: }
$$

IL $A$ PER \& BROTIERS, PUBLISIIERS, FRA YKLIX SQUARE

1860 . 
Entered according to Act of Congress, in the year 1840, by Marsh, Capen, l.yon, and Webb, in the Clerk's Office of the District Court of Massachusetts. 


\section{ADVERTISEMENT.}

Turs volume is submitted to the public with diffdence. The subject is foreign from the usual course of the author's studies, and was at first undertaken for the lecture room, rather than for the press. Large portions of it have been delivered in the form of lectures before young men, in Lyceums, and Mechanies' Institutes, and also before the students of the College with which the anthor is comected.

Some of the Chapters in the Third Part, especially those on Cloth-manufacture, Metallurgy, and Glass-making, are little more than compilations; and the author regrets, that, several years liaving elapsed since they were first drawn up, lie is unable to give proper authority for all his statements, or to refer, in every case, to the source from which he drew his materials, and, he doubts not, in some instances, his language. He would, however, instance Dr. Bigelow's 'Elenents of 'Technology,' Babbage on the 'Economy,' and Ure on the 'Philosophy, of Manufuctures,' Ure's 'Dictionary of the Arts,' and McCullocl's 'Statistics of the British Empire,' as works to which he has been greatly indebted, especially in a recent revision. 'The work will be found to contain some notice of most of the late improvements in such Arts as are cliscussed. 
It is hoped that this volume may prove to be a conrenient Manual for those who are engaged in industrious pursuits, and also for students, and for popular reading. To grive a complete view of Technology, was far from the author's intention, and has been rendered unnecessary by the able works of Drs. Ure and Bigelow. He aspires to no higher office than that of introducing the student to a subject of vast extent, and inciting him to pursue it. So far as it presents a formal and somewhat extended riew of the connexion between Science and Art, this treatise may claim to fill a place not yet occupied in our literature. The author is but too sensible, lowerer, that it will be found defective; and should it contribute, in any degree, to prepare the way for a more copious and accurate work, he will see it superseded without regret.

Residing at a distance from the publishers, the author has found it impossible to revise the shee's, as they passed through the press. For this important service, he has been indebted to the kindness of a friend, Dr. E. HaLe, of Boston, who has been untiring in nis attention to it, and who, besides several amendments, has added to the work about twenty pages of original mititer. To him the reader is indebted for the description of printing and the account of Dixon's transferring process, in the body of the Work, and for the article in the Appendix, describing Galvinic Engraving.

The Author would also express his acknowledgements to Mr. J. W. INgraman, the able and indefatigable Supervisor of the works incorporated into 'The Scunol Library, for the care and accuracy with which he has superintended the execution of the work, especially in the selection and arrangement of the engravings, and for the useful information embodied in the glossary.

Union College, ?

October, 1848. 


\section{CON'TEN'L'}

Preface,

\section{PART I. \\ CHAPTER I.}

Introduction,

CHAPTER II.

The Arts dependent on Science, . . . . . . . 21

CHAPTER III.

Other advantages which the instructed has orer the uninformed Artisan, . . . . . . . . . . 26

Sumiary of Prifciples ix Part I., . . . . . 36

\section{PART II.}

AGEATS EMPLOYED IN THE ARTS. PAGE 39.

CHAPTER I.

Chemical Agents,

\section{CHAPTER II.}

Nechanical Agents employed in the Arts, . . . 47

Inertia of Bodies, . . . . . . . . . . . . 48

Centrifugal Force, $\quad$. . . . . 50

Compound Motion, . . . 51

Centre of Gravity, . . . . . . . . . 52

CHAPTER III.

Mechanical Agents.-Animate Forces, . . . . 54 Inanimate Forces, -Gravity, . . . . . . . . 56 


\section{CHAPTER IV.}

Mechanical Agents.-Inanimate Forces,-Gravity, . 60 CHAPTER V.

Mechanical Agents.-Inanimatc Forces,-Gravity, . 68 Elasticity, . . . . . . 71

CHAPTER VI.

Mechanical Agents. - Inanimate Forces, - Heat, Steam,

CHAPTER VII.

Machinery employed in the Arts, . . . . . 87 Sumary of Principles in Part II., . . . . . 103

\section{PART III.}

Rationale OF THE ARTS. PAGE 107.

CHAPTER I.

Agriculture, Chemical, . . . . . . . . 108

CHAPTER II.

Chemical Agriculture, . . . . . . . . . 115 Mechanical Agriculture, . . . . . . . . . 118

CHAPTER III.

Architecture,

CHAPTER IV.

Architecture continued, . . . . . . . . . . 128

CHAPTER V.

Manufacture of Cloth, Paper, Sc., . . . . . 137

CHAPTER VI.

Co:ton Manufacture, . . . . . . . . . . . 145

CHAPTER VII.

Cloth Manufacture.-Paper-making, \&c. . . . . 152

Chemical processes employed,-Bleaching, . . . 159

Scouring, and Cleansing, and Dyeing, . . . . 101

Calico-printing, . . . . . . . . . . 164 
CHAPTER VIII.

The Domestic Arts, . . . . . . . . 170

Fermentation, . . . . . . . . . . . 172

Distillation, . . . . . . . . . . . 177

Culinary Processes, . . . . . . . . . . . 179

Management of Milk, . . . . . . . . 181

Preserving of Food, . . . . . . . . . . 185

CHAPTER IX.

Arts of working Metals, Mining, \&c., . . . . . 189

CHAPTER $X$.

The Manufacture of Glass, . . . . . . . 199

CHAPTER XI.

Pottery and Porcelain, . . . . . . . . 207

CHAPTER XII.

Copying, including Casting, Printing, Engraving, \&c. 213 Dixon's Transfer Process, . . . . . . . . 228

\section{CHAPTER XIII.}

Locomotion,

CHAPTER XIV.

The Progress of the Arts, . . . . . . . . $\$ 46$

CHAPTER XV.

Influence of the Useful Arts on National Welfare, 260

\section{APPENDIX.}

I.

Nature and Objects of Technology, . . . . . 293

II.

Classification of the Arts, . . . . . . . . . 294

Mechanical Arts, . . . . . . . . . . 295

Chemical Manufactures, . . . . . . . . 301 


\section{III.}

Connexion of the Useful and Fine Arts,

303

IV.

The Importance of Science to the Mechanic,

306

$\checkmark$.

Progress of English and American Agriculture, . . 395 VI.

Improvement in Food, Clothing, and Lodging, . . 343 England, in the Reign of Elizabeth, . . . . . . 314 " in the reign of George II., . . . . . . . 349 Scotland, . . . . . . . . . . . . 351 United States, . . . . . . . . . . . 357

Notices of the mode of Living in England previous to

Elizabeth, . . . . . . . . . . 358 In reign of Henry VII., . . . . . . . . . 359 " " Edward III., . . . . . . . . . 360

VII.

Manufacture of Amcrican Iron, . . . . . . 376

VIII.

Engraving by Galvanic Electricity, . . . . . 382 IX.

Ancient Rate of Travclling, 391

$\mathrm{X}$.

Influence of Improvements on Human Welfare, . . 393 XI.

Ancient and Modern Philosophy compared, 395

XII.

Technological Instruction, 397

Note on the Cotton Manufacture, . . . . . 401 Glossary, . . . . . . . . . . 403 INDEX, . . . . . . . . . . 423 
THE PRINCIPLES

or

\section{SCIENCE APPLIED TO 'THE ARTS.}

\section{PART 1.}

\section{CHAPTER I.}

I NTRODUCTION

Man, considered with reference merely to his physıcal powers, seems, in many respects, inferior to other animals. With less strength and hardihood than some of them, he has, at the same time, less fleetness and agility than others. He is but imperfectly provided with weapons for his defence; he has no adequate means for procuring the subsistence required by his fastidions taste and delicate constitution ; and, though tenderly alive to the vicissitudes of climate, and dwelling in all latitudes, he has not been supplied with that warm covering, of fur or wool, which has been bestowed by Nature on every other warm-blooded animal. Left, therefore, to his bodily powers, man would be, of all animals, one of the most defenceless and wretched.

The story of Robinson Crusoe shows, in a striking manner, with what difficulty he maintains even life, when deprired of some of lis customary tools and weapons, and left without the assistance of his fellows. Had Crusoe been cast upon the island, naked, and without the stores and ammunition which lie procured trom the wreck, he would hardly have been able to live 
a month.* The same fact is still more strikingly illustrated, by the recent adventures of Ross Cox, who, while travelling with a company of traders, in the Northwest Territory, was one day, when he had fallen asleep, accidentally left by his companions, and not found again, till several days after. It happened, that, owing to the extreme heat of the weather, he had dirested himself of his weapons, and of nearly all his clothing, which were carried off by the party. He was left, therefore, like other animals, to his natural resources; and the picture which he gires, of the extremities to which he was quickly reduced, by hunger, by the torturing stings of insects, the terror of wild beasts, and the impossibility of tracing his companions, is equally affecting and instructive. It is quite evident, that, if he had not been most opportunely found, he must soon have perished.

Yet, in spite of these disadrantages, man has become, by means of his intelligence, and by coöperating with his fellows, the lord of the creation. Surrounded with natural powers, which can be pressed into his serrice, he has been enabled, by his reason to observe and comprehend, and by his hand to apply, these powers, until, from the weakest and most helpless of ani-

* Our readers are aware, that this delightful and instructive romance of Defoe was fomded on the adventures of Alexander Selkirk, a sililor, who, being at rariance with his captain, requested to be left on an nuinhabited island. He carried with him, besides his clothes, a musket, an iron pot, a can, a hatchet, a knife, mathematical instruments, and a Bible. His means of support and self-defence, therefore, were, to a great extent, artificial. It may possibly be objected, that our examples of man's natural imbecility are iaken from individuals who had once lived in civilized society, and had thus been rendered effeminate; and that we ought rather to adduce the case of those who have lived, like animals, only in a state of Nature. One or two such individuals have been discovered, within the last century, living alone, in forests ; as, for example, Peter, the IVild Boy, in Germany, and the sarage of Avignon, in France. They were fonnd, however, in the lowest plysical and intellectual condition, subsisting on the bark of trees, minable to distinguish, by touch, between a carved and painted surface, and having hardly a trace of humanity. Such cases afford the most conclusive proof, that, as men, we owe most of our power and dignity to culture. 
mals, he has become the most powerful and dreaded. Not only animals, with their fleetness and strength, but even winds, and waves, and heat, and gravity, have been trained to obey him; and, operating by means of machinery, they now fabricate for him, almost without intervention on his part, the choicest food and raiment; transport him, with the celerity of the deer or the antelope, from place to place; and surround him with all the comforts and conveniences of life.*

To designate, generally, the means, by which such results have been attained, we employ the term art. In the carlier periods of society, the useful arts $\dagger$ are cultivated chiefly from necessity, and without regular principles. The processes are rude, and are extended little further than imperious necessity requires. But at later periods, when men have leisure to trace the propcrties of matter and the relations of cause and effect ; when their wants multiply and become more refined, and when time has elapsed, sufficient to furnish them with important and well-established principles, these processes become more rigorous and scientific. Instead of being random experiments, made without forethought, and on no definite grounds, they become judicious and systematic arrangements, whicli aim at embodying, in

* The power of man over the nature and amount of regetable and animal proluctions is scarcely less wonderful. "He has clanged the crab into the apple; the harsh and astringent sloe into the delicious plum; the coarse and bitter seaside brassica into the caluliflower; and has improved and augmented the corn-tribes, to an incredible extent." These are but examples. In the animal world, it is the same. All domestic animals, whether used for food, service, or pleasure, "have sprung from a few wild and unaltractive snecies, and have been made what they are, in a great degree, by the intervention of man. Moreover, the most useful of these virieties of animals have been transported by man into every region of the globe to which he lias himself been able to penetrate."-Proul's Brilgewater Treatise.

† The arts are divided into $u s e f u l$ and fine arts. The former are so called, because their nain object is utility; whereas the principal object of the latter is to gratify imagination and taste. Some arts, however, are of a mixel nature, being both useful and ornamental. To practise the fine arts, in perfection, requires genius. Excellence in the useful arts is more the result of imitation. 
a machine or a method, some wellknown law. Thus it appears, that, though the useful arts may precede science, at first, they will subsequently follow and be guided by its light. In whatever proportion the discoreries of philosophers multiply and become practical, in just the same proportion will these arts be perfected, and the phrsical resources and enjorments of mankind be increased. Hence the importance of that connexion which subsists between the PHrSICAL SCIENCES and the USEFEL ARTs, to illustrate which, will be the principal object of the following pages.

Few subjects are entitled to more attention, both from the student and the practical man. Thile science has been too prone to abstract researches, too much inclined to keep aloof from the haunts of business and industry, the arts, on the other hand, have been too well content with rules, adopted empirically, and followed blindly and without reflection. The pursuits of the scholar and the artisan, which have really the same object in riew, and which ought to have been prosecuted in unison, have not only been liept apart, but have been the subjects of mutual suspicion and ridicule. The philosoplier has loolied down upon the labors of the artisan as sordid and degrading. The artisan, in his turn, has ridiculed the speculations of the philosopher as visionary and unprofitable. 'The result of this two-fold misconception has been pernicious in the extreme.

In the first place, it has tended to render the labors of science barren and useless; causing them, at one time, to be wasted on frirolous subjects, and, at another, to reject or underralue the aid of practical and mechanical skill. It has yet more frequently, perlıaps, impaired the success of the practical man, persuading him to persist in emploring expensive, circuitous, and ineffectual, methods, for attaining that, to which science would have conducted him by a short and easy path. One of our objects, in the present Work, will be, to expose the consequences of this misconception, and to show. at the same time, that the study and the work- 
shop ought to stand side by side, and carry forward their labors in conjunction; the one being employed in investigating principles, the other, in applying them; that science has performed but half her work, unless she has deduced from lacr discoieries some useful art or invention; and that art has never mastered even its own processes, until it has become master of the reasons as well as of the details.

Nor is it the man of science, or the practical man, alone, for whom this subject ought to have interest. It has claims upon all persons engaged in liberal studics, and especially upon those, who, in this age of enterprise and invention, are in a course of elementary education. Our houses are filled, and our persons covered, with the most curious and useful productions of the arts. Ought we to remain ignorant of the processes by which they are fabricated? Above all, ought we to be ignorant of the physical laus on which their fabrication depends? In such processes, man is but the humble agent. The mighty power, which works out the result, resides in nature, where it has been planted, and is continually sustained, by the Divine hand. There it operates, with silent but ceaseless activity, and, while moulded, in some slight degree, to our purposes, and employed in supplying our wants, is carrying on, orer wider scenes, its mighty operations; imparting its influense to the whole body of the earth, and air, and sea ; extending its sway, perhaps, over other planets and systems, and contributing to sustain and carry forward the order of the whole material world. That power, for instance, which keeps our planet in its course, and moves forward atl the parts of the solar system in one unceasing and harmonious round, is the very same power which gives mechanical value to a waterfill, causes the plumb-line to take a vertical direction, first raises the vapor which forms the clouds, and then brings it back, in gentle dews and fertilizing showers, to glaclden the thirsty soil! And this is but one of a thousand instances. How interesting. then, to trace these 
principles, as they thus operate, at the same moment, through the rast mechanism of Nature and in the minute contrivances of man; to see that, while they assist in wheeling planets and suns through their mighty and " unshaken rounds," they are, at the same moment, performing for men the humblest offices of service! fit emblems of that Being, for whom nothing is too vast, nothing too minute! of that Jesus, who, while charged with a world's deliverance from sin and death, could still condescend to manufacture wine for the marriagefeast of the poor, and to wash the feet of his lowly disciples!

Independent, however, of the interest which this subject must possess, for every liberal and inquiring mind, it has claims of a more urgent nature. It is a fact, generally overlooked, but none the less true, that hardly any branch of seience can be studied, nor any profession prosecuted with advantage, without some acquaintance with the theory, economy, and history, of the Useful Arts. Take the Mathematical and Physical Sciences, for example. As generally studied by the young, they present to the mind little else than abstractions; principles, which seem too vague and too farfetched, to be brought down to the "business and bosoms of men." Hence, the lassitude with which they are pursued, and the sad facility with which they are forgotten. How different would it be, if the pupil were early accustomed to trace these principles to their practical applications; if, from the school or lecture-room, he were conducted to the shop or the manufactory, and were there to see these principles toiling in man's service, and becoming most efficient contributors to his welfare! This course is actually adopted, in many of the schools of Germany and France; and the consequence is seen in the quickened interest. the increased precision, and stronger grasp, of the pupil's mind. He sees, hears, feels, that these Laws of Nature are no barren generalities, but are most powerful and useful agents; that art succeeds only so far as she observes 
and respects these Laws; and that the highest and most benignant triumphs of human industry are equally the triumphs of Nature, and of that science, whose province it is to interpret Nature. .

Does the student weary, then, orer the theorems of his Euclid, or the formulie of lis Algebra? Let lim be taught how these very theorems and formula are employed by the engineer, in his nice adjustments and calculations; by the mariner, as lic shapes his unerring course across the trackless sea; by the astronomer, as lie passes the limits of this little carth, seems to set his foot on the most disiant planet, and takes measure of its size, its density, and the span of its orbit. A single property of similar triangles, which, to the mere student of the Elements, looks like matter only for trivial curiosity, is found, by the student of the arts, to be the seminal and prolific principle, out of which has grown the whole theory of trigonometrical measurement, whether applied to common surreying, to the measurement of an are of the meridian, or to detcrmining those rast distances which separate us from the remotest and nost erratic members of the solar system. It is the same with Chemistry and Mechanical Philosophy. 'Teach them in their uses, as well as in their theory. and they will no longer seem but a tissue of hard names and dreary abstractions. They will be seen to sherl their concentrated light orer the humblest processes of the artisan, and to open before him prospects of improvement, as interminable in extent, as they are animating in their influence.

Nor is it only to the student of physical and mathematical science, that the study of the useful arts offers this advantage. If, from the study of Nature you turn your attention to the constitution of society, to the laws which regulate its progress and welfare, you will find, even there, that acquaintance with the economy and history of the useful arts is beneficial, both in guarding the mind from error, and in revealing the true principles which have governed the past, and must inevi- 
tably control the future. Is it, for instance, Political Economy that you would master, - the causes which regulate the production, distribution, and consumption, of wealth? Would.you ever bear in mind, too, that the ultimate end of a sound and benevolent econoiny is not so much wealth, as welfare; not so much the nccumulation of material products, as the multiplication of all those means and appliances which tend to raise man in the scale, as well of moral and intellectual, as of physical, being; that wealth is not an end, but only one of the means, of national, as it is of individual, improrement; and that the industrious elasses, being the most numerous, in a State, and therefore the most important, their advancement is to be the great object of the statesman's policy? Yes! Would you write deep upon your minds and hearts these great but neglected principles? Go to the forge and the workshop. Study, in their economy and theory, and adso in their history, those arts which are the real agents in producing and distributing wealth. See where other nations have erred in fostering them, leaving men to decay, if the arts could but flourish; taxing labor, instead of capital,- - the necessaries, instead of the luxuries, of life ; and degrading the human soul, with all its intelligence and immortality, into a mere appendage to machinery. Learn how the artisan is to be proteeted against the evils incident to inventions and improvement, while, at the same time, you teach him that his permanent welfare is promoted by these rery inventions; that his interests are bound up with those of the wealthiest capitalist; and that he needs nothing but intelligence and virtue, to enable him, in this land of freedom, to reap his rightful share of profit and adrancement.

Our limits do not permit us to enumerate all the respects in which a study of the useful arts is calculated to shed light orer other departments of human inquiry. History needs its aid. in tracing the progress of man, from barbarism to civilization; from the darkness of ignorance or tradition. and the ronrseness of unbri- 
dled sensuality, to the benign light of literature and the conseious dignity and refinement of moral freedom. Poetry needs its aid, in supplying illustrations to arrest the ever-rarying taste of a busy and excited age; and even theology, though conversant only with high and holy things, need not disdain to borrow lessons from this lumble and unpretending source. It becomesnot him, who is given to sacred studies or devout contemplation, to turn away from the useful arts, as though they were silent in the service of God, or "yielded but faint praisc." They tell of man's organization, which has fitted him so armirably for the fabrication of instruments and the labors of industry. They tell of that gift, which attests the agency of Infinite wisdom and power-exhaustless ingenuity, - an ingenuity which is erer multiplying expedients to vanquish time and space, to subduc refractory substances, and to transform into uscful and pliable agents the wildest and most stormy elements of nature. They suggest a comparison,how greatly to the honor of the Creator!-between the mimic processes of human art, and those boundless morements which are ever going forward, silently but harmoniously, through the regions of space.

Nor let it be thought that it is the student, alone, who would profit by an acquaintance with this branch of knowledge. To say nothing, in this place, of the mechanic and artisan, where is there a profession, the members of which could not profit by studying the application of science to the arts? The merchant, for cxample, would evidently be aided, when he traffics in the products of these arts, by understanding the principles which regulate the manufacture of them, the changes and improvement which are making in that manufacture, and the causes which are likely, from time to time, to vary the supply or demand. The lawyer is often called to defend or impugn the validity of patents, to litigate contracts made between mechanics and their employers, or to try causes involving the operations of a machine or the management of a factory. Can he 
hope to do justice to his clients or to his own character, unless he can seize with readiness upon the principles and language appropriate to the case, and employ them with judgement and skill? The same thing is yet more strikingly true, in many other pursuits; and I hazard little, in saying, that there is, in the present age, scarcely an employment, to which a man can derote his talents or his capital, that does not call for some acquaintance with the theory, as well as with the practice, of the useful arts.

Entertaining these riews of the importance of our subject, we shall endearor to discuss it, in a manner which will interest all classes of readers. It will be our main object, in the following pages, to exhibit the arts as dependent on principles, as being, in fact, the practical REstLTs of the discoreries which have been made in the various departments of physical science. It is said of Lord Bacon, that, having collected a great number of books on Gardening and Rural affairs, and found them destitute of the information he sought, he caused them all to be piled up in his court-yard, and set on fire; uttering, at the same time, these memorable words: "In all these books, I find no principles; they can therefore be of no use to any man." To shield this humble work from condemnation, on such grounds, has been the Author's special aim; and he has also endearored, by bringing into prominent view the laws, on which processes in the arts depend, to establish the claim of these arts to be ranked among the subjects of liberal and academical study. At the same time, it has been his desire to treat the subject in a manner calculated to interest persons engaged in the various mechanical and chemical arts, and in agricultural pursuits. The time has arrived, when knouledge will more surely command success, than at any former period of the world; and when, without knowledge, no practical man can be secure of permanent success. The Author will have more than attained his object, if, on the one hand, he can succeed in impressing, upon any considerable 
number of minds, the great importance of taking practical views of science; and on the other, if he can impart, to persons engaged in the arts, any useful hints, respecting the principles and processes with which they are called to deal.

This Treatise is divided into three parts.

'The first part is deroted to illustrating, by argument and historical faets, the Dependence of the Arts on Science.

The second part treats of the Principal Agents, Mechanical and Chemical, which are employed in the Arts; and also of the Elements of Machinery.

The third part exhibits, briefly, and in connexion witl their rationale, the principal operations in Agriculture, Architecture, Cloth Manufacture, The Domestic Arts, Metallurgy, \&c. \&c.

It may not be improper, in closing this Chapter, to remark, that, in giving to the arts, under consideration, the customary name of useful arts, we would by no means intimate, that they alone are useful, or that they are preeminently so. Such arts, after all, belong to the world without us. It is their province to apply: the laws of matter, which have been discorered by science, so as to change, for some useful purpose, the form, position, or internal structure of masses of matter. Creations though they are, of mind, and proud monuments of its exhaustless ingenuity, their immediate and most palpable use is only to increase the outward or physical comforts and accommodations of mankind. But there are arts, sometimes called the Liberal Arts,- - the direct object of which is, to more and elevate mind-which, for example, would enlighten reason, gratify taste, fill the imagination with visions of ideal beauty or greatness, and incite the will to high and holy resolve. Of this class are, Education, which proposes to develope and discipline, in due proportion, the various powers and susceptibilities of the soul ; Eloquence, which, employing language as its instrument, would act on the con- 
duct and sentiments of men, through the medium of their reason, taste, feelings, and fancy; Government, which aims to give such direction to the energies of men, living together as political societies, as will fulfil the demands of justice, and best promote the "greatest happiness of the greatest number ;" and finally, poetry, painting. music, and the like-fine arts, as they are called,-which would move, to their lowest depths, the fountains of thought and feeling that are lodged within us. These, it is crident, are suprenely useful, since they touch our highest and most enduring interests, and speak, at the same time, to our most generous sensibilities.

It is a fact, worthy of much more consideration than it has yet received, that each of these arts, too, is founded on science; that, as the physical arts can be carried to their utmost perfection, only by those who are well versed in the laws that govern the material world, so the liberal arts can be successfully cultirated and illustrated, only by those who have profoundly studied man; who have gazed, with enlightened and admiring ere, on that masterpiece of Divine wisdom, - the human soul, with its capabilities, its untiring energies, its restless longings after the beautiful and good, its Protean rersatility of thought, feeling, and action. As the (so-called) useful arts are but the practical application, to physical purposes, of mechanics and chemistry, so the liberal arts are but the carrying out, to definite moral results, of a higher philosophy,-- the philosophy of human nature: and he alone is qualified to practise, -nay, he alone is qualified thoroughly to appreciate and enjoy them, who, to practical skill, has added an intimate knowledge of the workings of the human heart, both in individuals and in societies. Tre may talie occasion, hereafter, to enlarge upon this truth, and enforce it by suitable illustrations. We notice it, at present, merely that we may guard against the supposition, that the arts, now under consideration, because called useful, are so, alone; and that the liberal and finc arts are only fitterl to amuse, or, at the best, to embellish and refine. 


\section{CHAPTER II.}

TIIE ARTS DEPENDENT ON SCIENCE.

IT is the maxim of a prudent man, always to keep the law on his side. While lie does so, it aids him in his labors, and protects him in the enjoyment of his blessings. Now, what is true of human laws, is yet more eminently true of those natural laws which the. Creator has impressed on material substances. 'These laws are absolute and immutable. They cannot bend to suit the convenience or exigencies of men; nor can they be violated, without inflicting on the transgressor certain injury. And operating, as they do, on every side of us, and serving to determine the properties of every object and the results of every movement, they cannot even be neglected with impunity. Under their direction, the mechanism of Nature moves forward, with uniform and irresistible energy. 'They resemble a mighty engine, which, if rightly managed,-that is, according to its nature and properties,_may be made to work out the most wonderful and important results; but which, if mismanaged, will inflict on him who attempts to guide it, only injury and loss.

But these laws, the proper application of which to human uses is so important and yet so delicate, can be ascertained only through Science. Science explores the hidden mechanism of Nature, and discovers by what laws it is regulated. It traces ont the order which the Deity has established in His works, and shows how this order may be made subservient to the purposes of man. Art avails itself of this knowledge, arranges its materials according to these natural laws, and endeavors to effect, on a small scale, what the Creator is constantly effecting throughout His material empire. To attempt an arrangement, without such linowledge, would be like attempting to superintend the movements of a stcam- 
engine, while ignorant of its nature and powers. What should we expect, if the engineering of our steam-boats were committed to men who had never examined nor studied their machinery? Should we not feel that the lives of the passengers were in peril? Should we not fear that serious if not fatal derangements would ineritably take place, and that such derangements would hardly, if ever, be repaired? What better can we expect of those, who, in any of the arts, attempt to employ powers or properties of which they are ignorant? What shall prevent them from attempting things, which, in their very nature, are impossible? or from employing means inadequate or actually opposed to the end they have in view? or from adopting tedious, expensive, and laborious, methods of accomplishing their purposes, instead of those which are short, economical, and easy? or, finally, from leaving unattempted, what, with proper Fnowled ge, they might not only have attempted, but have accomplished, without dịficulty?

"Knowledge is power." Instruct the artisan in the powers and principles of Nature, and he can always employ them in the cheapest and most effectual manner. But ignorance has no security from error. If right, it is right only by accident, or by following some arbitrary rule; and, since accident is subject to no rule, and arbitrary rules must often fail, through some defect in themselves or their application, it follows, that failures must often occur, unnecessarily. Ignorance, thercfore, is weakness. If the weakness be not observed by others, or felt by the artisan himself, it is only because he and his employers are alike uninstructed. It must be apparent to every mind, that, if the physician were unacquainted with the structure and functions of the body, if lie knew little of the nature of diseases or of the properties of medieinal substances, his art would become the art of killing, wather than of curing. But there is surely little more quackery, in attempting to treat an animal system, of the nature of which we are igno- 
rant, than there is in undertaking to manage inanimate agents, respecting which we are equally ignorant. It can saror but little more of presumption, for a man, whe is unacquainted with anatomy, to undertake the treatment of complicated fractures or dangerous wounds, than it does for lim, who understands neither the laws of motion nor the principles of machinery, to offer to construct or repair a complicated engine or instrument. In some cases, both may succeed; and, since the structure of most machines is less intricate than that of a limb, it is not to be doubted, that the uninstructed artisan will succeed more frequently than the minstructed surgeon. But instances will often occur, in which both nust fail. The limited knowledge acquired from experience will not reach the case, and the operator is left to the mortifying alternative, of trying randon experiments or of declining to act.

It will not be inferred, we trust, from these remarks, that we undervalue the aid which may be derived, by practical men, from experience. We know, that, by means of it, they acquire a slill which no books can communieate, and without which the most extensive theoretical knowledge would be of little avail. Nor is it my purpose to institute a comparison between the relative values of science and experience, in eases where only one can be attained. In the present age, and in our country, both can be liarl. While the apprentice is receiving the practical directions of his master; while he is habituating his eye to wateh, and his hand to guide, the rarious processes of his art; he may, at the same time, be studying the principles on which that art depends: In every process, he avails himself of some law of Nature. That law he may be made to comprehend ; and we maintain, that, having been made to comprehend it, having ascertained the general and universal principles on which his operations depend, together with such collateral linowledge as he can gather, with ease, from works on popular science, he will have a vast advantage over the artist who works merely 
from experience or by arbitrary rule. These advantages we propose to specify.

I. In the first place, he will be prepared for a greater number of emergencics. However great the expericnee of the artisan, it cannot but happen, that he will meet, in practice, many cases which are new. Some change in the quality of his matcrials, or in the construction of lis tools, or some new fact developed in the course of his operations, will place him in a situation hitherto untried. His master's directions will not avail him, for they never contemplated such a case. His own experience will not suffice, for it reaches to no such contingency. One of those books, called Guides for carpenters, masons, \&c., will not answer, for it gives only arbitrary rules for such cases as have fallen under the immediate eye of the author or of his informers. Whith$\mathrm{er}$, then, shall he resort? If he attempt to investigate the problem for limself, and fund some solution, it is an attempt for which he is disqualified by his previous habits. Instearl of being accustomed to refiect upon his own labors, to investigate the reasons, the why and the wherefore of them, he has gone through them mechanically, like a dray horse; he lias never even dreamed that they could furnish occasion for sober and intense study. If, aroused for the first time to this truth, he sets himself to "eflect closely upon the case before him, he has, to guide his inquiries, no knowledge, either of the laws which occasion this novel difficulty, or of those other laws, which might have furnished a remedy.

Suppose, for instance, that a farmer, accustomed to tiil a cortain soil, were to remove, where he is called to deal with one entirely different. Having found, on his first farms, that plaster, and certain systems of culture, were profitable, he will proceed, if he be one of your practical farmers, who trusts entirely to experience, and laughs at book-learning, to employ the same system here. But perhaps it is without success. His plaster secms to kill vegetation, and his system of eulture ends in a meager erop. Now, what shall he do? Neither 
his own experience, nor any rules that he has heard, from his father or his ncighbors, prepare him for such an emergency; and very possibly his new ncighbors have not yet discovered the proper mode of treating the soil which they cultivate. His only alternative, therefore, is to work on, at random, trying onc experiment after another, liaving no principle to guide, ur, precise object to direct, his course; and expending money and toil, perhaps for years, without success.

The uninstructed artist, therefore, is not prepared for new emergencics. He can more only in one dull routine ; and over that, he travels almost without observation or thought. If he had becn accustomed, however, from youth, to regard the processes of his art as specimens of yet more extensive operations, which God is carrying on, throughout all Nature; as examples of comprehensive principles, which are at work in all places and at all times, and which enbrace innumerable other instances, generally thougl not preciscly similar, he would not have been so easily bafled. Having studicd and mastered the great lairs on which his art depends, he would be prepared for difficulties, and often would have converted into sources of profit, what has now prored only the occasion of defeat and disappointment. He rould have found, in science, not mercly the experience of his instructers or predecessors in the same art; but THE Experience of ALL MANKIND, BOTH PIILOSOPHERS AND ARTISANS. The very object of science is, to present us with the result of all their obscrvations and experiments, on any given subject, embodied in the simplest and most 1.cgular form.

Take the farmer, for example, to whom we have just referred. IIad he been acquainted with a small work of Sir II. Dary's, entitled 'the Principles of $\Lambda$ gricultural Chemistry,' or with a similar work, by Chaptal, he would have learned, that the treatment of soils, by manure, is a chemical process; that the manure required by any soil depends upon the constituents of that soil, 
and the proportion in which they are combined; and that it is in the power of the chemist, if to his scientific knowledge he adds experience, to determine, beforehand, the proper quality and quantity of the manure which ought to be applied in any given case. So with the gardener, who, laboring in a particular district, has seen great benefits result from the mixture of different soils. On remoring to another district, he would naturally expect, if he relied solely on his experience, to find similar effects from the same mixture. But, if he be a scientific gardener, he will be careful, before resorting to that mixture, to examine his new soil, both on the surface and at some depth. He will find out whether it has the same essential qualities; and if not, he will endeavor to ascertain what are its characteristic excellences and defects, and then determine, by the application of chemical principles, what mixture of soil, or what sort of manure, is requisite.

\section{CHAPTER III.}

OTHER ADFANTAGES WHICH THE IXSTRECTED HAS OVER TIIE UNIXSTRUCTED ARTISAX.

II. A second and most important advantage, enjoyed by the artisan who combines science with practical skill, is the command which it gives him over simpler, cheaper, and more certain, methods of attaining his ends. It may be affirmed, we beliere, with entire safety, that there is no art, the processes of which are yet reduced to their utmost simplicity. Not only are inventions, at their first introduction, encumbered with much that is extraneous and unnecessary, but eren processes, which have been transmitted from age to age, instead of becoming more simple, appear, in many cases, to have gathered intricacy from time. Take, for example, the manufacture of soap, one of the most sim- 
ple as well as ancient of arts. It is capable of demonstration, that this process, as generally conducted, is defective in sereral respects; and that, by substituting, in some cases, different materials, and in others, now modes of treating them, an essential saving might be realized, both of materials and time.

Another cause, which seriously interferes with success in the arts, is, the spurious quality of many of the substances emploved. Without some means of detecting adulterations, the artist must often use substances deficient in the qualities required, and of course his results must be uncertain and unsatisfactory. Now, all these difliculties might be obviated, by a moderate acquaintance with chemistry and mechanical philosophy. These seiences suggest simple but yet certain means for testing the purity of substances, and they point out, at the same time, the shortest path to any required object. How wonderfully have the processes of bleaching, and tanning, and sugar-refining, been simplified and abridged, since they first attracted the attention of chemists! What immense improvements are constantly taking place, in the machinery of our large factories! Indeed, there is no department of life, in which a knowledge of science does not serve to simplify and improve our operations. "Though a man," says Lord Brougham, "be neither a mechanic nor a peasant, but only has a pot to boil, he is sure to learn, from science, lessons, which will enable him to cook his morsel better, save his fuel, and both vary his dish and improve it." "The art of good and cheap cookery is intimately connected with the principles of chemical philosophy, and has received much, and will yet receive more, improvement, from their applications. It will be sufficient, under this head, to add two other illustrations, which we borrow from Mr. Herschel's admirable 'Diseourse on the study of Natural Philosophy.'

"In the granitc quarries, near Seringapatam, the most enormous blocks are separated from the solid rock, by the following neat and simple process. The work 
man, having found a portion of the rock sufficiently extensive, and situated near the edge of the part already quarried, lays bare the upper surface, and marks on it a line, in the direction of the intended separation, along which a groove is cut, with a chisel, about a couple of inches in depth. Above this groore, a narrow line of fire is then kindled, and maintained till the rock below is thoroughly heated, immediately on which, a line of men and women, each prorided with a pot full of cold water, suddenly sweep off the ashes, and pour the water into the heated groore, when the rock at ouce splits, with a clean fracture. Square blocks, of six feet in the side and upwards of eighty feet in length, are sometimes detached, by this method, or by another equally simple and efficacious, but not easily explained, without entering into particulars of mineralogical detail."

"Hardly less simple and efficacious is the process, used in soine parts of France, where millstones are made. When a mass of stone, sufficiently large, is found, it is cut into a cylinder, several feet high, and the question then arises, how to subdivide this into horizontal pieces, so as to make as many millstones. For this purpose, horizontal indentations, ö groores, are chiselled out, quite round the cylinder, at distances corresponding to the thickness intended to be given to the millstones, into which wedges of dried wood are driven. These are then wetted or exposed to the nightdew; and next morning, the difierent pieces are found separated from each other, by the expansion of the wood, consequent on its absorption of moisture : an irresistible natural power thus accomplishing, almost without any trouble and at no expense, an operation, which, from the peculiar hardness and texture of the stone, would otherwise be impracticable, but by the most powerful machinery, or the most perserering labor."

III. A third advantage, which the practical man derives from science, is, that it enables him to appreciate proposed improvements. The arts of the present age are characterized by nothing more striking, than by 
their rapid and almost incredible progress.* Competition is so eager, and economy in operations so indispensable, that there is a perpetual tasking of the human intellect, to invent some cheaper, neater, or more rapid, combination. Hence it is, that one improvement is scarcely introduced, before another supersedes it. A thousand minds are engaged, perhaps at the same time, in the earnest pursuit of some contrivance, which will enable them to sare a small fraction in the cost of production; and such contrivance, when once discovered, must either be adopted by all, or be the means of diverting to its fortunate proprietor the entire profits of the trade. It becomes, therefore, an object of the utmost importance to the mechanic and manufacturer, to be able, when a new method is proposed, to judge intelligently of its claims. He is to be equally on his guard against the skepticism which unhesitatingly condemns all new systems, and adheres, most pertinaciously, to whatever is old; and against that credulity which is ready to yield a blind and implicit assent to the promises of interested projectors. But nothing, evidently, can save him from one or other of these extremes, but that knowledge of principles, which will enable him to weigh the reasons for any proposed improvement, and to estimate its probable value. And as sucin knowledge is necessary, that he may appreciate improvements, $\uparrow$ so is it necessary to assist him in

* The increasing powers of the steam-joom are shown in the following statement, furnished by a manufacturer.

"A very good hand-ueaver, twenty-five or thirty years of age, will weave $t u^{\circ}$ pices of 9 -Sths shirting a weck.

"In 1S23, a steam-loom weaver, about fifteen years of age, attending two looms, could weave seren similar pieces in a week.

"In 1S26, a steam-loom wearer, about fifteen years of age, attending two looms, could weave tuclre similar pieces in a week; some, could weave fifteen picees.

"In 1S33, a steam-loom weaver, from fifteen to twenty years of age, assisted by a girl, about twelve years of age, attending fonr looms, could weave eighteen similar pieces in a week; some could weave tuenty picces."

+Dr. "'re states, in his Philosophy of Manufactures, that "prodigious sums are wastefully expended, every year, by manufacturers, 
introducing and applying them. In the present state of the arts, and especially of important branches of manufacture, it is no longer safe, says Judge Story, to be ignorant. "It is not mere dexterity of hand, or mechanical adroitness or industry, that can secure to an individual a successful issue in his business. Without some science, to master improvements, as they occur, and to keep up, in a measure, with the spirit of the age, it will often happen that a mechanic, before he has reached the middle of life, will find himself superseded by those who, though much younger, have begun life under mora favorable auspices."

A fourth advantage which science gives the instructed over the uninstructed artisan is, that it enables him to become an improver of the art at which he works, and even a discoverer in the sciences connected with it. $\mathrm{He}$ is daily handling the tools and materials, with which new experiments are to be made, and daily witnessing the operations of Nature, whether in the motions and pressure of bodies, or in their chemical actions on each other. All opportunities of making experiments must be unimproved, all appearances must pass unobserved, if the artist has no knowledge of principles; but, with this knowledge, he, of all men, is most likely to strike out something new, which may be useful in art, or curious and interesting to science.* His practised eye and dexterous hand enable him to embrace the many opportunities afforded him for such improvements; and, if he labors in a large manufactory, both the motive and opportunity to make them are peculiarly great. The processes being on a large scale, and con-

which would be sared by a more thorough acquaintance with the principles of science and art," which apply to their business; that "crafty projectors are perpetually pressing hazardous innorations upon their adoption," and that he "has known not a few cases, where a complete system of good machincs, capable of doing excellent work, had been capriciously turued out of a cotton factory, and replaced by another, of greater expense, but of less produclive powers."

* See Brougham's Discourse on the Advantages of Science. 
sequently very expensive, it becomes the more important to devise means of saving material and labor, while the very magnitude of these processes often brings out facts and principles which, in ordinary operations, would have remained imperceptible. But the importance, in this respect, of scientific attainments will become more apparent, if we consider the following qualifications, which are absolutely necessary to enable any one to become the author of important improvements in the arts.

I. He must know enough of the laws of Nature, not to attempt impossibilities. Nature itself has placed insuperable difficulties in the way of many of the objects which liave exercised the ingenuity, and wasted the property and lives, of ardent but ignorant inquirers. Who, for cxample, that were acquainted with the laws of chemical composition, or with the physical constitution of man, would have spent their lives and fortunes, as the alchymists did, in the pursuit of the philosopher's stone, or the elixir of life? Who, that understands the laws of motion and gravitation, would ever hope to invent perpetual motion, or a machine to multiply force and velocity at the same time? How many monuments of the ignorance of their projectors do we find in the models of a patent-office, and indeed in many of the undertakings of common life! One man attempts what the laws of Nature have peremptorily forbidden. Another attempts an object, practicable in itself, but by means totally inadequate or inappropriate. This one opens a mine, establishes machinery, and expends a hundred thousand dollars, to discover,-what a geologist would have told him at the outset,- that no ore can be obtained. Another man proposes to increase the heat of his furnace, by forcing in steam instead of air, and the result is, that the fire, instead of being increased, is blown out; a result which a slight knowledge of chemistry would have prepared him to expect. $\Lambda$ third projector prepares a vessel* for sub-

$$
\text { * Ser paige } 74 .
$$


marine examinations; but, not estimating, properly, the pressure of water, at different depths, is erushed to death during the first experiment. How important, then, to gather from science the light neeessary to protect us from the delusions of an excited imagination, and to guide us in the way of safe and profitable enterprise!

II. When oceupied with inventions, in any department of the arts, the inventor ought to be informed of the improrements which have been already made in that department; otherwise, he may consume his time, labor, and money, in merely reproducing what has long existed ; and that, too, perhaps, in a preferable form.

III. He must have sufficient acquaintance with the sciences related to his pursuits, to resolve the various questions which will occur, in the progress of an invention. It is obvious, that, after the first and most important step is taken, in the inventire process: after the important principle has been mastered, and light seems to shed itself orer the whole inquiry ; many obstacles are still to be orereome, many unexpected difficulties are to be met, many toilsome days and nights consumed in niee adjustments and alterations. In some instances, utter failure has resulted, at this stage of the process, for the want of the requisite knowledge; and in others, important inventions have been arrested and painfully delayed, from the same eause. It is stated, that, after Fulton had securely achieved, in his own opinion, the invention of the steam-boat, months were consumed by him in making the necessary calculations upon the resistance of fluids, in order to ascertain what was the best form of the boat, to secure a successful issue to his experiment. It is also stated, by Judge Story, who, in the course of his judicial labors, has had occasion to examine the history of the cardmachine of Whittemore, and of the nail-machine inrented by Perkins, that half the labors of those $\mathrm{cx}$ -

* See Lecture before the Boston Mechanics' Institution, November: 1829. 
traordinary men would have been saved, if they had been originally instructed in the principles of mechanical science. "It is ccrtain," he adds, "that, with his later aequirements in science, one of them would not have laid aside, for a long time, the creations of his own genius, as if in despair that it could ever attain maturity." If it be objeeted, here, that inrentions are often made by men unacquainted with science, we may armit it, without impairing, materially, the force of our argument. Accident will sometimes cast up important improvements, in such a way, that the artist can hardly fail to seize upon them. It will generally be found, howerer, even in these eases, that the invention is not matured, without the aid of the man of scicnec. But, in a large proportion of instances, improvements are not only perfected, but originally made, by him. It has often happened, that substances and processes, though brought to light, have remained unemployed, for centuries, owing to the want of some sagacions and enlightened mind, to apply them to their appropriate uses. And when we trace the history of Inrentors, whosenames do we find most illustrious on the roll? Are they not the names of Archimedes, Galileo, Huygens, Hooke, Otto,-Guericke, Volta, Franklin, Watt, Dary, Wollaston, and others, names more eminent in science than even in art. The truth is, that but comparatively few inrentions have been produced by accident, or by uninstructed artisans. 'They are generally made by persons of competent. knowledge, who are in pursuit of them. What enabled Watt to make his improvement on the steamengine, but those hints which he derived from the chemical lectures of Dr. Black, * and those mathematical and mechanical attainments which he derived from constant and arduous study? Even Arkwright, who has often been quoted as an instance of an uninstruct-

- Is a work lately published, extracts are giren from some of the papers of Mr. Watt, denying his indebtedness to Black. Whatever may be the fact, Watt doubtless owed his invention to study, not accident. 
ed inventor, is now known to have been a man perfectly conversant with machinery, and to have deroted at least fire years to the inrention of the spinning jenny; and then, he was obliged to call in the aid of others. Sir H. Dary discorered his admirable safety lamp, by which so many lives have been sared in the English mines, only after a long series of philosophical experiments, on which he bestowed the utmost powers of his great mind. And it is stated, by Lord Brougham, that the new process of sugar-refining,-by which more money has been made, in a shorter time and with less risk and trouble, than was ever, perhaps, gained from an inrention, before, - was discorered by a most accomplished chemist, and was the fruit of a long course of experiments, in the progress of which, known philosophical principles were constantly applied, and one or two new principles ascertained.*

A brief surver of the history of the arts will conduct us to the same conclusion. We shall find, that improvements in these arts hare generally been preceded by discoreries in science; and that, when the latter has slumbered, the former have remained nearly stationary. In the long lapse of time which interrened from Archimedes to Galileo, scarcely one important discorery was made, in mechanical philosophy; and it is not a little curious, that, during the same period, hardly any progress was made, in the mechanic arts. The samie night which shrouded the genius of discovery seemed to brood orer the talent for invention. No sooner, howerer, did Galileo perceive those great truths which have immortalized his name as a philosopher, than he began to apply some of them to the combinations of art; and the impulse which he gare to the spirit of discovery extended itself to invention, and has rendered the progress of science and art, erer since, one and indirisible. It is within the last serenty-five years, howerer, that this connexion has been most striking and apparent. During this period, chemistry has taken its rank among the

* See Lord Brougham's Discourse on the Adrantages of Science 
sciences; unprecedented advances have been mad? in mechanics and physics; and even geology, mineralogy, and physiology, have received most important and unexpected accessions. Now, it is precisely during this same period, that the useful arts have pressed forward, with the most rapid strides. Scarcely a discovery has been made in science, which has not forthwith been turned to some useful account. The steam-engine; the use of chlorine, in bleaching; the raried and important applications of platinum, chrome, iodine, and other substances, which have been brought to light entirely by the researches of the chemist;-are but a few among many instances of the service which has been rendered to the arts of industry, by the labors and discoveries of science.

We have thus enumerated some of the practical advantages which flow from the application of science to the arts. There are other advantages, of a moral and intellectual character, which are entitled to at least a passing notice. The habit of studying the theory as well as the practice of an art, cannot but have the happiest influence, in enlarging and liberalizing the mind. It leads the artist to regard his occupation as something more than mechanical drudgery; as a liberal and intellectual pursuit, fitted to exercise the powers of his mind, and to raise his thoughts from the humble workmanship of man to that raster mechanism, which bespeaks the wisdom and power of the Almighty. It affords unfailing topics for reflection and conversation, during his hours of labor, and provides resources of an intellectual character, on which he can draw, in seasons of leisure and at the advance of old age. It seems, indeed, high time, that the years which have hitherto been employed by the apprentice, in learning the mere handicraft of his art, should be employed, in part at least, in studying its principles, and in tracing the operation of those principles throughout the works of Nature. It is more than time, that a higher moral and intellectual taste should be rultivated among the artisans of every coun. 
try, and that hours, now wasted in dissipation or frittered away in frivolous reading and conversation, should be deroted to the acquisition of knowledge and the cultivation of virtue. In an age like this, when every species of manual labor is rendered more and more precarious, by the changes which are perpetually taking place in the arts, it is the obvious interest of the laboring man, to prepare himself, by reading and reflection, either to embrace a new employment, or to conform himself to sudden and unexpected vicissitudes. Independent, however, of interest, there are higher considerations, which address him as an intelligent and immortal being, and which urge him to embrace the opportunities for improvement which have been rouchsafed him by a kind Providence, eren in lis ordinary arocations.

\section{SUMNARY OF PRINCIPIES, IN PART I.}

\section{TRODUCTIOY.}

I. Though naturally inferior to many of the animals, in strength and agility, man becomes their superior, by means of the Arts.

II. These Arts are, in the first instance, suggested by necessity; afterwards, they are improved by Science.

III. The application of Science to the Arts has been neglected, to the prejudice, both of the philosopher and the artisan. The discoreries of the one have often remained unproductire, for the want of practical linowledge ; and the manual shill of the other lias frequently accomplished little, because it required the aid and guidance of Science.

THE ARTS DEPENDENT ON SCIENCE.

I. Material substances are subject to fixed laws.

II. They cannot be employed, except in olsedience to those laws. 
III. They cannot be employed in obedience to such laws, unless the laws are understood.

IV. And they cannot be understood, without Science.

V. Science camnot be superseded by experience, nor by arbitrary rules; since these teach nothing but disconnected facts and processes. It is Science alone that teaches us laws of the requisite simplicity and generality.

VI. A linowledge of such laws confers great adrantages on the laboriug man:-

1. As it prepares him for new emergencies.

2. As it gives him command of the simplest, cheapest, and most economical, methods of attaining his ends.

3. As it enables him to appreciate proposed improvements, especially in his own art.

4. As it qualifies him to become himself an inventor or discoverer.

5. As it tends to enlarge his mind and improve his moral character. 



\section{PAR'T II.}

AGENTS EMPLOYED IN TIE ARTS.

EFfects are produced in the useful arts, chiefly by the powers of Nature. Man is but the minister or agent of these powers.* His agency is confined, for the most part, to such an arrangement of substances, as will secure the action of their natural properties. He can do little by means of his own strength. Even the morements of his body, though modified by the principles of life and rolition, are still subject to the laws of matter, and are exerted in obedience to those laws. When he acts upon other bodies, he can influence them only so far as he pays striet regard to their qualities, and to the relations which connect them with surrounding substances. It has been well said, that he, who would command Nature, must first learn to obey her.

One principal end proposed by the arts is, to supersede, as far as possible, the necessity for man's exerting his physical strength at all. They propose to substitute intelligence, in the place of brute force, and to enable him to employ, in the attainment of his ends, those mighty agents which reside in the material world. Hence it may be useful, before we take up the several Arts, to consider the most important of these agents,

* Man, according to Bacon, has a twofold uffice, in regard to Natare. He is first to interpret, and then to obey, her laws. II province, as an intellectual being, is to ascertain her mode of operating; as an active being, to produce, by artificial means, and for some useful purpose, a recurrence of her operations. "Homo, natura minister et interpres,"-.Man, the servant and nuterpieter of Nature,-is the phrase with which he opens his Novum Organum, and forms the fundamental principle of his method of philosophizing. 
and also the machinery, by means of which they are brought to act in giren cases.*

The agrents employed in the arts are of two kinds, Chemical and Mechanical.

\section{CHAPTER I.}

\section{CHEIICAL AGEXTS.}

I. (a.) All chemical agents act in obedience to one power or principle, which we shall endearor to explain. It is called, chemical affinity. Br this affinity, we mean neither more nor less than a tendency which particles of different kinds have to unite, when brought rery near each other.t This tendencr is apparent in certain compounds; as, for example, of water and alcohol; which, if shaken together, will remain permanently in union; whereas oil and water, though agitated ever so much, form no union, but will separate the moment they are allowed to subside. The reason is, that

* A mechanical manufacture, being commonly acenpied with one substance, which it conducts throngh metamorphoses in regular succession, may be made nearly antomatic ; whereas a chemical manufacture depends on the play of delicate affinities between two or more substances, which it has to subject to heat and misture, under cirenmstances somewhat uncertain, and must remain, therefore, to a corresponding extent, a manual operation. The best example of pure chemistry, on self-acting principles, which I hare seen, was in a mannfacture of sulphuric acid, where the sulphur being kindled, and properly set in train with the nitre, atmospheric air, and water, carried on the process, through a labyrinth of compartments, and supplied the requisite heat of concentration, till it brought fortl a finished commercial product. The finest model of an automatic manufacture, of mixcd chemistry, is the fire-colored calico machine, which continuonsly and spontaneonsly, so to speak, prints beautiful webs of cloth, witi admirable precision and speed. It is in a cotton mill, however, that the perfection of automatic industry is to be seen : it is there, that the elemental powers have been made to animate millions of complex organs, infusing into forms of wood, iron, and brass, an intelligent agency.-Ure.

† Affinity mast be distinguished from cohesion. Cohesion unite: particles of the same kind; affinitr, those of different kinds. 
between water and alcohol there is an affinity, but none between water and oil.

We see the operation of affinity, also, in solutions. $\Lambda$ liquid dissolves a solid, merely because the particles of the liquid have an affinity for those of the solid, stronger than the cohesion by which the latter are held together. 'Thus, water dissolves sugar, because its affinity for the saccharine particles is greater than the cohesion which binds these particles to each other. It fails to dissolve rosin, (or camphor, except in a slight degree,) because, in these substances, there is either no affinity for water, or this affinity is so weak, that it cannot overcome the cohesion which unites the particles together. It is obvious, therefore, that cohesion opposes the action of affinity; and that, when we wish substances to unite, by their aftinities, quickly, and in large quantities, we must take measures to lessen the cohesion. This is effected by heat, which lessens the coliesion, by causing the particles of the body to recede from each other; and also allows the particles of the fluid to enter the pores of the solid. It is also effected by division of the solid into minute parts, by agitation, \& c., - $-\mathrm{cx}-$ peclients which facilitate the action of aflinity, by bringing the two substances into intimate and simultancous contact. This explains why hot liquids are more powerful solvents than cold ones; why powdered sugar dissolves in water more readily than lumps; and why, in order to assist solution, we shake or agitate the containing ressel.

(b.) IVe see, then, that chemical combinations are caused entirely by affinity, and could not exist without it. How important they are in the arts, we all know. Many solid substances would be of no use, unless we could dissolve them; and to know by what liquid they can be dissolved, and what causes may oppose or assist the process, is evidently of the highest importance.

In addition to this, there is another very important property which characterizes the power of solution in many cases. It is limited. In some compounds, bo- 
dies may be united, in all possible proportions. Equal measures of water and alcohol may be united; or one drop of the former with a gallon of the latter; or a drop of the latter with a gallon of the former, or in any intermediate proportions; and, in every ease, the union will be perfect, uniform, and permanent. But, in most solutions, the liquid cannot combine with more than a certain definite quantity of any solid or aeriform body. Thus, water can only take up a certain known weight of common salt; or alcohol, of camphor. The point, at which the dissolving power of the liquid ceases, is called the point of saturation. The liquid itself is then said to be saturated. When solutions are made, as in the arts, on a large scale, it is evidently of the utmost importance that we should know where this point of saturation stands, that we may not waste time and material in attempting to push the process beyond a limit fixed by the inviolable lans of Nature.

(c.) Again. It is worthy of remark, that, when a liquid has been saturated with one substance, it is often capable of combining, at the same time, with a second and a third. 'Thus, water, which has taken up its full proportion of common salt, will dissolve a further quantity of Glauber's salt, and a yet further quantity of Epsom salt. On this fact is founded a very convenient process for obtaining these salts from sea-water, (which always contains them,) by gradual evaporation. When a given quantity of the water is evaporated down near to the point at which the least soluble salt saturates the liquid, that salt will begin to crystallize. Thus we obtain common salt. A still further evaporation gives Glauber's salt; and the remaining liquid holds dis. solved a quantity of Epsom salt. It is obrious, that such a process ean never be carried on, with economy and success, without a knowledge of the relative solubility of these substances.

(d.) Having noticed the case, in which one substance has different degrees of affinity for two or more others, 
we take this opportunity of presenting a striking principle, which applies in many such cases. The difference in the affinity may be so great, that it will occasion both decomposition and the forming of a new compound. For example: if we take spirits of camplior, (a solution of camphor in pure alcohol,) and pour a little water to it, we shall find the camplior precipitated, in a solid form, to the bottom. 'The reason is, that the alconol has a much greater affinity for the water than it has for the camphor; in consequence of which, the latter is separated, and resumes its solid state, and a new combination is formed of the water and alcohol. Here, as a substance seems to make choice or election of one substance rather than another, with which to unite, we apply the term elective, and call it elective affinity; and since there is but one decomposition and one new compound formed, it is called, single elective affinity.

There is another case, in which double decomposition and composition will take place ; that is, the two original bodies being both compound, will each be decomposed, and two new compounds produced, from a mutual exchange of ingredients. For example: talic sugar of lead (which is a compound of vinegar and lead) and white vitriol, (which is also a compound, formed by uniting sulphuric acid with a metal called zinc.) If these substances, in a state of solution, be mixed; the vinegar in the sugar of lead, having a stronger affinity for the zinc of the other compound than it has for the lead, will forsake the latter and unite with the zine; while, on the other hand, the sulphuric acid, having a stronger affinity for the lead than for zinc, will quit the latter and unite with the former. Thus, we shall have two new compounds; the one composed of vinegar (or acetic acid) and zinc, and hence called acetale* of

* Chemical compoumls have names so arrangerl, as to iudicate tho simple sulstances of which they are composerl, and also the proportion in which those sulsstances combine. Thus, when au acid so combines with an oxide, or other base, as to nentralize it and be itself neutralized, the uame of the compound is forned by changing tho last syllable of the acid from ic into ate, or from ous into ite 
zinc; the other, of sulphuric acid and lead, and hence called sulphate of lead. This is called double elective afinity. This beautiful principle affords to the artist, who understands it, a ready mode of separating $a$ salid from a solution; of purifying mixtures, $\delta \cdot c$.; and is of most extensive application in the useful arts.

II. (a.) We come now to another modification of affinity, still more curious and interesting. In the compounds of which we have spoken, the affinity exerted is comparatively weak. The compound retains the properties of its ingredients, which seem unchanged by the combination, and takes a character intermediate between theirs, - a circumstance which contributes greatly to the usefulness of solutions, and without which, indeed, they could have none of their present value. In the mode of action which we shall now consider, and which may be termed, by way of eminence, chemical composition, the affinity acts with more energy, the union effected is more intimate, and is generally attended with such an entire change of properties, that we cannot discover in the compound any trace of the ingredients. Thus, two gases, oxyen and hydrogen, being combined, in certain proportions, form $v$ ater, a fluid substance, entirely destitute of the characteristic properties of either of its constituents. So, if mercury be united with a certain proportion of chlorine, which is a gas, it forms a solid, well known in medicine by the name of calomel, and which differs entirely from its ingredients, in form, appearance, and taste, and in its effects on the animal system. So. amain, if we unite an acid and an alkali, as oil of ritriol and soda, a compound results, which has neither the intense acidity or

Thus, acetic acid, combined with zine, gives acetale of zinc; aceious acid, combined with zinc, would give acetite of zinc. An acid takes $i c$, when it contains a larger proportion of the acidifying principle, that is, oxygen: ous, when it contains a smaller portion. Thus, four proportions of oxygen give nitrous acid, five proportions, nitric acıd, Ec. So sulphate of lead is thus called, because it is a coinpond of sulphuric acid and lead. In this compound, there are, of course, three simple substanees, oxygen, sulphur, and lead. 
corrosive power of the vitriol, nor the acrid bilterness and power over color of the alkali. The active properties of each substance are destroyed or neutralized, and a compound, distinguished for its mildness, is obtained ; just as, in the preceding case, a compound of very active propertics resulted from the union of ingredients comparatively incrt.

(b.) These compounds are distinguished by another remarkable characteristic. Whererer or in whatever quantity found, they are not only composed of the same ingredients, but of these ingredients combined in exactly the same proportion. Thus, if water be found in any instance to consist (as it always docs, if pure) of cight paris of oxygen and one of hydrogen, it may be assumed, as a permanent and universal law, that all other pure water, wherever obtained, will contain the same ingredients, in the same proportions. Were these ingredients in any other proportions, the resulting compound would not be water, but some substance of very different properties; and this conducts us to another very singular law, which is, that the same ingredienls, combining in different proportions, produce compounds differing essentially, not morely from the ingredients themselves, but also from one another. The union of mercury and clilorine, in one proportion, gives calomel, a useful medicine; while, united in a different proportion, they give corrosice sublimale, a deadly poison. How important is it, for all who prepare medicines, or any compound in the arts, to understand this law. If ignorant of it, they have no security, cither that they will obtain the compound that they desire, or that some other one, fatal to their designs, may not be produced. The following cxample will illustrate the importance of this knowledge to the medical practitioner. Of two medicines, either might be administered separately, without injury, and perhaps with benefit; whereas, if both of them should be given in conjunction, or at nearly the same time, the most dreadful conscquences might ensuc; since the product 
of such a combination might be poisonous. And, on the other hand, two useful medicines might be so related, that, if administered together, the one would completely neutralize the other.

(c.) But we have not yet unfolded all the wonders of this wonderful principle. We have seen, that, in this class of chemical compositions, ingredients may unite in different proportions. But the range of combination is vastly more limited, here, than in the case of solutions. There, the constituents might combine, in all proportions, within a certain limit. But here, they must always combine in the proportion of certain numbers, which are called their proportional numbers. Thus, in whatever compound we meet with oxygen, we shall find, that is mintity may be expressed by eight, or by some multiple : eight; as sixteen, twenty-four, thirtytwo, forty, \&c. Hydrogen always unites in the proportion of one, or of some multiple of one ; sulphur, in the proportion of sixteen ; chlorine, of thirty-six, \&c.*

Where the compound is formed by the union of two substances, one or both of which are already compounded, the proportional number of that substance will be expressed by the sum of the proportional numbers of its ingredients. For example: if water, a compound of oxygen and hydrogen, unites with lime, it will be in the proportion of $8+1=9+$ (which is the sum of hydrogen and oxygen) to $20+8=28$ which represent the proportions of calcium and oxygen in lime. It is also a law of chemical combination, that the quantities of any two substances, which combine with the same quantities of a third, will also combine with one another: that is, if eight parts of oxygen will combine with one part of hydrogen, and with sixteen parts of sulphur,

* This is called the law or principle of definite proportions.

+ It may be well to mention, here, for the benefit of those readers who are not familiar with mathematical signs, that + means plus, more, or added to $;$ - minus, less ; $\times$ multiplied by $; \div$ divided by $;=$ equal to. As $8+1=9$ means, 8 plus (or more) 1 (or 1 added to 8 ) equals $9 ; 9-1=8$ means, 9 minus (or less) 1 is equal to $8 ; 3 \times 4$ $=12$ means, 3 multiplied by 4 is equal to $12 ; 12 \div 4=3$ means, 12 divided by 4 is equal to 3 . 
then the two latter, that is, one of the hydrogen and sixteen of sulphur, will combine together.

These laws, it will be perceired, must gire great simplicity to chemical combinations. The number of simple substances, which play an important part in such combinations, is small; and, if the proportional numbers for these substances be remembered, as they easily may be, an individual can determine the proportions in which the ingredients combine, in all given compounds, without difficulty, and without having recourse to books.

T'hese laws of affinity, which we have thus endeavored to explain, lie at the foundation of all chemical science, and admit of innumerable applications to the useful arts. They regulate the operetions the bleacher, dyer, tanner, brewer, and baker :' 'sssist or mar the labors of the husbandman, glassmaier, metallurgist, manufacturer, \&c., and are therefore entitled to the serious attention of all persons connected with these important pursuits. It will be our object, when we come to treat of these arts, to illustrate the applications here referred to, at greater length, and to show, by numerous cxamples, the necessity of understanding a principle, so perpetually at work, and which is equally powerful, whether employed as an auxiliary or encountered as an antagonist.

\section{CHAPTER II.}

MECHANICAL AGENTS EMPLOYED IN THE ARTS.

Chemical agents act only at insensible distances, and are confined, in their operation, to changing the interior constitution of bodies. Mechanical agents, on the contrary, act at sensible distances, leave the interior constitution of bodies unchanged, and alter only the position or form of their masses. These agents are called forces or prime movers; and comprehend the 
strength of animals, water, wind, steam, \&c. Before we enter upon the examination of these forces, however, it will be necessary to cxhibit, in few words, certain fundamental Laws of nотіоs, which apply to all bodies and forces, alike; and which ought to be thoroughly understood, by every person who is engaged, directly or indirectly, in mechanical operations.

I. The first law is, that masses of maiter never. change their state of motion or rest, unless exicrnal force is applied. This is merely saying, in other words, that matter is inert, or has no power of voluntary action. That a body never passes from a state of rest to that of motion, without the application to it of some force, is erident enough to all. But it is not so evideni, that a body, once in motion, would never stop, except from the same cause. This will become apparent, however, if we consider, that a body, rolling over a smooth surface, will continue nuch longer in motion, than if the surface be rough; and that, if the surface be thoroughly polished, and very hard, a top has been lnnown to continue spinning upon it, for hours. If, in the latter case, we could do away friction, entirely, and remore all the resistance presented by the air, the motion would undoubtedly continue a very long time; and we know of no reason why it should ever stop. It should be added, here, that, as a body once in motion las no power of stopping itself, so neither has it any power of changing its raie of motion; and it will continue, therefore, to move for ever, with uniform velocity, unless some force be applied, to retard or accelerate.

INERTIA OF BODIES.

rThis law, which is commonly called the law of inertia, suggests some very important rules for regulating motion and machinery, and serves to explain a great many interesting facts. For example: if you would put in motion a large mass, you must take time; since, each particle of the mass being inert, the inertia of the whole can only be overcome gradually. Hence, a judicious 
driver never strikes his horses at starting, lest the sudden exertion of their strength against an inert load should injure them, and break the harness. Hence, also, on railways, they connect the cars by flexible springs, in order that the different cars may be put in inotion one after another, instead of compelling the engine or horses to overcome the inertia of the whole train at one effort.

We sce the same principle in the case of a large boat lying in water. A sudden pull, though very strong, scens to have no eflect upon it; whereas, a slight force, if it be applied steadily, till it has had time to pervade the entire mass, will produce motion. In other cases, however, where our object is not to move the whole mass, but to detach a small part of it, we should apply the force suddenly. Thus, in breaking off fragments from rocks, metals, pottery, \&ce., the blow nust evidently be riolent, that the part may be broken off, before the motion communicates to the whole mass. This explains why we can discharge a pistol ball through a pane of glass, without brcaking, or even cracking, any part, except just that through which the ball passes. Also, why, if a board be suspended freely, a pistol ball can be driven quite through it, without communicating any sensible motion to the board. Also, why a tallow candle, discharged from a musket, can be driven, like a bullet, through a pine board; and why a cannon ball, coming from a great distance, and moving at a comparatively slow rate, does so much more damage than a shot coming from some point very near.

Thus much, respecting the application of this law of inertia to the case of bodies, which are to be put in motion, and which exhibit a tendency to rest. It admits, also, of many interesting applications to bodies already in motion, and which exhibit a tendency to continue this motion. Thus, it is owing to inertia, that we find it so difficult, when running fast, to stop ourselves, suddenly; that we fall over, forwards, if the moving surface, on which we have been standing: as 
the bottom of a wagon, for example, is unexpectedly stopped; and that we receive such serere falls, wlien we leap from a carriage in motion to the ground. To this same principle we are to refer the serere concussion communicated even by small bodies, when they are moving rapidly. It should be remarked, here, that the force with which a body mores, and the consequent efforts which it makes to continue in motion, depend on the velocity as well as on the quantity of matter. A hammer is a small body; but, owing to the great relocity which is communicated to it by the arm, as it descends, it is capable of inflicting a very severe blow. So with the flail, in threshing; the balls used in muskets and cannon; the battering ram of the ancients; the pile-engine, \&c. Another very interesting application of inertia is in the fly-wheel, which is used in machinery, for the purpose of maintaining a uniform rate of motion, and to which we shall have occasion hereafter to refer.

\section{CEXTRIFUGAL FORCE.}

The inertia of matter gives rise, also, to a different but very interesting class of facts. If bodies are moving, they have a tendency, as we hare seen, to continue in motion, with uniform relocity; and we now add, that this tendency is always to carry them in a right line. Hence, if they move in curres, there is a continual effort to talie a rectilinear course, in the direction of tangents to those curres. This effort is called the centrifugal force of a body, and has a very important influence on the motion, both of bodies in space and of machinery. We have familiar examples of it, in the water and mud which fly off from the periphery of carriage wheels, when in rapid motion ; ${ }^{*}$ in the force with which stones escape from a sling, which has been whirled rapidly round; in the greater liability of a carriage to upset, when it is turning a corner; in the hol-

* The velocity given to grindstones, in some manufactories, is so great, that fragments are broken off, by this centrifugal tendency. 
low shape which the water in a vessel assumes, if that vessel be revolved quickly round its axis, \&c. \&c. Valuable use is made of this centrifugal tendency, in the construction of millstones,-the grain always being received between the stones, in the centre, and carried outwards of itself: also, in the lathe which is used by potters and glassmakers; and, above all, in the machine called a governor, which was first applied by Watt, to regulate the supply of steam, or any other moving power, to machinery.

The second law of motion is, that any change in the place of a body must be proportioned to the force impressed, and in the direction of that force. This is sufficiently evident, in the case of a single force, or of two or more forces acting in the same right line, and when the body is free to move in the direction of that line.

\section{COMPOUND MOTION.}

There are other cases, however, (as, for instance, that of a boat rowed across a river which has a rapid current,) in which the body is acted upon, at the same time, by two forces at certain angles, either greater than, equal to, or less than, right angles. Thus, if a body at B, Fig. 1, be acted upon, at the same instant, by two forces, at right an- $\mathrm{C}$ gles with each other, one impelling it towards $\mathrm{C}$, and the other towards $\mathrm{D}$, it is important to know in what,direction it will $\mathrm{E} \%$..... D move, and at what rate. Suppose, that the first force, acting alone, would have carried the body through the line $\mathrm{B} \mathrm{C}$, in one second, and that the other force, acting alone, would liave carricd it through $\mathrm{B} \mathrm{D}$, in the same time; acting together, they must carry the body, in one second, to a point which shall be just as far from $\mathrm{B} \mathrm{D}$ as $\mathrm{C}$ is, and just as far from $\mathrm{B} \mathrm{C}$ as $\mathrm{D}$ is; that is, to $\mathrm{E}: *$ and the body itself will have described the

* For the action of the perpendicular force cannot prevent the full eficet of the horizontal; nor, vice versa, would the action of the horizontal force prevent the full effect of the perpendicular one. There 
diagonal of the parallelogram. The same law holds good, whatever be the inclination of the forces; and hence we have the general principle, that a body, acted upon by two forces, describes the diagonal of a parallelogram, the sides and angles of which represent the intensity and direction of those two forces; and will do this in the same time in which, by the action of one of the forces, it would have described a side, and with a uniform relocity.

From this principle we see how, in machinery, we may substitute two forces, acting at angles, instead of a single force; or, on the other hand, how we may substitute one force instead of two, three, four, or more, forces. Suppose we have three forces, and wish to find one which will produce the same effect. We must determine its direction and intensity. To do this, we take the lines representing two of the forces, and construct a parallelogram from them; and, in the diagonal, we have a single force equiralent to the two. Taking this diagonal, with the third force, we construct another parallelogram; and the diagonal of this last parallelogram will give us the equiralent of all the three forces, and will represent its intensity and direction.

\section{CENTRE OF GRATITY.}

One of the most interesting applications of this principle is, in investigating the properties and determining the place of that point in a body, which is called its centre of gravity. The sercral particles of matter in a body being solicited by gravity, we may consider it as acted upon by a great many different forces, which, if reduced to one, will always pass (whatever be the position of the body) through a certain point in it, around which its parts seem to balance each other, and which, if supported, will gire support to the whole fore, the body, at the end of a second, must be both in the rertical line, $\mathrm{C} \mathrm{E}$, and in the horizontal one, $\mathrm{D} \mathrm{E}$, that is, at $\mathrm{E}$, their point of intersection ; and must have described, during this instant of time. the diagonal lime, $\mathbf{B} \mathbf{E}$. 
mass. 'The stability of edifices and other masses of matter depends, therefore, on the position of their cen. tre of gravity. If a line, drawn from this centre, per pendicular to the horizon, falls within the base, the body will evidently stand; and its stability will be greater, the further that line falls from the side of the base; so that the stability is greater, in proportion to the size of the base, as compared with the perpendicular height of the centre of gravity. If it falls without the base, the body will fall instantly; if upon the side of the base, the body will stand with what is termed unstable equilibrium, and be overthrown by the applieation of the slightest force.

Where bodies, like carriages, are to be moved, and are subject to inclinations, towards one side and another, it is necessary to place the centre of gravity low ; othcrwise, a slight inclination will throw the perpendicular line without the base, and cause the body to be orerthrown. In Fig. 2, A B represents a wagon, on the slope of a hill; C D represents the level of the ground; E F the base of the wagon and the slope of the hill. If the wagon be so laden, that the centre of gravity be at $B$, the perpendicular, B E, will fall within the

Fig. 2.

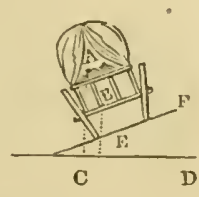
base, and the wagon will stand. But if the load be so altered, that the centre of gravity be raised to $A$, the perpendicular, A C, will fall outside of the base, and the wagon be overset. The difficulty which the young child finds, in walking, arises principally from his inability to keep the centre of gravity of his body over the base. Quadrupeds have, in this respect, an advantage over the young of other animals.

To determine the position of the centre of gravity in a body is important, on many accounts; but especially, because, when a force is to be applied to a body to more it, it should be made generally to pass through the centre; otherwise, a rotary as well as progressive motion would be communicated to the body. 
There is a third law of motion, which is generally called the principle of action and reaction. It consists in the fact, that, to every action of one body on another, there is an equal and contrary reaction. That is, in other words, if I strike a blow with my fist, the fist receives just as severe a blow as it inflicts. If one vessel, under full sail, strike against another, at rest, it receives a shock just as great as that which it communicates. It is on this principle that a bird is able to support itself in the air, by beating with its wings against the air below. This air, being struck, reacts against the body of the bird, with a power sufficient to keep it in its place, or to enable it to rise and fall, at pleasure.

\section{CHAPTER III.}

MECHANICAL AGENTS CONTINUED.

Havisg considered the three fundamental laws of motion, we now proceed to the forces, which may be employed to produce motion. They are of two kinds, animate and inanimate.

AYIMITE FORCES.

The animate forces consist of the strength of men and animals. As this depends upon the principle of life, respecting which we are entirely ignorant, and as the strength of an animal is influenced by his constitution, state of health, the climate in which he lives, and rarious other causes, it is impossible to ascertain the laws which regulate it, as accurately as ne can ascertain those which regulate inanimate forces. Still, many experiments and calculations have been made, and principally to ascertain the most advantageous modes in which an animal can be worked; the velocity and load with which he can work most eflectively or permanently; the relative strength of different 
animals; and the comparative cconomy of using them. It has been ascertained,

1. That the most advantageous method of employing the strength of a horse is in the act of drawing a load; and the least advantageous, in carrying a load, especially up hill: while, as one might infer from the perpendicular position and structure of his body, the reverse is the case with man, and that rowing is, perhaps of all ways of applying human strength, the most eflective.

2. That an animal will work most effectively, from day to day, if his relocity be small and his load large; that the working rate ought never to be more than one half, nor generally more than one third, of the greatest veloeity with which the animal can travel without load; and that, with this relocity, his load should never be more than four uinths of the greatest which he can bear. Thus, if the greatest speed with which a horse can travel, without a load, be twelve miles per hour, and the greatest load which he can carry, without moring, be four hundred pounds, he will work, permanently, with most advantage, when his rate of going is four miles an hour, and his load about one hundred and eighty pounds.

3. That a horse can exert an effective force, from day to day, equal to that of six men; and an elephant, a force equal to six liorses: and,

4. That, considering the expense of keeping a horse, which is not greater than that of keeping a man, nor more than one sixth of that of keeping an elephant, his fitness for different kinds of service and any kind of road, and his uniting fleetness with strength, he possesses a great advantage, in regard to economy and convenience, over every other animal,* for general use.

In regard to employing human force, or, in other words, the strength of men, it is obvious,

* Fxceplion must be made, in parlicular climates, in favor of the enmel, mule, \&c. ; and, in our own country, the ox is to be preferred, for farm-lahor. 
1. That it is of all forces the most expensive,-since it costs as much to feed a man as a horse, while he can perform only one sixth part of the service.

2. It is the least convenient, since the power of the individual is confined within very narrow limits, both of speed and strength; and, in many linds of work, it is impossible to employ a large number of men together. It is obrious, for example, that no number of men would be able to drag a stage-coach, at the rate of twelve miles an hour; and, to show the comparative inefficiencr of human labor, in anotlier way, we may mention the statement of Homer, that twelve women had to be constantlr emplored at the hand-mills, in the louse of Ulysses, in order to grind corn enough for his family, - a work which might have been performed by a rery small stream of water, or by a single horse.

3. Human force, when exercised without intelligence, has a degrading influence on the mind and heart. Hence, wherever we can substitute animal or other brute force for that of men, we are bound to do it, that the power of the latter may be reserved for cases, in which they can exert intelligence and skill, and have scope for the exercise of their moral affections. Freemen revolt at the idea of being chained to the cars of the wealthy or powerful; or at taking the place of brutes, in the plough or at the mill. Should they not be equally anxious to aroid other occupations, which exert no healthful infuence on the character, and which could be performed with as much effect, and with greater economy, by animals, or even by inanimate forces? Examples of such occupations ma! be found in churning, threshing, hayraking, spinning: roenting: \&c. \&c.

IXAXISTE FORCES.

Under this head are included, gravity, water, wind, steam, \&c., which may all be referred, indirectly, to three sources : to wit. grarity. elasticity, and heat. 
I. Gravity.-As a moving force, gravity acts on solids, fluids, and aeriform substances.

(a.) It causes solid bodies to descend towards the centre of the earth, and hence the use of the plumbline, which, always taking that direction, is of course perpendicular to the horizon, and serves, therefore, in building, to determine the perpendicular, and also the level. It also carries bodies down inclined planes, and down the descending branch of the arc of a pendulum; in which last case, it communicates, during the descent, sufficicnt force to the body, to carry it upwards, to the same height, on the ascending branch of the arc. It draws projectiles towards the earth, and of course out of the right line which they would otherwise describe, and thus puts a limit to the range of ordnance, in war, and to the useful effect of fire-engines, $\mathcal{E c}$. In the clock, the weight, so called,-that is, the gravity of some solid substance drawing on the machinery,serves to orercome the resistance which is presented to the motions of the pendulum, by friction and the air, and to render the ribrations of this pendulum permanent and isochronous; that is, of equal times.

These applications of gravity, as a moving force, though suggested, in some cases, by artisans, lave been perfected, in almost all cases, by men of science. To their nice researches and calculations we owe whatever rules are now employed in gunnery, and in regulating the motion of bodies falling through space or de scending on inclined planes. In all these cases, the result depends upon a property of motion, which we have not yet mentioned. This may be called uniform acceleration. If a ball, lying on a level surface, be struck, it will move with a velocity which would continue, if there were no friction or other resistance, always the same. Now if, instead of a single blow, it were to receire several blows, at regular intervals, the relocity would go on increasing; and if each blow were given with the same force, the increase would evidently be uniform: that is, if a body, having receired one 
blow, passes through sixteen feet, in the first second, it will pass through double that number of feet, in the next second, because it has received another blow, while it retains all the motion communicated by the first. The spaces, therefore, described in the successire seconds, would be as follows : $1 . . .16 ; 2 \ldots .32 ; 3 . . .48 ; 4 . . .64$; \&c. Here, the velocity increases, each instant, by the same quantity, that is, sixteen feet; and hence is said to be uniformly accelerated.

Now, grarity, as a force, may be said to act upon descending bodies, in the same manner, by successive impulses; only that these impulses, instead of taking place at intervals, take place in the quickest possible succession. The effect, however, on the motion, will be much the same. It will be accelerated, and the acceleration will be uniform; or, in other words, may be represented by a constant quantity. It is found, by experiment, that if a body fall freely through space, it will pass through 16.1 feet in the first second of time. But as, during this second, gravity has been all the while acting, the velocity has increased, and has become such, at the end of the first second, that, if gravity were then suspended, and the body left to its acquired force, it would fall, during the second second, through 32.2 feet; so that 32.2 represents the regular acceleration, from second to second, or the accelerating force of gravity.

The spaces described, therefore, in the successive seconds, by the influence of gravity, would be as follows: $1 . . .16 .1 ; 2 . . .48 .3 ; 3 . . .80 .5 ; 4 \ldots .112 .7$; \&c.an arithmetical series, of which the first term is 16.1, and the common difference, 32.2. Now, the sum of any number of terms, in such a series, as we know fronı arithmetic, is equal to the half sum of the first and last terms multiplied by the number of terms; and any individual term is equal to the product of the common difference into the number of terms to that place, $m i$ nus the first term. Hence we may perceive, that, having learned, by experiment, the rate at which falling 
bodies are accelerated, we have very simple rules for asccrtaining, (1) the whole space, through which a body, falling freely, would pass, in a given number of scconds; and (:) the space which would be described, in any one of those seconds: and these rules are of the utmost practical utility.

Respecting these laws, let it be remarked, (1) that they apply to all bodies, alike; whence it follows, that, if the resistance presented by the air were remored, a light body would descend as rapidly as a heavy one,-a fact which is verified by the guinea and feather experiment $; *(2)$ that they apply also to bodies descending inclined planes, or through the arcs of pendulums, with the single exception, that here, the accelerating force being diminished by the reaction of the plane, will be less than 32.2 , and will depend on the degree of inclination which has bcen given to the plane or arc; and (3) that these laws were never known till the seventeenth century, when they were discovered by a distinguished philosopher, Galileo; previous to which, mankind were unable to arail themselves of the valuable improvements to which they have given rise.

* In this experiment, the air is cxluausted from a glass re ceiver, as perfectly as possible ; and a guinea or other heary substance is dropped, at the same lime with a feather, from a point where they were previously placed, at the top of the receiver, on the inside. They reach the bottom at tho same lime.

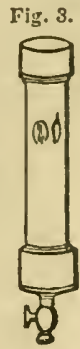




\section{CHAPTER IV.}

MECHANICAL AGENTS.-(GRAVITY CONTINUED.)

(b.) Gravity acts as a moving force through fluids, in the case (1) of water-wheels; (2) of fluids discharging through pipes or orifices, flowing down rivers, canals, \&c. ; and (3) of the hydrostatic press, bellows, \&c.

1. Water Wheels.-These are of three kinds, the overshot, undershot, and breast-wheel. In the overshot-wheel, the water acts simply by weight. It is reccived at the top of the wheel, which is nearly on a level with the reservoir or pond, by a bficket; and, acting on the circumference, serves to draw it round, thus giving a rotary motion to the wheel. Similar buckets are attached to the whole circumference; and, since those on one side of it may all contain water at the same time, they will act together, to turn the wheel. It is evident, from an inspection of the wheel, that its useful effect will be increased by increasing the number of buckets, and by retaining the water in them as long as possible. To this, howerer, there are certain limits. Thus, if a

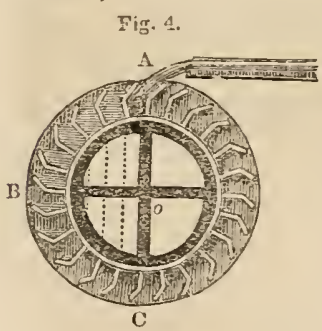
buclict, passing round from $A$ through B to C, Fig. 4, were to retain its water, after passing $\mathrm{C}$, it would retard rather than accelerate. So, while at $\Lambda$ and $\mathrm{C}$, it could produce no useful effect, but would tend, on the contrary, by its pressure on the axle at $o$, to increase the friction, and thus to retard the motion, while at other points, very near to $A$ and $C$, towards $B$, a similar though less effect would ensue. Hence, there is a certain form of buckets, which is most advantageous;*

* Being so constructed, as to retain the water long enough, and yot not too long. 
and this form can be ascertained in 10 way but by scientific researcl.

So, again, there is a certain velocity with which an overshot-wheel should move, in order to produce the greatest useful eflect. This will be evident, from considering two extreme eases. If the wheel be so loaded as to render the wcight of water insufficient to move it, the velocity becomes nothing; and it is evident, that the efficet becomes nothing. If, on the other hand, the wheel be supposed to turn, as rapidly as the water would fall freely, it is evident, that the effect of the water in the buckets will be nothing, since they will descend as fast as the water itself would. Between these limiting cases, there is of course an intermediate velocity, which will produce the best possible effect; and to aseertain it requires, in some degree, that union of science and skill, which distinguished a Śmeaton or a Bossut.

In like mamner, respecting undershot-wheels, on which water acts by impulse rather than weight, there are delicate questions, as to where they are to be user, and with what number of floatboards, which call, in many eases, for the skill of the mathemaFig. 5.

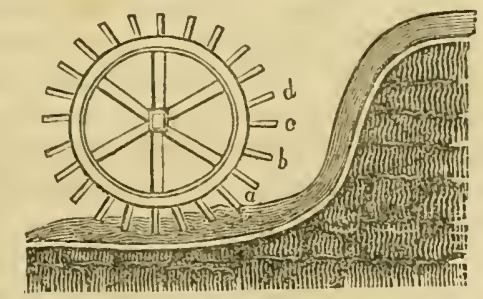
tician and philosopher.

A breast-wheel is one in which the water strikes against the bucket or float, either in a line with the horizontal diameter, or still lower. It may, in the first casc, lave buckets, similar to those of the overshot wheel, as in Fig. 5. In the other ease, where the water is ad-

Fig. 6.

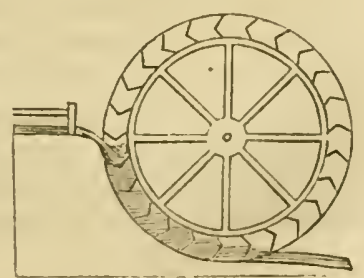

S. A. 


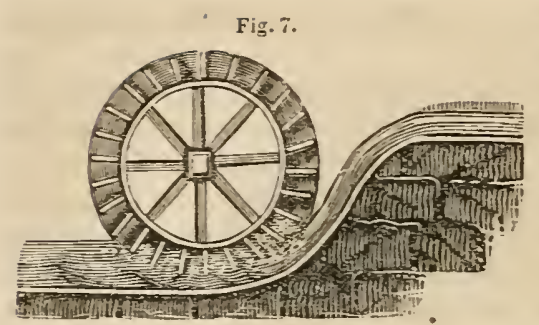

mon undershot-uheel, as in Fig. 7.

2. Fluids flowing through orifices, pipes, canals, \&.c. - When an orifice is opened in a ressel or reservoir containing liquids, the liquid flows out with a relocity equal to that which a heary body would acquire by falling through the height from the level of the fluid in the ressel to the orifice. And so its motion, al-

Fis. 8 .

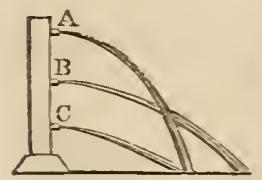

mitted below the horizontal diameter, the wheel is enclosed in a channel which it nearly fills, and is furnished with floats, or paddles, like those of the comcharged through a given orifice in a given time; that is, with what relocity it will be discharged ; or how long it will take to empty a ressel of given dimensions, through an orifice of given size; or how large an orifice must be made, in order to obtain a requisite supply of fluid, in a given time. Thus, when an engineer undertakes to supply a city with water, he ascertains how much will be required for daily or weekly consumption; then determines the elevation of his reservoir above the town; and from these, as data, must calculate how much diameter of pipe will be necessary to afford the supply. Here, of course, allowance is to be made for friction against the pipe; for leakage, \&c.; and it will be evident to every one, that, to make such calculations with accuracy requires all the skill of the scientific and practical engineer. 
3. Hydrostatic pressure.-(a.) Fluids have one property which distinguishes them remarkably from solids, and by which they modify, essentially, the action of gravity. This is, that their particles, being held together by a very slight cohesion, are ready to move at. the slightest force; and experiment proves, that they can be at rest only when they press and are pressed, equally, in all directions. Hence, if water be confined in a ressel, and pressure, to any amount, be applied to a square inch of that water, a pressure, to an equal amount, will be transmitted to every square inch of the surface of the ressel in which the water is contained. For example: fill a cask with water, and then insert a small tube in the top; fill this tube with water, and it is evident that it will press upon $\mathrm{AB}$, where the tube is inserted, with a force equal to the weight of the water in the tube. Suppose this to be one pound; then the pressure on the inside of the ressel will exceed one pound as many times as

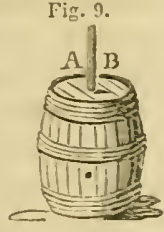
that inside surface exceeds the area $A B$, which may be many thousand times. Hence, we may, by this simple process, burst the strongest cask, and have a pleasing and striking proof of the principle under consideration.

It is on this principle that we construct the hydrostatic bellows. A vertical tube is made to communicate with an apparatus like a common bellows, except that it has no ralsc, or opening, at the under side. If the tube holds an ounce of water, and has an area or caliber equal to the one thousandth part of that of the top board of the bellows, an ounce of water in the tube will balance a thousand ounces resting on the bellows. 'The upper surface, or top board, being free to rise, mav be used for raising weights,

Fig. 10.

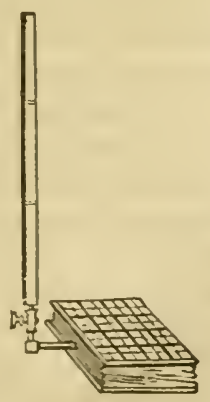


applying pressure, \&c. On the same principle, $\mathrm{Mr}$ Fig. 11.

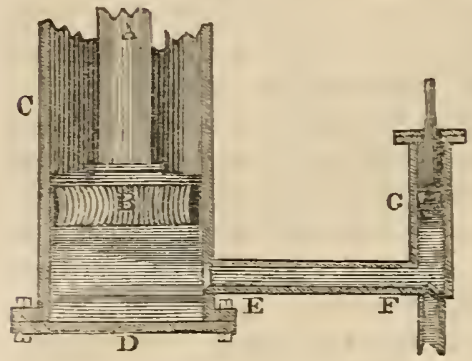

Bramah constructed his hydrostatic press, an instrument of such prodigious force, that, by means of one no larger than a common teapot, we cut asunder a bar of iron, as easily as we cut a slip of pasteboard.*

(b.) It follows, from the property of fluids which we have just mentioned, that their pressure against any surface is proportioned, not to the bulk or quantity of the fluid, but only to the size of that surface, and to the height of the fluid above it. Thus, in the cask with a tube inserted in it, or in a conical ressel which stands on the base, the pressure is just as great as though the cask or vessel had been throughout of the size of the largest part. And, on the other hand, if it were funnelshaped, the pressure against the lower extremity would be no greater than though the ressel were throughout of the same diameter as at the bottom. If the surface against which the fluid presses be perpendicular, or inclined, as in a dam, then, in order to find the amount of pressure, we multiply the number of square feet in that dam,-not into the whole height of the fluid, but into the distance from its surface to the centre of grarity of the dam. The increase of pressure, in proportion to the depth, shows the necessity of making banks of canals, and the sides of tubes, in which water is to be conreyed, stronger in proportion to the depth. It is needless to make them of the same thickness throughcut; since, if they are strong enough for the greater

* The piston 1 mores in the iron cylinder $\mathrm{C}$, being made air-tight by the packing at $\mathrm{B}$. When water is driren by the forcing paup $\vec{G}$, through the small tube $F \mathbf{L}$, into the crlinder, the piston is raised, slowly, but with great porrer. 
pressure below, they will be stronger than is necessary for that above.

From the principles now stated, we may learn the reason why dams, and the banks of canals or rivers, sometimes blow $u$, as it is termed. If water can insinuate itself under a bank or dam, even although the layer were no thicker than a clollar, the pressure of the water, in the canal or dam, will force it up. Similar effects sometimes follow from the water which settles beneath the foundation of buildings, if it be connected, in any way, with other water having considerable perpendicular height. It has even been supposed, that partial earthquakes may have been produced, and large fragments of monntains detached from their bases, by the same cause.

(c.) The level of fluids.-Another consequence of this equality of pressure in fluids, combined with their gravity, is, that, when a fluid is at rest, its surface is level. This is equally truc, whether the liquid is contained in an ordinary vessel, or in a tube bent like a $\mathrm{U}$, or in a teapot or teakettle. The fluid will stand at the same height, in all parts of the ressel, in one branch as in the other; in the spont or nose, as in the ressel itself. It follows from this, that, though water, when unconfined, as in open canals, can never rise above its level, at any one point, and can nerer more upwards; yet, on being confined in close cliannels, it will rise as high as its source, or as the point whence it came. Upon this principle depends the construction of fountains for spouting fluids; also, those useful contrivances for conveying water, by pipes, iil a far more casy, clieap, and effectual, way, than by the vast structures, called aqueducts, which the ancients emplored to carry their supplies of water, in artificial rivers over arches, for many miles. In such ease, the stream must have been running down, all the way; and consequently, a fountain, fed from it, could not, at its termination, furnish the water at the same height as at its source. Upon the same principle, also, namely, that a fuid at rest is al$f^{*}$ 
ways level, depends the construction of levelling instruments, for ascertaining whether any given surface Fig. 12.

is level, or a given line, horizontal; for finding what points are on the same level with any other given point, or how much they are below or above it. Fig. 12 is a water level.

(d.) Specific Gravity.-If a solid be freely suspended in a liquid, it will weigh less than when in air. Now; the upward pressure of the liquid against the bottom of this solid, or, in other words, the loss of weight in the solid, must be just equal to the pressure which would have been exerted against a portion of liquid occupring the same place; or, in other words, must be just equal to the weight of a bulk of the liquid as large as the solid. If equal bulks of the solid and fluid would weigh the same, then the solid will remain freely suspended in the fluid, at any point, without support. If the solid weigh less than an equal bulk of the fluid, it will rise, till the part immersed is of the same bulk as a portion of fluid, which, if weighed, would just equal the whole u'eight of the solid. If it weigh more, it will sink, by a force equal to the difference in weight of equal bulks of the solid and liquid; and generally, $a$ body of given bulk, by being immersed, loses as much in its u'eight as an equal bulk of the fluid u'eighs. If, then, we would find the relative weights, or, what is the same thing, the specific gravities* of solids, we

* For the sake of conrenience, one substance (rrater) is assumed as the standard, and its gravity being expressed by 1 , the relative gravity of an equal bulk of any other substance will be expressed by a whole number or fraction, which stands for its specific gravity. Thus numerical tables of specific gravities are constructed.

It might seem, at first sight, that the relatire or specific grarity of two solids would be ascertained more readily, by simply weighing them in air. This would be so, if we conld obtain two bodies of precisely the same bulk; since it is the relatire weights or densities only of bodies of equal bulk, that we seek. But the exact balk of bodics, of irregular figure, cannot be ascertained. Thus, Hiero would know whether all the gold which he gare the joweller has been worked up in the crown, or whether an inferior metal has been 
immerse them, successively, in water, or any other liquid, and sec how much of their weight, in each case, is lost. If, on the contrary, we would find the relative weights of two or more fluids, we take the same solid, and immerse it, successively, in each of those fluids, and the weight lost, in these sereral eases, will show the relative or specific gravities of the fluids, which will be in the direct ratio of their densities.

We owe the invention of the method of ascertaining specific gravities to Archimedes. He had been required, by Hiero, King of Syracuse, to determine whether a gold crown, which had been made for him, was adultcrated or not. While studying this problem, he happened to bathe, and observed that the water in the bath rose, as his body was immersed. He then inferred, that the rise would be always proportioned to the bulk of the body immersed, and that, if two bodies, of equal wcight but unequal bulk, were plunged in the fluid, the rise, being directly as the bulk, would be inversely as the density or specific gravity. 'This suggested to him a ready mode of testing the purity of the gold crown; and generally, we may remark, that the purity of any substance, such as drugs, chemical preparations, coins, liquids, $\&$ c., may be readily ascertained by the method of specific gravity. Different instruments have been eonstructed, for detecting adulterations in various substances, such as the oleometer, for oil, the lactometer, for milk, \&c.

mixed with it. He cannot tell by weighing the crown against the gold, in air, since they may have equal weights, and yet not be of the same degree of purity. But if, on being weighed in water, each loses the same proportion of its weight, this is evidence that they are of equal bulk, and therefore of equal density, or specific gravity. 


\section{CHAPTER V.}

MECHANICAL AGENTS.-(GRATITY CONTINEED.)

(c.) The gravity of AERIFory Bodies, such as the atmosphere, gases, \&c., acts (in connexion with their inertia and elasticity) as a moring force, in the case of pumps, barometers, windmills, sailing-vessels, fire-engines, \&c. That air has gravity or weight, may be proved by weighing a flask, from which the air has been withdrawn. It will be found, when filled with air, some grains heavier than when emptied. Now: it is found, by experiment, that the pressure of the atmosphere on a square inch is equal to about fifteen pounds; that is, that a column of this fluid, whose base is one inch square and whose height is that of the atmosphere, weighs fifteen pounds. Consequently, it follows, that a horizontal surface sustains a weight or pressure amounting to fifteen times as many pounds as there are square inches in its extent. If, then, we have a solid substance, with an horizontal surface; for example, a piston, placed in a vertical crlinder, and there is no resistance below it, it will be forced down, by a mechanical pressure of fifteen times as many pounds as there are square inches in its end; and in this way a mechanical agent, of power limited only by the magnitude of the piston, will be obtained. Before this force can be exerted, however, a vacuum must be formed; that is, the air must be withdrawn from one side of the piston; and, if this be done br mechanical means, as is the case in the pump, it is obrious, that it must require just as much force to do it, as will be subsequently gained by the pressure of the atmosphere on the other side.

Again: the air may exert its moving force, by being applied to water. This is the case in the common pump. To understand the principle of this instrument, let us suppose a bent tube. Fig. 13, contain- 
ing water in the portion $\Lambda \mathrm{BC}$, and open at both ends. The water will stand at the same height, in both branches. If, now, the air were withdrawn Fig. 13. from the branch $\mathrm{CD}$, the pressure of the air on the water at $A$, in the other branch, would force it downwards towards $B$, and thus cause a rise of the water, in the other branch, B D. It would continue to rise, until the weight of water, in the branch $\mathrm{B} \mathrm{D}$, was sufficient to balance the pressure of the atmosphere, added to the weight of the water $A B$; and before that equilibrium can take place, might discharge itself at D. Here, the branch B D may represent the barrel of the pump, A B the water in the well.

Some notion of the common or suction pump may be gathered from the annexed diagram, (Fig. 14.) in which C L is the barrel of the pump, $\mathbf{B}$ a box fixed in the inside of the eylinder, just above the surface of the water in the well, and $\mathrm{D}$ another box, or piston, attached to the rod $c d$, and moved by a powcr applied at 2 . Both $B$ and $D$ are so formed, as to prevent the passing of any air between them and the sides, and lave valres, $b$ and $d$, opening upwards, similar to the valves in a common lellows. If, now, the piston $\mathrm{D}$ be drawn upwards, it will evidently carry the air before it, and leave a racuum between itself and $B$. But as the air presses on the wa-

Fig. 14.

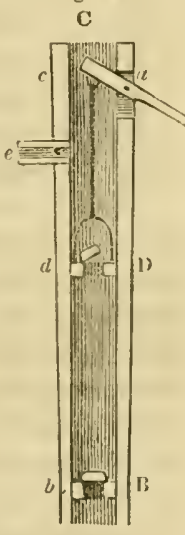

I. ter in the well, outside of the barrel, it will force it up, to supply this vacuum; and, after having passed above $B$, the valve $b$ will be shut, by its downward pressure. At the returning stroke of $\mathrm{D}$, the water will pass through the valve in $D$; and, on raising $D$ again, will be driven out of the spout at $e$. Here we see, at once, that the moving power is applied at $a$, and that the pressure of the air is used merely as an intermediate agent, to effect, with greater expedition and convenience, what might 
have been effected directly, as in a common well, by the same power.

In the barometer, the mercury in the tube is sustained by the pressure of the air. If a vacuum be created in a glass tube, of sufficient length and closed at one end, and if the open end be inserted in a basin of mercury, the fluid will rise to the height of twenty-nine or thirty inches, because a column of mercury of this height weighs just as much as a column of the atmosFig. 15. phere of the same base. This instrument,

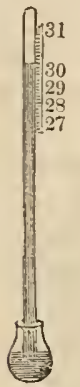
(Fig. 15, ) is very useful, in showing those changes in the pressure of the atmosphere which usually precede storms.

If the column of the atmosphere which sustains the mercury becomes lighter, the mercury will of course fall, and vice versa. The instrument has also another important use. If we are ascending mountains, the column of atmosphere above us must be constantly growing shorter, and of course lighter; and hence, if we carry a barometer, the fall of the mercury will indicate the various heights to which we attain. It may be proper to add, that the weight of the atmosphere was not discovered till the sixteenth century; and that to this discovery we owe the barometer, as well as many improvements in the construction of pumps. Previous to the time of Galileo, philosophers explained the ascent of fluids in a racuum, by saying that Nature abhorred a vacuum: and when it was subsequently found that water would never ascend above thirty-two feet, (the point at which its weight, together with the elasticity of the residual air, just balanced the pressure of the atmosphere,) they explained it, by saying, that Nature's horror of a vacuum did not extend beyond that distance!*

In windmills, where the machinery is turned by the

* See further, on this subject, Vol. i, p. 19, \&c., of a work en titled, 'Pursuit of Knowledge under Difficulties,' forming the four teenth volume of 'THE SCHOOL LIBRARY.' 
wind striking (as in undershot water-wheels) against the vanes of a wheel, and so, also, in vessels propelled by wind striking against the sails, air acts not so much by gravity as by inertia. To adjust these vanes, so that the wind will strike upon them with the greatest effect, and will act only while it contributes to impel the machinery, is a problem which has exercised tine most accurate experimentalists and the most profound mathematicians. It is a beautiful proof of the truly mathematical principles on which the works of creation are formed, that the method of arranging the sails, ultimately adopted in the windmill, bears a striking resemblance to the arrangement of the feathers and wings of birds. These feathers are so adjusted, that, when the wing descends and strikes against the air, it will present the greatest possible surface; whereas, when it is raised, to renew the stroke, it presents the least possible surface So in the windmill, the position of the sail varies, on opposite sides of the wheel, that, in the one case it may receive the full force of the wind, and in the other case may suffer it to pass by.

II. Elasticity.-In fire-engines, airguns, airpumps, \&c., a new property of air is brought into view, which we call elasticity. It acts, in the common fire-engine, in conjunction with the gravity of the air, and in the airgun, in conjunction with that equality of pressure, which is a property of aeriform bodies as well as of liquids. In virtue of its elasticity, the air tends to expand itself; and

it be condensed, or compressed into a space smaller han that which it naturally occupies, it will, if suffered to expand freely, exert a force just equal to that which has been employed in compressing it. Thus, in the fireengine, water is forced into an airtight vessel, which laad been previously filled with air: as the water enters, it crowds the air into a smaller and smaller space, by which means, the elasticity of the latter is so much increased, that it reacts upon the surface of the water, and drives it out through the spout of the engine. Here, the water is thrown out by the air, with no greater force than has 
been preriously applied to work the pistons; so that there is really no gain of power. The adrantage is, that, by interposing the air, we get an agent which acts by continuous pressure, and not by intermitting strokes. So in the airgun: by condensing air within the breech of the gun, we procure a force, which, on being released, will act instantaneously, and with a power equal to all the separate effects made in the process of condensing it. If we attempted, by mere manual force, to project a bullet, we should produce but little effect. Condensed air serves as a magazine, in which we can treasure up and combine a great number of these separate exertions of our strength, and cause them to act simultaneously.

It may give us some impression of the value of science, as connected with the arts, if we consider, that scarcely one of the important powers which we have just considered was employed by the Greeks and Romans, in the days of their greatest civilization and renown. They had neither waterwheels, * windmills, nor airpumps. To procure bread for his family, a Greek had no flour-mills, except such as were mored by liand or by animals. Neither had he sawmills, to supply boards and lumber for edifices; nor fire-engines, to rescue cities and habitations from the devouring element; nor hydrostatic presses, to coneentrate, within a small compass, immense pressure : nor metallic pipes, to convey water over hills and valleys, without the expense of arches and mason work; nor, in fine, the airpump, to withdraw substances from the contact of the atmosphere, so as to observe the effect on combustion, sounds, respiration, and regetable life.

But, while we acknowledge the rast benefits which

* This remark requires some qualification. Beckmann says: "The first certain information we have of the invention of uatermills is not older than the time of Julius Cæasar. Cattlemills continued in such general use, that, near three centuries afterwards, there were more than three hundred at Rome ; and, A. D. 39S, some public enactments were made, which show that, even then, watermills were considered a new establishment." 
have been conferred by these inventions, in modern times, we must remember, that even yet the principles on which they depend are by no means generally understood. Multitudes, even of those who are called to deal continually with those principles, have no proper conception of them, and commit many blunders and waste a great deal of money, which a little knowledge would have enabled them to save. The two following instances will be sufficient illustration of this fact : "A respectable gentleman, of landed property, in one of the middle counties of Scotland, applied to a friend, a lecturer on chemistry and natural philosophy, in order to obtain his advice respecting a pump-well, which he had lately constructed at considerable expense. $\mathrm{He}$ told him, that, notwithstanding every exertion, he could not obtain a drop of water from the spout, although he was quite sure there was plenty of water in the well, and although he had plastered it all around, and blocked up every crevice. When his friend inspected the pump, he suspected that the upper part of the well was airtight, and, consequently, that the atmospheric pressure could not act on the surface of the water in the well. He inmediately ordered a hole to be bored, adjacent to the pump, when the air rushed in, with considerable force; and, on pumping, the water flowed copiously from the spout. 'The gentleman was both overjoyed and astonished; but it is somewhat astonishing, that neither he, nor his neighbors, nor any of the worlimen who had been employed in its construction, should have been able to point out the cause of the defect; but, on the other hand, should have taken the very opposite means for remedying it, namely, by plastering up every crevice, so as to produce a kind of vacuum within the well." **

* Dick, on the Improvement of Society. We once linew a man to carry a series of aqueduct pipes to the bottom of a well sixty feet deep, and thence over the top down into a neighboring valley, below the level of the bottom of the well, for the purpose of supplying water to a sinall manufactory, as a syphon. If he had known that water rises in the syphon, as in the pump, in consequence of 
After the diving-bell was invented, it was considered desirable to devise some means of remaining, for any length of time, under water, and rising at pleasure, without assistance. "Some years ago, an ingenious individual proposed a project, by which this end was to be accomplished. It consisted in sinking the hull of a ship, made quite watertight, with the decks and sides strongly supported by shores, with the only entry secured by a stout trapdoor, in such a manner, that, by disengaging from within, the weights employed to sink it, it might rise of itself to the surface. To render the trial more satisfactory and the result more striking, the projector himself made the first essar. It was agreed, that he should sink in twenty fathoms water, and rise again, without assistance, at the expiration of twentyfour hours. Accordingly, making all secure, fastening down his trapdoor, and provided with all necessaries, as well as with the means of making signals, to indicatc his situation, this unhappy rictim of his own ingenuity entered, and was sunk. No signal was made, and the time appointed elapsed. An immense concourse of people had assembled to witness his rising, but in rain; for the ressel was never seen more. The pressure of the water at so great a depth had no doubt been completely under-estimated; and the sides of the ressel being at once crushed in, the unfortunate projector perished, before he could eren make the signal concerted, to indicate his distress."

the pressure of the atmosphere, and that this pressure will force is up only a little more than thirty feet, he might have been spared the cost of the attempt and the mortification of its failure.

* Sir J. Herschel, on the Study of Natural Philosophy. 


\section{CH.APTER VI.}

MECHAIICAL AGEXTS.- (IMATIMATE FORCES CONTINUED.;

III. Heat.-Havisg thus explained how gravity and elasticity are employed, as moving forces in the arts, we come, in the third place, to consider Heat.

Its use as a mechanical agent depends upon the power which it has of expanding bodies. If a bar of metal be accurately measured, and then raised to a red lieat, it will be found longer than before; and stil! longer; if it be raised to a white heat. It is for this reason that the mechanic heats the iron tire of a wagon or coach wheel, and the iron hoops of a cask, before putting them on; and also the rivets which are used in binding together the iron plates of which boilers are made. Being, by this means, expanded, they are easily fitted to their places, while the contraction which follows binds the adjacent parts together, and holds them firmly.

A striking instance of the use, as a mechanical agent, to which this expansive power of metals may be applied, occurred some years since, in Paris. The weight of the roof of the abbey of St. Martin was forcing the walls asunder, and the following method was taken to restore them to their perpendicular position. Holes were made, at opposite points, in several parts of the wall, through which strong iron bars were introduced, so as to extend across the building, their ends projecting outside the walls. Large nuts were placed upon their ends, and screwed up, so as to press upon the walls. Every alternate bar was then heated, by powerful lamps, so that its length was increased by expansion, and the nuts, before in close contact with the walls, retired to some distance from them: the nuts were then screwed up to the walls, and the bars cooled. 'The pro- 
cess of cooling restored the length of the bars to what it had been before the heat was applied, and the nuts were drawn together by an immense force. The same process being repeated with the intermediate bars, and this being continued, the walls of the building were gradually restored to their perpendicular position.

The expansion of bodies by heat affords us the means of constructing instruments to measure different degrees of temperature. The principal of these are, the conmon thermometer, and the pyrometer of Wedgewood. The thermometer consists of a small tube, terminating at the bottom in a bulb, containing mercury or spirits of wine. The air having been previously expelled by heat, the tube is closed at the top, to prevent its return, and a racuum being thus produced, above the fluid, it is free to expand when heat is applied. 'This expansion is indicated by a rise of the fluid; whereas the contraction produced by cold causes the fluid to descend. A scale, attached to the tube, and divided into degrees, measures these variations, and thus indicates the temperature. In diriding this scale, it is usual, in the first place, to fix the two points, at which the mercury stands, when the temperature is sufficiently low to freeze water, and suficiently high to boil it. These are obtained, by immersing the instrument with the scale, first into melting ice, and afterwards into boiling water. The intermediate space is then divided into a certain number of degrces, the number being different in different linds of thermometers. If the bore of the tube be throughout of the same size, these spaces or degrees will be equal in length; otherwise, they will be unequal. It is evident, that that portion of the tube to which they correspond must always be of the same capacity.

The pyrometer is an instrument used for measuring higher degress of temperature than are indicated by ordinary thermometers. It depends upon a property of pure clay, which forms an exception to the general 
expansion of bodies by heat.* This clay, when much heated, contracts. The contraction is first observed when the clay acquires a red heat, and continues to increase, until it vitrifies; the reduction of bulk being permanent, and amounting, in the whole, to about one fourth. In order to take adrantage of this property of clay, Mr. Wedgewood construeted a gauge of brass, consisting of two straight pices, two feet long, fixed upon a plate a little nearer to each other at one end than at the other, the space between them, at the widest end, being five tenths of an inch, and at the narrowest, three tenths. 'The converging pieces were divided into inches and tenths of inches. 'The pieces of clay, the contractions of which were to be measured, were of a cylindrical form, flattened on one side, and of such a size as to be exactly adapted to the wider end of the gauge, so that it might slicle further in, in proportion to the degree of lieat applied to it. A scale was adapted to this clay, each degree of which is equal to one hundred and thirty degrees of the ordinary seale in thermometers. The temperature of red licat, which corresponds to one thousand seventy-seven and a half degrees of Fahrenheit's scale, was assumed as the commencement of Wedgewood's; and it was found, that the instrument could be used to measure temperatures as high as thirty-two thousand two hundred and serenty-seven degrees of Fahrenheit. $\nmid$

Steam.-It is evident, that the forces of expansion and contraction, by heat and cold, which we have now considered, act through spaces so limited, that they can

* Another remarkable exception to this law is fond in freczing watcr When near the freezing point, water does not contract, as we should px. pect, from the inerease of eold, but, on the contrary, expands; so that a given quantity fills more space, when frozen, than it did previously. It of course becomes specifically lighter, which may suggest to us the reason of this apparent anomaly. If ice were heavier than water, it would subsicle, as soon as formed, in suceessive flakes to the bottom: this process wonld conrinue, nutil the whole of the water, however deep, would hecome solid. The efiects wonld evidently be most disastrous.

$f$ Later olsservations show, that owing to irregularities in the entraction of the e!ay, Wedgewond's instrument is not to be relied on. Daniell's is preferable-he uses platiua. 


\section{be used as mechanical agents very rarely, and only un- der peculiar circumstances.*}

A much more important agency, which heat exerts in the mechanic arts, results from its power of changing the form of bodies. With the operations of this power we are all familiar, in the case of water. Below the temperature of thirty-two degrees of the common thermoneter, that substance exists in the solid form, and is called ice. Above that temperature, it passes into the liquid state, and is called water; and when raised to the temperature of two hundred and twelve degrees, under ordinary circumstances, it passes into the aeriform state, and is called rapor. It is to this last change that we wish, at present, principally to call the attention of the reader.

* It may not be irrelerant to notice, here, the injurions effect which is somctimes exerted in the arts, by the expansive power of heat. In warm weather, for example, it lengthens the pendnlnm rod of a clock, and causes it to go too slow: a derangement which we shall better apprecinte, when we are told, that a difference of the one hundredth part of an inch, in the length of the rod, will occasion a loss of ten seconds in twents-four hours. This irregularity in the going of a clock is corrected, most commonly, by means of what is termed the gridiron pendulum, - the rud being composed of sereral parallel bars, like those of a gridiron. These bars, being of different metals, expand unequally, and serve, therefore, to compensate the irregularities of each other. Again, when we suddenly heat one side of a glass ressel, the great expansion causes it to break. If the heat is applied to both sides, at the same time, so that thev heat and expand, cqually, there is little danger of breaking. In . Vuture, the expansive power of heat produces the most salntary effects, by creating currents of air, which carry off superfluons heat from one part of the earth, while they serve to mitigate the severity of cold at uther parts.

The effect of heat, in expanding bodies, is strikingly exemplified, also, in the immense system of steam-pipes, which are frequently emplored to heat manufactories, extending, in some cases, to three hundred feet, in a straight line. "When fire-proof factories, of iron and brick, were first built, in England, the columns, which supported the successire floors, being hollow, were intended to admit steam, and to be the channels of communicating heat to the apartments. It was soon found, howerer, that the lengthening and shortening of a columinar range of eighty or ninety feet high, by a clianging temperature ranging as high as one hundred and serenty degrees of Fahrenheit, was so considerable, as to impair the stability of the most solid edifices. Hence horizontal steam-pipes were substituted, being suspended near the ceiling, by swinging rods of iron, and so adjusted, 35 to give free play to the expansion and contraction." - Dr. Ure. 
In the transition of water from the liquid state to the state of vapor, or steam, an immense change of bulk takes place. In this change, a solid inch of water enlarges its size about one thousand seven hundred and twenty-eight times, and forms one thousand seven hundred and twenty-eight solid inches of steam. This expansion takes place, accompanied with a certain force or pressure, by which the vapor has a tendency to burst the bounds of any ressel which contains it. The steam which fills one thousand seven hundred and twenty-cight solid inches, at the temperature of two hundred and twelve degrees, will, if cooled below that temperature, return back to the liquid form, and occupy only one solid inch, leaving one thousand seven hundred and twenty-seven solid inches vacant; and if it be included in a close vessel, it will leave the surfaces of that ressel free from the internal pressure, to which they were subject before the return of the water to the liquid form.

If it be possible, therefore, alternately to convert water into rapor, by heat, and to reconvert the vapor into water, by cold, we shall be enabled, alternately, to submit any surface to a pressure equal to the elastic force of the steam, and to reheve it from that pressure, so as to permit it to more in obedience to any other force which nay act upon it. Or, again ; suppose that we are enabled to expose one side of a movable body to the action of water converted into steam, at the moment that we relieve the other side from the like pressure, by reconverting the steam, which acts upon it, into water; the movable body will be impelled by the unresisted pressure of the steam on one side. When it has mored a certain distance, in obedience to this force, let us suppose that the effects are reversed. Let the steam, which pressed it forwards, be now reconverted into water, so as to have its action suspended: and, at the same moment, let steam, raised from water by heat, be caused to act on the other side of the movable bndy; the consequence will obviously be, that it 
will now change the direction of its motion, and return, in obedience to the pressure excited on the opposite side. "Such is, in fact, the operation of an ordinary lowpressure steam-engine. The piston, or plug which plays in the cylinder, is the movable body to which wo have referred. The vapor of water is introduced upon one side of that piston, at the moment that a similar vapor is converted into water on the other side, and the piston moves by the unresisted action of the steam. When it has arrived at the extremity of the crlinder, the steam, which just urged it forwards, is reconrerted into water, and the piston is reliered from its action. At the same moment, a fresh supply of steam is introduced upon the other side of the piston, and its pressure causes the piston to be moved in a direction contrary to its former motion. Thus the piston is movea in the cylinder, alternately in the one direction and in the other, with a force equivalent to the pressure of the steam which acts upon it. A strong metal rod proceeds from this piston, and communicates with proper machinery, by which the alternate motion of the piston, backwards and forwards or upwards and downwards, in the cylinder. may be communicated to whatever body is intended to be mored."

"The power of such a machine will obriously depend partly on the magnitude of the piston, or the morable surface which is exposed to the action of the steam; and partly on the intensity of the pressure of the steam itself. The object of converting the steam into water by cold, upon that side of the piston towards which the motion takes place, is to relieve the piston from all resistance to the moving power. This renders it unnecessary to use steam of a tery high pressure, inasmuch as it will have no resistance to orercome, except the friction of the piston with the cylinder, and the ordinary resistance of the load which it niay have to move. Engines constructed upon this principle, not requiring, therefore, steam of a great pressure, have heen generally called, "lor-pressure engi.cs." The 
reconversion of the steam into water requires a constant and abundant supply of cold water, and a fit apparatus for carrying away that which becomes heated by cooling the steam, and for supplying its place by a fresh quantity of cold water. It is obvious, that such an apparatus is incompatible with great simplicity and lightness, nor can it be applied to cases where the engine is worked under circumstances in which a fresh supply of water cannot be had." *

* The following view, Tig. 16, of Wall's double-acting condensing steam-engine, will render this deseription more intelligible to the

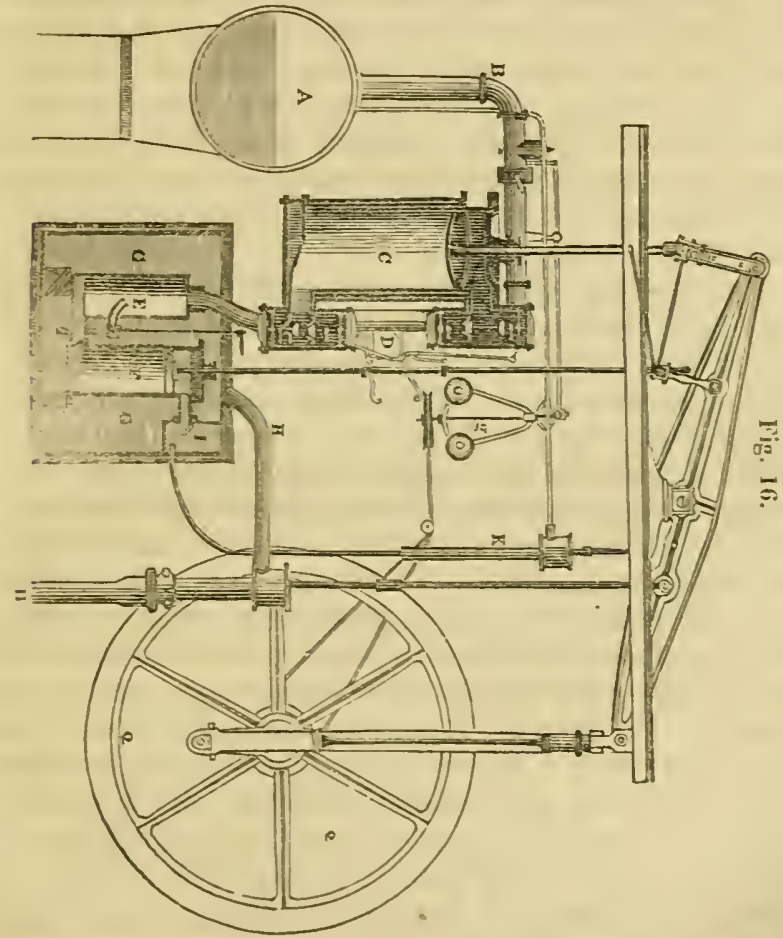

young reader. A, boiler; $B$, steam-pipe, conveying the steam to the cylinder, C ; D, eduction-pipe, which conducts the steam from 
"The reconversion of steam into water, or, as it is technically called, the condensation of steam, is, however, by no means necessary to the effective operation of a steam-engine. From what has been abore said, it will be understood, that this effect relieves the piston of a part of the resistance which is opposed to its motion. If that part of the resistance were not remored, the pressure of steam, acting upon the other side, would be affected in no other way than by having a greater load or resistance to overcome; and if that pressure were proportionately increased, the effective power of the machine would remain the same. It follows, therefore, that, if the steam upon that side of the piston towards which the motion is made were not condensed, the steam, urging the piston forwards on the other side, would require to have a degree of intensity, greater than the steam in a low-pressure engine, by the amount of the pressure of the uncondensed steam on the other side of the piston."

"An engine, working on this principle, has therefore been called a high-pressure engine. Such an engine is relieved from the incumbrance of all the condensing apparatus, and of the large supply of cold water necessary for the reduction of steam to the liquid form ; for, instead of being so reduced, the steam is in this case simply allowed to escape into the atmosphere. The operation, therefore, of high-pressure engines will be readily understood. The boiler, producing steam of a very porrerful pressure, is placed in communication with a cylinder, furnished, in the usual manner, with a piston; the steam is allowed to act upon one side of the piston, so as to impel it from the one end of the cylinder to the other. When it has arrived there, the communication with the boiler is rerersed, and the steam

the cylinder to the condenser, $\mathrm{L}$; F, air-pump, which removes the water and air from the condenser; G G, cistern of cold water, surrounding the condenser; $H \mathrm{H}$, pump which supplies the cistern, $\mathrm{G}$, with cold water ; $I$, cistern containing hot water, from the condenser; $\mathrm{K}$, pump to convey the hot water from the cistern. $\mathrm{I}$. to the boiler, $\mathrm{A}$. 
is introduced on the other side of the piston, while the stcam, which has just urged the piston forwards, is permitted to escape in to the atmosphere. It is evident, that the only resistance to the niotion of the piston, here, is the pressure of that portion of steam, which does not escape into the air; which pressure will be equal to that of the air itself, inasmuch as the steam will continue to escape from the cylinder, as long as its clastic force exceeds that of the atmosphere. In this manner, the alternate motion of the piston in the cylinder will be continued; the efficient force which urges it being estimated by the excess of the actual pressure of the steam from the boiler above the atmospheric pressure. The superior simplicity and lightness of the high-pressure engine must now be apparent; and these qualities recommend it strongly for all purposes in which the engine itself must be moved from place to place."

Mr. Gordon an engineer thus enumerates some of the applications of this plastic power, when treating of the substitution, in England, of inanimate for animate power, in locomotion. "Considered in its application to husbandry, the cottager looks forth upon the neat paling which fences his dwelling; it was sawed by steam. The spade with which he digs his garden, the rake, the hoe, the pick-axe, the scythe, the sickle,-every implement of rural toil which ministers to his necessitics, are produced by steam. Steam bruises the oil-cake which feeds the farmer's cattle; moulds the ploughshare which overturns his fields; forms the shears which elip his flock; and cards, spins, and weaves, the produce.

"Applied to architecture, we find the Briarean arms of the steam-engine every where at work. Stone is cut by it, marble polished, cement ground, mortar mixed, floors sawed, doors planed, chimney-pieces carved, lcad rolled for roofs and drawn for gutters, rails formed, gratings and bolts forged, paints ground and mixed,

* See Ediuburgh Review, No. 111, art. Inland Transportation. In Fig. 17, on the next page, a view of the iuternal construction of a locombive high-pressure steam-engine will enable the reader the bet- 
paper made and stained, worsted dyed and carpet wove, mahogany veneered, door-locks ornamented, curtains and furniture made, printed, and measured; fringes, ta s-

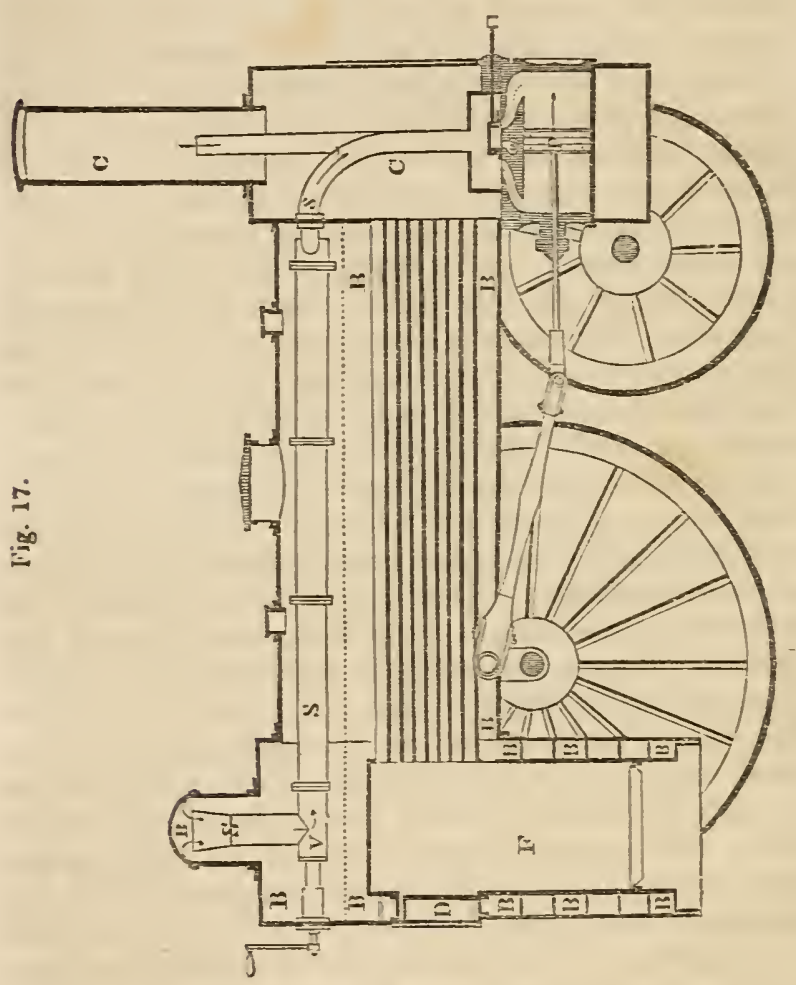

sels, and bell-ropes, chair-corers and chair-nails, bell. wires, linens, and blankets, manufactured: china and earthen-ware turned; glass cut, and pier-glass formed ; the drawing-room, dining-room, kitchen, pantry, closets, \&c., all owe to steam their most cssential requisites.

ter to understand this description. B B, boiler ; C, chimney ; D, door by which fuel is introduced to the fire, F; P, Piston; S, steam-pipe. 
"Should the question be asked, what has enabled the inferior proprietors to wcar two hats a year instead of going bare-headed or sporting the bonnet which their fathers wore; what has clothed them in suits of excellent broadcloth, and given thein ability to ruffle it with the first-born of the land; what has donned for their wives, ladies' apparel, made their boys rejoice in a plurality of suits; and, in the bridal hour, busked their daughters in robes, delicate in texture as the spider's web, beautiful in color as the rainbow's lues, and for elegance such as never in their grandame's younger days, eren Duchesses wore; what plaited her bonnet, tamboured her net, wove her laccs, knitted her stockings, veneered her comb, flowered her ribands, gilded her buttons, sewed her shoes, and even fashioned the rosette that ornamented their ties? The answer is,_-steam."

We have thus shown, how heat may be employed in producing motion. It may be proper to remark, in concluding the subject, that this is not the only nor perhaps the most important use, to which that powerful agent may be applied in the arts. Heat forms an almost universal fuser, which enables us to reduce the most refractory substances, and to orercome degrees of coliesion which seem to defy every other agency. It serves not only to prepare our food and warm our habitations, but also to smelt ores, and render metals malleable; to harden clay for the various uses of the builder and the houseliceper; and to extract, from mixtures of alkali and sand, that beautiful substance, which decorates our tables, reflects our persons, and guides the feeble vision of age and infirmity over the page of wisdom, and in the pursuits of industry.

To procure this principle, therefore, by artificial means, and to apply it to the various purposes of life, must be one of the most important and comprehensive of all the arts. It is an art, however, which has received comparatively but little attention. The chemical laws of heat have been investigated, with equal ingenuity and success. But the application of these laws to the pro- 
cess of producing and using heat has been less studied, and has by no means made the progress, which might have been anticipated, from its importance. One reason of it may be, that mankind have been so long employed in building fires, and applying heat to its various uses, that they cannot be persuaded that they need instruction in regard to a subject so familiar; and they are slow, therefore, to study it on strict and philosophical principles. Another reason undoubtedly is, that we are usually so engrossed with the object to be attained by the use of heat, and have reason to be so well satisfied with our success, that we have felt little temptation to scrutinize the means employed. Still, it is an unquestionable truth, that the economy of heat has not yet passed its infancy, and is probably destined to undergo a great, and, if we mistake not, a speedy, revolution. It will be our object, in the remaining paragraph of this Chapter, to state some of the defects which appear to characterize this art, in its present state, and some of the most important objects which appear to be still unattained, at least in ordinary instruments.

The greatest want, connected with the practical economy of heat, is that of fixed principles, to regulate the construction of furnaces and other instruments. They are now too generally made at random, or according to rules which have been established only by custom, and for which no sufficient reason can be assigned. The true basis, on which all such constructions should rest, must be found, it is presumed, in the discoreries which have been made by chemical philosophers, respecting the different radiating and conducting powers of rarious substances and surfaces, as well as respecting the nature of combustion and the capacity of certain principles for supporting it. These, if properly considered, would suggest the requisite conditions for generating heat, which must alwars be the same; and also the proper means of applying or using it, which should evidently vary, with the object to be attained. Not the least among the errors which are generally commit- 
ted, by practical men, seems to be, that these two processes, so cssentially distinct, and which often actually counteract each other, are confounderl, and frequently carried on in the same apartment. I furnace, to generate heat advantageously, should evidently be raised to a very high temperature, which can be effected only by surrounding it with non-conducting substances, and by giving to its exterior the color and smoothness least favorable to radiation. But these very eircumstances, which fit a furnace for creating intense heat, entirely unfit it for distributing that heat to an apartment, or applying it to any external use. Hence might be inferred the necessity of having two parts to the apparatus;-one for generating or producing heat, and the other for using it. There are defects, also, in the prevailing mode of supplying air to the fuel to be consumed, in the form which is given to that fuel as a mass; in the practice of adding cold fuel frequently to the fire, by means of which its temperature is reduced, and its useful effect diminished; - on which we eannot enlarge in this place, but which have a material influence unfarorable alike to economy, convenience, and efficiency. **

\section{CHAPTER VII.}

MACHIXERT EMPLOYED IN TIIE ARTS.

Is order to employ the mechanical agents, which have now been considered, it is generally convenient, and even necessary, to interpose between them and the work to be done some contrivance, called a tool or ma-

* Since this paragraph was written, $(1834$,) the introduction of the hot blast into furnaces has created a new era in the history of industry. That, with other related improvements, wis intended to be foreshadowed in the passage above, being, at thit time, well known to the writer. A friend and relative of his, long known to the public, had proposed and introduced it, on a limited scale, some years before, and no doubt was entertained that it was destined to early and muiversal adoption. 
chine. Before we proceed to examine the rarious arts, it will be important to attend, for a moment, to the consiruction and use of these machines.

Man does not excel the inferior animals more in intelligence than in bodily structure. If he has reason, which enables hin to master every science, so has he a hand, which fits him for the practice of every art. The bee and the bearer have intelligence, sufficient to guide them in rearing habitations and procuring food; and they hare natural implements, which qualify them perfectly for the work. They need no tools, except the teeth and extremities with which Nature has prorided them. Man, on the other hand, has an intelligence, which qualifies him for erery office of duty or pleasure; and, instead of being fitted with natural implements, which could be employed only in one kind of work, he has thie hand, fitted to fabricate and grasp every species of artificial tool, and equally ready for erery occasion of peace and of war.

The powers of the human hand have been, in all ages, the subject of admiration. "By it," to use the language of Galen, (Book i., chapter 4,) "man erects the most various habitations. intrenches himself within camps or fenced cities, and weares the garment that protects him from the Summer's heat or Winter's cold. With this, he forms the rarious nets and snares, which give him dominion. as well orer the inhabitants of the water as of the air and earth; constructs the lyre and lute, and the numerous instruments emplored in the several arts of life; erects altars and shrines to the im mortal gods; and lastly; by means of the same instru ment, he bequeaths to posterity, in writing, the intellectual treasures of his own dirine imagination; and hence we, who are living at this dar, are enabled to hold converse with Plato and Aristotle, and all the renerable sages of antiquity." Indeed, without this particular formation, man, with whaterer sagacity he might be endowed, would no longer be the being he now is. "No bounteous grant of intellect, were it the pleasure of Hearen to make such grant," could raise him to his 
present lofty rank, in the seale of power and enjoyment, if, instead of the hand, he lad been formed with the claw of the tiger, or the talons of the eagle, or the hoofs of the elephant.

It is not without reason, then, that man has been defined, somewliat ludicrously, to be a tool-making animal. By nature, lie is destitute of the tools which are necessary, in order to supply his wants; but finding himself endowed with a hand, admirably fitted to make and wield theșe tools, he tasks his ingenuity, and soon produces them. How wonderfully does even the rudest cutting instrument enlarge the powers of the human hand! the fabrication of many things, which were previously beyond its means, becomes easy, and that of others possible, with great labor. Add the saw to the knife or the hatchet, and other works become possible, and a new course of difficult operations is brought into vicw: and thus roes man perpetually adrance in power and resources, till at last he provides himself machines, of the utmost complexity and perfection; machines, which supersede even the hand itself, and perform the most delicate and difficult operations, with all the precision and regularity of an intelligent being.

All machines, howerer complicated, are formed by combining a few simpler machines, commonly called the mechanical powers. Under this head are usually enumerated the lever, the wheel and axle, the inclined plane, the screw, the wedge, the pulley and rope. Of the lever, we have examples in the common crowbar and handspike; in the pump-handle; in the hammer: when used in drawing a nail; in a door opened by the liand; in steclyards, scissors, \&c.* Of the wheel and axle, we hare examples, in the windlass used for raising heavy weights, where the power is applied to the circumference of the wheel, and the weight, or resist-

* Levers are of turee linds. Fig. 18, is a lever of the first kind, resting on the fulcram, at $F$, to raise the weight, $W$, the power being applied at P. Fig. 19, is a lever of the second kind; W, the weight, being between the fulcrum, F, and the power, at l'. Fig. 20, is a lever 
ance, to the axle; also, in the capstan used on shipboard; in the crane; and in the grindstone, where the instrument, pressed on the stone, forms the weight or resistance, the power being applied to a crank, which corresponds to the wheel. It is obvious, that this wheel and axle is, in principle, merely a lever, with the addition of a rotary motion around the fulcrum, or axis."

of the third kind ; the power, $P$, being applied between $F$, the fulcrum, and $\mathrm{W}$, the weight.

Fig. 18.

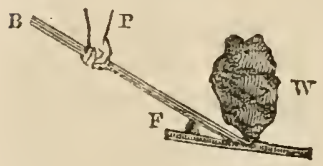

Fig. 22.

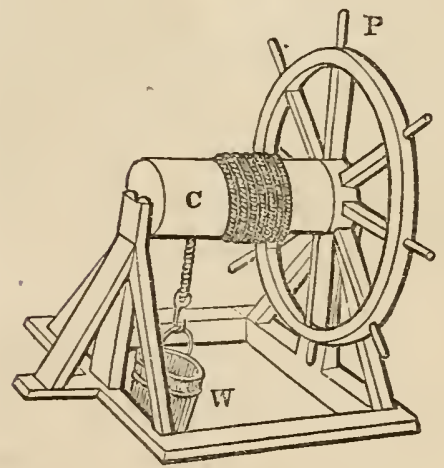

Fig. 22.

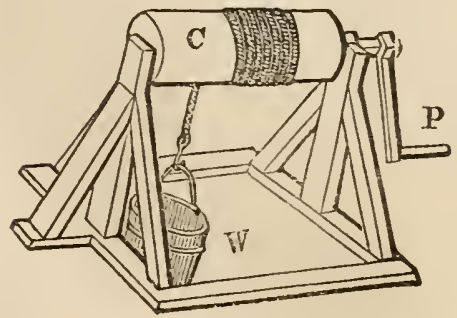

Fig. 19.
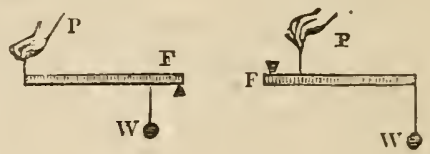

* Fig. 21 represents a wheel and axle; $P$, the power applied to the circumference of the wheel ; $\mathrm{C}$, a cylinder, or axle ; and IV, the weight to be moved.

Fig. 22 is the same, with a crank, $P$, in place of the wheel. 
Of the inclined plane, Fig. 23, Fig. 23. we have an example in the plank, which is used in letting down heavy casks into a cellar, or drawing them

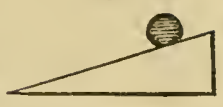
up; and the screw is in principle the same; being an inclined plane of the spiral form, like the stairs which we sometimes see in the inside or outside of a building, winding to the summit. In some cases, the spiral or screw is fixed, and the power is applied to a nut, as in Fig. 24. In other cases, the nut is fixed, and the screw, with Fig. 21. the weight attached, is moved through it by being turned, as in Fig. 25. The wedge, Fig. 26, is another spe-

Fig. 25.

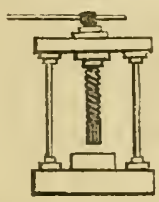

Fig. 26.

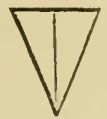

cies of inclined plane, being formed, in most cases, of two inclined planes united at their bases. In addition to the common wedge, we have, as examples of this ma chine, various cutting tools, such as axes, lnives, chisels, \&E. ; the nails and spikes to be driven into wood; the coulter of the plough, and the blade of a spade, \&c.

'The pulley and rope are sufficiently familiar, without other examples than in the annexed figures, $(27,28,29$,

Fig. 27. Fig. 28.

Fig. 29.
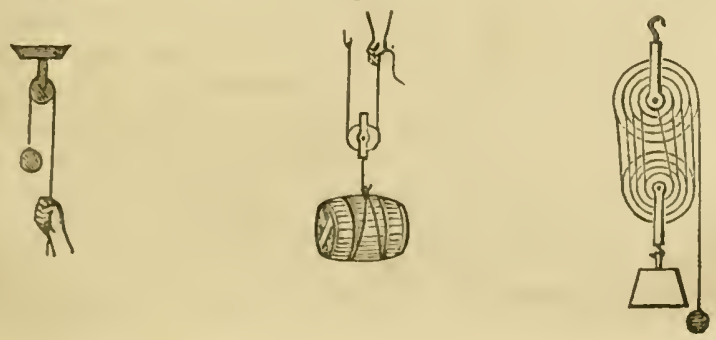
and are the same in principle with the lever. It is apparent, therefore, that the simple machines may be reduced to three classes: 1. The lever, and the wheel and axle. 2. The inclined plane, screw, and wedge. 3. The pulley and rope machine. It is by combining these machines, in various ways, that the machinery now employed in the arts, which is so various, and in many places so intricate, has been constructed. We propose, in this Chapter, to consider the several objects, some one or more of which it is always proposed to attain, by the use of machinery.

1. The first is, to divide a resistance too great to be overcome by a single effort of the moving powcr, so that it may be overcome by a series of actions, or by the continual action of the moving power. If a man were to apply all his strength directly to a rock or to a box of merchandise, which he wishes to elevate to some point, he might not be able to move it at all ; or at least might not be able to raise it to the required height. But with a lever, or a wheel and axle, or a pulley, he effects his object with ease. Here, he does not actually gain power. He gains the means of acting upon the resistance by degrees. It is like taking this rock to pieces, and carrying up the parts separately; and a little reflection must convince us, that when we employ a machine, we exert not only all the force which would be requisite in such a case, if we had not used the machine, but also as much more, as is necessary to overcome the friction and weight of that machine. It is a great error, and one to which we cannot too often advert, to suppose that, by any mechanical device, force can be generated, or eren augmented. Misled by such a notion, projectors have imagined that they could adjust levers, pendulums, \&c., that would act with a power greater than that which they derived from some external source. It is obvious, and should ever be kept in mind, that the inertia of matter, in virtue of which, no particle of it ever moves, except in obedience to some force impressed upon it, and in pro- 
portion to that force, renders all such projects entirely impracticable. Universally, to overcome a resistance, a force must be exerted equal to that resistance; and, as we have already said, if it be exerted through a machine, the force must be absolutely greater than the resistance.

But, on the other hand, force is made up of relocity and the quantity of matter; and hence, if the mass to be moved, or the resistance to be overcome, be much heavicr than the moving power, we equalize them, if we can, by giving to the resistance a much slower motion than that which the power has; thus making the greater velocity of the power compensate for its inferior weight, or mass. In all these cases, however, time must be lost; and it must be remembered, as a general principle, that whatever advantage is gained in respect to pover is lost in respect to time.* A man with a machine does no more than in the same time he would have done without a machine, provided he could have divided the resistance into separate parts. In many cases, however, this is impossible; and hence we are enabled, by the aid of machines, to efiect what, without them, wonld have been altogether beyond our porrer.

2. The second use of machinery is to enable us, $b y$ changing the direction of a force, to apply it more advantagcously. Thus, in lifting a weight out of a well, or raising ore out of a mins, it is obvious, with how much more effect a man can work, at the arm of a windlass, than he could draw directly upon the rope, stooping over the well. There are other cases, in which machinery, by changing the direction of a force that, in its natural state, is useless, enables us to apply it to important purposes. For cxample: in a steam-

- Archimedes is said to have bonsted, that, if he had a place on which to stand, he wonld mosc the earth. IIad such a place been furnished him, and had he becn able, moreover, to move with the velocily of a cannon ball, it would have taken him a million of years to have shifted the earth only the twenty-scven hundred thousandth part of an inch. 
boat, the piston of a steam-engine alternately ascends and descends, along a perpendicular ; $*$ whereas, the vessel, which it serves to propel, is required to move in a continued horizontal line. On the other hand, the stream of a saw-mill moves in a continued horizontal or perpendicular line, while the saw, which it drives, is required to have an alternating perpendicular movement. In the first case, the rectilinear alternating motion is converted into a circular onc, by means of the crank, a contrivance which, in principle, is much like the common winch, or like the key which winds a clock; and then the circular motion of the waterwheels, acting against the water, carries the ressel forward in a continued right line. As a general rule, a circular can be converted into a continuous rectilinear motion, and vice versa, by means of a toothed wheel and rack, as in Fig. 30 ; a continuous circular into an alternate rectilinear, as in the saw-mill, Fig. 31 ; or

Fig. 30.

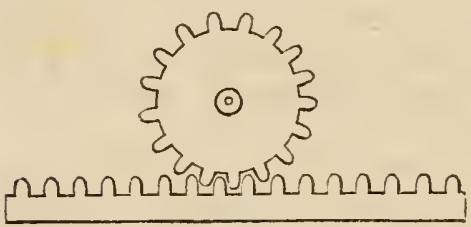

Fig. 31 .

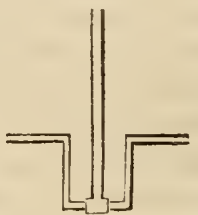

into an alternate circular, as in the balance-wheel of a watch, Fig. 32, and the pendulum of a clock, Fig. 33, (see page 95 ,).

3. The third object for which machinery is employed is, to change the velocity. In some cases, the work to be done, as spinning, turning, \&c., requires a great velocity. In others, the relocity requires to be smaller than that of the moving power, as in the smokc-jack. This change may be effected in various ways; for ex-

* We speak here of the engines common in this part of the country. On the Mississippi and its tributaries, the piston has a horizontal motion. 
Fig. \$2.

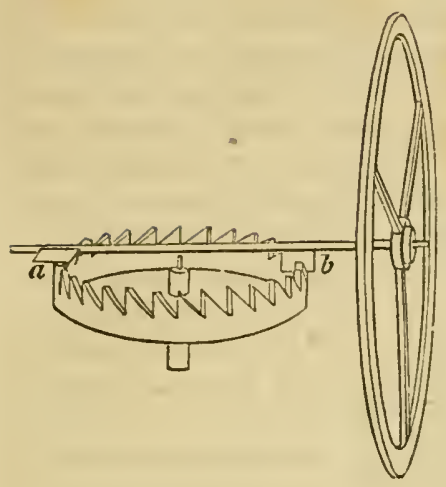

Fig. 99.

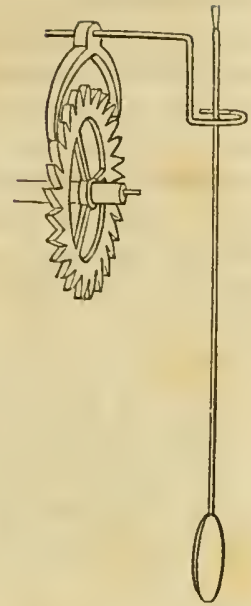

ample, by the lever. If it be a lever of the first kind, * it diminishes or increases velocity, according as the arm, to which the porrer is applied, is longer or shorter than the other arn. In a lever of the third kind, velocity is always increased, since the resistance is further from the fulcrum than the power. Hence, in the human arm, sheep-shears, tongs, \&c., which are levers of the third kind, a great part of the power is expended in procuring velocity, and the resistance, therefore, must be proportionally diminished.

The machine most frequently employed, however, in transmitting force and regulating velocity, is the wheel and axle. If a band pass from the circumference of one wheel to that of another and a smaller one, as in Fig. 34, it is evident, that, while the first and greater revolves once, the second must revolve as many times as its cireumference is less than that of the larger. 'This is the

Fig. 34.

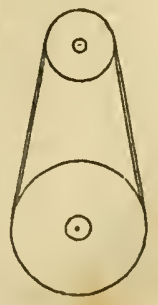

* See pages 89,90 , Figs. 18, 19, 20, for representations of the different kinds of levers. 
case with the spinning-wheel. Here, if the thread were twisted directly by the fingers, little work could be done But, by applying the power to a large wheel, which, by means of a band, gives motion to a small one, called the spindie, a great relocity is created, and not only more work is done, but it is done much better. Sometimes. the band passes from the circumference of one wheel to the axle of another, when there is a much greater gain in relocity. As bands are liable to slip, and cannot be employed where the resistance is very great,

Fig. 35.

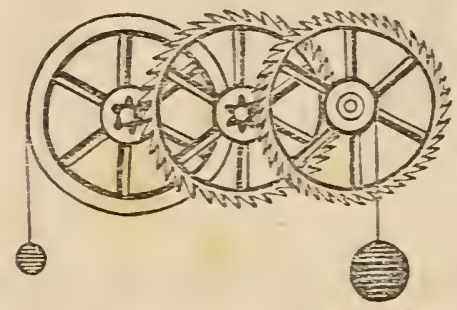

or the machinery is rery smooth, machinists hare substituted teeth, cut in the circumference of wheels; and pinions raised on their axes, as in Fig. 35. We have examples of these in the watch, in common

mills, \&ic.

In the larger and more important machinerr, means are sometimes adopted, to increase velocity; different from any that I have ret mentioned. For example: in converting cast into wrought iron, a mass of metal, of about a hundred weight, is heated almost to a white heat, and placed under a heary hammer, mored by water or steam power. This is raised by a projection on a revolving axis, and if the hammer derired its mo mentum only from the space through which it fell, it would require a considerably greater time to give a blow. But, as it is important that the softened mass of red-hot iron should receire as many blows as possible before it cools, the form of the cam or projection on the axis is such, that the hammer, instead of being lifted to a small height, is thrown up with a jerk, and almost the instant after it strikes against a large beam, which acts as a powerful spring, and drives it down on the iron, with such velocity, that by these means, about 
dcuble the number of strokes could be made in a given time. In the small tilt-hammer, this is carried still further. By striling the tail of the tilt-hammer forcibly agairist a small stecl anvil, it rebounds, with such velecity, that from three to five hundred strolies are rade in a minute.

In the manufacture of scythes, the length of the blade renders it necessary that the workman should move readily; so as to bring erery part on the anril in quick succession; this is effected, by placing him in a seat suspended by ropes from the ceiling; so that he is enabled, with little bodily exertion, by pressing his feet against the block which supports the anvil, to vary his distance to any required extent. It is stated by $\mathrm{Mr}$. Babbage, from whom we borrow these two illustrations, that this contrivance has recently been applied in the manufacture of anchors, an art is which it is of still greater importance.

4. A fourth object, for which machinery is used, is to regulate the application of forces; that is, to render the motion uniform. Mlost forces are of rariable intensity : others act only.by impulses; but, by employing regulators, governors, or fly-wheels, the motion communicated to the machinery may be rendered, in a good degree, uniform. In these contrivances, the machinist avails himself of the inertia of matter, in viltue of which it resists any change of relocity. The common fly-wheel is a ponderous wheel of iron, (p. 81 . Fig. 16, Q,) which requires a considerable force to move it ; but which, having acquired a certain motion, tends to retain it, and serves, therefore, to retard the machinery, when it would go too fast, or to accelerate it, when its motion is becoming too slow. The machinery does this, to a certain extent, itself; but where the uniformity required is rery great, its self-regulating power needs to be aided by some instrument of this lind. The porrer which the fly-wheel can exert, in maintaining motion, will appear from a fact stated by Mr Babbage. The proprietor of a large manufactory was 
showing to a friend the method of punching holes in iron plates, for the boilers of steam-engines. He held in his hand a piece of sheet-iron, three eighths of an inch thick, which he placed under the punch. Observing, after several holes had been made, that the punch made its perforations more and more slowly, he called to the engine-man, to know what made the engine work so sluggishly, when it was found that the fly-wheel and punching apparatus had been detached from the steam-engine just at the commencement of his experiment.

Another regulating machine is the governor, (p. \&1, Fig. 16, g;) which resembles a pair of tongs suspended by the handle, and having a rotary motion. The legs will separate, if the relocity of rotation be rery great; and in the governor they are so connected with the moring power, that, when they have been separated too far, or, in other words, when the machinery is moving too rapidly, part of the power is cut off. The pendulum (p. 95, Fig. 33) is another regulator, and in timcpieces is invaluable.

5. Another purpose, to which machines are applied, is the accumulation of force. In some cases, a force has too little intensity, to do the required work, and it becomes necessary to treasure up several separate efforts, to be discharged simultaneously. Of this, we have instances in the pile-engine and the condensing machine; and the fly-wheel is also used for the same purpose, in coining. In other cases, the force accumulated is designed to expend itself gradually, and through a considerable period, as in coiling up the spring of a watch, an operation which is performed in an instant, but which creates a power, that gives motion to a train of wheels, and measures the progress of time for the next thirty hours.

6. Another and perhaps the most essential use of machinery is in enabling us to employ a vast amount of force which would otherwise be lost to all useful purposes. Thus, for example, in the operations perform- 
ed by human strength, man can, in many instances, exert but a small portion of his own power, without maclinery. Give him the lathe, however, or the spinningwlicel, or the loom, so that he can use his feet as well as his hands, and his efliciency is increased twenty and even fifty fold. A yet more striking example of this saving of power is furnished in the means which machinery gives us of employing the inanimate forces of Nature, such as wind, steam, water, $\mathcal{S}$. These forces would be of little avail to mankind, without instruments interposed between them and the work to be done, in order to modify and regulate their action. Provided with such instruments, we are enabled to subject to our dominion the most tremendous agents of Nature, and to employ them, with ease, in operations which transcend alike the power and the dexterity of man.

7. Machinery renders important assistance, inasmuch as the work turned off by it is perfectly exact. It is very difficult, as we must have all observed, to construct, by means of the hand alone, any solid figure with perfect precision; and more especially, if that figure be bounded by curved surfaces. It is vastly more difficult, however, to malic several of these figures exactIy alike. But by the use of the turning lathe, any number of them may be turned off so perfectly identical, in figure and size, that they cannot be distinguished. Take the manufacture of boxes, for an example. If it be required to make the top of a circular box, which will fit over the lower part, it may be done in the lathe, by gradually advancing the tool of the sliding-rest, - the proper degree of tightness between the box and its lid being found by trial. After this adjustment, if a thousand boxes are made, no additional care is required; the tool is carried up to the stop, and cach box will be equally adapted to every lid. 'The same identity pervades all the arts of printing. The impressions from the same block, or the same copper-plate, have a similarity, which no labor could produce by the hand; the minutest traces being transferred to all the impressions, and no omis- 
sions occasioned by the inattention or unskilfulness of the operator.

It would be easy to extend this enumeration of the important objects which are attained by the use of machinery. We have yet said nothing of its influence in saving the materials employed in the arts; $;$ in accelerating the progress of natural operations ; $†$ and in lieeping such a register of its own operations. $\neq$ as to preclude, in many instances, the evils that result from the negligence and knavery of human agents. We have already adduced instances, sufficient to show, that it is by the power of machinery that we avail ourselves of the aid of natural agents, and employ them in ways which are at once the most effectual and yet the least expensive and troublesome; that, while it has the effect, in a great degree, to supersede human labor, it still multiplies the products of art, and renders them, at the same time, cheaper and more perfect. Indeed, it seems almost impossible to cxaggerate the immense influence, which the use of machinery exerts on the resources and enjoyments of mankind. It is not merely to his greater prowess in the field or to his more refined policy in the cabinet, that civilized man owes his superiority over the sarage. It is rather to his greater skill in pressing the powers of Nature into his service, and making them perform the tasks, and produce the fabrics, which, without machinery, would have remained unknown. When the future historian traces the progress of nations, he will not lay such stress as has been laid by former historians, on naval and military exploits; on the intrigues of states-

* An example of this may be seen, in the saving which is effected by substituting the saw instead of the axe or adze.

+ Striking instances of this are seen, in tanning, where, by sinply exhausting the air from the vats, a work, which formerly required a year, is now performed in a fow days.

† Examples of these contrivances may be found, in manufactories, in the instrument which is used to ascertain the rigilance of the watchman emplored during the night; in a machine which measures the goods as they pass rapidly through the hands of the opcrator; in a kind of stop-cock, which registers the quantity of a liquid or gas which may be drawn off in any giren time from a vessel; \&c. \&c. 
men and the intricacies of legislation: he will inquire rather, what, in each age, have been the discoveries of philosophers and the inventions of mechanicians; how art contrived to enlarge the capacity of a people for production, and ho: enterprise and industry, intelligence and virtue, were cmployed in drawing, from the bosom of the earth, the materials of their wealth and happiness.

We camnot close this part of the subject, without pausing to admire the provision which the Creator has made, for an urlimited improvement in the mechanic arts. The simple machincs are very few in number; and yet, by combining and recombining them, according to the end in riew, new instruments may be multiplied, without number and without end. It is said, that not less than three thousand and five hundred patents for mechanical improvements have been taken out in the United States, within the last fifty ycars. If to these we add the machines which have been invented, during the same period, in other countries, and especially in England, - of all countries most cminent in the useful arts; and if to these, again, we add the contrivances which were in previous use, we shall have a multitude which may well astonish us. Yet these form but a beginning. New forces are called into action, now wants exhibit themsclres, in this rich, enterprising, and elegant, age. New occasions arise for the excrcise of cconomy, in respect either to materials or time; and thus the inventive powers of man, which never grow weary, are roused to yet greater activity. Vast and almost incredible as have been the advances made in the employment of maclinery, during the last half century, it is probable that the next fifty years will exhibit rcsults, as much transcending these, as they transcend those of any preceding generation.

Nor can we forbear, in closing this subject, to adrert to the manifold traces of mechanism, which we find in the works of God. Human inventions are in truth but humble imitations of the grander machinery, which 
displays itself in the movements of the planetary system; in the appearances of inanimate Nature; and, above all, in the structure and functions of animals and plants. Here, we find a skill and contrivance, which are worthy of the Most High, and which leave, at an infinite distance, the puny efforts of human art. What mechanic has ever yet formed an instrument, with the flexibility, delicacy, and force, of the human hand? What human artist ever yet gazed on a specimen of his own handiwork, like that which called forth the admiration of the Psalmist, - that frame, clothed with skin and flesh, and fenced about with bones and sinews, so wonderfully and fearfully made by the finger of Omnipotence! Indeed, the most distinguished inventors have been content to. borrow hints for their operations from the humblest of the Creator's devices. When Smeaton had reflected long, in search of that form which would be best fitted to resist the combined action of wind and waves, he found it in the trunk of the oak. When Watt was employed to conduct a supply of water across the Clyde to the city of Glasgow, he borrowed his admirable contrivance of a flexible water-main from considering the flexibility of the lobster's tail ; and so when Mr. Brunell was engaged in superintending the construction of the tunnel under the Thames, it was from observing the head of an apparently insignificant insect, that he derived his first conception of the ingenious shield, which he introduced in advance of the workmen, to protect them from being crushed by the falling in of the earth.

It becomes us, then, while we trace the operations of human ingenuity, in adapting means to its proposed ends, to raise our thoughts to that Divine Architect, who has imprinted traces of His wisdom and power on all His works : causing the heavens to declare His glory, and the earth, throughout all its domains of land, and sea, and air, to show forth His handiwork! 


\section{SUMMARY OF PRINCIPLES, IN PART II.}

AGEXTS EMPLOYED IN TIIL ARTS.

\section{Chemical Agents.}

i. They all depend on one principle called Affinity.

1. Affinity is the tendency which particles of different kinds have to unite, when brought very near each other.

2. (a) It causes, two fluids or gases, when shaken together, to intermingle, if they have affinity, forning a chemical compound.

(b) It causes solids, when placed in liquids for which they have an affinity, to dissolre. These solutions have the following properties. a They sensibly retain the properties of the ingredients. $b$ A liquid can generally dissolve only a certain quantity of a solid. c Haring dissolved a portion of one solid, it can afterwards do the same for another and different solid. $d$ It will precipitate any solid, which it may hold in solution, provided another, for which it has a stronger affinity, be presented, and will unite with the second. This is called elective affinity. When there is but one decomposition, and one new composition, it is called single clective affinity. When there are two, it is called double electire affinity.

(c) Affinity also causes a more intimate union between bodies, giving rise to more energetic action, and producing new propertics. These compositions hare the following properties: a The ingredients wholly disappear, and entirely new characters are developed. 6 T'he nature of these characters depends on the proportion in which the ingredients combine; different proportions giving rise to entirely different substances, or compounds. c The number of proportions, in which the same ingredients combine, is definite and small, 
being always capable of being represented by a num. ber, or by some nultiple of that number.

Observation. The proper management of this principle constitutes nuch of the art of the tanner, bleacher, dyer, \&.c. \&.e.

II. Nechanical Agents.

1. Chemical agents act only at insensibie distances, and change only the interior structure of bodies.

2 . Mechanical agents act, on the contrary, at sensible distances, and change ouly the position or form of their masses.

To understand the nature of these agents, we must familiarize our minds to the three fundamental laws of motion. Namely,

i. Masses of matter never change their state of rest or motion, unless some force be impressed upon them.

ii. This change is always proportioned to the force, and in the direction of this force.

iii. To cvery action of one body upon another, there is an equal and contrary reaction.

The mechanical agents are, animate and inanimate forces.

I. Animate forces consist of the strength of men and animals.

(a) The time in which they can be exerted is necessarily limited.

(b) The manner must be determined by the structure and habits of the animal.

(c) The relative value of different animals depends on the expense of keeping them, the amount of force they can exert, and the variety of wars in which they can be used; from which we infer, that, of all animate forces, that of man is the least useful, and that of the horse the most so.

II. The inanimate forces are, srarity, elasticity, and heat.

i. Gravily.

(a) Gravity acts on solids, as on bodies falling through 
space, descending inclined planes, \&c., and causes them to move with a uniformly accelerated velocity.

(b) Gravity acts on water in the case (1) of waterwheels; (2) of water flowing through orifices, tubes, canals, \&c.; (3) by hydrostatic pressure, in case of the hydrostatic bellows, and of Brahmah's press; of water rising to its own level in bent tubes; and of the method of specific gravity discovcred by Archimedes.

(c) Gravity acts on air, in the case of the common pump, barometer, windmills, \&c.

ii. Elasticily acts on air, in the case of fire engines, airpumps, airguns, \&c., also on solids as in watch-springs.

iii. Heat acts as a mechanical agent.

1. By expanding bodics, as in metals.

This property of heat gives rise to iustruments for measuring the degrees of it, as the thermometer and pyrometer.

2. Heat acts as a mechanical agent, by changing the form of bodies, as in steam.

T'he numerous other important uses of heat, in the arts, call for improvements in the prevailing and very rlefective modes of generating and supplying it.

Machinerix enploved in the arts.

i. Its existence is to be attributed, 1. To man's want of natural implements; 2. To the admirable provision made, for the invention and construction of machinery, in the ingenuity of man's mind and the conformation of his hand.

ii. All machines, however complex, are composed of ccrtain elements, called simple machines, namely, the lever, the wheel and axle, the inclined plane, the screw, the wedge, the pulley and rope.

iii. The various and complex machinery, which has been formed by combining these elements, is uscful :

1. As enabling us to overcome great resistances, by diminishing their velocity, and operating upon them for a length of time.

2. As cnabling us to change the direction of the moving force. 
3. As enabling us to vary the velocity of the resistance, especially by increasing it.

4. As enabling us to regulate, or render uniform, the motion of the machinery.

5. As enabling us to accumulate force, to be expended instantaneously, or through a long series of separate actions.

6. As enabling us to employ a vast amount of force, which would otherwise be lost.

7. As it enables us to render our work more exact, and the different specimens more identical 


\section{PART III.}

RATIONALE* OF TIE ARTS.

Having completed our sketch of the principal agents employed in the Arts, as well as of the machinery by which they are applied to various uses, we proceed to consider the Arts themselves. It will be our object to state, perspicuously but briefly, the most important principles applicable to each art, and the influence which has been exerted by science, in facilitating and improving its various operations. We shall also endeavor to keep steadily in view, the great ends, to which all improvements should be directed, and to suggest some means, by which their progress might be hastened. The task is evidently too extensive for a work like the present; and the Author will fecl amply satisfied, if he can succeed in presenting any views, which are calculated to awaken inquiry among the laboring classes, or to invest with interest, to the miscellaneous reader, a subject so obviously important, and yet so generally neglected.

He proposes to consider, in the order here indicated, the following Arts:

I. Agriculture. II. Architechure. III. Cloth Manufacture, including Dyeing, Bleaching, and Paper-making. IV. The Domestic Arts, including Brewing, Distilling, and Wine-making. V. The Avts of Working Metals. VI. 'The Manufacture of Glass and Porcelain. VII. The Arts of Copying. VIII. Locomotion. IX. Some reflections on the progress of the Arts, past, present, and to come. X. Influcnce of the Arts on National Welfare.

* That is, an explanation of the principles. 


\title{
CHAPTER I.
}

\author{
AGRICUETLRE.
}

THis has justly been termed the parent of a l the arts. The art first practised by mankind; the one from which ther derive the means of subsistence; and which is connected, therefore, most intimately with the comfort of all ; forming the occupation, too, of a large majority, in every civilized country, and exerting upon their health, happiness, and moral habits, the most beneficial influence; it must erer occupy the highest place in the estimation of the statesman and philanthropist. We assign it this place, however, not so much on acco:unt of its importance, as because it serres to illustrate, in a striking manner, the dependence of the arts on chemical and physical science. In as far as Agriculture proposes to improve the natural productiveness of the soil, it must derive its principles chiefly from chemistry. In as far as it proposes to plough, sow, and perform the other processes of husbandry, with the least possible labor, it must be indebted to mechanics. $\dagger$

It appears, then, that there are two branches of Agriculture, which will successirely call for our attention,Chemical and Mechanical.

I. Chemical Agriculture.-One of the first objects of the husbandman is. to increase the natural productiveness of the soil. Few soils possess, by nature, a

* In England, it is otherwise. It has been computed, that not more timan one ilifil of the inlabitants of that country are employed in husbandry. In every other country, the proportion is much larger. In France, two thirds; in Italy, a little more than three fourths; and in the Cnited States, not much less than jire sixths.

+ Our limits do not permit us to explain the application to Agriculture cf other sciences. It must be obvious, however, that, in order to deal with plants, we ought to know something of their structure, properties, and use; and this we learn from botany. In that branch of luusbandry which relates to animals, we require some knowledg of animal piysiology and medical science. 
sufficient supply of those substances which form the food of plants; and where they do possess such a supply, they would still, unless properly treated, soon become exhausted, by culture. Hence the importance of providing artificial means for improving or sustaining the productive qualities of the soil. These means consist in fallowing, green crops, convertible or alternating husbandry, burning, irrigation, and manure. 'To which of these the farmer shall resort, in any given instance, is an all-important question; and one which he cannot easily settle, without the aid of chemistry. If land be unproductive, there must be some defect in the constitution or condition of the soil; and oftentimes this defect can only be discovered by chemical analysis. Does this analysis show that the soil contains some noxious principle, such as the salts of iron? Chemistry teaches how this principle may be decomposed, by means of lime. Is it asked, what lind of limestone should be employed, in any given case? A simple chemical test will enable us to resolve the doubt. The value of ehemistry will become more apparent, however, if we attend a little to the rationale of agriculture.

It has been found, by careful observation and experiment, that the principal food of plants is carbonic acid gas, almospheric air, and the humates* of polass and lime; all which are nixed with water, and presented. to the suckers, at the tip of the root-fibres, to be thence carried into the interior of the plant. The first two are also taken in through the leaves. The carbonic acid gas is necessary, in order to supply the carbon which forms the solid or woody fibre of the plant. 'The atmosphere is needed, partly in order to supply azote, which is a chief ingredient in the gluten of wheat and in various other plants, and partly in order to supply oxyenen. The humates of potass and lime are necess-

A humate is a compound, formed by the maion of potacs or lime with loumic acid. Humic ucid is more generally knws in the bouks by the name of ulmic ucid., It is pron. $\mathrm{er}$, also, to add, that, accurding to the listest writers on Vegetable Plyysiology (such as Liebig and Johnston), the voflucnce of the humates is incousiderable. 
ry, because the humic acid (in addition, doubtless, to other important uses which are not well understood,) renders soluble the lime and potass, which must enter more or less into the composition of all plants, and are in some the principal constituents.

These, then, being the food of plants, it becomes the object of the farmer to procure the most ample supply of them. In the wise economy of Nature, large quantities of these substances are constantly generated. Carbonic acid is continually thrown out, by the respiration of animals, and by the combustion and putrefaction of regetable substances. The different parts of the atmosphere are mingled together by winds or changes of temperature, and are successively brought into contact with the surface of the earth, so as to exert their fertilizing influence; while potass and lime, together with humen, * form a large part of the substance of the earth. Ample magazines of the food for plants having been thus prorided, a principal office of the husbandman consists in collecting and applying it to the soil under his care.

It must be remembered, that none of these principles are taken into plants at the root. except when dissolved in water. The first object, then, to be attended to, in agriculture, is, to have the soil supplied with water, and to have this water minutely diffused through its mass.t This is effected, in part, by dividing the soil, with the plough and harrow: so that the rain may enter, and be circulated, while superfluous water is allowed to escape by evaporation. Another mode of carrying off superfluous water, while it serres to supply the necessary moisture to the soil, is draining, which, in this country, is not sufficiently appreciated. Care must be taken,

* A name, giren to the substance yielded by the decomposition of regetable or animal matter. It is a black or brown powder, called, by Davy, "a peculiar extractire matter of fertilizing quality," and which the chemists of France hare denominated terreau.

$\dagger$ It is not unlikely that water, besides being a purveyor of food for plants, is itself an aliment. Hydrogen forms a large part of many plants. 
however, lest the water, in its circulation, more so rapidly, that the roots cannot take up the nutritive principles which it contains. On the other hand, it may more too slowly, so as to choke up the mouths of the small vessels, or it may, by deposition, lose its uutritive properties. It is also necessary that the quality of the subsoil should be attended to ; as, in cases where this soil consists of stift elay, or marl, or rock lying in a horizontal position, the water settles, and remains stagnant.*

After thus providing for the proper diffusion of water through the soil, the next duty of the husbandman is, to see it supplied with the necessary quantity of carbonic acid mas, and of the humates before mentioned. The first of these substances is produced, not only by the respiration of animals, but also by the decomposition of vegetable and animal substances; from which decomposition, the humic acid is also freely formed. Now, in order to procure this supply of regetable matter for decomposition, we may, in the first place, allow land to lie fallow, by which, the crop of weeds will rot, and form a regetable mould; or, secondly, we may raise green crops, as they are called, consisting of buckwheat, clover; pease, $\mathcal{L}$. ., which are to be ploughed in, while standing, and before they are ripe; or, in the third place, we may apply vegetable and animal manures, in which the process of decomposition has already commenced. The last two of these methods are much preferable to the first, which is now little followed. $\dagger$

* There are three linds of drains, -open, under, and furrou, drains. The umder have a great adrantage over open drains, in point of durability, efficiency, and ultimate chcapness. They are not enongh used, by Americin farmers. The furrow drain is of recent introduction, and is hardly known, except in Scoich and English husbandry. The ficld is laid into ridges, of twenty or thirty feet broad, in the direction of its slope, and under-drains are laid in every central furrow.

† "Fallowing," says Chaptal, "was nccessary, as long as grains only, all of which exhaust the lands, were cultivated. But at this day, when we have sunceeded in cstablishing the cultivation of $\mathrm{n}$ great 
Another measure, introduced by modern agriculturists, and the object of which, more especially, is to prevent the exhaustion of the soil, is, the rotation of crops. It is founded on the three following facts: First, some plants, such as wheat, rye, \&c., as they have but few leares, and can derive but little nourishment from the air, are found to draw much more from the earth than the green crops, and those of the root kind, which do not mature their seeds; and therefore, if cultivated continuously, will in a short time entirely exhaust the soil. Hence the grains are succeeded by clover, beets, turnips, potatoes, \&c. Secondly, each species of plants has its own proper food, so that a soil, containing (as most soils do) food for difierent species, may vield largely to one, after the food for others is exhausted. Thirdly, plants with bulbous roots, like the potato, turnip, beet, \&c., serve to divide and loosen the soil, and at the same time send down their roots and radicles to its lower stratum, whereas the roots of grain, \&c., spread near the surface.*

Manures are, mineral, regetable, or animal.

1. Among the mineral manures, $\dagger$ are clar, sand, marl, and lime, in its various forms of quicklime, chalk, gypsum, \&c. \&c. Which of these is to be employed on a piece of land depends, of course, on the nature of the soil, and the plants to be reared. If the soil be deficient in the power of holding or circulating water, this deficiency is to be supplied by sand, if there is an excess of clay; or by clay, if there is too much sand; or by marl, according as it has predominance of clay or lime. If, again, the soil is wanting in some of those principles which constitute the food of plants, it must

variety of roots and artificial grasses, the system of fallowing cao no longer be supported by the shadow of a gool reason."

* The adrantage of root hushandry resalts, so far as the soil is conresmed, fr tin the fact that plauts exhaust the soil most whe: coing to sead Ifence biennal plasts, hibe the turup and beet, rore much less exhatisting than the grains.

+ Strictly spenking, muneral manuris are not su much food for plants as agents fur Freparing their foul, and also for wring f.rm, strength, and firmness, to their structire. Annther use is to prepare regtables to hecome food for animals. The bones of animals, the sheli of the ezg, \&ir., are formed from the lime and phospoorns taken in with the foor and drut:. 
be manured by substances best calculated to afford these principles. We lave already remarked, that lime and potass enter into the composition of plants, as may be proved by reducing them to ashes, which will always be found to contain more or less of these substances. It is obvious, that they are introduced through the roots into the plants, and that, if we would supply them, it must be by mingling them with the soil. Hence, one of the important uses, in manuring, of ashes, of gypsum, or the sulphate of lime, of quiclilime, S.c. In the preference of one of these manures to another, we must be determined by the nature, both of the soil and of the crop. If the soil be clay, it requires lime; and if the crop be Indian corn, clover, the grasscs, \&c.. it should be gypsum, rather than quicklime.

2. Animal manures (among which are included the dung of various animals, urine, bone-dust, * horn-shavings, fish, woollen rags, \&c.) are particularly valuable, first, because they decompose rapidly; and secondly, because they afford large quantities of azote, a principle necessary in all plants, but especially so in wheat, cabbage, broccoli, turnips, and radishes, of which azote is a principal constituent.

3. Vegetable manures are useful, on account of the carbonic acid and humic acid which they yield, on fermentation; and also, because, when applied before the straw is completely decomposed, they serve to loosen the soil, and render it lighter, while the process of fermentation, being continued, has the advantage of warming the soil and thus assisting germination. Nuch discussion has taken place in connexion with this subject,-Sir H. Dary maintaining that manures ought never to ferment

* The use of bone-dust has effected a rast and beneficial change in English lusbandry. It is said to be adding aunually sixteen millions of bushels of grain to the produce of her fields. Two bushels of bonedust, properly applied, will, on some soils, do as nuch good as a load of barn-yard manure. Eight hundred thousand dollars' worth are annually imported into Great Pritain. Pone-mills hase recently been established near Boston, Providence, New York, Albany, \&c., but the manure, as yet, is hardly known in the L'nited States. 
at all, before they are used, while others, and especially practical farmers, have contended, that rotten dung, or that which has undergone at least a partial fermenta tion, is more valuable, inasmuch as it retains moisture longer, and has in it a large proportion of humic acid. The truth probably lies partly with both sides, entirely with neither.**

In regard to manures, we conclude with the following practical observations. "The most common manure consists in a mixture of animal, regetable, and mineral, substances, such as farm-yard litter, night soil, mud from the streets, dust from the roads, or earth from the bottom of ponds and rivers, abounding with organic remains of fish, shells, and rotten plants. Before being laid upon land, it usually requires being well turned up, and exposed to the air for some time; but as soon as it is spread, it should be ploughed in, to prevent loss by eraporation. As to the depth, below the surface of the ground, to which it should be deposited, it may be remarked, that this should never be below the reach of the roots of the plants it is intended to nourish ; for, in proportion as it is dissolved and liquefied, it will naturally descend. And it is better to manure lands in the Spring than in the Autumn, lest the Winter rains should dissolre it too much, and endanger its sinking below the roots of the crop. With regard to the quantity of manure, it is a commodity so scarce, that it is not likely to be employed in excess. This occurs, however, sometimes in garden-culture, and it produces a strong and disagreeable flaror in the regetables. But the stock of manure is generally so limited, that it has been the study of agriculturists to discover some means of compensating for deficiency, rather than to appre-

* The truth is probabls expressed by General Armstrong, in these words: "If we wish io obtain one great crop, the rotted dung is best; but when we look to more permanent improvement, the long dung is to be preferred." Experiments show that the first crop, after the manore is applied, is largest with short dung, bol that in subsequent years it is not so great. 
hend danger from excess. 'This compensation has been found in a judicious rotation of crops."

\section{CHAPTER II.}

CIIEMICAL AGRICULTURE CONTINUED.

Tuus far, we have considered the food of plants. There are other important principles, which, if they do not serve as food, are yet as useful, by way of stimulants, as salt is to us; and which, as chemical agents for digesting the food of plants, are quite indispensable. These are, Light, Heat, and Electricity. $†$ How indispensable the first two of these are, to regetation, is well linown, by crery practical cultivator. From light, plants derive their green color, their taste, smell, and nutritive qualities, as is apparent from the pale and sickly appearance, and the deficient flavor and odor, of such as are reared in the dark. Heat, as erery one knows, is necessa$r y$, in order to have the seeds germinate, and to promote their rapid and healthy growth. It assists the fermentation and putrefaction, by which the necessary supply of carbonic acid gas and liumic acid is produced; while, at the same time, it accelerates the flow of the sap through the ressels of the plant. Since, in Agriculture, the light and heat are derived from the sun, the proportion, in which the soil receires these principles, will depend upon its texture and upon the position of its

* Among oller adrantages of what is termed root cullure, tliat is, the raising of beets, turnips, potatoes, \&c., is the addition which it makes to the manure of a farm, by enabling the farmer to support a larger number of caltle. "It treblcs," says Buel, "the amount of callle food, and doubles the quantity of manure." See "Farmer's Companion,' (Forming the sixteentl volume of 'THE SCHOoL LrBRAR $\left.{ }^{\prime}, '\right)$ chapter xvi., on Root Culture, page 163.

t Grapevines in the south of Europe are often furnished with eleetric conductors. Davy "found that corn sprouted more rapidly in water positively electrified by the Voltaic battery, than in water neg atively electrifiel.": 
surface. In our latitude, the rays of the sun fall so obliquely upon the earth, that a level surface will obviously receive less light, than if it were inclined towards the sun. When, therefore, early vegetation is required, and the soil is strong enough to bear much heat, it will be useful to give it an inclination in this direction. In light soils, however, where there is a tendency to parch, for want of moisture, this position would give the sun too great power, and is therefore to be avoided. The texture of the soil is broken up by the plough and harrow, and thus fitted to receire heat from the sun, while it carries off superfluous moisture, by evaporation. But it should be remarked, that such eraporation abstracts heat rapidly from the earth, and thus occasions, in some cases, the frosts, from which crops are apt to suffer. Similar frosts are occasioned, also, by what is termed radiation; that is, by the passing off of heat from the earth, at night, owing to which, it becomes very cold, and the rapor in the air is congealed. Hence the practice of covering plants, at night, and the use of snow, in protecting them. These serve to prevent the radiation, and thus keep the earth at a temperature friendly to regetation, or at least not fatal to the life of the plant.

This brief sketch of the method, by which the productiveness of the soil may be maintained and increased, will be sufficient to prove the importance of knowledge, and especially of scientific linowledge. In many respects, the farmer may be regarded as a chemist, conducting experiments on an extensive scale. Plants are the substance with which he deals, and the natural properties of the soil, combined with manures, light, heat, \&c., are the agents employed. If he would employ these agents successfully, he must surely understand their nature, and the mutual influence which they exert on each other. He must understand, also, something of the structure and functions of plants; the office performed by the roots, leaves, bark, \&c. \&c., a knowl- 
edge which belongs to vegetable physiology. Many of the errors, which are committed in agriculture, would be avoided, if the farmer would consent to unite a largor portion of scientific information with his practical skill. In such case, he would not apply the same manures indiseriminately to all soils. He would not suffer land to lic waste, which might easily be rendered productive. Nor would he be content with a meager crop, from soils, which, with very moderate expense and labor, might be increased in their fertility fourfold.

We are far from supposing that any linowledgre of science can supersede a practical acquaintance with the operations of a farm. We would merely contend, that, while the cultivator gathers knowledge from personal cxperience, he ought not to disregard the light which may be afforded by the experience of others, and by the researches of science. It is sufficient proof of the value of these rescarches, that their authors have been the men who have suggested the most important improvements in modern agriculture. If British agriculture is now the admiration of the world, it is because such men as Davy and Sinclair, Anderson and Kaimes, Young and Colie,-men who have united philosophical sagacity with patient experiment,-liare deroted their high powers to its improvement.

It is stated, that the celebrated Lavoisier, memorable; alike, for his scientific genius and his political nisfortunes, ${ }^{*}$ cultivated two hundred and forty acres of land, in La Vendec, on chemical principles, in order to set a grood example to the farmers; and his mode of culture was attended with so much success, that he obtained a

* During the terrors of Rol,espierre's reign in the Freneh Revolution, Lavoisier remarked, that he foresaw he should be stripped of all his property, and accordingly would prepare to enter lhe profession of an apothecary. But his fate was already sealed ; and he was executed, in May, 1794, for the pretended crime of having adulterated snuff with ingredients injurious to the health of the citizens! On being arrested, he besought that at least time should be allowed him for completing some experiments in which he was engaged; but the reply was, "the liepublic does not want savans or chemists, and the conrse of justice cannot be suspended." 
third more of crop than was produced by the usual method; and in nine years, his annual produce was doubled. It is not to be questioned, that, were this course to become general, similar effects would every where cnsuc. It is not easy to set limits to the productireness of the earth. Chinese culture show's that it may be carried far beyond any point which we are accusiomed to fix, and it is probable that every farmer, if he would make the experiment, might realize the apologue of the Roman vine-dresser.

Having two daughters, we are iold, that when the oldest was married, he gave her a third of his vineyard, for a portion; notwithstanding which, he had the same quantity of fruit as before. When his youngest daughter was married, he gave her half of what remained; and still, because he bestorved on the portion reserved as much labor as he had formerly bestowed on the whole, the produce of his vineyard was undiminished. If this result was attained, when cultivators were ignorant of many of the important principles now acted upon, what might we not expect from farmers, who, uniting science with experience, should confine their labors to small parcels of land? We are aware, that the clieapness of land in this country, and the high price of labor, may render it expedient for the American cultivator to deviate, in this respect, somewhat from the practice of older countries. But we may still inquire, whether the practice of cultivating large farms imperfectly is not carried too far for the interest of the farmer; and whether, if he must own much land, he would not derive more benefit from it, by confining his operations to such portions as he can afford to till more thoroughly and manure more abundantly.

II. Mechanical Agriculture.-In performing the operations of husbandry, we employ implements, or machines; and it is interesting to remark the assistance which they have rendered, both in saving labor and improving the culture. The recent and material improvements, which have been made in these machines, both 
as it respects variety and construction, ought to be an object of especial interest to the American farmer, since the high price which labor bears in this country tends very much to diminish his profits. It is not without some surprise, therefore, that we have learned, that such improvements are sometimes vicwed by him with distrust, and that machines are often known and extensively used in England, before they can secure an introduction into this country.

Among the ancient Greelis, as we learn from Hesiod and Theophrastus, the ground was broken by a rude plough; seed was sown by hand, and covered with a rake; the grain was reaped with a sickle, threshed with a flail, then winnowed by wind; and, when wanted by the family, pounded in mortars or quern-mills, into ineal. Now, we have ploughs, moved with less power, and yet serving to turn up the earth much more effectually: : the clods are broken, and the surface smoothed, by a harrow, which has been recently much improved in structure and efficiency. The sced is frequently planted and covered, by the use of machines, called drills, with more accuracy and economy than it could be done with the human hand: the grain is reaped, by an instrument called a cradle, much more rapidly than it could be with the sickle; and the reaping machine, which has been used for several years, by the Scottish farmers, seems to promise, that the labor can be entirely performed by machinery. Maving been reaped, the grain is threshed out by a machine, instead of the flails or the tread of cattle; winnowed by fanning mills, which create artificial wind for the purpose: and ground up by water or wind mills, at an expense thirty times less than would be incurred by the use of the ancient handmills.

Our limits do not permit us to trace the progress of improvement, in this branch of machinery, nor to describe the construction of the implements now in gener-

* Stcam-ploughs, of various forms, have been invented. In some cases, the moving power is stationary ; in others, locomotive. 
al use. But we may remark, that these inventions have generally been made by men, who, to a knowledge of practical agriculture, joined some acquaintance with scientific mechanics. Their influence upon the amount of grain produced by cultivation is obvious. If one man can now produce, by the aid of machinery, five times as much as was raised in ancient Greece, it follows, that the quantity of fond, rielded by a given amount of labor in a country, and consequently the quantity of artificial comforts, of every description, which are enjoyed, will be increased in the same proportion. In assuming the increased production, occasioned by machines, to be firefold, we believe that we have not exaggerated. We have been informed, by very intelligent cultivators, that the improvements made within the last twenty years, in the implenents of husbandry: have effected a saring of more thom half the labor necessary on a farm: or, which is nearly the same thing, have enabled the farmer, with the same manual labor, to double the productions of his estate.

We are not to wonder, therefore, at the siriling innprorement which has taken place, within a few centuries, in the condition of the cultivators of the soil; and not in their condition only, but in that of all classes of society. Two or three hundred years ago, the liusbandmen of Europe were not only slaves, bound to labor, for life, on the soil where ther first saw the light, and to devote much of the proceeds of their labor to a master; but these proceeds, owing to ignorance of the proper principles of husbandry, to the want of machines, and to the consequent imperfection in culture, were wholly inadequate to supply the necessities of the people. Hence the fearful famines, which often risited those countries: famines, in which men, women, and children, perished, by thousands, and the survirors were compelled to subsist for months, on the bark of trees, acorns, and pignuts. Hence the miserable condition, at this moment, of the peasantry in Spain and Portugal, who have rery poor implements, and hardly any 
knowledge of agriculture. If, instead of being subjected to such visitations, England is now able to subsist all her population, a population tenfold greater than she had at that period, and if this subsistence is in every respect more abundant and refined than was then thought necessary, it is to be attributed, almost entirely, to the introduction of better machines and improved systems of culture.* The number of cultivators has not increased, in a proportion by any means as rapid as the population; and yet that country presents, at this moment, the unexampled spectacle, of a land, in which less than one third of the whole population is employed in agriculture, and still the soil is producing stores of regetable and animal food, which, if properly preserved $\uparrow$ and distributed, would afford an ample and eren luxurious subsistence for every family.

\section{CHAPTER III.}

\section{ARCHITECTLRE.}

Nexr to Agriculture, one of the earliest and most mportant employments of mankind was the building of edifices, for habitation, worship, and defence. In no art do we see more striking evidence of the various and ever-progressive powers of the human mind. The insect and the quadruped erect their habitations under the guidance of a blind but unerring instinct, and hence they are at all periods alike, and receive no improve-

* Sec Appendix V., on Progress of Agriculture in England and in the United States.

+ An immense amount of grain is wasted annually, in England, as in the United States, in distilleries and breweries, in subsisting superfluous dogs, horses, \&c. The quantity of malt, made into beer in the United Kingdom, in the year ending October, 1833, was $40,164,792$ bushels. In the year 1838 , it was $40,505,566$ bushels. In England alone, 55,045\% aeres of land are under cultivation for hops to be used in making becr. 
ment with the lapse of time. But man rears his edifices, by means of an intelligence which is extremely fallible, but, at the same time, ever improving. Hence his earliest efforts are rude and imperfect. The materials are inconvenient and perishable, the forms ungraceful, and the structure unstable. But, gathering wisdom from his experience, he constantly improves, till at length he erects buildings unending in their variety, beautiful in their form and finish, and fitted to withstand the violence of the elements and the waste of time. In our remarks in this Chapter, we shall speak only of Architecture as a useful art, and shall endearor to illustrate its dependence on, 1. Geometry; 2. Chemistry: 3. Mechanical Philosophy.

It mar add to the interest of the subject, if we introduce some instances from the architecture of Nature: tending to show, that, in her work, she has erer proceeded on the same principles which are slowly discorered by men, and which, had they been more carefully observed, might have suggested improvements, at a much earlier period. In speaking of the structure of the human body, it has been declared, by the most emiinent anatomist now living, : : That the foundation of the Eddystone lighthouse, the perfection of human architecture and ingenuity, is not formed on principles so correct, as those which have directed the arrangement of the bones of the foot; that the most perfect pillar or ling-post is not adapted with the accuracy of the hollow bones which support cur weight; that the insertion of a ship's mast into the hull is a clumsy contrivance, compared with the connexions of the human spine and pelvis ; and that the tendons are composed in a manner superior to the last patent cables of Huddart, or the ret more recently improved chain cables of Bloxam."

1. We are first to illustrate the applications of geometry to architecture. When a builder or architect proposes to erect an edifice, one of his most important duties is, to calculate the expense, and make an estimate 
of the amount of materials and labor which will be required. Now, in order to do this, he must deduce, from the linear dimensions of the proposed house, what number of cubic feet or yards must be excavated for the cellars; how many cubic yards must be laid up in brick and stone; and how much timber will be requisite, for the frame, roofing, \&c. But these calculations can hardly be made, without some knowledge of geometry; and to make them in all the new and unexpected cases which may occur, in the present state of the arts, requires much more than a smattering of the science. Then, again, the architect, in order to prepare himself, has often to draw designs of the building; to exhibit ground-plans and elevations; to determine, by construction or calculation, the inclination which must be given to the faces of stone in his masonwork, or to the extremitics of timbers which are to join at a certain angle, or to the edge of corering which he proposes to apply to various solids. In such cases, it is obrious, that his calculations must depend upon geometry, and cannot be made, in all cases, with proper accuracy, without some knowledge of its principles.

At other times, he may be required to dispose a given quantity of material in such shape, as to afford the most space or accommodation : and again, he may be required, having a certain space, (as a room, ) to build it up with cells or closets, so as to leave no racant space; to expend the least possible material, and yet secure the most strength. Now, these questions can be answered, in the first instance, only by skilful geoneters; and the rules which they have discovered cannot be applied, with uniform accuracy, by the ignorant and mechanical workman. Mathematicians have ascertained, that in the former of these cases, the sphere is the figure which best answers the condition; and that the nearer the solid approaches a sphere, the greater the space which it will contain within a given surface, or with a given amount of materials. They have ascertained, further, that to fill a room with cells, as required above, 
these cells must be constructed with six sides, and that the roof and floor must be made of three square planes meeting in a point; and they have shown yet further, by a demonstration belonging to the highest parts of algebra, that there is one particular angle, or inclination, of those planes to each other, where they meet, which makes a greater saving of materials and of work. than any other inclination whatever could possibly do. Now, it is a most remarkable fact, that bees build, and ever have built, their cells exactly in this shape, and thereby save, in this operation, both materials and labor more effectually than was possible to man, until very lately. And thus it is, that truths, which are found out by philosophers, only after ages of improrement, in the most difficult branch of the most dificult science; which not even a Newton reached; (for the principle here referred to was discovered by one of his celebrated followers :) these truths are ever present to the mind of that Being, who guides the instinct of the humblest insect, and suffers not a sparrow to fall unnoticed to the ground.

2. The applications of chemical science to architectwie are numerous and important. When the builder has finished his estimates and drawings, he proceeds, in the next place, to collect his materials. In doing this, he must remember, that the edifice, which he is about to erect, will be exposed to the action of many natural laws, which tend to destroy it. The air contains oxygen, which tends to destroy metals by corrosion ; to decompose rocks, when they contain either iron or alkaline substances; and to produce on regetable substances, gradually, the same destructire effects, as are produced rapidly by combustion. Water, both that which circulates through the earth and that which falls from the clouds, operates as a powerful solvent, not only on timber exposed to it, but also on many other bodies; and especially on stones, which contain calcareous or alkaline ingredients. Part of this effect it owes to carbonic acid gas, which, being mixed both with water 
and the air, acts, especially in the vicinity of large towns, as a powerful principle of decay. In addition to these, we may add heat, which, though not perhaps directly a cause of decay, becomes so, in consequence of the frequent changes which the temperature of the atmosphere undergoes; and also electricity, which acts as a destroying agent, in consequence of the diflerent clectrical states in which bodies are to be found.

Now, against these agencies, it is the business of the architect to guard. His worlis derive their principal value from permanenee. They are ereeted, not for the accommodation of an individual or a generation; but for the accommodation of successive individuals and generations, if possible, through all time. Our estimation of his art never rises so high, as when we look on some structure, which, from its adamantine base, has beheld successire gencrations, as they have risen and disappeared; when we see that his workmanship has stood unmored, by physical ricissitudes and moral revolutions, and that, ages after the mind which designed and the hand which reared it, together with all the busy actors of the same period, have passed away, it stands in humble initation of the works of God,-unbroken, fresh, and still the same.

But thus to guard, in the most effectual manner, against the ravages of time, especially against those of a chemical nature, calls for some knowledge of chemical science. This science teaches the builder how to select his materials, and where to dispose of them, so that they shall be most secure from the influence of decay. It teaches him what rocks contain principles of dissolution; what metals are most liable to rust or corrode, and in what situations they would be most secure from this change; of what ingredients his brick or tile should be composed, and at what temperature they should be burnt, in order to render them most durable and useful; what causes tend to destroy regetable substances, how far these causes can be guarded against by seasoning, charring, covering with paint or resin- 
ous substances, impregnating with salt or oil, providing a circulation of diy air, \&c. \&c.

A rast expense is every year created, by the premature decay of wood employed in ships and other structures which are exposed to the vicissitudes of weather, and especially if they are subjected to the influence of warmth combined with moisture. Though trees of difierent species vary greatly, in the durability of their wood, yet none of the species commonly emplored are capable of withstanding, for many years, the effect of unfavorable exposures. In addition to superficial decar, they are subject to a disease called $d r y$-rot, which commences in the interior substance of the wood, and, instead of being retarded by paint or the other means of prescrration usually employed, is rather accelerated; sincc these substances have the effect of closing up the pores of the wood, and preventing the escape of the unhealthy exhalations. How to guard against this disease has become a most important question, and one which will be answered only by persons well acquainted with the chemical construction, both of regetable substances and of the agencies which cause them to decay.

Another occasion, which calls for chemical knowledge, is the composition and application of the rarious cements. It is weli known, that these important substances must be compounded differently, according as they are the uniting medium between bricks and stones, or between regetable or animal substances; and also as they are immersed in water or exposed to the action of the air. Respecting their composition, in these different cases, much must unquestionably be learned from experience. It is obvious, however, that their action is to be referred to chemical laws, and that the man who understands these laws must, other things being equal, have superior skill in selecting the ingredients, in blending them together, and in providing against any new emergencies which may occur. 
3. We come now to consider the dependence of Architecture on mechanical philosophy.

The design of an edifice may be perfect; the estimates and plans may be drawn with the utmost accuracy; and the materials collected may be of the most durable kind: and still, unless the masonry and the carpentry are executed according to nice mechanical principles, the edifice may of itself tumble into ruins. Gravitation is a great law of Nature, which may contribute, according as a building is constructed, to its stability and permanence or to its dilapidation. To render it firm, the centre of grarity of the mass must be directly over the base; and lience the necessity of upright pillars and columns, and of a limited height. The weight of the superstructure must be supported by a sufficient foundation, and points in the building, at which there is a great stress or strain, must be proportionally strengthened. Timbers, which are to support weight, such as the girders of a floor, Ece, must be so constructed, that they shall present the necessary support with the least possible material. Arches are to be secured at the points where the pressure accumulates, and composed of materials not likely to crush or yield under great weight.

It is obvious, therefore, that the architect should be able to foresce what pressure will fall upon his foundation: to what degree of strain or stress the different parts of the superstructure will be subject; at what points this strain will accumulate, and by what materials, and by what shape, and what disposition of them, it ean be resisted. We can hardly hear these questions, without pereeiving that they involve rery numerous and difficult principles, to ascertain which has exercised the ingenuity and science of the profoundest mathematicians, as well as of the most accurate experimentalists. Our limits do not allow us to multiply illustrations; but we should do injustice to the subject, if we did not briefly refer to some of the discoreries which have been made respecting the arch, the proper form and adjustment 
of columns intended for support, and the limit which has been fixed, by the laws of Nature, to the magnitude of edifices, and to that of their sereral parts. This will aftord us an opportunity of showing, from the architecture of the human body, that the finest efforts of human skill are but humble copies of that of the Creator.

\section{CHAPTER IV.}

\section{ARCIITECTURE CONTIXUED.}

(a.) THE arch was unknown in the architecture of the Egyptians* and Persians, and probably in that of the Greeks. We first meet with it in the structures of the Romans, by whom it was employed in bridges and triumphal edifices, though not with much skill, ret on a magnificent scale. We shall understand the principle of the arch, if we conceive a number of pieces of stone or brick, shaped like obtruncated wedges, (that is, not sharp,) joined together by their faces, and all pointing downwards. They must evidently form a curved mass, which, if supported at the extremities, will not only stand, but will be rendered more firm by any weight pressing upon its top, since this weight is made to compress all the parts at once, and nearly in the same degree. The supports on which an arch rests are called piers, or abutments. The whole pressure evidently centres at these points, tending not so much to sink the abutments, as to spread them apart. Hence the care with which the abutment is secured, by anchoring it deep in the earth, or loading it with

*It is maintained, by some, that the arch must have been linow. to the Egyptians at a very early period, since it is found among the ruins of Thebes, \&ic. It is doubtful whether, in the instances referred to, the structures are very ancient. The arch seems to have been an Eiruscan inrention, and to have been emplored in the Cloaca Maxima at Rome, as early, many suppose, as the time of the Tarquins. 
heavy weights. While it retains its place, any pressure, applied downwards, at the top of the arch, or even on its sides, if it be of the proper form, will only tend to bind the stones, which compose it, more closely together. The advantage which the arch has, for resisting pressure, may be scen in the common watchglass face, which, if plane, would evidently be very liable to break; also, in the superior strength of the round junk bottle, as compared with those which have flat sides and square bottoms; and abore all, in the impossibility of breaking an $\mathrm{eg} g$, by pressing it endwise between our hands.

Now, it is a striking fact, that those parts in the human body, which are most liable to pressure, are constructed on the principle of the arch. The foot, Fig. 36 ,

rig. 36.

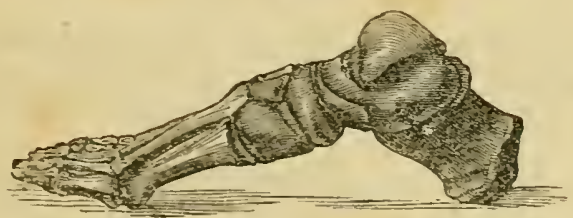

sor example, which is required to give a firm and unyiclding support to the body, is composed of three arches; one extending from the heel to the toe, and resisting pressure in that or the opposite direction; Another across the foot, and another horizontally, or, as it were, around from the ball of the foot to the heel. These arches are composed of bones, wedged together like the courses of stone in masonry, which, though movable in some positions of the foot, become perfectly imnovable, when the weight of the body bears direetly over it, and when, of course, a firm foundation is most needed.

So, again, the skull, Fig. 3\%, -which is peculiarly exposed to injury, from falls, blows, Ece, and which, at the same time, covers the most important organ of the body,-forms an arch, or, what is essential!y the same, 
Fig. 37.

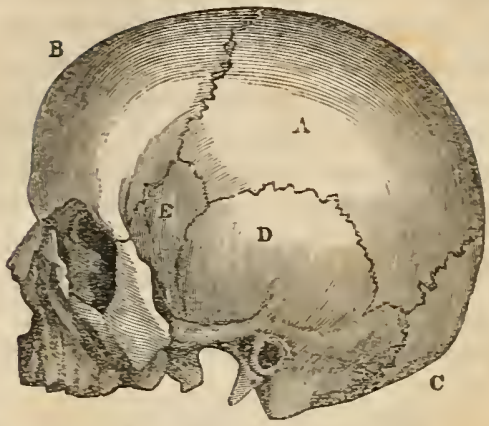

A, the parictul bone.

B, the frontal bone.

C, the accipital bone.

$\mathrm{D}$, the temporal bone.

$\mathrm{E}$, the sphenoid bone.

a dome. The two parietal bones, as they are called, which form the sides of the skull, Fig. 33, rest against

Fig. $3 \gtrsim$.

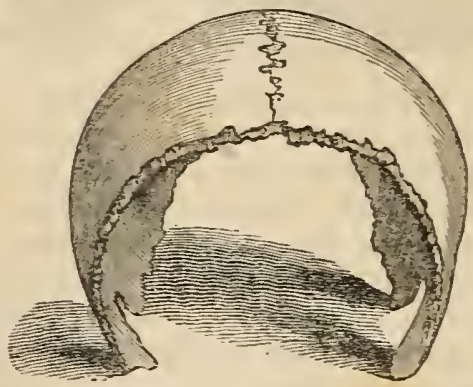

each other, at the top of the head, and form an arch. This arch lies, at its extremities, on two bones, called temporal bones, which answer as abutments; and it is most interesting to observe the provisions made to prevent the spreading of this arch, which would result from a load or pressure being laid upon the top of the head. In the first place, the lower or temporal bone 
laps over the parretal, so that the latter cannot be thrust out horizontally, without breaking it; a contrivance similar to the pinnacles and buttresses in Gothic architecture. In the second place, a bone, called the sphenoill bone, supporting the two temporal bones, passes across the head, from side to side, just as, in the roof of a house, the tie-beam is used, to prevent the rafters from spreading the walls; or as, during the construction of an arch, the straining-piece is uscd, to prevent the sides of the arch from being crushed in. It is worthy of obserration, too, that those parts of the head, which would strike upon the ground when a man falls, namely, the centre of the forehead, the projecting point of the skull behind, and the lateral centres of the parictal and frontal bones, are strengthened, just as we strengthen those joints in an arch, which are exposed to the most pressure; that is, by increasing their convexity and thickness, and also by ridges of bone on the inside, which correspond with braces used by carpenters at the angles in the centring of a bridge, or the frame of a roof.

(b.) We proceed to notice one or two of the principles which regulate the use of columns in architecture. Perhaps the most curious is that discovered, I believe, by Galileo, which tcaches, that, if a given amount of material is to be made into a column of given length, it will be strongest when it takes the shape of a hollow cylinder. The advantage which this form has, in resisting pressure, is twofold: first, a small quantity of matter, when emplored as a column, for support, is not so likely to bend, if arranged in a hollow cylinder, as if it were condensed into a solid one, of much smaller diameter. Secondly: it is, under the same circumstances, less likely to breal. To illustrate this: when a column, or other piece of timber, bends, and brealis, it is evident, that a twofold effect is produced. On the one side, the particles are crushed into one another; and, on the other, they are torn asunder, like the snapping of a rope: so that, betwixt the portions acting in a manner so different, there is an intermediate neutral 
part, which might be taken away without materially weakening the column. Accordingly, it has been found, by experiment, that hollow shafts, in machinery, are nearly as strong, as though they were made solid, and of the same diameter; and much stronger, than if the same amount of material had been put into a solid form, with a much smaller diameter; and hence, also, the hollow columns, masts, \&c., which are now used in buildings and in ships.

In forming the bones of the human body, the Creator has proceeded upon the same principle. Finding it necessary to combine strength with lightness, he has made these bones, for the most part, in the form of hollow cylinders filled up with the thin substance called marrow. Fig. 39. Wherever increased strength is

Fig. 39.

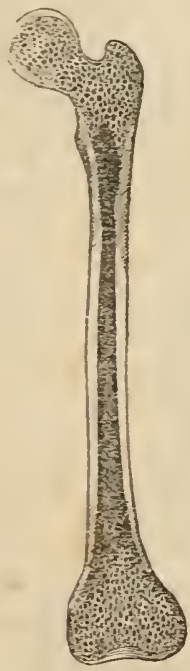

Fig. 40.

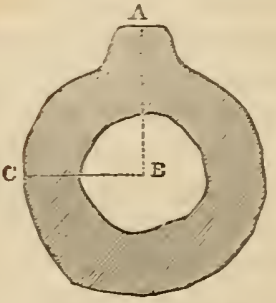

$A$, the spine, or ridge, running along the bone, B C.

necessary, he has attained it, by furnishing ligaments to one side of the bone to make it more tough, and a hard ridge, or spine, to the other side, to make it more capable of resisting compression. Fig. 40. Indeed, there 
are a thousand objects, such as quills, reeds, the grasses, Ec., which show that strength is uniformly given, by Nature, with the least possible cxpense of materials. It was this fact to which Galileo appealed, when he was arraigned before the Inquisition on the charge of atheism. Being asked, if he beliered in a God, he pieked up a straw, which had stuck to his garments. If, said he, there was nothing else in Nature, to teach me the cxistence of a Deity, even this straw would be sufficient. Such a straw, if made solid, and yet of the same quantity of material, would be so thin, that it would bend and break under the slightest weight; whereas, in its present form, it is able to support an car, which is leavicr than the whole stalk.

(c.) Another important principle, first noticed by Galileo, respects the limit which must be set to the magnitude of works in art. It may be illustrated in this manner. A soft stonc, projecting from a wall, may make a stile strong enough to support a person's weight; but if it were necessary to double its length, the thickness must be more than double, or a freestone substiiuted: and if it were necessary to make this freestone project twice as far from the wall, even if doubled in thickness, it would not be strong enough to bear a proportioned increase of weight. Granite must be placed in its stead, and even the granite would not be capable of sustaining four times the weight which the soft stone bore in the first instance.* In the same way, the stones which form an arch of a large span must be made of the hardest granite; clse their own weight would crush them. 'The same principle is applicable to the bones of animals. The material of bone is too soft, to admit an indefinite increase of weight. And generally, we may conclude that greater beams and bars, in carpentry, must be in greater danger of breaking, than smaller ones; and that what appears very firm, in a model, may he very weak, or even fall to pieces by ils own weight,

* See Sir C. Bell, on Animal Mechanics. 
when it comes to be executed in larger dimensions, according to that model. Hence it follows, that ships, temples, $\mathcal{E}$., of vast magnitude, cannot be erected, since the parts of their frame would necessarily fall asunder by their own weight. In like manner, if trees were of enormous magnitude, their branches would fall off; $*$ and animals, of magnitude much greater than any we now know, would be unable to sustain their own weight. As to marine animals, the case is difierent, since they are sustained, chiefly, by the specific gravity of the water, and are, in fact, known to be sometimes vastly larger than the greatest land animals.

In speaking of the application of mechanical science to architecture, we should not omit the machines which are used in preparing materials and depositing them in their proper positions. In the infancy of society, this is accomplished by the rudest instruments, and almost entirely by the exertion of human strength. For example: the people of Mexico and Peru, when first risited by the Spaniards, had neither carts, sledges, nor beasts of burden; but transported all their materials by mere manual labor. They linew nothing of scaffolds, cranes, or other machines, now used in erecting buildings; and were even ignorant of the use of iron. And yet, with no means of brealing their stones, but with flints, nor of polishing them, but by rubbing them against each other, they raised structures, which are beheld with admiration at the present day, and which nearly rival the greatest edifices of ancient India or Egypt. It is probable, that these last were erected in nearly the same manner. An ancient historian states, that the mere labor of raising from the ground the :tones which compose the great pyramid in Egypt,

* The architecture of trees exhibits an application of mechanical principles hardly less wonderful than that exhibited by the human body. The gradual enlargement of the trunk, as the tree gains elevation, its greater diameter at the base or tapering form, the tapering of the branches, the roundness of the stem, \&ic., all show that it takes precisely that form which best fits it for resisting the natural forces at war with it. 
and fastening them in their proper places, occupied one liundred thousand men for twenty years, (and this number was oxclusive of those who were employed in hewing and transporting.) It has been calculated, that the same labor might be performed by thirty-six thousand men, using the steam-engines of England, in a single day. It would seem to be evident, from this fact, (if it can be relied on,) that the building arts in Egypt must have been in their infancy, and that every thing was accomplished by main strength. Indeed, we are assured by the same historian, that these pyramids were formed of different bodies or stages, rising one abore another, like stairs; and that stones were raised from one to another step by means of the simplest lever. He adds, that over these they laid a covering of masonry, making a plane surface, by bcginning at the summit and working downwards. A similar method scems to have been pursued, in building the great temple at Mexico, and the rast pyramids, remains of which are to be found in various parts of South Anierica.

In this age, masses of stone, which could not be separated from the quarries, without the strength of one hundred men, are broken off, by a few pounds of powder. 'They are split into the requisite size and form, with the utmost regularity, by employing the expansive power of heat and of moisture: they are brought from their bed in the quarry or valley, with sixtyfold less labor, than if no contrivance were used for diminishing friction: they are transported from place to place, on rivers, canals, and rail-roads, with a still greater gain of power; and then they can be raised to their places, by the power of steam or animals, - we had almost said, without the intervention of man. In truth, his labor is almost reduced to the mere mental effort of superintending and directing the operation of mechanical powers.

Much of this improvement in the art of building has been the result of corresponding improvement in 
mechanical science. The effect which it has produced on society, not only in saving labor, but in multi plying comforts, is wonderful. When instruments are rude, and knowledge imperfect, few edifices can be reared; and these few must be comparatively rough and uncomfortable. The rich and powerful, it is true, as they can command human labor, may build their palaces of splendor and luxury. But they are built by a people, subsisting, like the ancient laborers in Egypt, on the poorest fare, and having only huts to cover them. It is stated, that, in one uncivilized country, which contains as many inhabitants as the island of Great Britain. there are but ten thousand houses, while the latter island contains two hundred and fifty times that number: and also that the finest house of the barbarians is vastly less commodious, than the poorest dwelling in England. The reason is obvious. The people of that country have neither machinery nor skill. Houses, therefore, can only be erected with great labor and expense, and in a very rude way. Consider what a quantity of waste, both of time and materials, is sared, and what regularity of form is secured, by a carpenter's tools. With his foot-rule and chalk-line, he measures off exactly as much wood as he needs; with his saw he cuts out, with the utmost precision, in a few minutes, a pattern, which with a knife he could not extract in a whole day; nor then, without great waste. His liatchet, planes, centre-bits, \&c. \&c., are all so many machines; to reduce labor, save material, and insure accuracy: and thus it becomes possible for the humblest individ. ual to have the shelter of a comfortable dwelling, and to have it provided with decent and eren ornamental furniture.

Compare the dwellings, even in considerable towns in England, down to the reign of Elizabeth, with those found in the same towns, at the present day. The greater part of the houses had no chimneys; the fire was kindled against the wall, and the smole found its 
way out, as well as it could, by the roof, the door, or the windows. The houses were mostly built of wattling, plastered over with clay; the floors were of earth, strowed, in families of distinction, with rushes. The beds were only straw pallets, with a log of wood for a pillow. In this respect, eren the king was no better of than his subjects; for, in the time of Henry the Eighth, we find directions, "to examine, erery" night, the straw of the ling's bed, that no daggers might be concealed therein." In the discourse prefixed to Hollingshed's Chronicle, published in $15 \% \%$, the writer, speaking of the progress of luxury, mentions three things, especially, that were marrellously altered for the worse in England:-the nultitude of chimners lately erected; the great increase of lodgings; and the exchange of treene-platters ints pewter, and wooden spoons into silver and tin; and he complains bitterly that nothing but oak, for building houses, was then regarded: "for when our houses," says he, "were built of willow, then we had oaken men; but now that our houses are come to be made of oak, our men are not only become willow, but a great many altogether straw, which is a sore alteration."

\section{CHAPTER V.}

MANUFACTURE OF CLOTII, PAPER, ETC.

Tins forms one the most interesting as well as important branches of the arts. To convert the short and weak fibres of wool, cotton, $\mathcal{E}$., into strong and flexible textures, adapted to a great varicty of purposes, might seem to be the highest etlort of human ingenuity. And yet it is an effort, which, under the pressure of necessity, is made at the earlicst periods of civilization. Animals have been provided by their Creator with a covering suited to the zones.in which they dwell. But man, the universal elenizen, the inhabitant of every

* The abore statenents are made on the authority uf Bceliman (Hist. of Inventions).

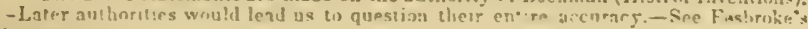


zone, has been left to supply this ever-rarying want, by the efforts of his own industry and skill. At first, he may be satisfied to clothe himself in the skins which he has taken from the animals destrored in the chase. Choice; howerer, soon conspires with necessity, in prompting him to seek a more convenient, comely, and salubrious covering. Hence we find, in the earliest records of human history, notices of "fine linen ;" and there is little doubt, that both cotton. and wool were manufactured, the former in India and the latter in Greece, at very remote periods of their history. At such times, patient industry, joined with manual skill, succeeds, though destitute of science, in accomplishing, with considerable accuracy, complicated processes, which are now executed with yet greater perfection, and almost entirely by machinery. It will be our object, in treating of this subject, to explain the principles on which the manufacture of cloth, paper, $\mathbb{C} c$., depends, and to show its connexion (as conducted at present) with mechanics and chemistry.

I. The constituent fibres of cloth, paper, \&c., are held together, principally, by friction and adhesion among themselves. The efforts of the manufacturer are directed to interwearing or intermixing them so together, that any force which is applied will tend, as in the arch, rather to bind them together than to separate them. This is accomplished, in different ways, according to the material which we use, and the purpose to which the fabric is to be applied. If we would manufacture cloth, we commence by twisting the fibres together into small threads, and then we unite these threads into a continuous texture, by wearing. If it be our object to make cordage, or ropes, the threads are united, not by wearing, but by twisting alone; and finally; if we propose to make paper, or the felt for hats, the fibres, instead of being twisted, are united principally by pressure.

Previous to being united, the fibres are in all cases subjected to a treatment, which is calculated to render 
them more flexible, eren, and uniform. Thus, flax is broken and hatcheled, in order to exclude the husk and coarse fibres, and to render the remainder even and pliable: cotton is picked and carded: wool is either carded or combed, according as its fibres are shorter or longer, and then oiled, to enable these fibres to move freely upon each other, luring the process of spimning and weaving: furs, and other materials for felting, are intimately mixed together, by borring : and the rags, from which paper is generally made, are minutely subdivided by cutters, and immersed in water, till they form a thin, uniform pulp.

The most common mode of uniting flexible fibres is by twisting; and as this is nerer effected without some machine, we shall have occasion to describe it more particularly, when we come to speak of spinning by machinery. Wearing is a more complicated process. Threads are arranged longitudinally and parallel to each other, which are called the warp, and these are crossed at right angles by another thread, called the woof, weft, or filling, which, in common weaving, passes alternately over and under the threads of the warp. In twilled goods, however, it crosses only at the third, fourth, fifth, or sixth, threads; and, when great fineness is wanted, only, in some cases, at the sixteentl. In wearing gauze, the threads of the warp, instead of remaining parallel, are crossed, and partially twisted to the right and left, alternately, at each stroke of the loom. In lace, the threads of the weft, instead of moving at right angles to the warp, are made to pass in cross directions, and obliquely round the warp threads, so as to produce the hexagonal meshes, which distinguish this kind of fabric. In velvet, plush, and corduroy, as also in Prussels and Turkey carpets, the threads are drawn up in loops, which are eut open, and

* This depends on the viloration of an elaslic spring, which, moxing rapidly baekwards and forwards through the fur, is well calculated to renove all irregularities, and dispose them in a light and uniorm arrangement. 
thus form a soft uniform nap. In Kidderminster $\mathrm{cal}$ pets, Marseilles quilts, \&c., there are two webs, each consisting of a separate warp and a separate woof, which intersect each other at intervals, so as to produce a definite figure. It should also be added, that the warp and weft are not always of the same material; linen, cotton, \&c., being often used as a filling, for woollen; and there are other cases, as in the Turkey carpet and in tapestry, where both are of linen, and are yet concealed by the wool, which is introduced to produce the figures, and gire to the fabric its fine and ornamented surface.

When the web has been woren, it needs, in many cases, some additional process, in order to fit it for convenient use. Thus, cotton, when taken from the loom, is covered with rough down, formed by the projecting ends of the fibres, which is generally removed by burning,- the heat being applied and withdrawn so rapidly, as not to injure the texture of the cloth. Woollens require to be scoured, in order to remore the oily matter previously applied; and to restore roughness to the fibres; and, if composed of short wool, the web is found so loose and open, that it must be submitted to another operation, called fulling. This is performed by a fullingmill, in which the cloth is immersed in water, and subjected to repeated compressions, by the action of Jarge beaters formed of wood, which repeatedly change the position of the cloth, and cause the fibres to felt, and combine more closely together. By this process, the cloth is reduced in its dimensions, and the beauty and stability of the texture are greatly improved. The tendency to become thickened, by fulling, is peculiar to wool and hair, and does not exist in the fibres of cotton and flax. It depends on a certain roughness of these animal fibres, which permits motion in one direction, while it retards it in another. It thus promotes entanglement of the fibres, which serves to shorten and thicken the woven fabric.

The nap. or downy surface of broadcloth. and also 
of hats, is raised by a process, which, while it improres the beauty, tends somewhat to diminish the strength, of the texture. It is produced by carding the cloth with a species of bur, the fruit of the common teasel, which is cultivated for the purpose. This operation extracts a part of the fibres, and lays them in a parallel dircetion. The nap, composed of these fibres, is then cut off to an eren surface, by the process of shearing.

II. Machinery used in the manufacture of cloth, \&.e. -It is obrious, that, without the aid of machinery, the human hands could do very little at twisting and weaving flexible fibres. Hence the spinning-wheel and loom are among the earliest inventions of human ingenuity. Among the Greeks and Romans, spinning was the chicf employment of the women. The rites of marriage directed their attention to it, and the distaff and fleece were not only the emblems, but the objects, of the most important domestic duties of a wife. The machinery employed in wearing, though rude in construction, was in principle similar to that still in use; and the process of fulling and preparing the cloth seems to have resembled the modern practice, in erery particular point, except that of shearing the nap, with which the ancients do not appear to have been acquainted. In early records, we do not read, however, of cloth being measured, which appears to have arisen from a custom of weaving no more cloth in one piece than was sufficient to form a single dress.

Muslins are to this day manufactured by the primitive boor, in India, probabiy without any material alteration of the form in use during the earliest ages of its invention. It consists merely of two bamboo rollers, one for the warp the other for the cloth with a pair of gear; the shuttle performing the office of the batoon. This simple apparatus the Indian weaver frecuently erects under the shade of a tree. He digs a hole, large enough to contain his legs, and the lower part of his gear ; he then stretches his warp, by fastening the rollers at due dis- 
tances, on the turf, and suspends the balances of the gear from the spreading branches of the tree; two lonps beneath the gear, into which he inserts his great tıns, serve instead of treadles; and with his long shut. tle he draws the weft through the warp, and afterwards closes it up to the web.*

Until the middle of the last century, all spinning was performed by hand, with the aid of the common spinning-wheel. Locks of cotton or wool, previously carded, were attached to a rapidly-revolving spindle, driven by a large wheel, and were stretched or drawn by the hand, at the same time that they were twisted by the spindle upon which they were afterwards wound. Flax, the fibres of which are longer and more parallel, was loosely wound upon a distaff, from which the fibres were selected, and drawn out by the thumb and finger, and at the same time were twisted by frers, and wound upon a bobbin which revolved with a velocity somewhat greater than that of the fyers.

The first effort made to substitute machinery, on a larger scale, in the manufacture of flexible stufis, was in 1767, when Richard Hargreaves, a carpenter, in Lancashire, England, introduced the spinning-jenny, which gave the means of spinning twenty or thirty threads of cotton, with no more labor than had been previously required to spin a single thread. In its simplest form, it resembles a number of spindles, turned by a common wheel or cylinder. It was doubtless a great improvement upon the one-thread wheel; but still had two important defects, first, because it required to be worked by liand; and secondly, because the

* Ulloa mentions, that the Indians of South America have no other method of making cloth, than by taking up thread after thread of the warp and passing the woof between them, by the hand; and he adds, that they are thus frequently engaged, for two or three years, in the weaving of hammocks, coverlids, and other coarse cloths, which a European would, by means of his loom, produce in as many days, or probably hours. From inscriptions on their monuments, it would appear, that the ancient Egyptianswere not unacquainted with the use of the shuttle. 
thread spun by it could only be used as weft, not being twisted hard enough to answer the purpose of warp.

This deficiency was supplied, two years after, by Richard Arkwright, * a barber of Preston, who invented the water-spinning-frame, a machine, which may be moved entirely by water or steam, and which does the work of the liuman fingers, upon a vast number of threads, of any degree of fincness, in the same time that was previously required to produce a single thread; and does this work, too, with much greater precision. This ingenious man and great benefactor of the human race, $\dagger$ informs us, that he derived the first hint of his machine from seeing a red-hot bar of iron elongated, by being made to pass between rollers.

His spinning-frame consists of two pairs of rollers,

* For a notice of Arkwright, see the second Volume of 'Pursuit of Knowledge under Diltieulties,' heing Volume xv. of 'TuE SCFOOL LIBRARY', Larger Serics.

t Mr. Baines seems to have lave shown, that the merit of being the original discoverer of this great invention is due to a $\mathrm{Mr}$. John $\mathbf{W y a t t ,}$ who took out, in the name of Mr. Lewis Paul, a foreigner, a patent, wherein the process of spinning by rollers is distinctly described, so early as 1738 , or thirty-one years before Arkwright's patent. And it furtler appears, that, in $17+1$ or $17+2,16$ yatt erected a mill at Birminglian, which was turned by two asses, and attended by ten girls. Some of the yarn, spun by this mill, is still in existence. Owing, however, to the imperfectness of the machinery, the want of skill, capital, or some other canse, this undertilking was speedily abandoned. 'The invention was soon after tricd, on a larger scalc, at Northampton, but with no better success. It appears, from the special reference made to them, in the case printed by sir Richard Arkwright, in 1786 , that he was fully aware of these attempts to spin by machinery; but it is not known, whether he was aware of the principle on which they proceeded, or had seen the patent referred to. Indoubtedly, however, the presumption seems to be, that he had seen it; and if so, he cannot be regarded as the inventor of the spinning frame. But, notwithstanding this deduction from his extraordinary merits, enough will still remain, to justify the claims of Arkwright to the respect and gratitude of mankind. 'The machine he constructed, though in prineiple the sarne, differed matcrially, in its form and make, from tlat of IVyatt. In the hands of the latter, the invention, how ingenious soever, was of no practical utility; ani all traces of it seem to have been lost. If Arkwright did not invent it a second time, he did what was equally important; he made it available in practice, and slowed how it might be rendered the most prolific source of individual and publip. wealth.-.ICCulloch's Statistics of the British Empirc. 
turned by means of machinery : the lower roller of each pair is furrowed or fluted, longitudinally, and the upper one is covered with leather, to make them take a hold of the cotton. If there were only one pair of rollers, it is clear that a carding of cotton passed between them would be drawn forward by the revolution of the rollers, but it would merely undergo a certain degree of compression from their action. No sooner, however, has the carding, or roving, as it is technically called, begun to pass through the first pair of rollers, than it is received by the second pair, which are made to revolve with (as the case may be) three, four, or five, times the velocity of the first pair. By this admirable contrivance, the roving is drawn out into the desired degree of fineness, a twist being given to it, by the adaptation of the spindle and fly of the common flax-wheel to the machinery.

'This instrument has been since applied to the spinning of wool ; the spindles being mounted on a carriage, which passes backwards and forwards, so as to stretch the material at the same time that it is twisted. The application of machinery to the spinning of flax and hemp is rendered very difficult, by the length and comparative rigidity of the fibres, which prevent us from preparing them by carding, as cotton and wool are prepared, or from drawing them by rollers. Many efforts have been made to spin flax by machinery; but, thus far, with no great success, except in the production of coarse threads.* The manufacture of fine threads, such as those used for cambric and lace, has continued, until very lately, to be performed by hand, upon the ancient spinning-wheel. In the manufacture of silk, machinery is now applied, on the most extensive scale, for winding, spinning, and weaving:

* This remark needs qualification. Fine threads are now spun by machinery ; and, according to Dr. Ure, (Dictionary of the Arts,) the art his been brought to a perfection in Leeds, (England,) and Dundee, (Scotland,) little short of that for which the cotlon trade has been so long distinguished. 
It is impossible, in a work like the present, to describe, or even notice, the vast variety of maclines, which are now employed in eloth manufacture. As the cotton machinery is peculiarly interesting, on account of the great use made of it in this country, we shall briefly describe the various processes pursued, in transforming the raw cotton, as it comes from the field, into cloth.

\section{CHAP'TER VI.}

COTTON MIANUFACTURE.

'Tre first process in the manufacture of cotton is called ginning, the object of which is, to cleanse the cotton from the seed. There are two machines, for this purpose, called the rolling-gin and the saw-gin. The essential parts of the first, are two small cylinders, revolving in contact or nearly so. The cotton is drawn between the rollers, while the size of the sceds prevents thom from following. The saw-gin, invented by our countryman, Mr. Whitney, is used for the green-seed cottion, the sceds of which adliere too strongly to be separated by the other method. It is a recciver, having one side covered with strong parallel wires, about an eighth of an inch apart. Between these wires, pass a number of circular saws, revolving on a common axis. The cotton is entangled in the teeth of the saws, and drawn out through the grating; while the sceds are prevented, by their size, from passing. The cotton, thus extricated, is swept from the saws by a revolving cylindrical brush, and the seeds fall out, at the bottom of the receiver.* 'To this ingenious contrivance, the

* American cotton is gencrally known by the names of seaisland and upland. 'The former grows along the low, sandy shores of Carolina, Georgia, \&c. It is long in the staple, has an even, silky texture, a yellowish tinge, is easily scparated from the sced, and is decidedly superior to every other description of cotton hitherto brought to market. Unfortunately, however, it can be raised only in certain situa 


\section{cotton-growing States of our Union owe all the wealth} derived from that culture. Previous to 1789, those States had not raised a pound for exportation; and even subsequently, though the cultivation was encouraged, by a duty of three cents a pound on imported cotton, it languished, solely on account of the difficulty of separating the seed from the fibre. Since Mr. Whitney's invention was introduced, the amount raised has increased so rapidly, that in 1834 it averaged more than one million of bales, or one hundred and eighty thous-

tions ; so that its quantity is limited, and has not, in fact, been at all increased, since 1\$05. At present, ninety-seren or nineţ-eight per cent. of the cotton prodnced in the Lnited States consists of what is denominated upland, from its being grown on the comparatirely hirh grounds at a distance from the coast. Thongh of varying qualities, it is all short stapled; and its separation from the seed and pod, if attempted by the hand, is so very dificult, that the cotton is hardly worth the trouble and expense. This, however, was the only way in which it conld be made avalable, for home use or exportation, in 1791 ; and, had any one then rentured to predict, that ten millions of pounds of upland cotton would ever be exported, he rould hare been looked upon as a visionary dreamer. But the genins and talent of Mr. Eli Whitney did for the cotton planters of the Lnited States what Arkwright did for the manufacturers of England. He invented a machine, by which the cotton wool is separated from the pod, and cleaned, with the greatest ease and expedition; and, in this war, doubled the wealth and industry of his conntrmmen.- (Pitkin's Statistics of the United States, page 109, ed. 1S35.) Mr. Whitney's inrention came into operation in 1793 ; and in 1794 , one million sis hundred and one thousand seren handred and sixty ponnds, and in 1\%95, five millions two hundred and serenty-six thousand three hundred pounds of cotton were exported! The effect of the machine was, like that of Arkwright's, all bat miraculous. The exports of cotten from America, duriug the year which ended $30 t h$ September, 1838 , amounted to the enormons sum of fire hundred and ninetr-fire millions nine hundred and fifty-two thousand two hundred and ninety-seren pounds ; worth, when shipped, sixty-one millions fire hundred and fifty-six thousand eight hundred and eleren dollars. And it is not going too far to say, that, had not Whitney"s or some equivalent machine, been invented, there is no reason to think that the exports, during the above year, would have exceeded thirty-four millions of pounds, if $s 0$ mach; so that the existence of the other five hundred and sixty millions of pounds, with the greatest part of that retained for home consumption, may be ascribed to Mr. Whitner's machine, as to its real source and origin!

The amount exported from October 1,1539 , to Angust, 1840, was about seven handred and fourtecn millions of pounds. 
and tons, annually. The amount raised in 1839 was more than two millions one hundred and sixteen thousand nine hundred and sixty bales, or three hundred and cighty-one thousand tons; one, among a thousand similar instances, of the eflect of labor-saving machines in stimulating industry.

2. The next process is to open, clean, and spread, the cotton, preparatory to carding. This is done, by first spreading out the contents of different bags, of different kinds of cotton, in separate horizontal layers, one over another. This heap, or bing, having been pressed down in the manner of a haystack, the cotton is then torn down by a rake from top to bottom, by which means, if the work be skilfully done, the contents of the different bags must be collected together, into masses of uniform quality.

The cotton, being in matted masses, or flocks, is then loosened, and partially cleaned from dirt, by means of the willow. This instrument, as its name would intimate, was originally a willow basket, but is now a cylindrical box of wood, with revolving iron spikes.

The revolutions, being rery rapid, (six luundred in a minute,) serve both to winnow and loosen the cotton, the heary impurities falling down, through the bottom.

The cotton then passes to the scutching machine, in order to be more thoroughly opened and purified. This instrument is so contrived, that it beats, scutches, and blows. After passing slowly through feeding rollers, made of wood, the cotton is struck by a set of beaters, revolving sixteen hundred or more times in a minute. It is thus passed through two sets of rollers, and subjected to two sets of beaters.

The cotton is then taken to the spreading machine, the use of which is to spread a given weight of cleaned cotton into a given length and breadth, in order to its being presented of uniform thickness to the next machine

3. Up to this stage, the fibres of the cotton cross each other in erery direction. The use of the next operation is to disentangle them, to draw them out, and 
lay them parallel to each other. This is called carding. The cotton is carried over the surface of a revolving cylinder, which is covered with card-teeth, of wire, and which passes in contact with an arch or part of a concave cylinder, similarly corered with teeth. From this cylinder, called the breaker, the cotton is taken off, by another, called the doffing cylinder, which revolves in an opposite direction; and from this, it is again removed, by the rapid vibrating motion of a transverse comb, otherwise called the doffing-plate, mored by cranks. It then passes through a second carding, in the finishing cylinder, from which it is carried through a lind of funnel, by which it is contracted into a narrow band or sliver, and received into tin cases in the state of a uniform continued carding.

4. The next step in the process is called drawing and plying; the object of which is, to arrange all the fibres of the cotton longitudinally, in a uniform and parallel direction, to do away all the inequalities of thickness. It is effected by the use of a double pair of rollers, similar to those already described in Arkwright's spinning-frame; the greater relocity of the second pair of rollers serving to draw out the roll of cotton into a smaller size, and these smaller rolls being then united, are plyed, by passing through the rollers a second and third time.

5. Roving the cotton, which is the next part of the process, gives it a slight twist, which converts it into a soft and loose thread, called the roving. The machine for performing this operation is called the roving-frame, or double-speeder. In order to wind the roving upon the bobbins of the spindles, in eren, cylindrical layers, the spindle-rail is made to rise and fall slowly, by means of heart-wheels in the interior of the machine. And as the size of the bobbins is augmented by each layer, the relocity of the spindles and of the spindle-rail is made to diminish, gradually, from the beginning to the end of the operation. This is effected, very ingeniously, by transmitting the motion of both through two op 
posite cones, one of which drives the other with a band, which is made to pass slowly from one end to the other of the cones, and thus continually alter their relative speed, and cause a uniform retardation of the velocity. IIence called, double-speeder.

6. The roving laving been wound on the bobbins, is transferred to the spinning-frame; and, in the manner already described, is reduced to a thread of the required fineness, the twist being given by flyers. Where thread of the finest kind is required, it is effected by also stretching the yarn, in the direction of its length, which serves to reduce those places in the yarn which hare a greater diameter than the rest, so that the size and twist may become uniform throughout. This is effected, as in spinning wool, by mounting the spindles on a movable carriage, called a mule, which recedes, when the threads are to be stretched, and returns, when they are to be wound up.* To show the astonishing

* At first, the mule carried only one hundred and forty-four spindles ; but by successire improvements it was rendered capable, about a dozen years ago, of working three or four linndred spindles. Its maximum capability was fur, however, from being yet attained ; and several mules are now at work in Mauchester, and other places, earrying the extraordinary number of from seven to eight hundred spindiles, and a few as many as eleven hundred spindles.

Various attempts have been made, it different periods, to work the unule solely by machinery, without the aid of manual labor. I3ut none of the contrivances for that purpose were altogether suecessful, till the self-acling mule of Messrs. Sharpe and Roberts, of Manchester, came recently into the field. 'The machinery is so constructed, as to roll the spindle carriage out and in, at the proper speed, withont a hand touching it ; the only manual labor employed in these maelines being that of the children who join the broken threads. Formerly, the machine had to be rolled in by land, and required the strength of a man. The machine seems to have come very near perfection, producing a cousiderably greater quantity of yarn, of a more uniform twist, and less liable to break, than mules wrought by the hand; at the same time that it has the important advantage of rendering the mill owners independent of the combinations and strikes of the working spinners. Mr. Baines inentions, that the patentees informed him in March, 1834, that they had then made five hundred and twenty self-acting mules, containing upwards of two hundred and eighty thousand spindles, and that that number was likely to be more than donbled, in the course of the year.-.IC Culloch's Statistirs of the British Empirc. 
minuteness to which the cotton thread may be reduced, we may state, that one pound has been spun into a thread one hundred and sixty-seven miles long.

7. The spinning process being completed, that of weaving begins. The first step, preparatory to wearing, is, to form a warp, the threads of which were formerly attached to as many pins, and drawn out to the required length; but as this method required too much room, a warping machine was subsequently used, in which the mass of threads, intended to constitute a warp, was wound, in a spiral course, upon a large revolving frame which rose and fell, so as to produce the spiral distribution.

These methods, however, are now superseded, in this country, by a warping machine, invented by the late Paul Moody, of Lowell, Massachusetts, long distinguished as a machinist, and the author of several great improvements in the spinning, roving, and dressing, frames. The most interesting part of this machine is a contrivance, which he introduced, for stopping the machine, if a single thread of the warp breaks. To effect this object, a small steel weight, or flattened wire, is suspended by a hook, from each thread, so that it falls, if the thread is broken. Beneath the row of weights, a cylinder revolves, furnished with several projecting ledges, extending its whole length, parallel to the axis. When one of the weights falls, by the breaking of its thread, it intercepts one of the ledges, and causes the cylinder to exert its force upon an elbow, or toggle-joint, which disengages a clutch, and stops the machine. After the thread is tied, and the weight raised, the machine proceeds.

The process of weaving I have already described, as far as my limits allow. For the last twenty years, looms, driven by water or steam, have been substituted for the hand-loom. The motions being principally of a reciprocating kind, are produced either by cranks, or by cams or wipers acting upon the weights or springs. The course taken by the cotton, in its various trans- 
formations, is thus briefly described by Mr. Baines, in his History of the Cotton Manufacture.

"The cotton is brought to the mill in bags, just as it is reccived from America, Egypt, or India, and is then stowed in warehouses, being arranged according to the countries from which it may have come. It is passed through the willow, the scutching-machine, and the spreading-machine, in order to be opened, cleaned, and evenly spread. By the carding-engine, the fibres are combed out, and laid parallel to each other, and the piece is compressed into a sliver. The sliver is repeatedly drawn and doubled in the drawing-frame, more perfectly to straighten the fibres, to equalize the grist. The roving-frame, by rollers and spindles, produces a coarse and loose thread, which the mule, or throstle, spins into yarn. 'To make the warp, the twist is transferred from cops to bobbins, by the winding-machine, and from the bobbins at the warping-mill to a cylindrical beam. This beam, being taken to the dressingmachine, the warp is sized, dressed, and wound upon the wearing-beam. The latter is then placed in the power-loom, by which machine, the shuttle being supplied with cops of weft, the cloth is woven.

"Such, without entering into minutix, are the processes, by which the regetable wool is converted into a woren fabric, of great beauty and delicacy; and it will be perceived, that the operations are numerous, and every one of them is performed by machinery, without the help of human hands, except merely in transferring the material from one machine to another. It is by iron fingers, teeth, and wheels, moving with exluaustless energy and devouring speed, that the cotton is opened, cleaned, spread, carded, roved, spun, wound, warped, dressed, and woven. The various machines are proportioned to each other, in regard to their capability of work; and they are so placed in the mill, as to allow the materials to be carried from stage to stage, with the least possible loss of time. All are moving at once; the operations chasing each other; 
and all derive their motion from the mighty engine, which, firmly seated in the lower part of the building, and constantly fed with water and fuel, toils through the day, with the strength of a hundred horses.* Men, in the mean while, have merely to attend on this wonderful series of mechanism, to supply it with work, to oil its joints, to check its slight and infrequent irregularities; each workman performing, or rather superintending, as much work, as could have been done by two or three hundred men, sixty years since."

\section{CHAPTER VII.}

\section{CLOTH MANUFACTURE CONTINUED.-PAPER-MAKIXG.- DYEING, ETC.}

Nothisg places in a more striking light the vast improvement which has taken place in the mechanical arts, since the era of Arkwright, than the condition of paper-machine factories.

Till within the last thirty years, the linen and hempen rags, and other materials from which paper was Inade, were reduced to the pasty state of comminution, requisite for this manufacture, by washing them with water, and setting the mixture to ferment, for many days, in close ressels, whereby they underwent, in reality, a species of putrefaction. It is easy to see that

* The moring power of a modern factory, besides its proper tasks of picking, carding, roving, spinning, weaving, \&c., does a great deal of miscellaneous drudgery. For example : it raises the coals from their bins in the yard, by a sloping series of buckets, like those of a dredging-machine for deepening rivers, and delivers them on an elevated railway platform, into a wagon, through the drop-bottom of which they are duly distributed among a range of hoppers, attached o the furnace-feeding machines. It also carries the work-people upwards or downwards, to any floor of the factory to which their business may call them. Morable platforms are constructed, capable of holding half a dozen persons, and enclosed in upright tunnels through which they more.-Ure. 
the organic structure of the fibres would be thus un. necessarily altered, nay, frequently destroyed. The next method employed was, to beat the rags into a pulp, by stamping rods, shod with iron, working in strong oak mortars, and moved by water-wheel machinery. So rude and ineffective was the apparatus, that forty pairs of stamps were required to operate a night and a day, in preparing onc hundred weight of rags. The pulp or paste was then diffused through water, and made into paper, by methods similar to those still practised in the small handmills.

About the middle of the last century, the cylinder or engine mode, as it is called, of comminuting rags into paper pulp, was invented in Holland, which was soon afterwards adopted in France, and at a later period in England and America.

The first step in the paper manufacture is, the sorting of the rags into four or five qualities. They are imported into this Country and England, chiefly from Germany, and the ports of the Mediterranean. At the mill, they are sorted again, more carefully, and cut into shreds by women. For this purpose, a table frame is covered at top with wire cloth, containing about nine meshes to the square inch. To this frame, a long steel blade is attached, in a slanting position, against whose sharp edge the rags are cut into squares or fillets, after having their dust thoroughly shaken out, through the wire cloth. Each piece of rag is thrown into a certain compartment of a box, according to its fineness; seven or eight sorts being distinguished. An active woman can cut and sort nearly one hundred weight in a day.

The sorted rags are next dusted, in a revolving cylinder, surrounded with wire cloth, about six fect long and four feet in diameter, having spokes, about twenty inches long, attached at right angles to its axis. These prevent the rags from being carried round with the case, and beat them, during its rotation, so that, in half an hour, being pretty clean, they are taken out, by the side door of the cylinder, and transferred to the engine, 
to be first washed, and next reduced into a pulp. For fine paper, they should be previously boiled, for some time, in a caustic lie, to cleanse and separate their filaments.

The rags are wasked and reduced to pulp, by means of a machine, sometimes called a stuff-engine, which consists of a cylinder, furnished, on its circumference, with short knires or teeth, which, as it revolves, act against another set of knires, that are fixed to a block, the rags being, at the same time, mixed with running water, and confined within a box that contains the rerolving cylinder.

The operation of grinding the rags requires nice management. When first put into the washing engine, they should be worked gently, so as not to be cut, but only powerfully scrubbed, in order to enable the water to carry off the impurities. This effect is obtained, by raising the cylinder upon its shaft, so that its teeth are separated considerably from those of the block. When the rags are comminuted too much in the washer, they would be apt to be carried off in part, with the stream, and be lost ; for, at this time, the watercock is fully open. After washing in this way for twenty or thirty minutes, the bearings of the crlinder are lowered, so that its weight rests upon the cutters. Now the supply of water is reduced, and the rags begin to be torn, at first, with considerable agitation of the mass, and stress upon the machinery. In about three or four hours, the engine comes to work very smoothly, because it has, by this time, reduced the rags to the state of half-stuff. They are then discharged into a large basket, through which the water drains away.

The bleaching is usually performed upon the halfstuff. At the celebrated manufactory of Messrs. Montgolfier, at Annonay, near Lyons, France, chlorine gas is employed for this purpose, with the best effect upon the paper, since no lime or muriate of lime can be thus left in it; a circumstance which often happens to Engish paper, bleached in the washing-engine by the in 
troduction of chloride of lime among the rags, after they have been well washed for three or four hours by the rotation of the engine. The current of water is stopped, whenever the chloride of lime is put in. From one to two pounds of that chemical compound are sufficient to bleach one hundred weight of fine rags; but more must be employed for the coarser, and darker colored. During the bleacling operation, the sliders are put down in the cover of the cylinder, to prevent the -water getting away. The engine nust be worked an hour longer with the chloride of lime, to promote its uniform operation upon the rags. The eylinder is usually raised a little, during this period, as its only purpose is to agitate the mass, but not to triturate it. The water-cock is then opened, and the washing is continued for about an hour, to wash the salt away; a precaution which ought to be better attended to than it always is, by paper manufacturers.

The half-stuff, thus bleached, is now transferied to the beating-engine, and worked into a fine pulp. 'This operation takes from four to five lours; a little water being admitted, from time to time, but no current being allowed to pass through, as in the washing engine. The softest and fairest water should be selected for this purpose; and it slould be administered in nicelyregulated quantities, so as to produce a proper spissitude of stuit for making paper.

For printing-paper, the sizing is given in the beating-engine, towards the end of its operation. The size is formed of alum, in fine powder, ground up with oil ; of which mixture, about a pint and a half are thrown into the engine at intervals, cluring the last half hour's beating. Sometimes a little indigo-blue or smalt is also adder, when a peculiar bloom color is desired. The pulp is now run off into the stuff-chest, where the different linds are mixed; whenee it is taken out, as wanted. 'The cliest is usually a rectangular ressel of stone, or wood lined with lead, capable of containing three hundred cubic feet, at least, or three engines full 
of stuff. Many paper-makers prefer round chests, as they admit of rotary agitators.

When the paper is made in single sheets, by hand labor, as in the older establishments, a small quantity of the stuff is transferred to the working-rat, by means of a pipe, and there properly diluted with water. This vat is a vessel of stone or wood, about five feet square and four deep, with sides somewhat slanting. Along the top of the rat, a board is laid, with copper fillets fastened lengthwise upon it, to make the mould slide more easily along. This board is called the bridge. The maker stands on one side; and has, at his left hand, a smaller board, one end of which is made fast to the bridge, while the other rests on the side of the vat. In the bridge opposite to this, a nearly upright piece of wood, called the ass, is fastened. In the vat, there is a copper, which communicates with a steampipe to keep it hot; there is also an agitator, to maintain the stuff of a uniform consistence.

The moulds consist of frames of wood, neatly joined at the corners, with wooden bars rumning across, about an inch and a half apart. Across these, in the length of the moulds, the wires run, from fifteen to twenty per inch. A sirong raised wire is laid along each of the cross-bars, to which the other wires are fastened; this gives the laid paper its ribbed appearance.

The water-mark is made by sewing a raised piece of wire, in the form of letters, or any figured device, upon the wires of the mould, which makes the paper thinner in these places. The frame-work of a wove mould is nearly the same: but, instead of sewing on separate wires, the frame is covered with fine wire cloth, containing from forty-eight to sixty-four meshes per inch square. Upon both moulds a deckel, or movable raised edge-frame, is used, which must fit very neatly ; otherwise, the edges of the paper will be rough.

The workman, provided with a mould, dips up a portion of the pulp, and holds it in a horizontal direction, shaking it gently. This is a very delicate operation; 
for, if the mould be not held perfectly level, one part of the shect will be thicker than another. The water runs out through the interstices of the wires, and leaves a fibrous coating, in the form of a shect, upon the bottom of the mould. The sheets, thus formed, are subjected to pressure, first between felts or woollen cloths, and afterwards alone. If intended for writing-paper, they are then sized, by dipping them in a thin solution of gelatin, or glue, obtained from the shreds and parings of animal skins. The use of the size is to increase the strength of the paper, and, by filling its interstices, to prevent the ink from spreading among the fibres, by capillary attraction. In blotting-paper, the usual sizing is omitted, and in printing-paper less is used. The paper, after being dried, is pressed, examined, selected, and made into quires and reams. Hot-pressed paper is rendered glossy, by pressing it between hot plates of polished nretal.

Paper is also manufactured by machinery, and one of the most ingenious methods is that invented by the Messrs. Fourdrinier. In this arrangement, instead of moulds, the pulp is received in a continual stream, upon the surface of an endless web of brass wire, which extends round two revolving cylinders, and is kept in continual motion forwards, at the same time that it has a tremulous, or vibrating, motion. 'The pulp is thus made to form a long, continual shect, which is wiped off from the wire web, by a revolving eylinder, covered with flannel, and, after being compressed between other cylinders, is finally wound into a coil, upon a reel prepared for the purpose. From this reel it is again unwound, by means of machinery, and cut into shects of uniform size.

The machine-made papers possess many advantages; they can receive, so to speak, unlimited dimensions;** they preserve a perfectly uniform thickness, throughout all their length; they may be fabricated in every season of the year; nor do they require to be sorted, trim.

* Pieces have been made, twelve hundred yards long. 
med, and hung up in the drying-house, operations which occasioned great waste, amounting to no less than one defective sheet out of every five. The continuous paper, at one time, retained the impression of the wire-wove web, on its under side; a defect from which it has been freed, by a pressure apparatus of Mr. Donkin.

The greatest difficulty, formerly experienced in the paper manufactured upon the continuous system of Fourdrinier, was to remove the moisture from the pulp, and condense it with sufficient rapidity, so as to prevent its becoming what is called water-galled, and to permit the web to proceed directly to the drying cylinders.* Hitherto, no invention has answered so well, in practice, to remore this difficulty, as the channelled and perforated pulp-rollers, or dandies, of Mr. J. Wilks, the ingenious partner of Mr. Donkin.

III. Chemical processes, employed in the manufacture of Cloth.-These are, Bleaching, Scouring or Cleansing, Dying, and Calico Printing.

1. Bleaching is the process, by which certain animal and regetable products, and especially such as are used as articles of clothing, are rendered white. The principal substances of the animal kingdom, which are subjected to the operation of bleaching, are wool and silk; those of regetable origin are chiefly cotton and flax. These bodies contain a quantity of coloring matter, which, though natural to them, is not an essential constituent; it appears, also, that the coloring matter is more readily acted upon by chemical agents, and suffers decomposition with greater facility, than the animal and regetable matters with which it is united. On these accounts, it is removed by operations, producing little or no injurious effect upon the texture or durability of the articles from which it is separated, and thus, not

* These are large, lollow, polished copper cylinders, heated from within by steam, and round which the moist sheets are carried, in order to be dried. Less than two minutes is required to transform the pulp into sheets of dry finished paper. 
only is their beauty increased, but they are fitted for the reception of the colors of the dyer, and the ornamental designs of the calico-printer.

The destruetion of the coloring matters, attached to the bodies to be bleached, is effected, either by the action of the air and light, of chlorine, or of sulphurous acid; which may be considered the three bleaching powers employed for manufacturing purposes.

Bleaching, by the influence of air and sunshine, is the most ancient, and still the most common, method, in several civilized countries; it is also supposed, by many, to be the least injurious to the texture of yarn and cloth. The operations it involves are very simple, consisting in the exposure of the goods upon a grassplat, to the sky, with their occasional aspersion with moisture, if necessary, in addition to the rain and dew. The atmospheric air effects the bleaching, by means of its oxygenous constituent, which combines with the coloring matter, or its elements, carbon and hydrogen, and either makes it nearly white, or converts it into a substance, easily soluble in water and alkaline solutions. This natural process is too slow, to suit the modern demands of the cotton and linen manufacturers. Fortunately for them, a new bleaching agent, unknown to our forefathers, has been discovered, in chlorine, formerly called oxymuriatic acid, an agent modified by chemistry so as to give an astonishing degree of rapidity, economy, and perfection, to this important art. It is, however, not a little surprising, that the science, which has so greatly advanced its practical part, should have left its theory far from complete, and should aftord no satisfactory answers to the two following questions: What is the action of the solar rays upon the coloring matter? How do air and chlorine operate upon this principle?

Chlorine was first used in the state of simple solution in water; afterwards, in order to lessen its destructive action, when used in too concentrated a state, it was proposed to add potash to it. This compound, 
howerer, was not found to answer the purpose; and the chloride of lime, generally known by the name of bleaching-powder, is now almost universally employed, especially in the bleaching of cotton; it is a compound, which answers the purpose, with economy, celerity, and safety.

The coloring matter of cotton, flax, and hemp, is insoluble in water, and appears to be of a resinous nature: it is partially dissolred by heated solutions of lime and potash, or soda; and by their use, and the application of a solution of bleaching-powder and diluted sulphuric acid, the coloring matter, which is not dissolred, is destroyed. Cotton is more readily bleached than flax or hemp; and these, more readily than wool: indeed, this last-mentioned substance, as well as silk, is generally bleached by the fumes of burning sulphur, or sulphurous acid gas, after they have been properly cleansed. Straw and feathers are also bleached by sulphurous acid gas. Wax is generally deprived of its color by mere exposure to air, light, and moisture.

With respect to the theory of bleaching, it may be observed, that the action of lime, and the allialies potash and soda, appears to be that of mere solvents; they probably dissolve the coloring matter, without effecting much alteration in its properties. The action of atmospheric air, and of chlorine, seem to be similar to each other, and very different from that of lime and the alhalies; the oxygen of the air, aided by the action of light and moisture, apparently combines with and destroys the coloring matter; and the chlorine, decomposing water, one portion of it forms muriatic acid, with its hydrogen, and another portion, whth its oxygen, probably gives rise to a compound of easy decomposition, the nascent oxygen of which, acting like that of the air, though more powerfully, produces the same oxidizing effect upon the coloring matter, but more perfectly, and in a much shorter period.

That water is necessary to the action of chlorine upon regetable coloring matter is shown, by immers- 
ing dry coloring matter in the dry gas, in which case, no decoloration whatever is effected, but it ensues immediately on the introduction of water.* The bleaching of rags. for paper-making, is eflected by the agency of chlorine. Paper, also, when written on, may be bleached by the same means.

There are some operations, in which the removal of color is hardly referrible to the process of bleaching; such, for example, is the decoloration of sugar, which derives its color, not from any natural cause, but the partial decomposition effected by heat. This is remov ed by what is usually termed animal-charcoal, or iroryblack; this powerful decolorant is also used in some chemical operations, for the same purpose.

2. Scouring and Cleansing.-Wool, in its preparation for dyeing, requires to be cleansed from a fatty substance, called the yolk, which is contained in the fleece. This is done by means of a weak alkaline solution, which converts the yolk into soap. Putrid urine is commonly employed, on account of its cheapness; the ammonia it contains being sufficient to remove the grease.

Silk, when taken from the cocoon, is covered with a kind of varnish, which, because it does not easily yield, either to water or alcohol, requires also the aid of a slight portion of alkali. Much care is necessary, however, in this operation; since the silk itself is liable to be corroded and discolored. Fine soap is commonly used; but eren this is said to be detrimental; and the white China silk. which is supposed to be prepared without soap, has a lustre superior to the European.

3. Dycing is the art of staining textile substances with permanent colors. To cover their surfaces with coloring matters removable by abrasion, would be to apply a pigment, rather than to communicate a dye. Dye-stuff can penetrate the minute pores of vegetable and animal fibres, only when presented to them in a state of solution; and they can constitute fast colors, only by passing afterwards into the state of insoluble

- Kane, in his Chemistry, seems to have showil that this statement in regard to the upepscity of water. Ihnugh generally made by chemists, is a mis:ake. 
compounds. Dyeing thus appears to be altogether a chemical process, and to require, for its duc explanation and practice, an acquaintance with the properties of the elementary bodics, and the laws which regulate their combinations.

Bergmann appears to lave been the first, who referred to chemical affinities the phenomena of dyeing. Having plunged wool and silk into two separate vessels, containing solutions of indigo in sulphuric acid, diluted with a great deal of water, he observed. that the wool abstracted much of the coloring matter, and took a deep blue tint, but that the silk was hardly changed. He ascribed this difference to the greater affinity subsisting between the particles of sulphate of indigo and wool, than between these and sill; ; and he showed that the affinity of the wool is sufficiently energetic, to render the solution colorless, by attracting the whole of the indigo, while that of the silk can separate only a little of it. He thence concluded, that dyes owed both their permanence and their depth to the intensity of that attractive force.

We have, therefore, to consider, in dyeing, the play of affinities, between the liquid medium, in which the dye is dissolved, and the fibrous substance to be dyed. When wool is plunged in a bath, containing cochineal, tartar, and salt of tin, it readily assumes a beautiful scarlet lue; but when cotton is subjected to the same bath, it receives only a feeble pink tinge. Dufay took a piece of cloth, woven of woollen warp and cotton weft, and having exposed it to the fulling-mill, in order that both kinds of fibres might receire the same treatment, he then subjected it to the scarlet dye: he found that the woollen threads became of a vivid red, while the cotton continued white. By studying these differences of affinity, and by varying the preparations and processes, with the same or different dye-stuffs, we may obtain an indefinite variety of colors, of variable solidity and depth of shade.

Dye-stuffs, whether of vegetable or animal origin. 
though susceptible of solution in water, and, in this state, of penetrating the pores of fibrous bodies, seldom possess, alone, the power of fixing their particles so durably, as to be capable of resisting the action of water, light, and air. For this purpose, they require to be aided by another class of bodies, already alluded to, which bodies may not possess any color, in themselves, but serve, in this case, merely as a bond of union, between the dye and the substance to be dyed. These bodies were supposed, in the infancy of the art, to scize the fibres, by an agrency analogous to that of the teeth of animals, and were hence called mordants, from the Latin verb mordere, to bite. Horrever preposterous this comparison is now known to be, the term derived from it has gained such a footing, in the language of the dyer, that all writers upon this art are compelled to adopt it.

Mordants may be regarded, in general, as not only fixing, but also occasionally modifying, the dye, by forming with the coloring particles an insoluble compound, which is deposited within the textile fibres. Such dyes as are capable of passing from the soluble into the insoluble state, and of thus becoming permanent, without the addition of a mordant, have been called substantive, and all the others have been called adjective, colors. Indigo and tannin are perhaps the only clyes, of organic origin, to which the title substantive can be applied; and even they, probably, are so altered by atmospheric oxygen, in their fixation upon stuffs, as to form no exception to the true theory of mordants. Mordants are of primary importance, in dyeing; they enable us to vary the colors, almost indefinitely, with the same dye; to increase their lustre, and to give them a clurability, which they otherwise could not possess. $\Lambda$ mordant is not always a simple agent; but in the mixture of which it consists, various compounds may be formed, so that the substances may not act directly, but through a series of transformations. Sometimes, the mordant is mixed with the coloring mat- 
ters; sometimes, it is applied by itself, first of all, to the stuff; and at others, both these methods are conjoined. We may dyc, successively, with liquors which contain the same substances, which will act differently, accordnng to the different mordants employed. One solution will give up its base to the stuff only when aided by heat; another acts better and more uniformly, when cold, though this is a rarer case.

When a mordant consists of a changeable metallic oxide, as of iron or tin, unless great nicety be used in its application, either no effect, or an injurious one, may be produced upon the dye. All these circumstances prove how necessary it is for the dyer to be thoroughly versed in chemical science. Each of the great dyeworks, in Alsace, celebrated for the beauty and fixity of their colors, is superintended, in the laboratory-department, by a gentleman, who has studied chemistry for two or more sessions in the universities of Paris, or some other eminent schools. The numerous complaints which have been made of the fugitiveness of the color of our calicoes, and especially of our cloth dyes, ought to rivet the attention of all great manufacturers and merchants on this important desideratum, and to lead them to supply it, by consulting qualified persons as to the best means of improving this great branch of national industry.

4. Calico Printing.-This is the art of impressing cotton cloth with topical dyes, of more or less permanence. Of late years, silk and woollen fabrics hare been made the subjects of a similar style of dyeing. Linens were formerly stained with various colored designs, but since the modern improrements in the manufacture of cotton cloth, they are seldom printed, as they are both dearer, and produce less beautiful work, because fla: possesses less affinity than cotton, for coloring matters.

The principles of calico-printing have been very profoundly studied, by many of the French manufacturers, who generally lieep a chemist, who had been ed. ucated in the Parisian schools of science, constantly at 
work, making experiments upon colors, in a wellfurnished laboratory.

Calicoes, muslins, \&c., intended for printing, must be, first of all, freed from their fibrous down, by the action of the singeing machine. This consists either of a semi-cylinder of cast-iron, laid horizontally, and kept at a bright red heat by a furnace, or of a horizontal range of gas-jet flames : over one of these, the plane of cloth is drawn, with a steady continuous motion, and at a rate suited to its texture. When gas flames are employed, a line of suction-tubes is placed orer the extended web, to draw the flame up through the interstices of the cloth, which effectually cleans the threads. The cotton cloth must be next well bleached, because the whiter it is, the more light will it reflect from its surface, and the more brilliant will be the color of its dyes. The first step in the bleaching process is boiling the cloth in an allialine bath, which, for delicate, fine goods, consists of a weak solution of soda, and for stronger articles, a nixture of slaked lime and water.

The goods are next steeped, for a few hours, in a leaden $\mathrm{Ol}^{\text {' wooden }}$ cistern, containing a weak solution of chloride of lime, usually called bleaching salt. They are once more rinsed. They are are now boiled in an alkaline lic, made of crude soda dissolved in water, and freed from its impurities by filtrations or subsidence. 'The goods are again rinsed, and finished by a steep in sulphuric acid, very largrely diluted with water. 'This remores any adhering particles of lime or iron, which would be apt to give the cloth, after some time, a yellow tint. They are last of all rinsed, dried, and sometimes smootlied under the calender, a machine composed of rollers and beaters, by which the fibres of the cloth are thickened, and the surface is both smoothed and polished.

If they are not ealendered, they are run through a machine, called in Lancashire the candroy, which spreads them smoothly in the act of rolling them upon a cylinder. 
There are four mechanical modes of printing calicoes ; first, by small wooden blocks, worked by hand; second, by large wooden blocks, set in a frame, and worked by a machine called the Perrotine, from the name of its ingenious inventor, M. Perrot, of Rouen; third, by flat copper plates, (a method now ncarly obsolete ;) and fourth, by copper cylinders, mounted in a machine of great elegance and productive powers, but of no little cost and complexity, called a one, two, three, four, or fire, colored calico-printing machine, according as it is mounted with one, two, or more, cylinders. The fifth color is generally applied, by what is called a surface-cylinder, covered with figures like types, in basrelief.

Calico-printing, by hand, is performed by applying the face of the block to a piece of woollen. cloth, stretched over one end of a sieve-hoop, and imbued with the coloring matter, of a thin pasty consistence, by means of a flat brush. The block is then applied to the surface of the cotton cloth, while extended upon a flat table, covered with a blanket, and the impression is transferred to it by striking the back of the block with a light mallet. This method, besides the great cost of labor which it involves, has the inconvenience of causing many irregularities in the execution of the work. It has been superseded, to a considerable extent, both in France and Belgium, by the Perrotine, a machine of a most novel and elegant description. Three thin wooden blocks, engraved in relief, about three feet long, and from two to fire inches broad, are successirely brought to bear on three of the four faces of a prismatic roller of iron, round which the cloth is successively wound. Each block rests on springs, which enable it to press with the delicacy of a skilful arm; and each receives its peculiar colored paste from a woollen surface imbued by a mechanical brush in rapid alternation. "We have seen this machine," says Dr. Ure, "operate in many print-works, with surprising speed and precision; its moring shaft being driven, 
either by arms or by a steam pulley-band. One man, with three children for superintending the three colors, can turn of about thirty pieces, English, in a day, which is the work of fully twenty men and twenty children in ordinary block-printing. 'To print a piece of cloth by hand, the block must be applied four hundred and forty-eight times, for each color. The machine, noreover, may be conducted by persons with little manual dexterity, and therefore entitled to comparatively low wages. The use of the Perrotine is spreading rapidly into every quarter of the continent, even into Russia ; though hitherto unknown in England. It executes a style of work different, in some respects, from that of the eylinder. This latter machine is a hollow cylinder of copper, fully three feet long and three or four inches in diameter, whose surface is engraved, not by the hand-graver, but by the mechanical pressure of a steel roller, from one to two inches in diameter, and three inches long, which transfers the figures engraved on it to the relatively softer copper.

"The engraved cylinders are mounted upon a strong iron shaft, or arbor, carrying a toothed wheel at its end, in order to put it in train with the rotary printing machine, for one, two, or more colors. On a roller, at the upper part of this apparatus, are wound whole calico webs, stitched together, the end of which is then introduced between the engraved copper eylinder and a large central cylinder, covered with a blanket, against which it is made to bear, with regulated pressure. The engraved cylinder turns on the top of another cylinder, covered with woollen cloth, which revolves with the former, while its under part is plunged in an oblong trough containing the dyeing matter, which is of a pasty consistence. The engraved cylinder is thus supplied witis an abundance of impressible color, and is cleared from the superfluity, by the thin edge of a flat ruler, made of bronze, called vulgarly the doctor, (ductor,) which is applied obliquely to it, with a gentle force. The cylinder, after its escape from this wiping tool, acts 
upon the calico, and rolls it onwards, with its rerolution, imparting its figured designs with great precision."

The improvements which hare been made, within the last serenty-five years, in the manufacture of cloth, paper, \&c., have added, in an almost incredible degree, to the physical enjoyment of mankind. Fabrics, which were previously regarded as articles of luxury, and worn only by the affluent, now make part of the ordinary vestments of the poor. The calicoes which can now be purchased at six or seven cents a yard, would probably have cost fifty cents, seventy-fire years ago ; and all other cotton goods were in nearly the same proportion. Then, the finer kinds of these goods were imported from India, where they were manufactured, as we have already seen, in looms of the rudest construction, worked by hand. Now, the raw cotton can be imported from that country, made up into goods, in the manufactories of our own State, and returned again to Calcutta, paying the cost of manufacture and transportation, for fourteen thousand miles, and yet, after all, be sold cheaper than they can be bought of the Native manufacturer : and it is a fact, that, even in India, where labor is comparatively so very cheap, the Native weaver is driven out of business, by the competition of the English and American manufacturers, and is induced to give to the raising of cotton the time and labor which were formerly bestowed on spinning and weaving. If such be the effect in India, how much. greater must it be in our own country, where the manufactured goods cannot be subjected to a charge, in any degree so heavy, for transportation, and where the saring of human labor is an object of so much greater importance. It is estimated that in England, owing partly to the diminished price of the fabric and partly to the increase of wealth which has been produced by the cotton manufacture, thirty persons can now afford to wear cotton, where one could afford it, thirty years since. The increased consumption in this country is probably nearly 
as great. Persons, who can remember the habits of farmers and meclianics, forty years ago, assure us, that then, cotton was rery rarely worn by those classes; that shirting was generally made of coarse woolłen, or linen of domestic manufacture, - an article, which cost probably twice as much as good cotton cloth now costs and was yet of very indifferent quality. The improvement has not been less rapid, in the quality and quantity of woollen clotlis. $\Lambda$ few years since, a large proportion of all the woollen worn was manufactured in private familics, at great cost, and still was very coarse. Now, no family can afford to manufacture; and a material, which, thirty years since, would have becn purchased only by a gentlcman of some substance, is now within the means of the humblest mechanic and everyday laborer.* 'Take the single article of stockings, for example. It is but three or four centuries since knit hose were first worn at all ; and even one hundred years ago, not one person in five hundred could afford

* The amazing rapidity with which the production and consumption of cotton has increased, during the last seventy years, will be obvious, from the following facts :

1. In 1770, when Arkwright's improvenents began to be first introduced, the annual consumption of cotton in British manufacture was under four millions of pounds, and that of the whole of Christendom was probably not over ten millions. In 1838 , the consumption of cotton in Great Britain and Ireland was over three hundred millions of pounds, and that of Europe and the United States together, not less than six hundred millions.

2. From the statements of a writer in the Boston Daily Advertiser, who sigus himself 'a cotton manufacturer,' it would appear, that the above falls short of the truth. Ife represents the cotton raised in the United States, in 1820, to have been about one hundred and thirty-six millions of pounds; in 1838, six hundred and eighty-six unillions, - making an increase of fivefold, in eighteen years. The exports of cotton, from the United States, for the same years, were, for 1820 , one hundred and fifteen millions of pounds; for 1838 , six hundred and two millions of pounds.

3. According to the same writer, the consumption of cotton, in 1800 , in Great Britain, was fifty-two millions ; in 1820 , it was one hundred and twenty-six millions; and in 1837, it was three handred and fifty-seven millions; showing that the increase in the consumption, for the last eighteen or twenty years, has been nearly three times as great as in the preceding period of that duration. 
to wear them. But since the stocking-frame was in vented, the article has been produced by machinery, and now few persons are without them. What more certain sign is there, of abject porerty and wretchedness, than to see an individual in Winter without a pair of stockings!

\section{CHAP'TER VIII.}

THE DOIESTIC ARTS.

UNDER this title, we shall include the various meth ods of preparing and preserving human food. This food is rarely produced, by Nature, in that state in which it is most agreeable or beneficial to the human system. In order to be brought into this state, animal and vegetable substances are subjected to sereral different processes, which serve to soften their solid fibres, to extract or dissolve their nutritive or exhilarating principles, and in some cases to effect an entire change in their chemical constitution. It is to be observed, too, that these substances are no sooner deprived of life, than they tend to decompose, owing, in part, to the strong affinity which subsists between their constituent elements, and which inclines them to quit the state of combination in which they previously existed, and to form new combinations. To the spontaneous changes, which are thus produced, we give, in the case of regetables, the name of fermentation; in the case of animal substances, we call it putrefaction: and, as it is apt to render a substance useless, it is evidently very important, that the housekeeper should know how to anticipate and prevent it. Hence, this subject will lead us to treat of methods for preserving, as well as preparing, articles intended for food. There are other cases, however, in which fermentation may be turned to a very useful account, as in the manufacture of bread, beer, cider, wine, 
\&ic.; processes which depend almost entirely on the proper management of fermentation. We shall take occasion, therefore, to give a brief account of the principles on which these processes depend. We are aware, that some of them, such, for example, as the making of wine, have almost ceased to be domestic; but, as our object is chiefly to exhibit principles, we may associate the arts according to their agreement in this respect, and shall therefore treat, in this Chapter,

I. Of the various arts most intimately comected with fermentation, namely, bread-making, brewing, wine and cider making.

II. Of the management of heat, in distillation, and in the culinary processes.

III. Of the management of milk, and the making of butter and cheese.

IV. Of preserving animal and vegetable substances.

It is obvious, that all these are chemical arts, and it will be our principal business, in this Chapter, to exhibit the practical applications of that science. Various mechanical contrivances have been adopted for saving labor and time,* and also for improving the products of

* One instance of such contrivance may be seen in the machinery for making ship biscuit. The process adopted in the rictualling yaru at Gosport, (England,) is said to be as follows :

1. The meal and water are mixed, by being placed in a revolving eylinder, working lorizontally, and having its shaft armed with knives. The shaft being set in motion, the knives turn around through the meal and water, the dongl soon begins to assume a consistency, and in two minutes, five hundred pounds will be completely manufactured.

2. The dough falls into a trough, from which it is easily removed, and placed under the breaking rollers, to undergo the second operation, that is, kneading. These breaking rollers, two in number, and weigling fifteen hundred pounds each, pass backwards and forwards, over the dough, during the space of five minutes, when it will be brought to a perfect and equal consistener.

3. From the breaking rollers, the dough is ent into piees, eighteen inches square, and placed on boards, which are conveyed, by friction rollers, under a second set of rollers, to be rolled to the required thickness.

1. Being rolled, the dough is carried under the cutting and stamping plate, which, at the sause moment, cuts and docks, or pierees, the sheet of dough into forty-two six-sided biscuils, and these are then conveyed on carriages to the oren. 
these arts. But on these, we shall be able to bestow only a passing notice.

I. Fermevtatios.-There are two linds of ferntentation,* to be attended to in the arts, called vinous and acetous fermentation; so called, because alcohol is produced in the first case, and acetic acid, or vinegar, in the second. It is found, by experience, that the vinous fermentation, if carried too far, passes into the acetous ; and much of the art, therefore, of the baker, brever, and winemaker, consists in arresting the process at the proper point.

1. Tinous fermentation takes place in saccharine substances, or those which have sugar as an ingredient, and seems to consist in changing the sugar into alcohol and carbonic acid. This is the case in raising or working bread, where the saccharine matter of the flour is resolved into alcohol, which is carried off in baking; and into carbonic acid gas, which, being prevented from escaping, by the tenacity of the dough, heares and swells it, and gires it a porous consistency. We see the vinous fermentation, again, in the brewing of summer beer, where a mixture of molasses or honey with water is fermented by means of yeast, or some other learen, and a particular flavor imparted to it by spruce, ginger, \&c.

Formerly, all these operations had to be performed by hand, the expense being nearly four times as great, and the process much less clean and perfect. Biscuit nixed and cut by hand is unequally baked, becanse the meal and water do not combine thoroughly, and also because the biscuits are of unequal thickness. Hence it becomes what is termed finty.

A very ingenious machine for unaking biscuit has been invented by Mr. John Brace, of the city of New York. It turns off about ten hundred weight per hour.

* Strictly speaking, there are fire species of fermentation, 1. Saccharine, in which starch and gum are changed into sugar; this precedes the rinous fermentation. 2. Finous, in which sugar is converted into alcohol. 3. Mucilaginous, in which sugar is converted into slime, instead of alcohol. 4. Acetous, producing rinegar. 5. $P u$ trefactive. In all cases, fermentation involves the decomposition of the proximate principles (sugar, starch, gluten, \&c.) of organic bodies, and a new combination of the oxygen, carbon, hydrogen, (and in somo cases nitrogen,) which form their ultimate principles. 
The liveliness of the beer is owing to the carbonic acid generated by fermentation.

We see the vinous fermentation, also, in brewing the malt-liquors, such as ale, porter, \&e. Here, a liquid, called wort, which is produced by boiling hops, in a decoction of malt, is fermented, by the addition of yeast. The hops have the effect, not only of imparting a bitter aromatic taste to the liquor, but also of preventing the disposition, which previously existed, to acetous fermentation. It may be proper to add, that malt is grain which has been made to germinate by the artificial use of heat and water, the germination being arrested, as soon as the starch of the grain has been converted, by saccharine fermentation, into starch-sugar, and is thus fitted to produce a sweet liquid. Owing to the mucilaginous and extractire matters which are contained in malt liquors, they are greatly disposed to pass into the acetous fermentation, and are therefore kept with diffi culty.

In these cases, it will be observed, that the process of fermenting is not spontaneous, but must be excited by yeast.* How this substance produces the effect, is not well known. There are other cases, where fermentation takes place of itself, as in the manufacture of wine and cider. The saccharine juices of plants seem to possess some principle, which, by being cxposed to the air, is converted into yeast, or at least acquires the characteristic property of that substance, by absorbing oxygen.

Wine is obtained from the juice of the grape, currant, gooseberry, \&c. The grape is superior to all other fruits, for this purpose; not merely because it contains more saccharine matter, since that deficiency might be supplied by adding sugar, but on account of the nature

* Pread is frequently raised, in our newly-settled districts, by a mixlure of salt and warn water, with a small portion of flour. This composition must be kept standing, two or three hours, at the temperature of tepid water, and is then applied to the flour. New milk from the cow may be used instead of the water. 
of its acid. The chief, if not the only, acid principle in the ripe grape, when raised in a warm climate, is the bitartrate of potassa. But it so happens, that this substance is insoluble in the alcohol generated by vinous fermentation, and is therefore deposited, either during that process, or subsequently, while the wine is adrancing towards perfection, and hence the crust which we find on the inside of bottles which have held old wine. The juices of other fruits, on the contrary, contain the malic and citric acids, which are soluble both in water and alcohol, and of which, therefore, they can never be deprived. Consequently, the wine made of these juices (and the remark applies to cider) are only rendered palatable, by the presence of free sugar, which conceals the taste of the acid; and to obtain this, it is necessary to arrest the progress of the fermentation, long before the whole of the saccharine matter is consumed. For the same reason, these wines do not admit of being liept long; since, as soon as the free sugar is converted into alcohol, by the slow fermentative process, (which, though it may be retarded, by the addition of brandy, cannot be entirely prevented,) the wine acquires a strong sour taste.

2. Acetous fermentation generally follows that which is vinous; and in that case, seems to consist in changing alcohol into acetic acid or vinegar. It takes place most rapidly at a temperature above seventy degrees of Fahrenheit's thermometer, and is promoted by contact with the air, and by moisture. Hence, if it is to be prevented, as in making wine, cider, \&c., the liquid should be kept cool, and be excluded from air. It is important to remember, that the vinous is always apt to pass into the acetous fermentation; and that, to avoid this, requires the closest attention on the part of the manufacturer.*

* In making vinegar, our object is to excite the acetous fermenta tion. This is effected, by exposing the wine, cider, or beer, used for the purpose, in an open vessel, to the heat of the sun, in Summer, or :o that of a stove, in Winter. Some substance, calculated to sssist 
'To assist in preventing acetous fermentation, the manufacturer of wine sometimes fumigates his casks, by lindling linen rags, dipped in melted brimstone, and allowing the vapor to enter the cask. The effeet is, to confine the fixed air contained in the wine or eider, and to stop its fermentation. When once the acetous fermentation begins, howerer, it is impossible to restore the wine to its original state; and hence the various methods which have been derised, to conceal the acid in wine, so that they, who have not an accurate judgement in such matters, not unfrequently purchase swcetened vinegar, in lieu of wine. Nor is this the greatest evil of such adulterations. One of the substances, most commonly employed for the purpose, is sugar of lead, which, though it stops fermentation, and imparts a sweet taste to sour wine, is an active poison, and, when combined with wine, frequently occasions colic, and other diseases. The adulteration of wine is practised so extensively, that those who have investigated the subject assure us, that, where one gallon of pure wine is consumed in this country, ten or more, that have been fabricated in our seaports and other places, are used. Frauds, committed in the adulteration of spirit and wine, in the city of New York alone, amount,

fernienlation, is also added, such as yeast, a piece of dough, or the congulated ropy mucilage found in old vinegar, and which is generally called the inother of rinegar. In making vinegar from wine and malt, the lees, or refuse, of wine is also used, to promote fermentation. Vinegar may also be obtained from wood, (when it is called pyroligneous acid,) from whiskey, and from sugar, or molasses. To obtain it from sugar, the following method is taken. 'Ten pounde of sugar are added to eight gallons of water, with yeast, and raisins or grape cuttingz, for the sake of flavor, and perhaps to assist in the fermentation. Twelve pints of bruised gooseberries, or other fruits, are added; and, by a process similar to that for eider, a good vinega: is produced in the course of the summer. Vinegar is frequently adulterated, by having sulphuric acil mixed with it, in order to increase its acidity; and also by the addition of copper and lead. The adulteration may be detected by adding a little chalk, which, uniting with the sulphuric acid, will form a white insoluble powder; or by employing ammonia, when we suspect copper; or sulphate of soda when we suspect lead. 
it is supposed, to at least three millions of dollars, annually. On the arrival of a cargo of wine* in that city, it is often purchased up, at once, by the manufacturer, and in less than twenty-four hours its character is completely changed. It is poured into large vats, prepared on extensire premises, is mixed with sour beer, (most of the sour beer in our cities is drank by some one in this shape,) with cider, and certain proportions of certain drugs. In this way, by due mixtures, the same fountain is made to send forth, at one time, Madeira ; at another, Port ; at another, Sherry, \&c. To conceal the fraud more effectually, casks and bottles, bearing the original importing or customhouse mark, are bought at a price many times that of their real value, and, after being emptied of their contents, return to the manufacturer, and are thus made to perform the work of being accessary to fraud, many times. These facts, received from individuals who have been engaged in the manufacture and rending of factitious wines, show how applicable to New York, and other American cities, at this time, are the remarks made by Addison, respecting London, more than a century since. "There are," says lie, $\uparrow$ "in this city, a fraternity of chemical operators, who work under ground, in holes, caverns, and dark retirements, to conceal their mysteries from the observation of mankind. These subterranean philosophers are daily employed in the transmutation of liquors; and, by the power of magical drugs and incantations, raising, under the streets of London the choicest products of the hills and valleys of France. They can squeeze claret out of the sloe, and draw champaigne from an apple."

II. We now come to heat, as employed in distillation and in culinary processes.

* This wine is often adnlterated or fabricated, before it leaves its native land. Large manufactories for the fabrication of counterfeit wine exist in the south of Enrope, and a comparison of the produce of the vineyards with the quantity of wine exported shows that not a small proportion of the latter must be factitious.

+ Tatler, No. 131. 
1. Distillation.-This art is founded on the different tendencies which bodies have to pass into vapor, and to be condensed again by cold. It is employed in order to separate the more volatile substances, such as alcohol, the essences, essential oils, \&c., from other substances with which they are combined. This is accomplished, by applying heat to the compound, so regulated, that the volatile liquid will rise in vapor, leaving the other in a liquid state; and this vapor is then condensed, by passing through a worm, immersed in cold water. Sometimes the operation is conducted in a vesscl, from which the air has been expelled; and in that case, as fluids boil in a vacuum, at a temperature much below that at which they boil in the air, the extract is obtained in its most perfect state.

In the case of the essential oils, water is put into the still, along with the plant, in order to prevent the latter from being burned. The oil and water both pass over into the receiver, and the oil collects at the top or bottom of the water, according to its density. These oils are very useful, as solvents in the arts, and as medicines. In these respects they might often be advantageously substituted for alcohol, which, unfortunately for the world, has enjoyed much more repute than it deserves. It is doubtless useful in some chemical and pharmaceutical processes, and affords a very convenient solvent for resins, balsams, and the vegetable alkaline principles. It is certain, however, that on many occasions, when we now resort to it, the essential oils, or some other substitute, might subserve the same purpose. $A$ distinguished physician, when speaking of its use, as a medicine and as a beverage, says, "But if useless as a preventive, is not alcohol important in the treatment of disease? I admit that it is sometimes convenient; but I deny that it is essential to the practice of physic or surgery. Do we wish to rekindle the taper of life, as it glimmers in a fainting fit ; wo liave ammonia, and the volatile oils ; and, what is better than every thing else, cold water, to be administered by affusion. Is it required to produce 
a tonic effect, in the case of long-standing debility ? the tonic roots, and barks, and woods, impart their invigurating properties to water and acid. Are we called upon to relieve pain? opium is altogether superior to alcohol. Do we need a solvent for opium? we have it in the acetous acid. The black drop is one of the best solutions of opium ever invented.

"But what is to be done with the medicinal resins and aromatic oils,-must not they be dissolved in alcohol ? The medicinal resins do not constitute a very important class of remedies ; but they may be given in fine powder, rubbed with some inert friable substance, or dissolved in an essential oil, or made into an emulsion. The ordinary mode of using them does not carry them into the stomach in the state of solution, as they are instantly precipitated, in a flocculent form, on being thrown into water. As for the aromatic oils, they may be given in the form of liquid soap, or emulsion, rubbed with alkali, or sugar and water; and in this way they exert their specific effects.

"Is the physician required to prescribe a restorative? if quinine and bark, and bitters and metallic tonics, will not do, shall he prescribe alcohol? This is never certain, and always unsafe, inasmuch as there is imminent danger of a permanent relish being acquired for it ; nor does it compare, in its restorative powers, in cases where the complaint was not produced or modified by the previous use of it, with the pure fermented and well preserved juices of the grape and the apple. The factitious wines, extensively vended in our country, are poor restoratives; they contain a large proportion of alcohol.

"I maintain, then, that, taking into view the danger of making tipplers, by giving ardent spirit to the sick, and considering that all its medicinal virtues are found in other articles, mankind would not, on the whole, be losers, if it should be banished, not only from the houses of every class of the community, but also from the shops of the apothecary. 
"What is the secret of the witchery, which strong drink exerts over the whole man? I will try to tell you. After being received into the stomach, it is sucked up by absorbent vessels, is earried into the blood, and circulates through the alimentary organs, through the lungs, muscles, and brain, and doubtless through every organ of the body. Not a bloodvessel, however minute, not a thread of nerve, in the whole animal machine, escapes its influence. What is the nature of this influence? It disturbs the functions of life; it increases, for a time, the action of living organs, but lessens the power of that action; hence the deep depression and collapse which follow preternatural excitement. By habitual use, it renders the living fibres less and less susceptible to the healthy operation of unstimulating food and drink, its exciting influences soon become incorporated with all the living actions of the body ; and the diurnal sensations of hunger, thirst, and exhaustion, are strongly associated with the recollection of its exhilarating effects, and thus bring along with them the resistless desire for its repetition."

2. Culinary Processes. - The preparation of vegetable and animal food depends almost entirely upon tue proper management of heat. It is applied in two principal ways ; first, through water, for the purpose of cxtracting from vegctable and animal substances their nutritive or exhilarating principles. We have examples of this, in the making of tca, coffee, soups, \&c. Hot liquids are much more powerful solvents than cold ones; and hence, by boiling a substance in water, its soluble parts will be extracted and mixed with the fluid. In conducting this operation, two things require special attention; first, the quality of the water, which is often mixed with foreign substances, such as lime and calcareous salts. These render water hard, and may be precipitated to the bottom of the vessel, either by boiling, before we use the water, or, more perfectly, by adding a little soda or potash. This eflect of boiling explains why tea-kettles and boilers are so frequently 
incrusted on the inside. The quality of the water may be ascertained, before using it, by adding soda or potash. If it be impure, it will become turbid, and a white powder will be precipitated.

The second thing to be attended to, in boiling, is the vessel. As it is an object to secure a high heat, the ressel should be so constructed, as, on the one hand, to conduct the heat rapidly from the fire to the fluid within, and on the other hand, to prevent its escape at the sides and top. This is effected, in part, by having the bottom of the ressel black and rough, since such surfaces absorb heat more readily than those which are smooth and light colored. On the same principle, the top and sides should be polished, and of lighter color. It is also important, if we would maintain a high temperature, at the least expense of fuel, to keep the ressel closely shut, in order to prevent the escape of heat by radiation and conduction, and also, (since steam forms at two hundred and twelve degrees Fahrenheit,) in order to prevent steam from passing off through the spout or top, and thus occasioning a waste of heat. On this account, a ressel has been constructed, for the special purpose of preventing such escape of heat. It is called Papin's digester. The top and sides are surrounded with a non-conducting substance; the ressel is kept perfectly closed, and the temperature of the contained fluid is often four hundred degrees. It has been found sufficient to dissolve animal bones, and is used in extracting from them the gelatin which forms the principal material in the portnble soup, which is taken on long royages, \&c. Boiling is used not only to extract the soluble parts of vegetable and animal substances, but also to fit these substances themselves for becoming food. The precise change which it effects is but imperfectly understood. We know that vegetables, such as potatoes, \&c., which, before boiling, are watery, ill-flarored, and extremely indigestible, are rendered, by this process, dry, farinaceous, and very digestible ; and it is pretty well ascer. 
tained that this change consists, not merely in the softening of the fibres, the solution of some and the coagulation of others, of their juices and principles, but that these principles are decomposed, and combined anew, so that they are no longer distinguishable by the forms and properties which they previously possessed.

This remark applies, also, to the changes produced by dry-heat, on regetable and animal substances. Bread, for example, by being baked, is not only rendered lighter, by the expansion of the gas contained in the paste, but its constituen principles are so completely changed, that, on analyzing it, the proximate ingredients of the flour are no longer to be found. So in the roasting and baking of fruits, we sometimes find acid destroyed, saccharine matter formed, mucilage and gelly extracted, or combined anew, so that the product exhibits propertics very different from those of the raw material. 'The same is true of meats. When baked or stewed, the jelly, oil, and albunien, are separated, dissolved, mixed, or combined anew: Perhaps the simplest form of preparing meat is by roasting. Here, some changes, both of texture and composition, take place, but not so great, but that we can still detect, on analysis, many of its original properties.

Before learing the culinary processes, it might seem proper to advert to various spices and condiments, which are employed in giving flavor to food. To the influence which they exert, in preventing decay, we shall refer isereafter. The manner in which their flavor is extracted, by lieat and by fluids, must be sufficiently obvious. We proceed to consider,

3. The Management of Milk.-If milk be allowed to stand, it will separate into three distinct parts, of which it is composed. 'The cream, being the lightest, rises to the top, and the remainder, soon becoming sour, will be resolved into a solid coagulum, called curd, and a limpid fluid, which is whey. The separation of the curd from the whey may be produced artificially, by an acid; or by means of rennet, which is an infusion of the 
inner coat of a calf's stomach : the effect being due, in the latter case, to the gastric juice of the stomach. This is the course taken in making cheese. In order to make the best cheese, milk, which has stood a sufficient time, but has not been deprived of its cream, is heated very gradually, till it reaches the temperature at which it curdles; the rennet is then added; the curd is cut into small slices, and the whey gently remored, by suspending the whole mass in a bag. In this way, the cream is retained, and the flavor and richness of the cheese much improved. If the coagulation takes place suddenly, owing to too much heat, and the whey is speedily removed, most of the cream is carried off; and the cheese is poor, and without flaror. To make poor cheese is easy ; but to make good cheese is altogether the most difficult operation which derolves on the housewife. It requires a proper regulation of the temperature of a dairy, since too much heat causes the milk to sour, and too little interferes with the process of curdling. It requires, also, the selection of proper utensils, and the most scrupulous care in cleansing them. The acid contained in milk (and which is now known to bo lactic acid) will act upon copper, brass, or lead, and even upon earthen ressels, if they have been glazed with lead, producing a poisonous compound. Hence, vessels made of these materials should never be used for holding milk. Eren tin is not unobjectionable, since it is apt to combine, in a slight degree, with this acid, and thus a compound is formed, which adheres so closely to the ressel, that it can be remored only by the most careful washing, and which emits a disagreeable, fetid odor. In addition to this, the greatest care must be used, in heating and curdling the milk, so that it do not take place too suddenly; that the cream be retained, and yet that the whey be entirely expressed. The constant and unremitting attention requisite, in making cheese, is thus described by Sir John Sinclair, the eminent agriculturist. "If," says he, "a few spoonfuls of milk are left in the udder of the cow, at milking; if any 
one of the implements used in the dairy be allowed to be tainted, by neglect; if the dairyhouse be kept dirty, or out of order; if the milk is either too hot or too cold at coagulating; if too much or too little rennet is put into the milk; if the whey is not speedily taken of ; the milk will be in a great measure spoiled. If these nice operations," continues he, "occurred only once a month, or once a week, they might be easily guarded against ; but as they require to be observed during every stage of the process, and almost every hour of the day, the most vigilant attention must be kept up, through the whole season." Another author remarks, that "cheese varies in quality, according as it has been made of milk of one meal, of two meals, or of skimmed milk ; and that the season of the year, the method of milking, the preparation of the rennet, the mode of coagulation, the management of the cheese in the press, the method of salting, and the management of the cheese-room, are all objects of the highest importance to the cheese-manufacturer; and yet, notwithstanding this, the practice, in most respects, is still regulated by little clse than mere chance, or custom, without the aid of enliglitened observation, or of well-condueted experiment."

'The cream, which rises to the top of milk, consists of butter; caseous matter, which is the basis of cheese; and whey. II cream be put into a sack, and suspendecl, so that the whey may run off, the remainder will be cream cheese. If it be put into a vessel, and agitated, the butter assumes a solid form, and may be entirely separated from the whey and caseous matter by washing and kneading it. Whether the butter naturally exists in the crean or milk, and is distributed through it by means of mechanical suspension; or whether it is formed from it, during the process of churning, by certain chemical changes, which then occur, is not well known. The latter seems the most probable opinion. That churning is attended by important chemical changes ts certain. In all cases, considerable gas is extricated which is supposerl to bo carbonic acid gas. Oxygen 
also seems to be absorbed, and to this is probably owing the consistence of butter; since the oils are found to thicken, by exposure to oxygen. If these two changes do take place, they may serre to explain the fact, which is well known to butter-makers, namely, that butter is made much better and quicker, from cream slightly acid, than from that which is sweet; and that still the butter will be sweet, and the whey or buttermilk much less sour than the cream had been. The carbonic acid, which produces the acidity; escapes during the churning.

'To make good butter requires constant care and cleanliness. The milk should be kept not only in a clean and well-aired apartment, but in one, also, in which the temperature is regulated. Too much heat sours the milk before the cream forms; and too little prevents it from forming in proper quantities, and imparts to it a bitter and disagreable taste. Churning, too, is a delicate process. It must alwars take place in about the same temperature, and hence the practice, which seems at first riew inconsistent, of cooling the cream in Summer, during the churning, and warming it in Winter. The agitation, too, of the cream, should be kept up, without interruption, otherwise the butter will go back, as it is called, and it must not be too quick and riolent, for fear of imparting a disagreeable flaror to the butter. We need say nothing of the care requisite in working off the wher and caseous matter, applying salt, packing down, \&.c. It may not be amiss to remark, that "it is ascertained, by observation, that the milk, given by an animal during the latter half of the milking process, vields much more cream, than that which is obtained at first; and also that the cream, which first rises after the milk has been deposited in the dairy-pans, is both much greater, in a given space of time, than that which rises in an equal space several hours after, and of a greatly superior quality; that thick milk throws up less cream than thin, but of a richer quality; and that milk, that has been much agitated by carrying, and cooled 
before it is put into the milkpans, never throws up so much cream as that which is immediately deposited in them after milking. It is also known, that the milk is not the best, till about four months after the cow has calved; and that the degree of heat, most favorable to the production of cream from milk, is from fifty to fiftyfive degrees Falırenheit."

4. The preserving of Food.-All regetable and animal substances are liable to decay. This is owing to certain affinities which the different principles, composing these substances, have for each other and for surrounding bodies, stronger than those which had previously united them, and which inclines them, as soon as the living principle is extinct, to decompose and form new compounds. Thus, the carbon and hydrogen, which are found in all organized bodies, tend to appropriate to themselves so much oxygen, as shall convert them into carbonic acid and water. In the case of animal bodies, this tendency to decomposition is stronger than in vegetables, sincc, in addition to the three principles just named, which they liave in common with all vegetables, they contain nitrogen, or azote, an clement not found in most plants, and which has a strong affinity for all the above principles, especially for hydrogen.

This disposition to decay, though it exists from the moment that the rital principle is extinct, will not so soon manifest itself, without the aid of moisture, air, and a certain temperature. It is well known, in the first place, that substances kept in moist situations putrefy much sooner than those which are keptdry. The water probably acts, by softening the texture, and thus counteracting the agency of cohesion, which tends to keep the substance in its original state: a part of the effect may be owing, also, to the affinity of the water for some of the products of the putrefaction. Hence the importance of excluding all substances, which we would preserve, from moisture. Neat, thoroughly dried, may be kept a very long time. So may fruit, if carefully freed foom all moisture, and kept in a dry apartment, or $16^{*}$ 
packed in some substance which will absorb the moisture that may chance to collect, or exposed to a uniform heat, sufficient to expel the watery particles.

Air contributes to putrefaction, by uniting its oxygen with the carbon and hydrogen of the decaying substance. Hence, if we would preserve food, for a great length of time, we must endeavor to exclude the air, also. This is done, in the case of fruit, by putting it in bottles, from which the air had been previously expelled, by heat, and then sealing them up, air-tight. Another method has been brought into notice recently, called, Appert's process. The articles to be preserred are enclosed in bottles, which are filled to the top with any liquid; for example, with the water in which the article, if solid, has been boiled. The bottles are closely corked and cemented, to render them hermetically tight. They are then placed in kettles filled with cold water, and subjected to heat, till the water boils. After the boiling temperature has been liept up, for a considerable time,-in some cases an hour, but rarying with the character of the articles to be preserved,- the bottles are suffered gradually to cool. In this state, meats, vegetables, fruits, mill, and other substances, are preserved, perfectly fresh, without any condiments, for long periods of time; in some instances, for the space of six years. Instead of bottles, tin canisters are sometimes used, and rendered tight by soldering. The remarkable effect of this process is to be attributed, not altogether, perhaps, to the exclusion of atmospheric air, since some will remain in the liquid and other substances; but in part, also, to the influence which the heat has had, in fixing the small portion of atmospheric oxygen, that is present, by combining it with some principle in the other substances, so that it is no longer capable of exciting the fermentative action, which, in parallel cases. leads to decomposition.

The influence of certain temperatues, in promoting decay, is well known. In warm seasons and in hot climates, every thing tends to corruption. The heat acts, 
perhaps, by tending to separate, from one another, elements which are already combined. The temperature most favorable to putrefaction is between sixty and one hundred degrees. A strong heat is unfarorable, by cxpelling moisture; and a cold of thirty-two degrees, or the temperature at which water freezes, arrests its progress altogether. Bodies of men and animals have been found frozen, in situations where they had remainel for years, and even ages; and the recent discorery of an elephant in the ice of Siberia, a country in which this animal could have lived only at some era anterior to our history, shows that the period of this preservation is unlimited. Hence the utility of ice, in preserving alimentary substances in hot weather. In order to have its proper effect, it should be placed, with the substances to be preserved, in some ressel which will not give admission to the heat. Such ressels are made of two linings; the space between the linings being filled with charcoal, dry air, or some other non-conducting substance.

In addition to these methods of guarding against putrefaction, important service is rendered by a class of substances called antiseplics, from the power which they have of resisting decay. Of this class are sugar, alcohol, oils, acids, and salts of various linds. How they exert this influence is not well understood. It appears, howerer, that, in some cases, they combine with the substance to be preserved,-forming a less perishable compound, and probably, in other instances, they unite with and qualify the decomposing agents which are present. 'The influence of sugar, in a dry state, and in the form of syrup; of rinegar, and pyroligneous acid; of common salt, and alcohol; in pre venting decay, is familiar to all persons.

In the domestic as in other arts, improvements have been made, which have added essentially to human enjoyment. If we compare the food used at present with that consumed three centuries ago, by the laborer, or eren by the gentleman, we shall be amazed at 
the changes for the better which have taken place, both in the variety and quality. At that time, the garden vegetables, now used almost universally, and forming an important part of the food of erery class,-such, for example, as potatoes, beets, radishes, lettuce,-were yet hardly introduced into England, and could be found on the tables only of the most luxurious. The diet of the peasants, throughout Europe, is thus described by Fortescue, who lived in the reign of Henry the Sixth, of England: "They drink water; they eate apples, with bread right browne, made of rye ; they eate no flesche, but, if it be selden, a littell larde, or of the entrails or heds of beastes sclayne for the nobles or marchauntes of the lond." The rich had animal food, in abundance; but few of the other luxuries which load a modern table. Not to refer, however, to periods so remote, we shall find evidence of most striking clanges, if we revert merely to the commencement of the reign of George the Third. At that time, barley, ryc, or oaten bread, was the universal food of the working population in England. As late as the year 1764, the quantity of barley grain, in England, was equal to that of wheat ; it is not now more than one third of it, though the proportion converted into malt has been increased. Sir Frederick Morton Eden says, "About fifty years ago, so little was the quantity of wheat used in the county of Cumberland, that it was only a rich family that used a peck of wheat in the course of the year; and that was used at Christmas." At that period, even in the richest counties, barley-bread formed the universal food, not only of the common laborers, but also of the smaller farmers. Whereas, now, wheaten bread is eaten, almost universally, even in Wales, and the poorest districts. The consumption of butchers' meat, butter, cheese, \&c., has increased in a ratio nearly double of that at which population has advanced; and the same may be said of tea and sugar, those admirable substitutes for fermented and spirituous liquors.*

* See Appendix, VI. 
CHAP'TER IX.

ARTS OF WORKING METALS.

UNDER this title, we shall include all the methods adopted in the arts, I. For obtaining metals from their ores, and, II. For forming them into articles of luxury or use.

'I'hese arts present, to the reflecting mind, a subject of great and increasing interest. In the civilization of mankind, the metals exert a most important influence. Scarcely a comfort is introduced into our habitations, scarcely an improvement is made in the mechanical or chemical arts, without their aid. To this class of substances the husbandman, the carpenter, the smith, the housewife, and the manufacturer, are indebted, for nearly all their implements. The precious metals not only afford us jewelry and plate, but form the basis of our currency. Those of less value are wrought into ressels of every description, for household and manufacturing purposes; or furnish us with tools, furniture, and ornaments. And even that mineral, which, in its natural state, seems of all the least valuable, namely, iron,-what a value has been impressed upon it, by the power of Art! What would be our civilization, without iron? Who could cultivate the earth, or navigate the sea, or lay out and travel-roads, or weave cloth, or build houses, or construct machinery, without this substance ?*

An art so important to mankind, must soon have commanded their attention, and been carried to some degree of perfection. Hence we read, before the Flood, of Tubal-Cain, who was an instrueter of every artificer in brass and iron. What was the effect of that great catastrophe, on the useful arts, is unknown. Some intimations are gathered, from the ancient poets and his-

* See Appendix, VII. 
torians, which would lead us to infer, that the art of working metals, though not unknown, was extremely limited. This remark applies particularly to iron, wlich is extracted from the ore with more difficulty than most other metallic substances. Barbarous and semi-cirilized nations are found, who have been able to extract the more precious metals, but have never obtained iron. The estimation in which such a people hold this substance, and the eagerness with which, when a ship arrives, they inquire for it, might convey a useful lesson to those who are accustomed to regard it as of little value. The art of working iron was probably introduced into Britain by Julius Cæsar. A spot is now pointed out to the traveller, where a furnace was worked for six or seren centuries, and the rude state of the art, at that period, is inferred from the fact, that the mass of cinders accumulated, during so long a time, is not greater than would collect around some modern furnaces in a few months. The improvements which have been made consist chiefly in the introduction of machinery, and in the more skilful use of chemical agents. It will be our object, in this Chapter, to describe the several processes through which metals pass, on their way from the mine to the hands of those for whose use they are ultimately destined. These may be arranged under the following heads: I. Mining. II. Dressing ores. III. Reducing ores. IV. Working up the pure metals. It is obvious, that these processes must vary, according to the nature of the metal, and the use to which it is to be applied. We shall confine our explanations principally to those methods which are common to all the metals; and even here, we can hope to exhibit only a very imperfect sketch of an operation, which is often complicated and extremely delicate.

I. Mining.-Metals are rarely found in what is called their native state, that is, uncombined with other substances. Having a strong affinity for various simple bodies, such as oxygen, sulphur, arsenic, and other 
metals, they generally occur in combination with one or more of these, and are then said to be mineralized. But besides these substanees, with which they unite, chemically, and which serve, in some measure, to disguise their metallic properties, they are intemixed, mechanically, with various carths, which are termed their gangues, or matrices. The state in which they are found by the miner, and the manner in which he prosecutes his labors, may be gathered from the following description of the mines in Cornwall, England. An irregular erevice in the rock generally indicates the place where the metal is deposited. Instead of being collected at one point, it is scattered in veins and branches, so that it is impossible to say, beforehand, at what particular points the riches of the mine exist. Hence the necessity of proceeding on some fixed plan, in order to explore it, and put it into a state capable of being worked by a number of men. To effect this, a perpendicular pit, or shaft, is sunk, at a depth of about sixty feet; a horizontal gallery, or level, is cut in the earth, say both towards the east and towards the west, the ore and materials being raised, at first, by a common windlass. As soon as the two sets of miners have each cut or driven the level about a hundred yards, they find it impossible to proceed, for want of air. This being anticipated, two other sets of miners have becn sinking, from the surface, two other perpendicular shafts, to meet them. From these, the ores and materials may be raised; and it is evident, that, by thus sinking perpendicular shafts, a hundred yards from each other, the first gallery or level may be prolonged at pleasure. But while this horizontal work is carrying on, the original, or, as it is termed, the engine shaft, is sunk decper; and, at a sceond depth of sixty feet, a second horizontal gallery, or level, is driven towards the east and towards the west, receiving air from the various perpendicular shafts, which are all successively sunk down, so as to meet it. The main shaft is then sunk further; and, at the same distance, is driven a third, and 
then a fourth, gallery, and so on, to any depth. The lowest level, in one of the Cornish mines, is said to be nearly one thousand feet below the level of the ocean. These galleries are excarated, not so much for the sake of the ore which they yield, directly, as to enable a number of men to work together, in the subsequent operations. The ore and other materials are raised to the surface by steam, or by large capstans, worked by horses. Similar means are also used, in order to drain the mine of the water, which often accumulates, except where it is found easier to tap the hill, and thus discharge the water by drains.

Another important circumstance, in opening a mine, is, to prepare a proper support for the earth, which rests over the galleries. This is effected, in part, by the form which is given to the galleries; but more commonly, by leaving pillars of stone in their natural place, and providing artificial props, of timber, stones, and masonry.

II. The ores, having been raised to the surface, are in the next place dressed; that is, prepared for smelting. This includes the rarious operations of sorting, stamping, washing, and roasting. The first three are mechanical operations; the fourth is chemical. Sorting consists merely in the separation of the diferent pieces of ore into lots, according to the products they are expected to afford, and the treatment they are likely to require. After the ore is sorted, it is carried to the stamper, or stamping-mill, which consists either of hammers or iron cylinders driren up and down, and which serves to break up the ore, together with its gangue, into a coarse powder. To this, succeeds the washing of the powdered ore, in troughs or inclined planes, crossed by a current of water, the heavier ore remaining, while the lighter, earthy, and stony, substances are carried away by the water. The ore is then roasted, in order to drive off the sulphur, arsenic, and other volatile parts, which may happen to be combined with it, and also to oxidize any metals which 
may not be volatile. It is proper to remark, that some ores do not require all these operations; copper ore, for example, is not stamped, but is broken into small fragnients by the hammer. In other cases, rocasting is unnecessary.

III. Having been thus prepared or dressed, the ores are in the next place reduced or purified. The object of this is to separate them from any other ingredients, with which they may be combined, and to drive off the oxygen, imbibed in washing, or which is naturally present. This reduction is effected by fusing them with charcoal and a substance called a flux, which may be lime, fluor-spar, borax, or one of the earthy or metallic oxides. The charcoal attracts the oxygen to itself, and the lime unites with the earthy and silicious substances, forming a sort of glass, so that the metal melts, and falls to the bottom, in a pure state. This is called smelting. In other cases, as in reducing gold and silver, amalgamation is used; that is, the ore, after being pounded and washed, is combined with quicksilver, by which an alloy or amalgam is formed. This, after removing the more earthy parts, is enclosed in leather, and subjected to pressure, by means of which, the more liquid parts are forced through the leather, while the residuum, containing the greater part of the gold, remains. It is then subjected to distillation, in order to separate the quicksilver. In other cases, the metal is purified, by liquefying it with some other metal, of different specific gravity, or is subjected to the action of acids, or to other processes, according to the nature of the metal, and also of the substances with which it is found combined.

It may be proper, under this head, to say something of assaying, alloys, and solders. Assaying is the process of analyzing ores, in small quantities, to ascertain the proportion of pure metal which they contain. It is eflected by taking equal portions of the poorest, richest, and medium, ores, putting them together, and purifying them, in the manner already mentioned, which 
will yield a metal, more or less simple. If compound, this metal is further analyzed, by the use of acids and of alkalies, by distillation, amalgamation, \&c.

Alloys are compounds, formed by fusing two or more metals together. They are extensively used in the arts, because they are cheaper, harder, and more durable, than the pure metal. 'The most common alloys are plate and coins, which consist of gold or silver, alloyed with copper ; pewter, which is lead, alloyed with tin ; brass, pinchbeck, and tombac, which are composed of copper, alloyed, in different proportions, with zinc; bronze, composed of copper, zinc, and tin; and the metal of which printer's types are made, being an alloy of lead, copper, tin, and antimony. Another important use of alloys is, in the application of tin (a very fusible metal) to the surface of iron and copper vessels, to form a coat, and thus prevent them from rusting.

Solders are either simple metals or alloys, which are used to cement metallic joints, or fractures. Their value, like that of tin, depends upon the fact, that they melt at a temperature much lower than the metals which they are employed to join.

IV. The metal, having been thus brought into the proper state for making useful implements, is worked up, according to its nature, by casting, or by hammering. In casting, the metal is fused and poured into moulds, of the requisite shape, where it is allowed to cool. In this way, our stoves, kettles, cannon-ball, \&c., are cast. In the other case, the metal is heated to a red or white heat, by which it becomes more malleable, and is then brought into the requisite form, by hammering, grinding, \&c. We cannot do better than to take a single metal, and describe the various processes to which it is subjected. We select Iros, since it is the metal which, of all others, combines, in the greatest degree, cheapness with ductility, fusibility, and strength, and which is therefore more extensively used than any other metal. An iron wire can be easily bent or drawn out, and will at the same time sus- 
tain nearly twice as much weight as any other metallic wire of the same diameter.

As iron comes from the smelting furnace, it is in masses called pigs, and is cast iron. The principal changes through which it passes are, 1. Puddling and rolling, the effect of which is to burn away or squeeze out any foreign substances, which the metal may contain, and, by rendering it more malleable, convert it into wrought iron. 2. Case-hardening, which converts thic surface of wrought iron into steel, by immersing it in cast iron, while in a state of fusion. 3. Cementation, which converts iron into steel, by heating bars of the purest iron, in contact with charcoal, by which means carbon will be absorbed, and the weight of the metal increased, while, at the same time, it acquires a blistered surface. In this state, we call it blistered steel; when drawn down into smaller bars, and beaten, it forms tilted steel; and this, brolien up, heated, welded, and again drawn out into bars, forms shear steel. 4. Tempering, which, by heating stcel, gradually, to a certain temperature, deprives it of that hardness and brittleness which renders it unfit for practical purposes. These processes, howerer, will be rendered more intelligible, by the following description of the elianges through which a piece of iron passes, in order to become a knife-blade, which we take from a very entertaining and instructive little work, called, 'The results of Machinery.' "'The man who has a lump of iron ore," says the author, "has certainly a knife in the heart of it; but no mere labor ean work it out. Shape it as you may, it is not a knife, or stecl, or even iron,-it is iron ore; and, dress it as you will, it would not cut better than a brickbat, certainly not so well as the shell or bone of the savage.

"There must be knowledge, before any thing ean be done in this case. We must know what is mixed with the iron, and how to separate it. We eannot do it by mere labor, as we ean chip away the wood, and get out the bowl; and therefore we have recourse to fire 
"In the ordinary mode of using it, fire would make matters worse. If we put the material into the fire, as a stone, we should probably receive it back, as slag or dross. We must therefore prepare our fuel. Our fire must be hot, very hot; but if our fuel be wood, we must burn it into charcoal, or, if it be coal, into colie.

"The charcoal or coke answers for one purpose: but we have still the clay or other earth mixed with our iron, - and how are we to get rid of that? Pure clay, or pure lime, or pure earth of flint, remains stubborn in our hottest fires; but when they are mixed, in a proper proportion, the one melts the other.

"So charcoal or coke, and ironstone or iron ore, and limestone, are put into a furnace; the charcoal or coke is lighted at the bottom, and wind is blown into the furnace, at the bottom, also. If that wind is not sent in by machinery, and very powerful machinery, too, the effect will be little, and the work of man great; but still it can be done.

"In this furnace, the lime and clay, or earth of flint, unite, and form a sort of glass, which floats upon the surface. At the same time, the carbon, or pure charcoal, of the fuel, with the assistance of the limestone, mixes with the stone, or ore, and melts the iron, which, being heavier than the other matters, runs down to the bottom of the furnace, and remains there till the workman lets it out by a hole, made at the bottom of the furnace for that purpose, and plugged with sand. When the workman knows there is enough melted, or when the appointed time arrives, he displaces the plug of sand with an iron rod, and the melted iron runs out like water, and is conveyed into furrows made in sand, where it cools, and the pieces formed in the principal furrows are called 'sows,' and those in the furrows branching from them, 'pigs.' A single furnace will in this way make seventy-five tons of iron, in a week; or as much iron, in the year, as will make the blades of about one hundred and forty millions of knives, at an ounce to each blade. 
"But great as is the advantage of this first step of the iron-making, the iron is not yet fit for a knife. It is cast iron. It cannot be worked by the hammer, or sharpened to a cutting edge; and so it must be made into malleable iron, a kind of iron, which, instead of melting in the fire, will soften, and admit of being hammered into sliape, or united by the process of welding.

"The methods, by which this is accomplished, vary; but they in general consist in keeping the iron melted in a furnace, and stirring it with an iron rake, till the blast of air in the furnace burns the greater part of the carbon out of it. By this means, it becomes tough; and, without cooling, is taken from the furnace and repeatedly beaten by large hammers, or squeczed through large rollers, until it becomes the bar iron, of which so much use is made, in every art of life.

"Bringing it into this state requires great force; and the unaided strength of all the men in Britain could not make all the iron which is at present made, though they did nothing elsc. Machincry is therefore resorted to; and water-whecls, steam-engines, and all sorts of pow$\mathrm{crs}$, are set to work, in moving hammers, turning rollers, and drawing rods and wires through holes, till every worliman can have the particular form which he wants. If it were not for the machinery that is employed in the manufacture, no man could obtain a spade for less than the price of a year's labor; the yolies of a horse would cost more than the horse himself; and the farmer would have to return to wooden ploughshares, and hoes made of sticks with crooked ends. There would be labor enough, then, as we have already shown: but the people could not live upon the labor only; they must have profitable labor.

" $\Lambda$ fter all this, the iron is not yet fit for a knife, - at least for such a linife as an Englishman may buy for a shilling. Many nations would, however, be thankful for a little bit of it, and nations, too, in whose countries there is no want of iron ore. But they have no knowledge of the method of making iron, and have no fur- 
naces or machinery. When our ships sail among the people of the Eastern islands, those people do not ask for gold. 'Iron, iron!' is the call; and he, who can exchange his best commodity for a rusty nail, or a bit of iron hoop, is a fortunate individual.

"We are not satisfied with that, in the best form, which is a treasure to those people, in the worst. We must have a knife, not of iron, but of steel, a substance that will bear a keen edge, without either breaking or bending. In order to get that, we must again change the nature of our material.

"How is that to be done? The oftener that iron is heated and hammered, the softer and more ductile it becomes; and as the heating and hammering forced the carbon out of it, if we give it the carbon back again, we shall harden it; but it happens that we also give it other properties, by restoring its carbon, when the iron has once been in a ductile state.

"For this purpose, bars or pieces of iron are buried in powdered charcoal, covered up in a vessel, and kept at a red heat for a greater or less number of hours, according to the object desired. There are niceties in the process, which it is not necessary to explain, that produce the peculiar quality of steel, as distinguished from cast iron. If the operation of heating the iron in charcoal is continued too long, or the heat is too great, the iron becomes cast steel, and cannot be welded; but if it is not melted in the opcration, it can be worked with the hammer, in the same manner as iron.

"In each case, however, it has acquired the property upon which the keenness of the knife depends; and the chief difference, between the cast steel and the steel that can bear to be hammered, is, that cast steel takes a keener edge, but is more easily brolien.

"The property which it has acquired is that of bearing to be tempered. If it be made very hot, and plunged into cold water, and kept there till it is quite cooled, it is so hard that it will cut iron, but it is brittle. In this state, the workman brightens the surface, and lays 
the steel upon a piece of hot iron, and holds it to the fire till it becomes of a color which he knows from experience is a test of the proper state of the process. 'Then he plunges it again into water, and it has the degree of hardness that he wants.

"The grinding a knife, and the polishing it, even when it has acquired the requisite properties of steel, if they were not done by machinery, would cost more than the whole price of a knife, upon which machinery is used. A travelling knifegrinder, with his treadle and wheels, has a machine, but not a very perfect one. The Sheffield linifemaker grinds the knife, at first, upon wheels of inmense size, turned by water or steam, and moving so quickly, that they appear to stand still; the eye cannot follow the motion. With these aids, the original grinding and polishing cost scareely any thing; while the travelling knifegrinder charges twopence for the labor of himself and his wheel, in just sharpening it.

"As iron is with us almost as plentiful as stone, we do not think much about it. But there is a great deal to be done, much thinking and inventing, before so simple a thing as a shilling knife could be procured; and without the thinking and the inventing, all the strengrth of all the men that ever lived never could proeure it; and without the machinery to lighten the labor, 11 ingenuity could furnish it at a thousand times the expense."

\section{CHAPTER X.}

THE MANUFACTURE OF GLASS.

Tre metals afford a striking instance of the power of human ingenuity and labor, in imparting value to substances, which, in thcir natural state, are worthless. This appears still more conspicuously in the case of glass and pottery. The ores, from which metals are 
extracted, are frequently scarce, and can only be obtained at an immense expense of labor and time. The materials, of which glass and pottery are formed, exist, in abundance, near the surface of the earth, and in almost every neighborhood. Glass is composed of silicious sand or pouncled flint, mixed with potash or soda; which latter materials are readily obtained by burning vegetable substances. Pottery is a species of brick ; and, like it, is formed of clay, kneaded together, then moulded into the requisite forms, and hardened by heat.

The value of these substances, which are thus created from the most worthless materials, must be obvious to every one. They are equally important to science and the arts, and in domestic life. Take glass, for example. Without it, the astronomer would be unable to construct those instruments, with which he traces the movements, and counts the number, of the stars. The naturalist would be prevented from exploring the minute recesses of plants, and animals, and unorganized matter, by which means he ascertains their structure, and brings to light the myriads of animated beings with which they are peopled. Age and infirmity would be destitute of the means for repairing defects of vision, and thes be deprived of the innumerable benefits and pleasures which it was intended to afford. Our liabitations, instead of being irradiated with the clear light of day, would enjoy only the faint beams which could find their way through oiled paper, horn, or mica. The druggist would no longer be able to examine his medicines, nor the chemist his experiments, through the sides of transparent vessels. Mirrors to reflect the person would not now be found in every cottage, but would be a luxury known only in the palace, or the mansion of the rich ; and, instead of drinking-glasses and decanters, which now ornament every table, at a trifling expense, we should have to content ourselves with drinking-cups of tin or pewter, and jugs of stone. 
The art of making glass was probably first suggested by the sight of native crystal. It is certainly ancient, but was probably confined, among the Oriental nations, as well as by the Greelis and Romans, to the manufacture of ornaments and utensils. Its use in windows, and, what is hardly less important, in optical instruments, is a modern invention.* At what time glass was first introduced into the windows of churches is not absolutely known; but probably not before the third or fourth century. In the windows of private dwellings it was very sparingly employed, till the seventeenth century; and a hundred years have not elapsed, since many houses in England and our own Country were without windows, or lighted only through oiled paper, horn, \&ce. At present, owing to chemical knowledge and greater division of labor, the art is so perfect, that glass ressels and windows can be afforded by the humblest individuals. We propose, in this Chapter, briefly to explain the several processes employed in making glass, referring the reader, for a more detailel account, to 'Bigelow's Technology, $\dagger$ from which much of the matter of this Chapter is abridged.

Glass.-1. Glass, as we have already said, is composed of flint, fused with some alkaline substance. The flint is found in the sand of certain situations, or is obtained by heating common flints or quartz, red hot, and then plunging them into cold water. They turn white, fall to pieces, and are then pounded and sifted, before being mixed with the alkali. Pure silicious sand, however, is to be preferred, since it is already pulverized; and it may be found in several lo-

\# Glass windows are said to have been discovered in the buildings at Pompeii, formed of glass which must have been blown.

t Since the above was written, Dr. Bigelow's work, above alluded to, has been revised by the author, and, with many additions and alterations, republished as a part of 'THE Scroor. I, iBRARY,' (of which it forms volnmes xi. and xii. of the larger series,) with the title, 'The Useful Arla considered in connexion with the Applications of Science.' 
calities, among which, in this country, the banks of the Delaware are the most noted. With this silicious substance, which is the basis of glass, we mix potash or soda; and, if the glass be coarse, alkaline ashes of any kind, such as kelp, barilla, \&c. To these are added, in many instances, small quantities of lime and borax, to render the materials more fusible; and also, in some cases, some metallic oxide, which is used to increase the transparency and whiteness of the glass; or to impart to it a peculiar color.

2. Haring mixed these materials earefully together, we proceed to apply heat. This, in the first instance, must not be sufficient to fuse the materials ; otherwise, the alkali will be driven off, before it can be combined with the silica. At this stage, heat is used merely to expel the carbonic acid, and other gaseous and volatile matters, which would otherwise prove troublesome, by causing the materials to swell up while fusing. It is gradually increased, and the materials constantly stirred, for some hours, until they unite into a soft adhesire mass. The alkali having gradually combined with the silicious earth, the homogeneous mass, thus formed, is called frit, and the process by which it is procured, fritting. The frit is now placed in a crucible, made of the most refractory clays and sand, and deposited in the melting furnace. A quantity of old glass is commonly placed upon the top of the frit, and the heat of the furnace is raised to its greatest height, at which state it is continued thirty or forty hours. During this period, the materials become perfectly united, and form a transparent uniform mass, free from specks and bubble. The whole is then suffered to cool a little, by slackening the heat of the furnace, until it acquires sufficient tenacity to be wrought.

3. Glass is wrought by blowing, casting, and moulding. Blowing is one of the most interesting operations connected with this manufacture. The workman is provided with a long iron tube, one end of which he thrusts into the melted glass, turning it round until a 
certain quantity, sufficient for the purpose, is gathered, ol adheres to the extremity. 'The tube is then withdrawn from the furnace, and the lump of glass which adheres is rolled upon a smooth iron table, and the workman blows strongly with his mouth, through the tube, by which the glass is gradually inflated, like a bladder. The inflation is assisted by the heat, which causes the air and moisture of the breath to expand with great power, and enables the workman to give the glass any form he may choose. Whenever the glass becomes so stiff, from cooling, as to render the inflation difficult, it is again held over the fire, to soften it. If window glass is to be formed, the blowing is repeated, until the globe is expanded to the requisite thinness. It is then received by another workman, upon an iron rod, while the blowing-iron is detached. It is now opened at its extremity : and, by means of the centrifugal force communicated by rapid whirling, it is spread into a smooth, uniform sheet, of equal thickness throughout, excepting a protuberance at the centre, where the iron rod was attached. This protuberance is called a bull's eye; and being in the centre, no very large squares can be obtained from these circular plates. Hence, when larger sizes are wanted, it is usual to blow them in the form of cylinders, not more than four feet long. When plates of still larger dimensions are made, it must be effected by casting. The glass is melted in great quantities, in large pots or reservoirs, until it is in a state of perfect fusion, in which condition it is kept for a long time. It is then drawn out, by means of iron cisterns, of considerable size, which are lowered into the furnace, filled, and raised out by machinery. 'The glass is poured out, from these cisterns, upon tables of polished copper, of large size, having a rim elevated as high as the intended thickness of the plate. In order to spread it perfectly, and to make the two surfaces parallel, a heavy roller, of polished copper, weighing five hundred pounds or more, is passed over the plate, resting on the rims, at the edges. The glass, which is 
beginning to grow stiff, is pressed down and spread equally, the excess being drawn before the roller, until it falls off at the extremity of the table. When ornamental forms are to be impressed upon the surface of glass ressels, it is effected by using metallic moulds, into which the glass, while in a melted state. is blown, until it receives the impression on the outside. This process has been essentially improved, by the manuturers of American glass, who, in moulding, subject the material to pressure on the inside and outside (at the same time) of different parts of a mould, which are brought suddenly together by mechanical power.

4. When, through any of these methods, the glass has been brought to the requisite form, it is next subjected to the operation called annealing, which consists in remoring the glass into a furnace, whose heat is not sufficiently intense to melt it. and gradually withdrawing the article from the hottest to a cooler part of the annealing chamber, till it is cold enough to be taken out for use. This process is indispensable to the durability of the glass; for, if cooled too suddenly, it becomes extremely brittle, and flies to pieces upon the least touch of any hard substance. This effect is shown in the substance called Rupert's drops, which are made by cooling, suddenly, drops of green glass, by letting them fall into cold water. These drops fly to pieces, with an explosion, whenever the smaller extremities are broken. The Bologna phials, and some other ressels of unannealed glass, break into a thousand pieces, if a flint, or other hard and angular substance, is dropped into them. This phenomenon scems to depend upon some permanent and strong inequality of pressure : for, when these drops are heated so red as to be soft, and left to cool gradually; the property of bursting is lost, and the specific gravity of the drops is increased.

5. To anneal' $1 \mathrm{~g}$, succeed the processes of grinding and cutting. The object of the first is to polish the surface of the glass, so as to fit it for mirrors. \&c. It 
is performed in a manner very similar to that employed in polishing marble, execpt that the glass, being a harder substance, requires more labor and nicety in the opcration. The plate to be polished is first cemented to a table of wood or stone, with plaster of Paris. A quantity of wet sand or emcry is spread upon it, and another glass plate, similarly cemented to another wooden surface, is brought in contact with it. The two plates are then rubbed together, until the surfaces have become materially smooth and plane. 'The emery which is first used is succeeded by enery of a fincr kind, and the last polish is given by putty, or the oxide of iron, called colcothar. When one surface has become perfectly polished, the cement is removed, the plate turned, and the opposite side polished in the same way. In some cases, pure flint, reduced to powder, is substituted for emery. The advantage of it consists in the fact, that the mixture of glass and flint, which is left after the operation, is valuable for forming fresh glass.

Cutting is a species of grinding, by which successive portions of glass are ground away, and figures are given it, which appear as if made by the incision of a sharp instrux.ent. An establishment for cutting glass contains a great number of wheels of stone, metal, and woor, which are made to revolve rapidly by a steam-engine, or other power. The first, or rough cutting, is sometimes given by wheels of stone, resembling grindstones. Afterwards, wheels of iron are used, having their edges covered with sharp sand or emery, in different states of fineness. The last polish is given by brush wheels, covered witlı a putty, which is an oxide of tin and lead. To prevent the friction from exciting so much heat, as to endanger the glass, a small stream of water continually drops upon the surface of the wheel.

6. Coloring.-We have already stated, that the beautiful colors imparted to glass beads, cnamelling, ¿c., were produced by various metallic oxides, melted with the other ingredients, and combining in intimate union with them. Another method of coloring is 
termed staining; and consists in applying some color superficially, which vitrifies on being exposed to heat, and incorporates with the substance of the glass. This art was employed rery much by the ancients, in decorating the windows of churches, and cathedrals. It is often described as being no longer known; but erroneously, since nothing has been lost but the art of communicating certain peculiar colors, which are found in the windows of the ancient cathedrals.

Before dismissing the subject of glass, we may notice a combination, which has been invented within the last century, and which has proved of inestimable importance, in the construction of telescopes. When flint glass (that is, a rery clear and comparatively soft glass, so called, because it was formerly made of pulrerized flint) is formed into single lenses, for telescopes, it is found that the objectglass (that is, the one nearest the object) imparts colors to the image formed by light passing through it, owing to a difference in the refrangibility of the rays which compose white light. In this way, the vision becomes indistinct, and the inconrenience was so great, as to render the refracting telescope nearly useless ; until an English artist, Dollond,* (who, like many English artists, was a man of science, as well as practical skill,) discovered a method of obriating it. This consists in making the objectglass in three separate parts, which fit exactly together, and which consist of different linds of glass. The dispersion occasioned by the first glass is partially corrected by the second, and still more by the third; so that the light, at last, emerges from the lens perfectly colorless, and forms a distinct image; and hence it is called the achromatic (or colorless) glass. It is an interesting fact, that the liuman eye is constructed of lenses combined in a manner somewhat similar, and is supposed to have furnished to the artist the first hint of his invention. The cavity of the eye, that most perfect of all optical instru-

* For a notice of Mr. Dollond, see 'Pursuit of Knowledge under Difficulties,' vol. ii, being rol. $x y$. of 'THE Schoor. LibraRY.' 
ments, is occupied by three substances, called humors, which serve, like a lens, to refract the rays of light. and to form an image on the retina. The humors are of different refractive powers, and have been supposed, by their successive action on the light, to correct any irregularity which might otherwise take place.*

\title{
CHAPTER XI.
}

\author{
POTTERI AXD PORCELAIX.
}

Certax clays hare a property, which renders them extremely valuable in the arts. They soften in water. and allow themselves to be kneaded and formed into moulds. These moulds, when exposed to heat, acquire a durable hardness, which fits them for being used

* It is noi certain that Dollond receired the first hint for his great invention from observing the structure of the eye; and $j$ now seens probable, that the resemblance referred to in the text is rather apparent, than real. Dr. Brewster has discorered that the haman eve is not achromatic; the deriation of the differently-colored ravs being too small to require any correction. That no provision for sach correction exists in the eve, is inferred from the fact, that, if we slut up all the pupil, except a portion of its edge, or look past the finger, held near the eyc, till the finger almost hides a narrow line of white light, we shall see a distinct prismatic spectrom of this line, containing all the different colors; an efiect which could hardly take place, if the eve were achromatic.

An improvement, which was recently made br II. Gainand, of Swizerland, in the manufacture of thint glass for lenses, has contributed, nearly as unch as the invention of Dollond, to restore the refracting telescope 10 use. The oxide of lead, which has been used, of late, much more freely than formerly, in usking glass, because it improves its whiteness and lustre, serres to inpair the value of the substance for optical purposes, by preventing that parallel arrangement of layers, of ditherent densities, which is necessarv, in order to prereat fisws. This difficultr has been so far obviated, that $\mathbf{M}$. Guinand has produced objectglasses for iclescones, nearly iwelve inches in diameter, and frec from flaws; and it is stated, that, while out of ten objeciglasses, made of English or French flint glass, onls onc, or two, at most, were found serviceable, eight or nine, ont of the same number, male ly. M. Guinand, turned out good. Iis nethod is unknown. 
either in buildings, or in forning utensils and ressels. Brick, tiles, and the lining of furnaces, are familiar specimens of this art. They are formed of coarse common clay, which is a mixture of argillaceous earth and sand, and are apt, from the iron which the clay contains, to turn red in burning. Earthen and crockery ware form other wellknown specimens, - the first being composed of common clay, similar to that of which bricks are made, and the latter of the purer and whiter clars, in which iron exists only in small quantities. Porcelain, the most beautiful and expensive kind of pottery, is formed only from argillaceous minerals, of extreme delicacy, united with silicious earths, which serve to render them semi-transparent, by means of its vitrification. The clay, which is used in pottery, causes the operation to differ essentially from that employed in making glass. There, the substances are softened by heat, and wrought at a high temperature; whereas, in this case, they are wrought while cold, and afterwards hardened by heat. It is impossible to explain all the details which enter into the manufacture of the different kinds of pottery. We shall merely describe those principles and processes which are common to them all, referring the reader, as in the last Chapter, to 'Bigelow's Technology.* These may be arranged under the several heads of. I. Preparing the clay. II. Moulding, or shaping. III. Burning. IV. Printing. V. Glazing.

I. Preparing the clay.-This consists in adding to it, in certain cases, a portion of silicious earth, which serves to increase the firmness of the ware, and to render it less liable to shrink and crack, on exposure to heat; and likewise partially to vitrify its surface. In the common clays, this artificial mixture of silica is unnecessary, since they have it in sufficient quantities already. In the finer clays, it is always required. The materia s being mixed with water, are formed into a 
paste, which is thoroughly beaten and lineaded, to render it duetile, and to drive out the air. This operation is performed in different ways, according to the fineness of the fabric. In the celebrated manufactory of Mr. Wedgewood, in England, the clay is brought into a state of minute division, by machinery. 1 series of iron blades, or knives, are fixed to an upright axis, and made to revolve in a cylinder, intersecting or passing between another set of knives, which are fixed to the cylinder. The clay, being sufficiently divided by the continual intersection of these blades, is transferred to a vat, and agitated with water, till it assumes the consistence of pulp, so thin, that the stony and coarser particles can subside, after a little rest, to the bottom, leaving the finer clay suspended. This last is then poured off, and suffered to subside; after which, it is passect through sieves of different fineness, and becomes sufliciently fine for use. To this pulp is then added about one fifth as much pulp of pounded flint, prepared in the same manner; and the mixture is then exposed to evaporation, by a gentle heat, until the superfluous water is dissipated, and the mass reduced to a proper consistency to work. To produce a uniformity in the thickness of the material, it is taken out, in successive picces, which are repeatedly divided, and struck or pressed together, until every part becomes blended with the rest.

II. Moulding, or shaping.-This is effected by throwing, pressing, or casting. In throwing, a piece of clay, of sufficient size to form the vessel, is placed upon a sort of table, or wheel, to which a rotary motion is given by the feet of the operator, or an assistant, and in some cases by a steam-engine. The potter begins to shape the clay with his hands, which are wet, to prevent its adhering. The rotary motion of the wheel gives it a circular form, and it is gradually wrought up to the intended shape, a tool being occasionally used to assist in the finishing. The handles, and other similar appendages, are made by forcing the clay, with a 
piston, through an aperture of the requisite size and shape. When formed, the handles are cemented to the ware, by a thin mixture of the clay with water, which the workmen call slip.

As the wheel, or table, can only be used in making vessels of a circular shape, when the form is different, the ressel must be made by pressing or casting. In pressing, moulds are made of plaster of Paris, half of the figure being on one side of the mould, and the other half on the other side. These fit accurately together. The clay being first made into flat pieces, of the thicliness of the article, one of them is pressed into one side of the mould, and the other into the other side. The superfluous clay being cut away, the two sides of the mould are brought together, to unite the two halves of the ressel. The mould being then separated from the clay, the article is complete, as to form.

In casting, the clay, in the state of pulp, sufficiently thin to flow, is poured into moulds made of plaster, by which the superfluous water being rapidly absorbed, the clay is deposited, to acquire sufficient solidity to preserve the shape communicated by the mould. When the ressels are finished, as to form, they are dried, either by cxposure to the air and sun, or by artificial heat, in a room of the temperature of eighty or ninety degrees.

III. Burning.-This is necessary, to give the requisite hardness. Vessels merely dried after the manner of some rude nations, in ancient and modern times, are extremely frangible. The burning is performed in ovens or kilns; and, in the better linds of ware, the articles are enclosed in cases or boxes of burnt clay, called saggars, and, by means of flame circulating among these cases, are raised to a red heat. The fire is kept up, from twenty-four to sixty hours, and the saggars suffered to cool before they are removed. On the intensity and duration of the heat, depend, of course, the strength and solidity of the ware. When taken from the oren, the ware is extremely bibulous, -that is, capable of absorbing a great deal of water. 
This is the case with our common brown and red earthen ware, which absorbs water in such quantities, that vessels in this state are used as coolers, being kept saturated with water, which, as it passes constantly to the outer surface, generates cold by its evaporation. This property of absorbing water renders necessary the next operation, which is termed

IV. Glazing.-CThis consists in covering the vessel with a vitreous coating. For this purpose, ground flint is mixed with an equal proportion of some metallic oxide, such as the oxide of lead, if we wish a yellow glazing; oxide of tin, if we wish it white; and if black, oxide of manganese. These materials are pounded to an extremely fine powder, and mixed with water, to form a thin liquid. The ware is dipped into this fluid, and drawn ont; whereupon, the moisture is absorbed by the clay, and the glazing particles remain upon the surface. These are afterwards melted, by exposing the ressel a second time to the heat of the kiln, and they then constitute a uniform and durable vitreous coating. In the European and American manufactories, they are obliged to burn the vessels, before glazing them, because the composition, of which the vessel is made, is not rendered capable, merely by drying, of resisting water, so as to bear dipping in the glazing fluid. In this respect, the Chinese have great advantages; their materials being such, that, after drying, they will bear immersion in liquid without injury. By this means, a great amount of fuel is sared. It is proper to add, that the ware commonly called stone ware does not require to be mixed with metallic oxides, but affords the materials of its own glazing, by a vitrification of its surfaces. When the furnace in which it is burnt arrives at its greatest heat, a quantity of muriate of soda, or common salt, is thrown into the body of the kiln. 'The salt rises in vapor, and envelopes the hot ware, and, by the combination of its alkali with the silicious particles on the surface of the ware, a perfect vitrification is produced. This glazing, consisting of an earthy glass, is insoluble 
by most chemical agents, and hence has great advan tages over the glazing formed of lead, which is apt, by the dissolving of the lead, to communicate a poisonous quality to the liquids contained in the vessel.

Where colors or pictures are to be imprinted on the ware, it must be done, in most cases, previous to the glazing. In China, Europe, and America, if elaborate pieces of workmanship are to be produced, the design, or drawing, is executed beforehand, with the pencil. But in the common figured white ware, the designs are first engraved upon copper, from which an impression is taken, on thin paper, with a color formed of some metallic oxide. This paper is then moistened, applied closely to the unglazed surface, and rubbed in, so that the coloring matter may be absorbed. 'The paper is then washed off, leaving the printed figure transferred to the sides of the ressels.*

Chinese porcelain differs from the finer kinds of pottery merely as to its materials, which are two varieties of feldspar, abounding in China, but not found in Europe or in this Country. Materials, however, of nearly the same kind, have been discovered, and porcelain is manufactured in Philadelphia, which, in respect to the elegance of its forms, and the beauty of the designs which are executed upon it, excels that of China. But in point of hardness, durability, transparency, strength, and the permanency of the glaze, the Oriental manufacture has not yet been equalied.

It must be erident to the reader, on the slightest reflection, that the arts described in this and the preceding Chapter, are most intimately allied with chemical science. Their progress has been proportioned to the intelligence and scientific skill which has been applied to them. It is less than seventy-five years, since, in England, the manufacture of pottery was limited to the coarsest kinds of crockery ware, and to small quantities even of these. Like our own country, it was depen-

- Transferring, as it is called, is on much the same principle. 
dent for such articles on Holland, Saxony, and China. Now, England exports, annually, near forty millions of pieces of earthen ware, to all parts of the world; and many of these are of a very fine quality. Much of this improvement is to be attributed to the increased resources, furnished by machinery and a knowledge of chemistry. Mr. Wedgewood, whose name has alrcady occurred in this Chapter, and who may be said to have created the manufacture of fine pottery in England, not only was himself a man of science, but employed, in his experiments, the constant aid of a distinguisherl chemist. In his attempts to improve the art, he was not content to grope in the dark, in the hope that he night blunder upon his object ; but he sought in the nature of his agents, carefully observed, for rules to guide his experiments and processes. The consequence is seen, in the abundance and beauty of the important fabric with which he enriched and benefited his country. Had he, and his successors in the same kind of manufacture, been satisfied to tread in the old paths, or to adventure improvements without the light of science, they might have left that manufacture where it was fifty years since, and we might now be compelled to use an inferior article, and yet pay for it a vastly higher price.

\section{CHAP'TER XII.}

COPYNG, INCLUDING CASTING, PRINTING, ENGRAVING, ETC.

Ove very important object in the arts is, to produce copies of an article; or, in other words, to produce a great number of articles which are exactly similar in form, size, and finish. To do this by hand would be not only difficult, but impossible. Hence the method of copying, by casts and superficial impressions, has been adopted, - an expedient which strikingly resembles machinery, in the facility and cheapness with which it 
produces the most finished specimens of workmanship We have already described the manner in which copies are taken, in the manufacture of some kinds of pottery and glass, and also in the metallurgic arts ; printing, engraving, and stamping, furnish us with other familiar examples.

We propose, in this Chapter, to make a few remarks, I. on the patterns, from which the articles are made, and II. on the methods of taking the impressions.

I. 'The patterns are formed of wood, metal, or plaster, according to the degree of pressure which is to be applied to them, and to the temperature at which the copy must be taken. If great pressure is necessary, plaster would not be sufficiently strong, and henee the pattern must be formed of metal, or, where the pressure is less severe, of wood. So, again, if the material is applied to the pattern, when very hot, the latter must evidently be composed of some substance, not liable, on the one hand, to take fire, nor, on the other, to crack, and fall to pieces. In casting iron, and other metals, the pattern is usually made up in sand, and is, in fact, merely a copy, from another pattern, which has been previously exeeuted in wood or metal. This first pattern, being placed in a mass of soft sand, sufficiently damp to adhere a little, is made, by pressure, to communicate its form, and is then remored. Into the cavities, which it leares in the sand, is poured the melted metal, which, on cooling, will assume, of course, the same figure with the original pattern. Plaster is generally used where no great pressure is needed in taking the impression, and when the pattern has to be taken directly from the object. Thus, in taking busts of the human face or form, plaster, when moistened, will, from its plastie nature, adapt itself exactly to the object, and is therefore peeuliarly fitted for this purpose. It is remored in separate piees from the face, and then reunited, to form the mould for future copies. In stamping, printing, and engraving, the pattern is almost always formed of metal; sinee it is better fitted 
both to take a high polish, and to bear great pressure. It may be interesting, to be informed of the method pursued in forming engravers' plates and printing types, which, of all patterns, are the most useful.

1. The plates on which the engraver draws his designs are generally metal, though in some cases he employs wood and stone; and hence the two species of engraving, called wood-engraving and lithography. The lines are drawn, in some cases, by mechanical, and in others, by chemical, agents. In mechanical engrating, the artist uses a sharp instrument called a graver, with which he either cuts out the parts which are to appear black or shaded in the picture, or leares them raised by removing the intermediate parts. In the finest kinds, called line-engraving and stippling, the shaded parts are cut out; in mezzotinto, which resembles painting in India ink, and also in wood cuts, they are raised. In the first of these, (mezzotinto,) the whole surface is roughened with a toothed instrument, called a needle, and the part corresponding to light is then rubbed down. In wood-engraving, the part left light is cut out.

In chemical engraving, the artist, in order to produce lines, arails himself of the chemical affinity which subsists between some of his materials. The most familiar examples of this arc, etching and lithography; to which we may now add the art of galvanic engraving. In etching, the engraver having prepared his plate, as in common engraving, proceeds to cover it, throughout its whole surface, with a thin coating of varnish, made of wax, mastic, and asphaltum,-sometimes, of rosin and animal oil. This varnish is blackened by the smoke of a lamp, in order that the operator may see the progress and state of his work. He then takes a needle, and, supporting his hand on a ruler, makes his drawing in the coat of the varnish, being always careful to penetrate to the copper. Having completed his design, he pours a quantity of diluted nitric acid over the plate, which is prevented from es- 
caping, by a wall of soft wax, surrounding the plate. By the action of the acid, all the lines or points, where the copper is exposed by the strokes of the needle, are bitten in, as the artist terms it; that is, impres sions are made, as if by cutting. When the acid has acted for some time, it is poured off, and those parts which are to be most lightiy shaded are stopped out (or corered) with ramish, to protect them from further action. New acid is poured for the sccond shades, which are next stopped out, and so the processes are repeated, alternately, till the piece is finished, and the varnish is cleaned off. Such engravings must evidently be coarse.

In lithography, a smooth slab is selected; of a species of marble, which will imbibe water, so that the ink used in printing will not adhere. On this, the lines to be copied, whether of writing or of a picture, are drawn with a composition, which has the double property of adhering to the stone, and of attaching to itself the printing ink. This composition, which is made of soap, tallow, white wax, shell lac, and lampblack, is used in a liquid form, so as to be applied with a pen, or a delicate brush; or it is solid, and moulded into the form of a crayon, or pencil. The writing or figure on the stone must be reversed; and the beauty of the copy will correspond to the delicacy of this drawing. When the stone is thus prepared, the impression is taken in a manner somewhat similar to that of copperplate printing. The stone being wet with a sponge, the ink is applied over the whole surface, but adheres only to the composition, leaving the intermediate parts perfectly clean: a sheet of paper is immediately placed upon it and pressed forcibly, and thus receires a perfect transcript of the figure on the stone.

In galvanic engraving, the shaded lines are raised, being deposited from a solution of copper on a plate of the same metal, by means of galranic electricity.*

* A description of the process will be found in Appendix, VIII. 
2. Types.-The movable metal types, those used in the printing of books like the present, are themselves copies, produced by casting from moulds of copper, called matrices. The lower parts of these matrices, which bear the impressions of the letter or character intended, are also copies, being made by punching with steel punches on which the same character exists on a raised surface. Nor are even these steel punches made without the aid of copying. Many of the cavities which exist in them, such as those in the middle of the punches for the letters $a, b, d, g, \mathfrak{E} c$., are produced from other steel punclies, in which these parts are raised, or in relicf. In forming stereolype plates, the process of copying is carried still further. The page to be stereotyped is set up with common movable types, which are obtained, as we have just seen, by copying, thrice repeated. On this pagre, plaster, in a liquid state, is poured, which, as it hardens, will receive a transcript of the page. From these plaster copies, or moulds, another copy is taken in metal, from which the printer takes his printed page. The present work is from stereotype plates. Thus it appears, that ordinary types are the third copy from the steel punch used in the first instance, and that the stereotype plate is the fifth copy; and that the letter, from the time it is first formed, has to go through six copyings, before it can reach the eye of the reader. The same remark applies to many patterns. They are themselves copies, - it being inconvenient, owing to the material of which they are composed, or to some other circumstances, to take them directly from the original.

It is obvious, that much of the labor involved in copying consists in forming the pattern. For instance, the ornamental plates for a stove, which are cast by four men, in lialf an hour, are taken fron patterns, the making of which occupied the same number of men perhaps a year. So an engraver may spend the labor of one or two years, in preparing a plate, from which he will subsequently take a hundred impressions in an lour; and, while the original plate, or pattern 
cost some hundreds of dollars, he can afford to sell inis copies for a few cents. This fact may serve to show the analogy between machincry and copying, to which we have already referred. Machines are often expensive; but this expense they not only repay, by the increased rapidity and accuracy with which they produce work, but they enable the manufacturer, by the same means, to afford his articles at a less price, and yet receive from them a greater profit.

II. We will now describe some of the methods, by which copies for general use are taken from patterns. The mode of taking casts must be sufficiently obvious, from what we have already said. The other species of copying may be reduced to four ; namely, Punching, Drawing, Stamping, and Printing.

1. Punching.-In this operation, a steel punch is driven by a blow, or by pressure, through a substance, which is to be cut in some required way. In some cases, the object is to make repeated copies of the same aperture, and the substance separated from the plate is rejected; in other cases, it is the small pieces cut out which are the objects of the workman's labor. Of the former lind, are the holes which are punched in the iron and copper plate for boilers, in colanders, strainers, \&cc., the ornamental patterns of open-work which decorate the tinned and japanned wares in general use ; the inlaid plates of brass and rosewood, called buhl work, which ornament our furniture, \&c. \&c. It should be remarked, however, that, in the last instance, both the parts cut out, and those which remain, are in many cases employed. 'The following are instances in which the only part made use of is that which is punched out, namely, the circular disks of thin cards, which are substituted instead of paper, for retaining in its place the charge of a fowlingpiece; the golden stars, leares, and other devices, sold in shops, for the purpose of ornamenting, made of paper and pasteboard; the small pieces of sheet-steel which compose the chains used. in connecting the mainspring and fusee in watches and 
clocks, \&c. It is obvious, that, in each of these cases, but especially in the first and last, it is of the utmost importance that the objects produced should be of the same identical form and size.

2. Diawing.-We give this name to certain processes in which a prescribed form is given to substances, by drawing them through holes. Of this nature are wire-drawing, tube-drawing, iron-rolling, \&c. \&c. In such copying, there exists but little resemblance between the copy and the original. It is the cross section of the thing produced, which is similar to the tool through which it passes. When the substance to be operated on is hard, it frequently passes, in succession, through several holes, and must also, in some cases, be annealed at intervals.

In wire-drawing, the metal to be converted into wire is made of a cylindrical form, and is then drawn forcibly through holes, which gradually diminish in size, and are circular, square, or half-round, according to the required form of the wire. In drawing the pinion wire, which is used by clockmakers, the draw-plate has holes which resemble a star, with from six to twelve rays. A short piece of this wire, about half an inch in length, becomes a pinion for a clock, the leaves of which, having passed through the draw-plate, are already bumished and finished.

"Nearly similar, in its mode of exccution, to wiredrawing, is the art of forming tubes of uniform diameter. After the sheet brass has been bent round and soldered, so as to form a hollow cylinder, if the outside diameter is that which is required to be uniform, it is drawn through a succession of holes, as in wire-drawing. If the inside diameter is to be uniform, a succession of steel cylinders, called triblets, are drawn through the brass tube. In making tubes for telescopes, it is necessary that both the inside and outside should be uniform. A steel triblet is passed into the tube, which is then drawn through a succession of holes, until the outside diameter is reduced to the required size. 'The 
metal of which the tube is formed is condensed between the holes, and the steel cylinder within it; and when the latter is withdrawn, the internal surface appears polished. The brass tube is considerably extended by this process, sometimes even to double its first length."

"Leaden pipes, for the conveyance of water, were formerly made by casting; but it has been found, that they can be made both cheaper and better, by drawing them through holes, in the manner of wire. A cylinder of lead, of five or six inches in diameter, and about two feet long, is cast with a small hole through its axis, and an iron triblet, of fifteen feet in length, is forced into the hole. It is then drawn through a series of holes, until the lead has extended from one end to the other of the triblet, and is of the proper thickness, in proportion to the size of the pipe."

"Iron-rolling.-When cylinders of iron, of greater thickness than wire, are required, they are formed by passing wrought iron between rollers, each of which has sunk in it a semi-cylindrical groove; and as such rollers rarely touch accurately, a longitudinal line will usually be observed in iron so manufactured. Bar iron is thus shaped into all the various forms of round, square, half-round, oval, \&c. in which it occurs in commerce. A particular species of moulding is thus. made, which resembles, in its section, that part of the frame of a window which separates two adjacent panes of glass. Being much stronger than wood, it can be considerably reduced in thickness, and consequently offers less obstruction to the light; it is much used for skylights."

It is sometimes required that the iron thus produced shall not be of uniform thickness, throughout. This is the case in rolling some forms of iron for rail-roads, for which purpose, greater depth is required towards the middle of the rail, which is at the greatest distance from the supports. This is accomplished, by cutting

* See Babbage, on copying. 
the groove in the rollers deeper at those parts where additional strength is required, so that the hollow, which surrounds the roller, would, if it could be unwound, be a mould of the shape the iron is intended to fit.

3. "Stamping.-1his mode of copying is extensively cmployed in the arts. It is generally executed by means of large presses, with a screw and heavy flywheel, and moved by hand, by water, or by steam power. 'The materials on which the copies are impressed are most frequently metals, and the process is sometimes executed when they are hot; and in one case, when the metal is in a state between solidity and fluidity. It is in this way that the coins which circulate as money are produced; as also ornaments for military accoutrements and furniture; buttons embossed with crests and other devices, as well as those of a hemispherical form; nail-heads, medals, \&c. In medals, which usually have their figures in higher relief than coins, a single blow is rarely sufficient to bring them to perfection. As this blow, however, renders them too hard to receire many subsequent blows, without injury to the die, they are removed, after being struck, is a furnace, where they are carefully heated red hot, and ammealed; after which, they are again placed between the dies, and receive additional blows. For large medals, and those on which the figures are very prominent, these processes must be repeated many times,--in some instances nearly a hundred."

4. Printing.-The impressions in printing are sometimes taken from ink applied to raised surfaces, and sometimes from cavities. Of the former kind, is the common printing from movable types ; also from stereotype plates, and from wooden blocks. Wooden blocks are used to communicate the inpressions which have

* The prodigious improvement which has been made in the art of printing, within the last thirty years, is strikingly illustrated by a fact mentioned in at late number of the Linglish Quarterly Review. Formerly, it required nearly three months to print a Number of that work, which is now printel in twice as many days.

19 
been carved upon them to paper; and, with the addition of small pieces of copper wire, of various forms, fixed into them, they also serve to cominunicate figures, of various colors, to calico and oil cloth.

Printing offices are so common, throughout the country, that a large proportion of our readers must have seen them in operation. But as there may be others, riho have not seen them, and the process is both curious and important, we subjoin a short description. The first step is to deposit the types in the case, which is a sort of drawer divided into compartments, or cells, and placed on a frame of convenient height. There are two cases on each frame, the upper containing ninety-eight, and the lower fifty-four, cells ; those in the lower, of unequal sizes, corresponding to the greater or less quantity required of each individual letter. "Although the ideas or words of one author would not, especially in his own opinion, at all suit those of his brother writer, yet the letters which compose them are found, in practice, to bear to each other exactly the same proportion."' The letters are not arranged in the lower cases in alphabetical order, but those most often used are placed in the most convenient position. "In the English language, the letter $e$ inhabits the largest box; $a, c, d, h, i, m, n, o, r, s, t, u$, live in the next sized apartments; $b, f, g, l, p, v, w, y$, dwell in what may be termed bedrooms, while $j, k, q, x, \approx, \mathfrak{a}, \boldsymbol{\alpha}$, double letters, capitals, \&c., are more humbly lodged in the cupboards, garrets, and cellars. The reason of. this arrangement is, that the letter $e$ being visited by the compositor sixty times as often as $z$, it is.evidently advisable that the letters oftenest required should be the nearest as well as in the greatest quantity. Short types, or quadrats, for spaces between the words, and those for the punctuation, are arranged upon the same principle. Latin and French books derour more of $c$, $i, l, m, p, q, s, u$, and $r$, than English ones, and for these languages the cases must therefore be arranged Rccordingly." 
"The usual way of filling cases with letters is, by distributing the type pages of books, which have been printed off. 'This is done with astonishing celerity. If the type were jumbled, or, as it is technically termed, in pi, the time requisite for recognising the tiny countenance of each letter would be enormous: but the compositor, being cnabled to grasp and read one or two sentences at a time, without again looking at the letters, drops them, one by one, here, there, and every where, according to their destination. It is calculated that a good compositor can distribute four thousand letters per hour, which is about four times as many as he can compose; just as in common life all men can spend money, at least twenty times as readily as they ran earn it.

"As soon as the workman has filled his cases, his next Sisyphus' labor is, by composition, to exhaust them. Glancing occasionally at his copy before him, he consecutively picks up, with a zigzag movement, and with almost the velocity of lightning, the letters he rcquires. In arranging these types, in the stick, or little iron frame which he holds in his left hand, he must of course place them with their heads or letter-ends uppermost; besides which, they must, like soldiers, be made to march the same way." For this purpose, the types are all cast with a mick on one of their sides, corresponding to the bottom of the letter, by which simple contrivance, the different parts of the type are easily recognised. The compositor, therefore, has no occasion to look at his types while setting them. He selects the proper letter, by directing his hand to its appropriate cell, and gives it its proper position in the stick, by fecling the different surfaces. "The composing stick liolds a certain measure of type, ánd as soon as it is filled, the paragraph, or fragment of paragraph, it contains, is transplanted" to a galley, or movable frame prepared for the purpose, whence it is made up into pages. "This process is repeated, until the pages composing a sheet, being completerl. are firmly fixed 
by wooden quoins, or wedges, into an iron frame called a chase; and, after having thus been properly prepared for the proof-press, a single copy is pullell off, and the business of correction then begins." The proof copy is carefully examined by a reader, who marks the errors in the margin, which the compositor corrects by picking out the wrong letter with a bodkin, and replacing it witl the right one. Another copy is then taken and revised, and sometimes sereral in succession, until the whole is pronounced correct.

The form, as it is called, is now ready for the press. If to be printed by a hand-press, it is placed on a morable bed, so that the pressman, after laying upon it a sleeet of moistened paper, can, by turning a crank with his left hand, roll it under the press, while, with his right hand, he pulls a lever, which brings down the full weight of the press upon it. He then rolls it back, and while he is employed in removing the sheet which has receired the impression, and laying on another, the types are supplied with ink. This was formerly done with a pair of leather balls, stuffed with wool. It is now done, more perfectly, with rollers, which pass orer the types, and with the additional adrantage, that the rollers can be managed by a boy, or even by machinery, whereas, the balls required a skilful workman. Great improvements have also been made in the press itself. Formerly, the pressure was made by a powerful screw worked by a lever. So much strength was demanded, to work it, that two pressmen were always required, to relieve each other, by working alternately at giving the impression and with the balls. Now; a double lever, united by a toggle joint, is substituted for the screw. By which, and other improvements, a single pressman is enabled to accomplish more work than two could, formerly, and in a better manner, and with less fatigue.

- In large establishments, most of the printing, from * See the London Quarterly Reriew, for December, 1S39, for a lively account of the operations of a large printing establishment, from which much of the ahove deseription is taken. 
the forms, is done on machine or power presses. These are worked ëither by a crank, turned by a laborer, or by horse, or water, or steam, power. There is a great variety of these, but they are generally so construeted, that the whole work is done by the machinery. A boy' or girl lays the sheet of paper upon a slender frame, when it is immediately drawn away, and a moment after is cleposited in a pile, already printed, in the most perfect manner. Most of the machines used in this country print only one side of the paper at a time, the process requiring to be repeated for the other side. There are some, howerer, and they are more common in England, that print both sides, at the same operation. It is stated that the Messrs. Clowes, the printers of the London Quarterly Review, have in operation, in one establishment, nineteen machines, each capable of printing a thousand sheets an hour.

There is perhaps no department of the arts, in which improvements have been made more rapidly, than in printing. In speaking of paper-making by machinery, it was said, that the paper is drawn out in a continuous sheet, being subsequently divided, for use. We hare seen it stated, recently, that a machine has been contrived and put in operation, by which the continuous undivided sheet of paper, passes directly into a printing machine, in which all the forms of a book of considerable size are placed around a cylinder, and there receives a full impression at one operation. Thus the unsightly rags, deposited in one hour in a papermaker's vat, in another, come out, not merely a paper of beautiful texture and complexion, but a full-sized printed book, ready for the binder's hands.

Examples of printing from carities may be secn in the case of copper plates, into which the characters have been cut by a graver; in engravings on steel, which are much more valuable than those on copper, since the plate will give off many thousand impressions, without sensible deterioration, whereas the copper soon becomes imperfect; in music-printing, which is usual- 
ly printed from pewter plates, on which the characters have been impressed by steel punches; and in calicoprinting, from cylinders of copper, four or five inches in diameter, on which the desired pattern has been previously engrared. One portion of the cylinder is exposed to the ink, whilst an elastic scraper, of stuffed leather, by being pressed forcibly against another part, remores all superfluous ink from the surface, previously to its reaching the cloth. A piece of calico, twentyeight yards in length, rolls through this press, and is printed in four or fire minutes.

Onc of the most ingenious and important applications of printing is in the production of colored maps. Instead of being first engraved on copper or steel, at a great expense, maps may now be printed from metal types, fixed in wooden blocks, to designate the position and names of places, the courses of rirers, $\mathcal{L}$. ; and the map is both printed and colored by machinery, and at one operation. A large sheet of white drawing paper is placed at the bottom of what seems, at first, to be an open box, - the sides of this box being corered with metal plates, and so adjusted, that they successirely shut and open, like a lid. One of them is colored blue, another yellow, a third red, and a fourth black. The black plate impresses on the paper the marks and names of cities, \&c., with the necessary lines, while the remainder serve to impart different colors to the rarious kingdoms, principalities, \&c. These plates are applied, in quick succession, to the paper, by means of machinery.

Analogous to printing is the process called embossing. The pattern being engraved on rollers, the substance to be embossed is passed through them; and, being subjected to very great pressure, is forced into the cavities, while the parts not opposite to any cavity are powerfully condensed between the rollers. In this way, a raised pattern is produced on the surface of leather, calico, \&c. We will conclude these brief remarks, by an account of a recent inrention of Mr. Per kins, which enables us to multiply copies of an engrav- 
Ing, very casily and cheaply, and, to all practical purposes, without any limit." "A cylinder of soft steel, pressed with great force against the hardened steel cngraving, is now made to roll slowly backward and forward over it, thus receiving the design, but in relief. 'This is, in its turn, hardened, without injury ; and, if it be slowly rolled to and fro, with strong pressure, on successive plates of copper, it will imprint on a thousand of them a perfect facsinile of the original steel engraving, from which it resulted. 'Thus the number of copies, producible from the same design, is multiplied a thousandfold. But even this is very far short of the limits to which this process may be extended. 'The hardened steel roller, bearing the design upon it, in relief, may be employed to make a few of its first impressions upon plates of soft stecl, and these, being liardened, become the representatives of the original engraving, and may, in their turn, be made the parents of other rollers, each generating copper plates like their prototypes. The possible extent to which facsimiles of one original engraving may thus be multiplied, almost confounds the imagination, and appears to be, for all practical purposes, unlimited." *

'The influence which has been exerted, by this art of copying, on the welfare of the human race, is wholly incalculable. 'To say nothing of the benefits bestowed by the other methods of copying, printing alone, by the stimulus which it has given to the mind, has created much of the science and art which we possess, and has conferred upon the multitude, in every country, almost all the light and civilization that they now enjoy. Previous to the invention of printing, and of the arts of manuficturing paper, (for without the latter the former would have been of little value,) books conld be multiplied only by the slow and expensive process of transcribing. This Volume, of which several thousand copies can be printed in a few hours, in a large printing-office, could not be transcribed once, by a single hand, short of many 
weeks, and at an expense of from twenty to fifty dollars.* For this work, the cost of which does not now exceed a dollar, an individual would have had to pay, previous to the invention of printing, at least twenty tines the same sum, and would have had, after all, an article vastly inferior, both in convenience and beauty. It is no exaggeration to say, that a library of one thousand rolumes can now be purchased for less money than would have been required, previous to the invention of the art of printing, for the purchase of fifty.

Copying by Transfer.-Another method of copying, is, by a direct transfer of the lines to be copied, whether a printed or written page, or an engraved picture, to the surface of a lithographic stone, from which copies are printed to an indefinite extent. Attempts of this kind had been made, for a long time; but not proving successful, they were abandoned as impracticable, until, within a few years, one of our own countrymen succeeded in the experiment. A method of copying, by this process, was announced, in Paris, in 1839 , as a new discorery, by Messrs. Duponts, (two brothers, one a printer, the other a lithographer;) but we are assured, on undoubted authority, $\uparrow$ that the same art was discorered and practised in this country as early as 1832, by Mr. Joseph Dixon, formerly of Salem, now of Taunton, Massachusetts. The minute details of the process are not revealed by either of the discoverers. It should seem, however, that substantially the same method is pursued by-both, although we are not aware that there is any reason to suppose that either is borrowed from the other. $\mathrm{By}$ the dates which are given abore, it will be seen, that the priority of discorery rests entirely with our countryman.

* The copyists of ancient days sometimes spent fifty years in transcribing and illuminating one copy of the Bible. Five hundred dol lars was paid for a single MS. concordance, and about the same price, per volume, was paid, in one instance, for a copy of the works of Livy.

+ Papers of that date, and specimens of the work done at the time. 
Mr. Dixon's method of transfer is applicable to any printing, whether old or recent. He first spreads a liquid, the composition of which he keeps secret, over the page or print to be copied. 'This page is then laid on a lithographic stone, to which, on being pressed, it immediately conveys a rerersed facsimile of itself. From this stone, copies are multiplied, at pleasure, in the usual manner of lithographic printing. The essential peculiarity of the process seems to consist in the properties of the fluid applied to the surface of the print, by which the original ink, however dried and hardened by age, is made to act on the stone with an influence precisely similar to that produced by the common lithographic drawing. It is exceedingly curious, and adds greatly to the value of the discovery, that all this is done without the slightest tarnish to the original print, or the least diminution, in any way, of its clearness or depth of color. The whole is done with such facility, that a page has been taken from a volume, transferred to stone, several copies printed from it, and the leaf restored to its place, in its original state, in sixteen minutes. Mr. D. exhibited specimens of his art at the Mechanies' Fair, held in Boston, in Sept. 1841.

It would be interesting, if our limits would permit, to grive a history of the steps of Mr. Dixon's discovery; as it would furnish another example of the happy influence of science in conducting an ingenious inquirer to a successful issue. The discovery was not accidental, but was the result of patient and long-continued research. Being a printer, and consequently familiar with the properties of the ink used in that art, and being also well versed in chemical science, it occurred to him, to seek for some substance that should exert such an influence upon the ink, as to enable him to obtain a copy. It was not until after many discouragements, and a long course of unsuccessful attempts, that he at length succeeded. In the mean time, his health becane much impaired, and his pecuniary means cxhausted, so that be has not been able to introduce his dis- 
covery so successfully to the public, as, under other circumstances, he might have done: nor to derive the benefit from it, to which its importance and value entitle him.

\section{CHAPTER XIII.}

\section{LOCOYOTION.}

THE progress of socicty in any country will be materially influenced by the means of intercourse and transportation which it enjoys. Where roads and vehicles are bad, and the intercourse in every respect limited, men are deprived of important incentives to exertion. The husbandman has little inducement to cultivate new land, or to improve his method of tillage, because the expense of transporting his produce to market will consume his profits. The mechanic and manufacturer, for the same reasons, have no motive for enlarging their operations, and hence, the community are but partially supplied with articles of convenience and luxury. Cheap and rapid transportation, by lessening the cost of commodities, and enabling us to carry to market those of a perishable nature, increases the number of consumers, and thus multiplies the enjoyments, while it stimulates the industry and enterprise, of men. It will generally be found, that nations improve, more or less rapidly, in proportion to the facilities which they enjoy for foreign and inland commerce. The remarks which we have to offer, on this subject, will naturally arrange themselves under the heads of I. The moving power employed in transportation; II. The vehicles; III. The roads. We shall endeavor to point out the respective adrantages and disadrantages of the different linds of locomotion, and thus enable the reader to judge of their relative economy; convenience, \&c.

I. We are to speak of the moving pouer employed 
in transportation. The first, and generally the only, power, employed in a rude state of society, is that of a man carrying a load. We have already, in a former Chapter, said something of its disadvantages. It is, of all modes of transport, the most slow, expensive, and inconrenient. A man on foot could carry but about twenty-eight pounds from Albany to New York in nine days. $\perp$ stagecoach can earry two or more tons, orer the same road, in two days; and a steam-boat a much greater quantity in less than twelve hours; so that, for all purposes of trade and intercourse, Albany is brought, by stagecoach, within a few miles of New York, compared with the rate on foot. Indeed, a package is now carried from New York to Albany as cheaply as it can be transported, on the back of a porter, from one part of Albany to another. "There can be no doubt, therefore, of the great advantuges which horse-power has over liuman force. Nor is there more doubt of the superiority of wind and steam power over that of the horse. Where animals are used, they must, besides the load which they earry, move the weight of their own body, and a great portion of their strength is thus employed. This portion, too, is found to increase, at a rapid rate, with the relocity; so that, beyond a moderate limit, advantage is lost, with every increase of speed; and at certain rates, which are by no means high, all useful effects disappear,- the whole power of the animal being expended in transporting himself. In the steansengine, on the contrary, speed does not diminish the efficiency of the moving power. A given quantity of steam, whether produced and expended slowly or quickly, will cost the sane sum, and will perform nearly the same work. Whence it appears, that, with no greater expense than would be requisite, if we used horses, to secure a very moderate degree of speed, we ean, by using steam, attain a rapidity greater than is ever attained by liorses in dranght. It is also worthy of remark, that, in a populous country, where the means of subsistence are dear, an immense quantity of food is 
consumed by horses. It is computed, that there are about a million of horses emplored in Great Britain, in the transport of passengers and goods; and that, to support each horse requires ąs much land, as would, on an arerage, support eight men.

Now, if this quantity of animal power were displaced by steam-engines, and the means of transport were drawn from the bowels of the earth, instead of being raised upon its surface, then, supposing the above calculations correct, land sufficient for the support of an additional population of eight millions would become at once arailable for that purpose; or, what amounts to the same thing, the means of support, for the present population, would be increased about one third. It ought not to be forgotten, howerer, that there are certain situations, as we shall see hereafter, in which steam-power cannot be introduced, and where the power of the horse, therefore, must still be emplored.-We proceed now to consider,

II. Vehicles used in Tiansportation.-The earliest and simplest mode of convering goods and passengers, as we have remarked, is to convey them by main strength. This mode is still practised, in some parts of the East; but it has been sticceeded, in more cirilized countries, by rehicles moving on land or water. An animal, which cannot carry more than three hundred pounds, will draw eight times that amount in a cart, over a good road, and fiftr times that amount, if placed in a boat on a canal. The most important object, to be attended to in the construction of these rehicles, is, to diminish resistance. On land, this resistance arises from friction between the moring body and the surface of the road. On water, it arises from the mass of fluid lying immediately before the boat. which must be pushed out of the way as the boat advances.

Theel Carriages.-1. Tarious expedients have been recommended, for lessening the friction of solids moring over each other. The effect of these expedients may be inferred, from the following experiment, which 
has been made upon a block of squared stone, weighing one thousand and eighty pounds.

a In order to drag this stone along the floor of the quarry, roughly chiseled, it required a force equal to seven hundred and fifty-eight pounds;

6. In order to put it in motion, when it was placed on rollers of three inches in diameter, it required but thirty-four ;

c. To draw it on these rollers, over a wooden floor, it required twenty-eight.

When the stone was mounted on a wooden platform, and the same rollers placed between that and a plank floor, it required twenty-two pounds; from which it appears, that, in the first instance, the force necessary to move the stone was nearly two thirds of its whole weight; whereas, in the last ease, it was only one fiftieth,-making the same force thirty-fire times more effectire, in one case, than it was in the other, to say nothing now of the effect of smooth surfaces. Hence we see the great advantage which is obtained, by substituting a rolling motion for a sliding one. This advantage is greatest where the rollers are separated from the heavy body to be moved, and are not constrained, as in the common wagon or carriage, to move round a fixed axis: as when rollers are placed under a house to be moved. In the wheels used for carriages, the conversion of sliding into rolling is less complete, but is still of great advantage. The friction, in that case, is transferred from the surface of the road to the centre of the wheel, or rather to the place of contact between the axletree and the box of the whecl, and is of course diminished, in the proportion of the diameter of the axletree to the diameter of the wheel. The rolling surfaces, also, being kept polished, and besmeared with some unetuous substance, are in the best possible condition to diminish fribtion. Moreover, when the wheel strikes against any abrupt obstacle in the road, such as a stone, it is converted into a lever, for lifting the load over the resisting object. If an $20 \%$ 
obstacle, eight or ten inches in height, were presented to the body of a carriage not supplied with wheels, it would stop its progress, or subject it to such riolence, as would endanger its safetr. But in the action of the wheel, the load is lifted, and its centre of gravity passes over, in the direction of an easy arc, (the obstacle. representing the height of an inclined plane, along which this centre of gravity moves.) In short, the difference in performing the same journey of a mile, by a sledge and a wheel carriage, is, that while the former rubs orer every roughness in the road, and is jolted by every irregularity, the rubbing part of the latter, the axle, glides very slowly orer a smooth oiled surface in a gently waving line. "It is stated, by Dr. Arnott, that the resistance is thus reduced to the one hundredth part of what it is in the sledge.

2. It must be obrious, from what we have said of the advantage gained by wheels, that those of a large size are in every respect preferable to small ones. They occasion less friction, and surmount obstacles more easily; do not sink so far into holes and other depressions; and their less frequent revolutions cause less wear to the wheels and less strain to the spokes.

It must be remarked, however, that, in carriages drawn by animals, the diameter of the wheels must be limited by the direction of the draught. The draught is exerted most directly; and of course most powerfully, when its line is nearly horizontal. Hence, the axle should nerer be higher than the horse's breast; and in practice, it is generally found expedient to have the point of draught a little lower. The reasons for this are, that, when a horse draws, since he does it principally by his weight, he naturally leans forward. to depress his breast; and he also exerts a greater force, in proportion as the line of draught passes near the fulcrum, which is in his hind feet. Moreover, when he draws obliquely upward, a part of his force is employed in lessening the pressure of the load on the ground, and in diminishing the draught. 
3. The reader has probably observed, that wheels are generally dished, to use the term of mechanics,- that is, are made with spokes inclined inwards. The principal advantage of this form is, that when the carriage inclines, the lower spolie becomes rertical, and thus has the greatest strength at the moment when the strain is greatest.

4. The fore wheels are made smaller than the lind ones, simply for the convenience of turning. In every other respect, the plan is disadrantageous, and is therefore abandoned on rail-roads. The notion, that the higher wheels, belind, help to push forward the lower ones, before, is without any foundation.

5. There has been much controversy, respecting the comparative utility of wheels having a broad or a narrow circumference. In opposition to broad wheels it has been justly alleged, that they are hearier than narrow ones, more expensive, and necessarily include in their path a greater number of obstacles. These disadvantages seem to be more than counterbalanced, however, in ordinary roads, by the ease with which they pass over rut holes; the less depth to which they sink in a soft road; and, above all, by their use in preserving and improving the road.

6. The only other point, to which we shall attend, is, the use of springs. These were originally introduced merely for the confort of the passenger, or to prevent the violent jolting of the load. It has been since found, that they are of no inconsiderable use, in diminishing the labor of draught. They lessen the shock which the animal experienees when the wheel suddenly strikes an obstacle; allow the wheel to rise, without lifting the whole load; and carry forward this load, by its own inertia, in a soft and steady advance.

Tessels.-Owing to the facility with which particles of a liquid move among themselves, the water, which heaps up before a vessel moving through it, will easily be displaced: hence it is found, that, with moderate velocity, bodies can be moved throngh water with much 
less force, than is requisite to move the same bodies on land. The resistance may be diminished, by giving a proper form to the ressel, as will appear from the following considerations. Suppose an oblong square box; as Fig. $41, \mathrm{~A} \mathrm{~B} \mathrm{C} \mathrm{D,} \mathrm{to} \mathrm{more} \mathrm{through} \mathrm{the} \mathrm{water} \mathrm{in} \mathrm{the}$

Fig. 41 .

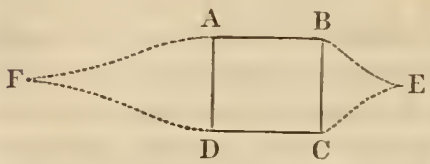
direction of its length, the pressure will be increased before and diminished behind, the water being heaped up just before the box, and depressed behind it, this effect increasing rapidly; as the velocity becomes greater. It is obvious, therefore, that the vessel will be resisted and retarded, by what is equiralent to two forees, namely, the increased pressure before, and the diminished pressure behind; and if we suppose these two to be equal, the resistance will eridently be just double what would be occasioned by the eleration of the water at the anterior extrenity. Now, this want of pressure behind may be obriated, by attaching to the hinder part of the box a tapering, or wedged-shaped, stem, A F D, which resembles, as nearly as possible, the cavity left in the water by the advancing body. This should be longer or shorter, in proportion as the velocity of the proposed ressel is intended to be great or small.

With respect to the resistance before the moring body, it is to be remarked, that the most of the accumulated water divides and passes off by the sides; an operation which will be assisted very much, if the shape of the bow be also like a wedge. Another reason why it should take this shape is, that, besides the water which passes off laterally, there is, when the moring body is square at the bow, a certain quantity of what is ealled dead water, pushed along in advance of it, nearly in the same manner as if it were a part of the body itself. It is evidently advantageous to occupy the place of this dead water with a bow, B E C, shaped, as nearly as possible, like it, and which must be lengthened, of 
course, in proportion to the velocity which we wish to gain. These observations will be sufficient to show the importance of constructing vessels very long, in proportion to their breadth; especially if they are required to be fist sailers. With these remarks respecting vehicles, we proceed to consider, in the third place,

III. Roads.-Comprehending, under this head, all routes which are used for the conveyance of goods and passengers, whether by land or by water, we propose to consider the relative advantages of land and water conveyance, and afterwards to compare some of the land-roads nost highly approved at the present day.

1. In the case of small velocities, water-conveyance has great adrantages over that of land. . It has becn ascertained, by experiments, that a lorse, moving at the rate of three miles an hour, will dray, on a canal, eight times as much as he can draw, at the same rate, on the smoothest rail-road; and since the resistance on a canal, owing to its being narrow and shallow, is greater than in the open sea, it follows, that in large rivers and on the ocean the relative gain of power is still greater. As we lave intimated, however, the superiority of water-conveyance exists only in the case of small velocities. A ressel, moving through water at the rate of three miles an hour, has to displace a certain quantity of water. If it moved at twice that relocity, or six miles an hour, it would have to displace twice as much water, and of course would require twice as much force to move it. But, in addition to this, owing to the increased speed of the boat, it must displace the water much more rapidly, and therefore must strike it with much greater force. In the çase mentioned above, the force, on this account alone, would lave to be doubled; and there fore, owing to both causes, namely, the greater quantity to be moved, and the greater force requisite to move it fast enough, the moving power must be quadrupled, in order to have the velocity doubled: and, for the same reason, it must be increased nine times, in order 
to have the velocity increased three times. Generally, the resistance to a body moving in water, and of course the power necessary to move it, increases, as the square of the velocity. It follows, therefore, that, in the case of bodies moving at the rate of nine miles an hour, the rail-road has some advantages over any conveyance by water; and with higher velocities, it has a still greater advantage, which increases very fast, in proportion to the velocity. Its adrantages orer a canal are still greater, in such case, for two reasons: first the resistance increases faster in proportion to the velocity, in a canal, than it does in a broad river, or in the open sea, owing to the obstruetions which the bottom presents to the displacing of the water; and secondly, on a canal, a velocity greater than four or five miles occasions such injury to the banks, by the agitation of the water, that it is inadmissible.

Hence we infer, that, in the case of velocities greater than six or eight miles, the rail-road is cheaper than the canal: whereas, with velocities of from two to four miles, the canal must always be the cheaper. In estimating the relative expense of different kinds of conveyance, however, account must be taken of the original cost of construction, and also of the capabilities of the route for employing the rarious moring powers. Thus, the original expense of a canal is materially greater than that of a rail-road: and, at the same time, no power, but that of horses, has yet been employed in moving boats upon it. Rivers have an advantage over either; inasmuch as they originally cost nothing, and admit the use, not only of steam-power, but also of winds and currents. On the other hand, however, it should be considered, that, in our climate, the navigation of both rivers and canals must be suspended, for several weeks or months during the Winter season.

2. In considering the different kinds of land-conveyance, and their relative advantages, we have only room to notice the two most prominent roads now in use, and which are, at present, the subject of frequent compar- 
ison, namely, McAdari and other stone roads, and Rail-roads. After a variety of experiments, it scems pretty well ascertained, that the power necessary to draw or impel a load, on a horizontal McAclam road, is at least eight times as great, as would be required to more the same load, on a level rail-road. It is obvious, therefore, that when a rail-road is level, it must have important advantages over the best road which can be formed of stone. The force of tracticn or impulsion, in such case, is but about the two hundred and fortieth part of the load drawn. When the level changes, however, the force of traction requisite increases, very rapidly. For example, if the road rises one foot in two hundred and forty, the tendency, from gravity, of the load to descend, would just equal the force previously necessary to draw or impel it on a level; so that the force of traction would liave to be doubled. 'To carry it up a planc, rising onc foot in a hundred and twenty, the moving power must be trebled; and quadrupled, to carry it up a plane, rising one foot in eighty.

From this, it is obvious, that the agent employed as a propelling power, on a rail-road having inclinations on it, must be susceptible of varying its energies within very wide limits: and this is one of the greatest practical difficulties with which the rail-road system has to contend. On a stone road, the increase in the power required by an ascent is absolutely just as great, as would be required by the same ascent on a rail-road; but not relatively so great: for on a stone road, the power requisite, even on a level, is so considerable, that the increase caused by an elevation is no material addition; whereas, on a level rail-road, the power of traction is so inconsiderable, that the increase produced by the. smallest inclination is severely felt.

This great variation, which is required in the propelling power used in rail-roads not level, has suggested the employment of stationary engines, at the principal points of elevation. As this, however, is expensive and inconvenient, another expedient proposed is, to main- 
tain a perfect level in the construction of the road. To effect this object requires, in most cases, a very large expenditure of capital. The great expense of construction, under any circumstances, renders it necessary that the line, connecting the principal points of intercourse, should be as short as possible. Hence arises the necessity of deriating very little from a straight course. Valleys must therefore be traversed by enbankments or viaducts; hills intersected by artificial chasms. A turnpike-road, on the other hand, may bc carried in. a winding course through an undulating country, avoiding hills of great acclivity, and, though the length be increased, yet the expenditure of moving power will be diminished.

Of the changes which have taken place in the state of society during the last century, not a few are to be attributed to the improved state of communication, both by land and water. Among the ancients, no nation seems to have appreciated the importance of having good roads. The Romans constructed them on a magnificent scale, for military purposes; and they derived from them, without doubt, rery important, though incidental, advantages, of a commercial and social kind. But even in that country, the ordinary facilities for trarelling and transport were rastly inferior to those which exist at the present day. Cicero spealis of a messenger, who was forty-seven days in, going from Rome to his government in Cilicia, in Asia Minor, a distance, which could be easily traversed, now, in less than a quarter of the time. To carry letters from Rome to Gibraltar then required a period of forty dars. In 1839 , travellers came from London to Niagara Falls in sixteen dars ; and, in 1840, from Liverpool to Boston in twelve days. The state of the roads in England, as late as the reign of Elizabeth, may be inferred from the following fact, recorded in the despatches of La Mothe Fenelon, who was at the time residing in London, as French ambassador. Intelligence of a rebellion, which broke out in Yorkshire, on the fifteenth of Norember, did not 
reach London till seven days after. 'The same distance is now traversed, by coach, over the common road, in twenty-four hours.*

It is impossible, in a work like the present, to specify all the consequences which flow from opening and multiplying the channels for human business and intercourse. Distant villages and provinces are brought nearer the capital. Nations, that were formerly strangers, and gazed at each other with coldness and suspicion, are now, by the constant and familiar intercourse of their citizens, almost merged into one. Misapprehensions, founded in ignorance and prejudice, are succecded by the interchange of fricndly offices, and active commerce. $\dagger$ Vast regions, not many years since sterile and neglected, have been transformed, as if by some magic influence, into cultivated ficlds and smiling landscapes. Of the powerful influence, which the opening of good roads has in awakening enterprise and improving the condition of a people, the following are striking, but by no means solitary, examples.

"In the Highlands of Scotland, at the beginning of the present century; the communication from one district to another was attended with such difficulty and danger, that some of the counties were excused from sending jurors to the circuit, to assist in the administration of justice. The poor people inhabiting these districts were almost entircly cut off from intercourse with the rest of mankind. The Highlands were of less advantage to the British empire, than the most distant colony. Parliament resolved to remedy the evil ; and accordingIy, from 1802 to 1817 , the sum of two hundred thousand pounds was laid out, in making roads and bridges in these mountainous districts. Mark the important consequences to the people of the Highlands, as described by Mr. 'Telford, the engineer of the roads.

"In these works, and in the Caledonian canal, about

$$
\begin{aligned}
& \text { *ee Appendix, IX. } \\
& \text { + See Appendix, X. }
\end{aligned}
$$


three thousand two hundred men have been aunually employed. At first, they could scarcely work at all; they were totally unacquainted with labor; they could not use the tools; but they have since become excellent laborers; of that number, we consider that one fourth left us annually, taught to work. 'These works may be considered in the light of a working academy, from which eight hundred have annually departed, improved workmen. These men have either returned to their native districts, haring had the experience of using the most perfect sorts of tools and utensils, (which alone cannot be considered as less than ten per cent. on any labor,) or they have been usefully disseminated throughout the country. Since these roads were made accessible, wheelwrights and cartwrights have been established, the plough has been introduced, and improved tools and utensils are used. The plough was not previously used in general: in the interior and mountainous parts, they frequently used crooked sticks, with iron on them, drawn or pushed along. The moral habits of the great mass of the working classes are changed; they see that they may depend on their own exertions for support; this goes on silently, and is scarcely perceived, until apparent by the results. I consider these improvements some of the greatest blessings ever conferred on any country. About two hundred thousand pounds have been granted, in fifteen years. It has been the means of advancing the country at least one hundred years." There are many parts of Ireland which sustain the same miseries and inconveniences from the want of roads, as the Highlands of Scotland did at the beginning of the present century. In 1823, Mr. Nimmo, the engineer, stated to Parliament, that the fertile plains of Limerick, Cork, and Kerry, were separated from each other by a deserted country, presenting an impassable barrier between them. This country was the retreat of smugglers, robbers, and culprits of every description. According to another engineer, Mr. Griffith, this tract, in 1824, was a wild, neglected, and deserted, 
country, without roads, culture, or civilization. 'The government ordered roads to be made through this barren district. In 1329 , in less than five years after the commencement of the roads, Mr. Griffith thus describes the change which had been produced: "A rery considerable improvement has already taken place in the vicinity of the roads, both in the industry of the inhabitants and the appearance of the country. At the commencement of the works, the people flocked into them, secking employment, at any rate; their looks haggard; their clothing wretelied; they rareiy possessed any tools or implements, beyond a small, ill-shaped spade; and nearly the whole face of the country was unimproved. Since the completion of the roads, rapid strides have been made; upwards of sixty new limekilns have been built; carts, ploughs, harrows, and improved implements, have become common; new houses of a better class have been built, new enclosures made, * and the country has become perfectly tranquil, and exlibits a scene of industry and exertion, at once pleasing and remarkable. A large portion of the money received for labor has been husbanded with care, laid out in building substantial houses, and in the purchase of stock and agriculumal implements; and numerous examples might be shown, of poor laborers, possessing neither money, houses, nor lands, when first employed, who, in the past year, have been enabled to talie farms, build houses, and stock their lands."

"How has the expedition of steam-boat conveyance" says Gordon "increased the productive industry and happiness of the land? It has brought the Scoteh farmer's cattle, fat and fresh, to the London butcher. It lias brought the cotton manufacturer of Dundec nearer to London than the manufacturer at Manchester is. The northern producer and the southern consumer are closer together. Our notions of space, despatch, and distance, have been completely altered. Instead of measuring by miles, we compute by hours. Dublin is brought within eighty hours of London, instead of be- 
ing sixteen days distant. Edinburgh is within forty hours of London, instead of being eight days distant: but we cannot enumerate the various radiating lines to which London is the centre. These lines have all been shortened, at least one half, and the energies of the kingdom are thus more compacted and concentrated."

Until within a very recent period, the use of steam has been confined to the navigation of rivers and bays, or, at most, to sheltered seas, at no great distance from land. But now, steam-ships traverse the broad Atlantic, with a confidence and safety, equal and even superior to that of the best ships mored by the winds. Communication between the old and new world is thus rendered not only frequent and rapid, but regular. The royal mail steam-ships pass in each direction between Liverpool and Boston erery month, (and, after the year 1840, they will go twice, monthly, with an exactness

- in the time of departure, and almost in that of arrival, equal to that of the mail between two contiguous towns. A similar sysiem of mail communication is established from England to the West-India Islands and South America, and also to many parts of the Eastern continent, especially to every part of the British possessions. By the orerland mail from India, which is conveyed by steamboats from Bombay to Suez, and from Alexandria to Europe, intelligence is received in England in a little more than two months, and in this country in three months, from its date in Bombay.

Recent improvements in rail-roads and locomotive engines have, in like manner, added greatly to the speed and comfort of inland travelling. It is within the recollection of persons now living, when the journey from Boston to New York, with the best facilities of the time, occupied six days of diligent travelling, and the first line of stagecoaches, establishcd at a somewhat later period, occupied four entire days. Now, the same distance is traversed, by several routes, in from twelve to fifteen hours. A train of cars arrives daily at Norwich, via Worcester, from Boston, a distance of one hundred 
and four miles, in four and a half hours, and the passilge from Norwich to New York is completed in about eight hours. The passage by the way of Providence and Stonington is accomplished with equal speed.

The same rapidity of communication by rail-road is extended from Boston into New Hampshire; to Portsmouth, by the way of Salem and Newburyport; to Lxeter, by the way of Andover ; and to Nashua, by the way of Lowell; and each line of road is likely, at no great distance of time, to be still further extended. The Western rail-road is in active operation from Boston to Springfield, on Connecticut river, and will soon be finished to Albany, New York; where it will connect itself with a series of rail-roads, much of which is completerl and the remainder nearly so, to Buffalo. So that it is confidently predicted, that, within a very few years, there will be a rapid steam communication, nearly all by rail-roads, between Boston, on the northeastern Atlantic coast, and St. Louis, on the Mississippi river. Almost every other part of the United States is in like manner traversed by rail-roads, either finished or in progress. From New York to Philadelphia, as well as extensively in the interior of Pennsylrania; from Philadelphia to Baltimore and Washington; and from these two cities to Richmond, Virginia, and thence to Charleston, South Carolina, and Savannah, in Georgia: and from several of the $A$ tlantic cities to the valley of the Ohio and Mississippi; the same, or nearly the same, facilities for swift and easy communication are found; or are in a state of active preparation. The journey from New Orleans to Boston is now made in about one fourth of the time, and with less than one tenth of the fatigue and risk, that it required only a very few years ago.

Not only are the facilities for travelling, and for the conveyance of information and of merchandise, steadily increasing, by the rapid extension of the roads themselves, but the improvements, which are made in their construction, and in that of the locomotive engines and 
cars, add constantly to their speed, as well as to their safety and comfort. 'Two or' three years since, fiftecn miles an hour was thought exceedingly rapid travelling; now, a rate of more than twenty miles an lour is maintained, habitually, on many roads in this country; and on the London and Birmingham rail-road, one hundred and twêlye miles, they travel regularly at the rate of twenty-three or twenty-four miles an hour. An express has been carried from Worcester to Boston, forty-five miles, at the rate of thirty miles an hour; and on the Great Western rail-road in England, expresses have been carried at the rate of sixty miles, and it is reported, cren at the rate of serenty-eight miles, an hour.

It is not improbable that considerable additions will also be made, at no great distance of time, to the speed of steam-boats. Some recent experiments, with Mr. Smith's Archimedean Screw, and with Captain Ericson's Propeller, seem to promise great advantages, both in respect to the speed, and to the safety and facility of management, of steam-ressels.

\section{CHAP'TER XIV.}

THE PROGRESS OF THE ARTS.

Is treating of the Arts, we have already made some remarks on the improrements which they have severally undergone, and the influence of these improvements, in augmenting the physical, and even the intellectual, enjoyments of mankind. It would be interesting, to trace these progressive improvements more accurately, from step to step; to show in what manner, and at what times, they arose; and to surrey the comparative amount of domestic and personal comfort which has peen enjoyed among civilized nations, at difierent periods of the world. 'The steps, by which man has thus gradually risen to a dominion over Nature, form one 
of the most interesting, and, at the same time, one of the most neglected, subjects of history. Dazzled by the splendor of courts, and by the pomp and perils of war, historians have generally lost sight of the most permanent and powerful causes of human welfare. 'Their works, too often, have been but scandalous memoirs; memoirs of the crimes and follies of the great, and of the subserviency and degradation of the multitude. With how much more of profit and interest should we peruse them, if they conducterl us into the habitations and assemblies of the people; if they made us acquainted with the customs, employments, and mode of life, prevailing there; if, by describing their furniture, implements, and habits of living, they introduced us, as it were, into their presence, and enabled us to estimate their knowledge of the arts. We know, indeed, no literary enterprise, which promises more for its author and the public, than what may be termed a Material History of our race, - a history, which, from the rich materials seattered through the poets and annalists of former ages, should draw a connected picture of civilized life, as that life has been varied, and, from age to age, improied, by the useful arts. Such a work would disclose the powerful influence which these arts exert, not only on the physical, but also on the moral and intellectual well-being of man. It would show, that civilization is the work, not of music or of playing on the flute, as the Athenian hero said, but of that $h_{n}$ dustry, which turns a small city into a great one. It would bring, also, into broad relief, the agency which Knowledge exerts, in augmenting human power and happiness; and would enable us to contrast our own condition, in these respects, with that of our distant ancestors. It would show how modern civilization has been modified by the industrious orders of society, and would enforce, with new solemnity and emphasis, the nomentous truth, that on their intelligence and virtue depend the best interests of mankind. Referring the reader, for some details on this subject, to an article in 
the Appendix,* I shall in this place content nyselt with pointing out what I conceive to be the leading feature of modern, as distinguished from ancient, art, and suggesting some of the consequences, to which the change has given rise.

The leading feature, which has characterized modern improvements in art, especially within the last century, is, the substitution of intelligence for mere physical force; the poucer of knouled ge for the power of muscle. The ancients were comparatively ignorant of the laws of Nature. They knew too little, either of the properties of bodies, or of the laws of motion, to accomplish much by machinery or artificial processes. Hence their reliance was placed mainly upon mere strength. Whaterer could be effected by the patient industry of indiriduals, or by the combined force of multitudes, was effected by them; and accordingly their temples, arches, and military works still stand, unrivalled monuments of munificence and patient toil. But these very works were deficient in many of the conreniences which are possessed by the humblest modern edifices; and were reared by laborers who lived in a style, compared with which, that of the modern laborer is one of splendor and opulence. In modern times, the nature of inanimate forces has been carefully studied. Mechanical contrivances, to adapt them to useful purposes, have been multiplied with astonishing rapidity; and, availing ourselves of these, we now attain our ends, not so much by the mere strength of our bodies, as by the skill and resources of our minds. The ancients, unable to supply the evermultiplying wants of our physical nature, inculcated the necessity of diminishing these wants, and practising a rigid self-denial. The moderns, on the contrary, believing that there is no limit to the powers of the ratural world, nor of man's inventive genius, rather invite and create new wants, that they may devise the means of a prompt and cheap supply. In one word;

$$
\text { * See Appendir, VT. }
$$


ancient art was the offspring of necessity; grew up from random trials and experiments; confined its operations to a narrow circle; and was cncumbered by many absurd and unnecessary details. Modern art, on the other hand, is the oftspring of science, and, under its guidance, has sought out the shortest and simplest route to its ends; pushed its labors into every department of the material world; and reduced to something like order the processes in every branch of human industry.

What have been the effects of this change? 1. The first onc entitled to notice is, the diminished respect which is every where felt for mere physical power, and the increased regard which is paid to intellect and knowledge. The time was, when individuals were rated very much according to their bodily prowess, and when nations rested their claims to glory and preeminence almost exclusively on the number and hardihood of their soldier-subjects. But in this age, it is far otherwise. Even in war, success is achieved, now, far more by science and skill than by the mere physical force of armies. In the various pursuits of industry, as well as in the learned professions, ascendency is procured entirely by talents and learning. No matter how poor and contemptible in his outward presence, or how deficient in muscular strength, the lawyer or the artist, who excels in the knowledge which pertains to his profession, and in the power of applying that knowledge, promptly and skilfully, to each new occasion as it arises, will most assuredly excel in the acquisition of wealth, fame, and influence. It has been true, in every age of the world, that knowledge is power; but never was this so empliatically true, as at present. In proportion as the human mind is enlightened, it learns its own dignity; discovers the magic influence conferred by science on its possessor; and comes to rate, at something like their real value, those humble attributes which it possesses in common with the brutes.

2. Another effect of this application of seience to the 
useful arts, and one kindred to that first mentioned, is, the more thorough and skilful combination of theory with practice, in other departments of life. It is a striking, and by some has been regarded as the essential, characteristic of this arge, that we view science and experience together as parts of one whole, and strive to make them move side by side. We employ experience to verify and correct the deductions of theory, and theory again to enlarge and systematize the observations of experience. But down to the present time, these two interests have lived apart; hare taken different routes; have been unknown to each other; or, if not unknown, have rarely met in order to cöoperate. When, for example, general principles or doctrines have at any time proposed to intermeddle with the affairs of government, they have rarely been able, says Guizot, to effect it, "except under the appearance and by the aid of fanaticism. On the one side, have been mere theorists, —enthusiasts, who would direct every thing according to abstract notions; on the other, men ignorant of all great and comprehensive principles,experimentalists, whose only guide was expediency. This state of things is happily drawing to a close. The world is less ready than it once was, to agitate for the sake of some abstract principle, some fanciful theory, some Utopian government, which can only exist in the imagination of the enthusiast; but, on the other hand, it is by no means disposed to put up with practical abuses and oppressions, however farored by prescription and cxpediency, where they are opposed to the just principles and the legitimate end of government. To insure respect and confidence now, statesmen,-nor they only, but all who in any department undertake to direct important interests,-must unite theory and practice. They must understand and acknowledge the influence of both. They must regard, as well principles as facts; must respect both truth and necessity; must shun, on one hand, the blind pride of the fanatical theorist, and, on the other, the no less blind pride of the libertine 
practician." To this better state of things, which is observable not only in matters of government, but also in education, in the labors of practical benevolence, in the concerns of domestic and public cconomy, various causes have conduced. But to my mind, one of the main, if not the main, cause of this improvement, will be found in the example, which, after the publication of the 'Norum Organum,'* was so early set, of blending physical seience with the labors of industry. The immense advantages, as well to philosophy as to practical life, which resulted from this union, could hardly have been lost on men in other pursuits. But add to this, the habits, which were thus formed, of considering every subject in comnexion with all the various circumstances and principles that affect it; of so calculat ing, combining, and opposing them, that, while the everlasting principle was placed boldly and prominently forward, so as not to be mistaken, care was also taken, that it should not be endangered; that its progress should not be retarded by a negligent or rash estimate of the circumstances which oppose it,-habits which would naturally be transferred to other pursuits, and thus become the usage and spirit of the investigating and reflecting world. + t

3. Another eflect of this change in the arts is, to render them more respectable. Among the ancients, the various handicrafts were thought too degrading and servile, to be practised by any save slaves and women. The processes were performed, as we liave already said, with little regard to principles; and when an improvement was made, it was regarded as a sort of mystery or charm, to be concealed from the vulgar eye, and practised only by adepts. Gradually, however, as war engrossed less attention, and a more decicled taste for physical conveniences and luxuries began to prevail,

* $\Lambda$ work by Lord Bacon, entitled, 'Norum Organum Scientiarum,' or a new method of employing the reasoning faculies in the pursuit of truth.

+See Appendix, XI. 
the useful arts rose in human estimation, and commanded the services of freemen, who formed a distinct class of society, and exercised considerable political influence. It was not, however, till within the past century, that these arts began to occupy their proper place. During this period, science has come forth from the cloisters in which she had been previously buried. Recognising the great truth, first taught by Bacon, that "the end of all science is to enrich human life witl useful inventions and arts," she has employed herself in studying and improving the processes of the shop and the manufactory. The finest minds, in the most elevated classes of society, think it no degradation, now, to be employed in superintending such operations. To have at their control the mighty and wonder-working energies of Nature is, they think, as high a prerogative, as to wield a disputed and imperfect sway over their fellowmen. Engaged in contributing, in no humble degree, to the power and resources of their country, in creating and diffusing the means of individual enjoyment, and in enlarging the dominion of their race over the world of matter, they think themselves entitled (and justly, too) to take rank with the members of any other profession. It should not be omitted, here, that, as a class, the mechanics and manufacturers hold the balance between other important interests; and that, in the history of this country, they have ever been found exereising a eommanding influence in favor of an independent, united, and constitutional, government.

4. Another efieet of the improvements, which have taken place in the useful arts, is one to which we have often adverted, already ; that is, they greatly increase the physical enjoyments of mankind. And this effect is by no means to be despised.* The happiness of a

* It is not unusual, even now, - formerly, it was very customary, to regard an increase of comforts as indicative of effeminacy, or as tending to it. "A story is told of a Highland chief, Sir Evan Cameron, that himself and a party of his followers being benighted, and 
being, constituted as man is, depends not a little on his food, raiment, furniture, implements, \&e. When these are abundant, and of good quality, they not only satisfy the cravings of appetite, but serve, also, to remove many temptations to sensuality and crime; afford leisure for intellectual improvenent ; and, by exercising thought, and gratifying taste, tend to refine and exalt the whole man. IIfnce it becomes an object of high importance to secure, for the mass of a people, the greatest possible amount of physical comforts, provided they are the fruit of their own industry and intelligence; and this lias been one of the most signal benefits conferred on mankind by modern art. One cannot contrast the habitations, dress, and style of living, which now prevail, in this and most other countries; with those which prevailed even only fifty years since, without being astonished at the improvements which have taken place. The change is such, that, were society to deprive itself of its new luxuries and conveniences, and return to the condition in which it was at that period, it would suffer both moral and physical degradation. It is stated, for instance, by a late writer, that he can

compelled to sleep in the open air, when his son rolled up a ball of snow and laid his heid upon it for a pillow, the rough old man kicked it away, exclaining, "What, sir, are you turning efieminate?" We doubt whether Sir Evan Caneron and his men were braver than the English oflicers who fought at Waterloo; and yet many of these marched from the ball-room at Brussels, in their holyday attire, and won the battle in silk stockings. It is an old notion, that plenty of the necessaries and conveniences of life renders a nation feeble. We are told that the Carthaginian soldiers, whom Hannibal carried int) Italy, were suddenly rendered effeminate by the abundance which they found around then at Capua. The commissariat of modern nations goes upon another principle ; and belieres, that, nnless the soldier lias plenty of food and clothing, he will not fight with alacrity and steadiness. The half-starved soldiers of Henry the Fifth won the battle of Agincourt; but it was not because they were half-starved, but becanse they roused their native courage to cut their way out of the peril lyy which they were surrounded. When we hear of ancient nations being enervated by abundance, we may be sure, that the abundance was almost entirely devoured by a feiv tyrants, and that the bulk of the poor were rendered weak by destitution." Rights of Industry. 
remember when the first carpet and the first umbrella were seen in a town little more than one hundred miles from London, and that, not more than fifty-five years ago ; that in the most respectable dwellings in the country villages of England, stone or brick floors were, at that time, almost the only ones in use ; that the cottages of the peasantry were almost universally without flooring, or plaster, or ceiling ; and that, in houses where glass tumblers, earthen-ware dishes, and knives and forks, are now regarded as absolutely indispensable, they had then no drinking-cups, except those made of tin or horn; scarcely any dishes, except the wooden trencher; used, in many cases, a lock of wool as a substitute for a fork, and benches and jointstools in the place of chairs and tables.

It is little more than a century, since the ordinary state of one of the most frequented roads in England was such, that it took Prince George of Denmark, who was on his way to meet the King of Spain, near Portsmouth, six hours, to travel, by coach, a distance of nine miles; and then the coach, as the Annalist states, had to be "poised by the nimble boors of Sussex," who frequently bore it almost on their shoulders, to save it from being overturned or stuck fast in the mire.

If we go back to the reign of Elizabeth,_associated in our minds with splendid processions and gorgeous festivals; when nobles kept on foot several hundred retainers and followers; when her Majesty ransacked Europe, and eren Asia, for the materials of her wardrobe; when Burleigh counselled, and Leicester intrigued, and Raleigh planned, and Bacon, like another Moses, pointed out to scholars the way to their land of promise; and Spenser, and Sidney, and Shakspeare, poured forth the strains which still vibrate in our ears and on our hearts,-what, at that brilliant epoch, were the domestic accommodations of the people, and even of the high-born and high-bred gentry, of the land? We have all heard of the substantial breakfasts of her Majesty's maids of honor, on beef and ale: but it has 
not occurred to us, perliaps, that these materials were used, not only at that repast, but also at noonday and evening, for the simple reason, that there was nothing else for them. The favorite beverage of the sex, in our age, was then unknown. 'The regetables, which now load the tables of erery class, had not been introduced into ordinary culture; and it was only the most opulent, who could afford the luxury, even of a potato, or a radish. Teomen of the best condition subsisterl on oat and rye bread, and pottage; and not even royalty itself was indulged with what is now rarely denied to the beggar, - that is, knit lose, or stockings, while the raiment, furniture, and houses, of the most respectable commonalty, were such as the parish pauper of the nineteenth century would consider insufferable. And yet this reign was considered, by those who had known Eugland in former ones, as remarkable for its luxuries. In the discourse prefixed to Hollingshed's Chronicle, which was published in this reign, the old men are described as mourning bitterly over the degeneracy of the times. There were three things, especially, which, in their estimation, were marvellously altered for the worse, since their young days; - "The first was, the multitude of chimneys lately erected ; whereas," say they, "in our young days, there were but two or three, if so many, in most uplandish towns of the realm; the religious houses and manor houses of their lords always excepted. But each made his fire against a rere dosse in the hall where he dinerl and dressed his meat, the smoke finding its way out as it could." The second was the great alteration in lodging; "for," say they, "our fathers and onrselves have lain full oft on straw pallets, covered only with a slieet, under coverlets of dlagswaine, and a good round $\log$ under our head, as a bolster. If it were so that the father or good man of the house had a mattrass or flock bed, and thereon a sack of chaff, to rest his head upon, he thonght himself as well lodged as the lord of the town." Pillows were thought fit only for sick women: and the author himself, as we have seen 
in a former Chapter, complains most pathetically, that "nothing was then required for building houses, but oak; for," says he, "when our houses were built of willow, then we had oaken men; but now that our houses are come to be made of oak, our men are not only become willow, but a great many altogether straw."

Such was life in England, in the dars of the Reformation; and what was it, think we, in earlier and darker days, before religious and intellectual freedom gave impulse to the spirit of improrement; before the invention of the printing-press and the mariner's compass, those prime movers of civilization; when the packhorse was the only vehicle of commerce, and cloth was spun and woven, and grain was ground, and the earth tilled, and metals worked, entirely by hand? Nay, if we would measure the influence of the useful arts, we must go back to Greece; and there, even in her high and palmy state, when every grove was sacred to philosophy and the muses; when every hill top was crowned with monuments of taste and beauty, which will be the wonder of all ages; when Pericles touched with naster hand the springs of popular feeling, and wielded, at will, the fierce democracy; even there, and then, we shall meet a people, who, in the language of the learned Goguet, were little skilled in providing conveniences: who were unacquainted with the use of linen, or shocs. or stockings; whose coats had neither buttons nor button holes; who knew the use, neither of stirrups, to mount, nor of saddles, to keep themselves on horseback; who were ignorant of the art of lighting themselves by the use of wax or tallow; and had neither wind nor water mills, nor clockwork, nor telescopes, nor chemical fluxes.**

5. Another effect of these improrements in the arts is, an increased economy. When the use of artificial products was confined, in a great measure, to the rich, and but few persons were engaged in manufacturing 
them, there was little occasion to study economy. But now, when the mass of the community seek to enjoy these products, it is all important to malie them cheap; and, at the same time, such keen competition prevails, among the makers of any article, that nothing lnut the utmost economy, in conducting every part of the manufacture, will enable an individual to secure a market, and yet command an adequate profit. It has accordingly become one great aim of the artisan, in conducting his business, "to grather up the fragments, that nothing be lost." In respect to labor and time, this is accomplished by the use of machinery; by the substitution of artificial for slower natural processes; and also by a device called the division of labor, which consists in such a distribution of the sereral parts of an opcration, among workmen of different ages and capacities, that each one shall have constant occupation for all his powers, and, by being confined to the same work, shall acquire greatly-increased dexterity, while he also sares the time which would be lost in passing from one thing to another. In respect to materials, also, amazing progress has been made in economy. We seem to be approaching a time, when valuable use will be found for every thing, however vile and apparently worthless. Take rags, for example. When they have ceased to be fit corering even for the beggar, and are cast out, loaded with filth, they are carefully collected, transported as precious freight from one country to another, and, after being washed and bleached, and subjected to the operation of cutters and presses, come forth a beautiful white fabric, ready to receive and transmit to distant places or ages, the records of wisdom, or the messages of business, or the confidential breathings of friendship. So bones and offal, which have been thrown into the streets, are picked up, and carried to the sal-ammoniac factory, where, after being boiled, distilled, Ec., they yield grease for soap; an oil, which, on being burned in ciose apartments, deposits the black sont called lamplalack; and afford, at the same 
time, the carbonate of ammonia, or hartshorn, the sulphate of soda, or Glauber's salt, and lastly, sal-ammoniac, or muriate of ammonia. Horns, which are attached to hides when purchased by the tanner, are separated, sold to the makers of combs and lanterns, who cxtract combs from one part; linife handles, the tops of whips, \&c., from another ; glue, again, from another ; fat for soap, from another ; the transparent part of lanterns, from another; and, finally, by grinding down the bony substance, which remains after all these operations, they have a manure, which they sell to the farmer. It would be easy to multiply examples of this kind, to any extent. The prussiate of potash, a beautiful crystallized mineral, which is seen in the shops of the chemist, is produced from the hoofs of horses and cattle; a black dye, for the use of calico printers, is extracted from old tin kettles and worn-out coal scuttles; bread, which, though not very palatable, is still nutritious and digestible, and by no means disagreeable, has been obtained from sawdust! and linen rags, mixed with a common acid, have been made, by chemists, to yield more than their own weight of sugar.

Such are some of the effects produced by a more systematic and general application of science to the arts. They are, indeed, astonishing. Had they been predicted a century ago, the prediction would undoubtedly hare been reccired with the greatest ridicule and incredulity. But, developed as they have been, gradually, they have only taught us, that things, regarded as impossible in one generation, may become easy in the next, and that the power of man over Nature has scarcely any limit, provided he understands and respects her laws. We look back, with no little feeling of superiority, on men who lived seventy years since, before the invention of the steam-engine, spinning-jen $n y$, and power-loom. These three inventions, alone, seem to have altered the whole face of civilization, and added immeasurably to the enjoyments and resources of our race. Who shall say, that the next fifty rears 
will not bring to light yet more powerful instruments than these; and cause the men of a more favored age to look back on ours as one of comparative imbecility. Indeed, when we think of the powers which Nature may yet have in reserve for the service of man; when we think of the new combinations of machinery which his ever-fertile ingenuity may yet devise; there secms to be hardly any conceivable limit to the degree in which the average physical condition of the human family may be improved. Science las but begun her career of discovery. Occupying higher posts of observation, having more perfect instruments, improved nethods of investigation, and an immensely-augmented number of observers, her former success has only prepared her for yet more brilliant conquests. And with the habits which now prevail, among both philosophers and artisans, such conquests cannot long remain barren. Each new principle will be tried and tortured, till it yields a profit to its discoverer, and adds its share to the great sum of human blessings.

We ask, in conclusion, what part shall be taken in this work by the scholars and artisans of America? They occupy a position peculiarly favorable for enlargin this domain of the arts. In this country, there are no artificial barriers in the way of discovery or invention. Genius, here, needs no titled patron. Art is hampered by no restrictions. The mechanic need not be confined, for life, to the place of his birth, as he virtually is by the law of residence in England. He is not compelled, as on the Continent of Europe, to wait till he has gained admission to some privileged craft or corporation, before lic can be allowed to set up for himself. His energies are not paralysed by the reflection, that every profession and trade is already crowded, and that there is no demand for his talents and industry. With a vast territory, yet unpeopled, before him; his labor in such demand, that cnterprise cannot remain a week unoccupied or unrewarded; privileged to select his own profession, and to prosecute it with all the powers which the Crea- 
tor has given him; he has motives to excrtion and improvement, never before reuchsafed to the mechanical and agricultural population of any country. WVith these advantages, then, let him combine a diligent study of the principles of Nature. Let him reflect upon the laws which regulate the processes of his art, and endeavor, by every means, to enlarge his mind, and prepare it for original and independent inquiries. Let him consider that he lives and acts in the very vicinity of properties and powers yet undiscovered, but which, when once known, will affect the condition of the civilized world. Why, then, should not he aspire to the honor of first perceiving and unfolding these powers? What shall prevent him, if his mind be but enriched from the stores of science, from exchanging the humble condition of a merc laborer, for that of a teacher and benefactor to his whole race? Nothing is needed, to fit him for such a work, but the awakening influence of knowledge, the invigorating exercise of thought, and the firm purpose, that, with the permission of God, he will tread, though at an humble distance, in the footsteps of a Tranklin, a Whitney, or a Fulton.*

\section{CHAPTER XV.}

INFLUENCE OF TIE USEFUL ARTS ON NATIONAL WELFARE.

I rave frequently had occasion, in the course of this work, to illustrate the connexion between the uscful arts and individual comfort. It has appeared, that every improvement in the principles or processes of an art has resulted in a substantial addition to the aggregate physical enjoyments of mankind, and has tended to lessen the distance which divides the less affluent from the more afluent classes of society. I propose, in this 
Chapter, to discuss the influence exerted by the cultivation of the useful arts on national prosperity.

'The prosperity of a people depends, other things being equal, on the amount and lue distribution of property; since property alone gives the command, not only of physical comforts, but of linowledge, refinement, and religious privilege,-the true elements of human happiness or prosperity.

Now, the amount of property, possessed by a people, will depend on the amount of labor and slitl which they apply, in developing their natural advantages and resources. These resources have, in themsclves, no value; that is, they malic no spontaneous contributions to the wealth or prosperity of a nation. 'The soil does not, of itself, bear the requisite kind and quality of food; the mine yields up, without labor, no implements of use or articles of luxury; the forest forms itself into no conrenient and comfortable abode for human beings. There must be industry; that is, the application, by men of muscular strength and intelligence, in order to educe from these natural sources, the substances and forms which are fitted to satisfy the wants, and promote the enjoyment, of mankind. The extent to which this is done will depend, first, upon the amount of muscular effort which is applied; secondly, and much more, upon the amount of intelligence; and thirdly, upon the extent to which the natural capabilitics of the country are improved. It it with a nation, as with an individual. In proportion as there is more labor; as that labor is more skilfully directed; and as that skill and labor cöoperate with more efficient natural and artificial agents; in that proportion will there be more produced, or a greater addition be made to what is usually termed exchangeable value.

T'o give greater interest, as well as definiteness, to the discussion proposed, I shall conduct it with special reference to our own comntry. It is well linown, that there has been much difference of opinion among us, from a very early period, in respect to the relative in 
fluence and importance of agriculture, commerce, and manufactures. This difference I cannot hope to adjust, and I shall not, on this occasion, attempt to draw any comparisons. I do not propose to inquire, whether, among a people situated as ours is, agriculture or manufactures be the more productive; but simply whether, in order to the attainment of the largest prosperity, the latter be not important, as well as the former; not whether the other useful arts ought to be cultivated to the exclusion of husbandry, but whether they ought not to be carried on in conjunction with it: not whether we should forego the moral and political advantages which we derive from the preponderance in our population of a sturdy, independent yeomanry, but whether, with these advantages, we ought not to combine those of an economical and intellectual character, which might be derived from building up, on our own soil, the various useful and ornamental arts.

I. Employment.-In which of these ways, then, by neglecting or encouraging the rarious useful arts, shall we provide, most effectually, in the first place, for the productive employment of all our population. Evidently, the first element in a nation's prosperity is, to have all the people employed, and enployed productively ; to have the greatest practicable amount of muscular effort applied continually to useful labor. Now, it is evident, that, in this country especially, agriculture cannot give constant and profitable occupation to all our labor. The climate and habits of society do not permit females to participate in the labors of the field: and the domestic occupation furnished by a farm can, in the absence of spinning and weaving, (which few farmers think now of carrying on,) furnish only partial employment to the average number of females who live in the country. So with children, and persons who have become disabled from field labor, by age or disease,--they are often competent to render service, but it is service for which there is little or no demand upon a farm. Add to this, that the labors of the adult hus- 
bandman are often suspended, by the inclemency of the weather, even in Summer, and in Winter give employment to little more than half his time; and that, owing to the impossibility of introducing a perfect division of labor in farming, the robust adult is often engaged on work which might as well be performed by a child; and it will be seen, that, where agriculture, or agriculture and commerce, (for the latter employs only males, and principally adult males,) constitute the only pursuits of a people, there must be a vast amount of labor constantly unoccupied; consuming, but doing nothing to reproduce.

The various arts and manufactures furnish an obvious expedient for employing this labor, and rendering it productive. They afford occupation proportioned to every variety of capacity. "In my recent tour," says Dr. Ure, speaking of England and Scotland; "in my recent tour through the manufacturing districts, I have seen tens of thousands of old, young, and middle aged, of both sexes, many of them too feeble to get their claily bread, by any of the former modes of industry, earning abundant food, raiment, and domestic accommodations, without perspiring at a single pore, screened. mean-while, from the Summer's sun and W inter's frost, in apartments more airy and salubrious than those of the metropolis, in which our legislative and fashionable aristocracies assemble. In these spacious halls, the benignant power of steam summons around him his willing subjects, and assigns to each the regulated task; substituting, for painful muscular effort, on their part. the energies of his own gigantic arm, and demanding, in return; only attention and dexterity, to correct such little aberrations as casually occur in his workmanship." It is estimated, that, in the United States, about one fifteenth of all the persons employed in manufactories are children under twelve years; that nearly two thirds of the whole number are females; and that of the residue; a large proportion are young persons under eighteen. The Lowell manufactories alone give employment to more 
than five thousand females; and throughout the whole of New England, if we include the manufacturing carried on in private houses, we should probably find, that not less than one hundred thousand females are profitably employed by the various arts and handicrafts; of which number, but a small proportion could find work, in connexion with farming, or as domestics in cities. These females receive, on the average, two dollars a wcek, in addition to board, so that the weekly wages of one hundred thousand would amount to two hundred thousand dollars, and to ten millions four hundred thousand dollars a year: and, if to this we add the wages paid to children, who otherwise would find nothing like adequate employment, we shall have a total of not less, probably, than fifteen millions of dollars, in the form of wages, paid annually, in New England, by the mechanic and other arts, to women and children, of which, a very large proportion, probably not less than one third or one half, is clear gain.

Even in New England, however, there is still lying dormant a vast amount of industry, which might be awakened, and rendered eminently productive, by cnterprise and capital, if they were judiciously applied to the various arts, and handicrafts.

Ii. Productive Employment.-But the useful arts contribute to the productive energies of a people, not merely by affording more employment for labor; they tend, also, to render that labor more skilful and efficient. The efficiency of labor depends, of course, on the intelligence and spirit which directs it, much more than on the mere amount of muscular effort. Hence, the nation, which would develope most rapidly its resources, should aim, first of all, to awaken and enlighten mIND; to train the people to habits of active thought and investigation; to incite them to the discovery and practical application of those natural laws, which govern the operations of industry, and above all, to give them temperate and virtuous habits. Now, the cultivation, together with agriculture, of the other useful arts, pron 
duces this effect. It quickens the general intelligence of a people, and prompts them to the most productive application of their labor.

1. It does this, in the first place, by affording scope for every variety of talent and tasle. Hany minds, which would remain forever inactive, if confined to the labors of the field, might be roused to strenuous and even brilliant exertion, in the workshop or manufactory, because there they would find the peculiar employment for which they scem to have been formed.

2. In the second place, the cultivation of the useful arts promotes activity of mind, by bringing men togeth$\mathrm{er}$, inciting them to competition, and opening an indefinite career for improvement. Social as we are by nature, we are rarely roused to the exertion of all our cnergies till we are brought into contact, and in some measure into collision, with our fellow-men, and especially with those engaged in the same pursuit. This eflect is evidently attained in the various arts, especially where they are carried on in large manufactories, and attained more completcly than is practicable in the operations of agriculture. It should be considcred, too, that the parts of a process are so graduated, that there is occupation for every degree of strength, skill, and talent, so that a child, who enters a manufactory, can see open before him a perfect series of employments, ascending, regularly, from the carding room to the throstle-frame, from the throstle-frame to the office of Superintendent, Engineer, or even Proprictor, each employment calling for greater intelligence and skill than the last, and cach proportionably more lucrative and respectable. The idea of confining an individual, for life, to a single operation, is now discarded from factory labor. Instead of having to spend a long apprenticeship, before his hand and eye become sufficiently skilled for certain mechanical feats, the system of decomposing a process into its constituent parts, and embodying each part in a machine, enables him, if he be a person of common care and capacity, to take charge 
of almost any part, after a short probation. On an emergency, or when interest invites him, he can transfer his scrvices to another department, thus rarying his task, enlarging his views, and becoming gradually acquainted with erery physico-mechanical combination. Indeed, the whole atmosphere of a large manufactory is rife with an intelligent activity, which extends its influence, not only to the inmates, but to the agricultural population of the vicinity.

3. There is another way, in which the useful arts contribute to quicken and enlarge the intelligence of a people. In the operations of an art, especially of those which are most improved, men behold a most striking and constant proof of the power of knowledge, and of comprehensive thought. The province of the husbandman is apparently limited to depositing his seed. 'The clements, over which he has but little control, cause it to germinate and spring up; and there are countless influences, beyond his reach, some friendly and some adverse, which will contribute to ripen or to blight the harrest. But in the operations of a large manufactory, mind seems to hare won a perfect mastery even over the elements of Nature. The fierce torrent is made to give motion to the most delicate and nicely-adjusted mechanism. The ponderous wheel moves round, and no resistance is so mighty, but it yields; no transformation so difficult, but, with the aid of wheels, pulleys, berils, pinions, cranks, it can be effected. 'The machinery, the distribution of labor, the organization, the police,-all give evidence, that mind has been at work; that it exercises perpetual superintendence; and that it is mind which has derived its wonder working power from knowledge alone. Nowhere do we see such impressive evidence of the intimate connexion between science and industry, as in the workshop and the factory. All that has been done, to abridgc labor and improve fabrics, is the obvious fruit of knowledge and reflection. On the one hand, science has furnished principles for the arts to apply : on the other hand, 
the arts have proposed problems for scicnce to resolve; and this mutual aid and dependence have becn the means of earrying both forward, at a rate continually accelcrated. Thus, example, the most powcrful of all teachers, admonishes the workman of the necessity of intellectual cultivation. It makes him familiar, too, with the idea of improvement. It suggests that the carcer of advancement, instead of having cnded, has but begum; and tlat, if he will but avail himsclf of the power, which knowledge and reflection bestow, it may be his lot to contribute to a future, and perhaps yet more brilliant, progress of the arts. Such reflections extend from the operative mechanic to the husbandman. It is the riew of what science has done for the mechanical and chemical arts, that has awakened the desire, which now begins to prevail so extensively among farmers, for more improved and scientific methods of culture. It should be considered, too, that agriculture must be indebted to these arts for improved implements and machines; and that native arts, alone, can furnish such as are well adapted to our system of farming.

III. We have thus shown how the useful arts contribute to national prosperity, by giving more full employment to labor, and also by rendering that labor more skilful, intelligent, and therefore more productive. But, in order to give to labor the greatest possible efficiency, another condition must be complied with,-it must avail itself of all the adrantages and capabilitics which have been bestowed upon the nation by the Creator. It must adapt itself to the elimate and position ; must put in requisition whatever natural agents are at hand; must substitute automatic or animal, for human, labor; must produce for a near or a more distant market, according to the expense of transportation, the extent of demand, \&e.

Now, when we look at the physical character of our own country, we cannot but be struck with the great variety of climate, soil, and industrial capability, which 
exists within our extended borders. We have the rich bottom lands of the South, and the granite hills and sterile plains of New England. We have, at the Northeast, a soil and climate producing little but timber, grass, and Indian corn; in the Hiddle Stales, districts admirably fitted for wheat, and other grains; and at the South, rich fields and sunny skies, which ripen the orange, girc full flaror to the sugarcane, and rield, in almost boundless profusion, cotton and rice. Then we have large rivers or canals, penetrating our territory; and opening outlets for the productions of industry ; rast inlaud seas, narigable by the largest ships, and lined by thousands of miles of fertile coasts : so that now, a barrel of Hour or pork can float, I had almost said, from the furthest point in our Western interior ; or a hogshead of sugar can be carried from the extreme South, without a mile of land-carriage, and at the most trifling expense, to the remotest village of Maine. But, on the other hand, there are rast portions of country which are emphatically sequestered, having no means of cheap and easy transport to the seaboard, or to any important market. When we consider this great diversity in the allotments of life, the roice of Nature,-may we not rather say, of Proridence,-seems very clear. To the farmer on the banks of the Genesee or of the Illinois, it says, raise wheat; to the husbandman on the banks of the Merrimac or Penobscot, it says, with equal clearness, raise no wheat; the soil and climate are against you ; and you can sustain no competition with your more farored countrymen of the West. To the farmer in the interior, who has no means of easy access to marliet, it says, your soil may be propitious to wheat, but, if you would raise and sell it profitably, you must create a market for it, in your own ricinity. You cannot compete, on any other terms, with those who have choice of the best markets of the world.

Here, then, a grave question presents itself. If the inhabitant of New England, of southern New York, of the interior of Pennsylvania, cannot compete with 
his fellow-citizens of more furored districts, in raising grain, what shall he do? Shall he be content to glean a bare subsistence from the rugged or secluded soil lie tills? or shall he put out the light of his dwelling, take a last look of the home of his childhood, the grave of his fathers, the village church and schoolhouse, and commence his line of mareh towards the wilderness? 'I'o many of these men, strangers as they are to despair, fertile in expedients, aceustomed to consult the intimations of Providence, that Providence has spoken a far different language. It has pointed to the bleak hill, corered with furze, as the very place on which to rear and subsist the warm-fleeced sheep. It has pointed to the forest, on that lill's summit, rich with timber for building, and to the stream hurrying around its base, and ready to perform the labor of many human hands. It bids them look at the mineral wealth, which lies treasured in exhaustless storehouses beneath their feet; to the iron, ready to form itself into all the implements of industry and use; to the coal, fitted to fuse that iron, to clcar away its dross and foreign admixtures, and transmute it into steel; to the salt, the granite, the marble, the lead: and it has seemed to say, were all these ereated in rain? Was it the intention of the Creator, that these should forever slumber in unexplored recesses, unemployed, and useless to man? Is it well, that we should cross the ocean, to procure what can be fabricated at our own doors? Is it right, that our more privileged countrymen, who till nothing but willing and prolific fields, should insist on raising grain for $u s$, unless they are willing that we should labor for them, in return, and be compensated for our labor? Is it good economy, that our wool, and cotton, and hemp, should be transported thousands of miles, in orler to be manufactured for our own use,-being thus subjected to a double freight, of which the cost falls principally on us, and forms not less than one sixth of their whole ralue? Why was such a rast territory given us, with such a variety of natural productions, and such facilities for $2: 3^{*}$ 
transforming them into articles of use and luxury, and transporting them to any required point, but that we should carry on, within ourselves, a complete system of industry and trade, distributing employments according to local advantages, and multiplying; between the different and distant parts of our confederacy, the ties of mutual interest and dependence?

The force of such considerations is materially enhanced, by another and a somewhat different one. This country is urged to foster and encourage the useful arts, not only on account of its many natural capabilities, and its great distance from the workshops of the old world, but also on account of the peculiar benefits which would redound to us from the substitution of machinery for human labor. It is this substitution, doubtless, which has tended, more than any, and perhaps more than all other, causes, to carry forward the useful arts, and to increase the physical enjoyments of mankind. But it has been made, to a great extent, only in mechanical and manufacturing pursuits. In agriculture, there has doubtless been considerable improvement in the construction of utensils and implements, and in the substitution of animal for human porver; but hardly any thing has yet becn done towards superseding the labor of men and animals by means of inanimate forces. The consequence is, that, while in husbandry the value of human labor may, within a century, have been doubled or quadrupled, it has been increased in the cotton manufacture two hundred times; so that one workman now produces as much cotton clotl, as two hundred did, in former times; and the cloth turned off by two hundred and seventy-two thousand two hundred and ninety-seven men, in the cotton manufactories of a district in England, would have required, under the old system, the labor of sixtyseven millions of hands; that is, of a population nearly three times as great as that of the whole kingdom. It must be evident, then, that if these wonderful expedients for saving labor are beneficial, they will benefit 
that people the most, by whom they are most extensively adopted and used.

I have intimated, however, that to this country the substitution of machinery for human labor would bring peculiar advantages. It would do so for two reasons. First. Labor, in the United States is said to be more expensive than in older and more populous countries; and it las been hence inferred, that we can never compete with them in mechanical industry. But in proportion as we substitute machinery for men, we diminish this inequality of expense, and place ourselves on the same footing with England or France. Secondly. Then, again, the inanimate forces which we employ in this country are cheaper than those of England. Manufacturers, there, are obliged to use steampower, or water-power at a very high rent; whereas, in the United States, water can be commanded in almost every district, and at a low rate. This fact was assigned by Mr. Kempton, a cotton-manufacturer of Pennsylrania, who was examined, a few years since, before a conmittee of the British Parliament, on the state of manufactures in America, as one of the reasons why American cotion goods were not only competing successfully with the British, in some markets, but actually gaining ground upon and eren excluding them.* He mentioned, for example, that the annual cost of one-horse power, in the United States, would be only fiiteen dollars and a half; whereas, in England, it would be fifty-five clollars and a half,-or as one to three and a half. No advantages, corresponding with these, could be gained by the exclusive pursuit of agriculture.

'There is another consideration, which seems strongly to recommend the promotion of the useful arts in this

* Iarge quantities of American cotton fabrics are now sent to Mexico, Brazil, Sc., on our own continent, and to India, China. Java, Borneo, Sumatra, Se., as well as to the Mediteranean, on the Eastern continent. 'I'hey are cousidered to be decidedly superior to liritish goods, of the same denomination, and are afforded at a cheaper rato. 
country. It is, that by such means, and by such means only, we can render our industry independent, in a greater degree, of the caprices of foreign legislation and the vicissitudes of Eurcpean polities. Were our whole population deroted to agricultural pursuits, there would be, of eourse, a vast surplus of agricultural products, to find rent in foreign markets. Now, nothing is more uncertain than the condition in which many of these markets may be found after an interval of nine or twelve months. Should the people be engaged in war, so that they cannot eultivate the earth, or procure supplies from distant eolonies; or should their erops be cut off by drought, frost, or rermin; their ports are thrown open, eargoes of our produce are disposed of at high prices, and our farmers are stimulated to increased outlays of capital and labor. Yet nothing is more likely than that, before the next harvest, those rery ports will be sealed hermetically, the armies that we have been subsisting be converted into productive laborers, and our farmers left witlout rent for their commodities.

It is evident, that nothing ean be more prejudicial to industry, nothing better calculated to entail ruin on individuals, or paralyse generally the spirit of enterprise, than these great and sudden fluctuations. They are inseparable, howerer, from a policy which malies us dependent oil foreign customers; and they have been sxperienced in this eountry in a most striking and dissstrous degree. Hardly had we settled down under a regular government, when the disorders throughout Eu:ope, eonsequent upon the French Revolution, threw into our hands the earrying trade of several nations, as well as the business of raising grain and cattle for the subsistence of their troops, Our exports rose from nineteen millions, the amount in 1791 , to sixty-seven millions in 1796; and reached the enormous amount of one hundred and eight milions in 1807. Then, the French 'dlecrees' and British 'orders in council' fell like a blight upon our industry, and our exports fell, in a sin- 
gle year, from one hundred and eight to twenty-two millions. By the year 1811, they had mounted up again to sixty-one millions; and then came the war of 1812 , to let fall another blight. 'Then, again, in 1817 and 1818, the British ports being open to our flour, and the exports of cotton being heavy, they rose to one hundred and eighty-one millions, for those two years; and in the two next following, the British ports being shut, they fell to one hundred and forty millions; twenty-one militions of the diminution being in the value of vegetable food alone.

For these ruinous fluctuations, there would seem to be but one remedy; and that is a home-market. Foreign nations act upon the policy of supplying their own necessities, whenever they are able, and will accept our breadstufis, in exchange for their manufactures, only when necessity compels. So long, then, as we depend solely or chicfly on their markets, our industry will be subject to unnatural elevations and depressions : our trade will want that most essential of all the characteristics of health, namely, steadiness. But let one portion of our people invest, as they liave done, their capital, enterprise, and labor, in the useful arts; they become consumers, on the one hand, of grain, thus furnishing the husbandman a market, and producers, on the other hand, of the manufactures for which he wishes to exchange that grain.

In such a system of exchanges, there can be little interference from abroad; while, at home, it is evidently the interest of all parties to confine themselves to their appropriate employment, to produce the greatest possible amount of their proper commodity, and to obtain for it, in the form of useful or elegant articles, the greatest possible return. In this way, the prosperity of one part of the country becomes the prosperity of every other. Each has its peculiar capabilities and its peculiar wants. If Maine wants the cottons of Alabama, the latter wants the wool and woollens of Maine. Bread from Rochester or Baltiniore, iron and coal from 
Philadelphia, lead from St. Louis, pork from Cincinnati, travel east, and return in the shape of cotton and woollen cloths, shoes and boots, cut-glass tumblers, straw hats, \&c. These, again, are changed and interchanged to and fro, many times; and thus do we secure a vast home trade, resembling foreign trade as well in the intcrvening distances as in the nature of the exchanges; blending in one, in truth, the advantages of both, "freed from the jealousies that have frustrated, and must ever continue to frustrate, the benevolent but impracticable theories of commercial intercourse, as between distinct nations ; prosecuted both along the ocean and the highways of the interior, in vessels built by our own mechanics, navigated by our own seamen, subsisted by our own farmers, untrammelled by imposts, and without the necessity even of a customhouse, except in form." I shall have occasion, hereafter, to adrert to the relative value of this, as compared with our foreign, trade. I speak of it, now, merely as a resource against the fluctuations of the latter, and as being peculiarly calculated to develope, with regularity and profit, the hidden wealth of the nation.

There is yet another consideration, which, to my mind, pleads strongly in favor of the encouragement of the useful arts. It is the independent position which such a policy enables us to assume, with respect to foreign nations. I am by no means insensible to the ralwe of foreign commerce, and of a friendly intercourse with the various nations abroad; nor do I desire to see them in the least degree abridged. IIardly a feature of our age is more gratifying, than the pacific policy and the spirit of commercial activity which now characterize the intercourse of states. But how is it that peace is most likely to be preserved, or trade regulated upon principles of reciprocity? Is it by assuming an attitude of commercial dependence, so that, when we come to treat with a foreign power, that power shall plainly discover that we are not in a condition to prescribe, but only to accept, terms, and that she will find account 
in playing the part of dictator? There was never wiser counsel than that of Washington, when he said, that, if we would preserve peace, we must show that we are prepared for the alternative of war. So it may be said, with equal truth, that, if we would carry on a profitable trade with foreign nations, we must show them that we are prepared to do without it. As intercourse is now conducted between states, no nation can be truly independent, which has not within itself the means of fabricating clothing, and the implements of industry and defence. Of this we have had most humiliating evidence in our own history. The reader must be aware of the straits to which the army that fought the battles of the Rerolution was often reduced, for want of ammunition, clothing, \&cc. When General Washington first took command of the army lying at Cambridge, in full view of the British forces, he found, to his amazement, and to the astonishment even of the officers who had been at the station, that there was not powder enough in the whole camp for nine cartridges to a man. There were also nearly two thousand men in camp without firelocks; and, although every cxpedient was tried to procure them, it was with little effect. The New-England goveruments had none to furnish. The militia, as their terms of scrvice expired, being reluctant to part with their arms, carried them away to their homes; and, there being no establishments where they could be manufactured, General Washington had no alternative but to sit down in inaction, bearing the murmurs of his men, and the dissatisfaction of the country, in silence, lest, by assigning the true cause, he should crpose his weakness to the enemy, and see the rising hopes of his country suddenly blighted. So it was on other occasions, especially during the encampment at Valley Forge. "Such was the scarcity of blankets," says a biographer of Washington, "that many of the men were obliged to sit up all night before the fires, being without covering to protect them, while taking the ordinary refreshment of sleep ; and in numerous in- 
stances they were so scantily clad, that they could not leave their huts."

After such experience, it was not surprising that the genius of our people for the useful arts. which had often manifested itself previous to the Rerolution, but had been carefully stifled by the mother country, should be again roused; and that many efforts should have been made for the establishment of domestic industry. Whoever is familiar with the history of the States, from the peace of 1783 to the adoption of the present Constitution, (1788,) must hare observed, that, to obtain efficient protection for our native shipping and infant manufactures was one of the leading motires, especially at the North, for wishing the establishment of an energetic federal gorernment. The Constitution was no sooner ratified, than petitions flowed in to Congress from every direction,- - from Boston, from Baltimore, and from Charleston,--inroking the strons arm of the government to protect and foster the industry of the country.

These petitions were seconded by the recommendations of Washington, by the researches and admirable Report of Hamilton, and by the harmonious action of Congress. It so happened, however, that the neutral position which, through the wise policy of Washington, was taken by the new government, in regard to the wars growing out of the French Revolution, served to malie us, for the time, the carriers and producers of food for foreigners, thus absorbing our industry in agriculture and commerce. But the "French decrees' and 'British orders' fell on these interests like an avalanche, (as we have seen,) in 180 7 ; and their effect had hardly subsided, before the war of 1812 came, and surprised us without any adequate means of supplying our own wants. So depressed, for instance, was the woollen manufacture, at that period, and so dependent, consequently: was our condition, that the Secretary of Whar was obliged to prefer a request to Congress, that existing laws might be so far repealed, as to 
allow the importation of six thousand blankets for the Indian Department, which was supposed, however, to mean, that our own soldiers could not be preserved from the inclemency of the season, even while fighting the British, unless they could procure blankets from British looms. This request was not granted; and the fearful privations endured by our troops, for the want of proper clothing, is too fresh in the memory of the present generation, to require more than a passing reference.

It was natural, that, during this war, while cut of from intercourse with Europe, our arts and manufactures should rapidly extend. The continnance of it, however, was short; and, at its close, we witnessed, in the deluge of foreign, and especially of British goods, which poured in upon us, onc of those systematic attempts to cripple our manufactories, which must frequently occur while our policy, in regard to them, is unsettled. "It was well worth while," said Mr. Brougham, during a debate in the British Parliament, when speaking of the losses incurred by the British exporters in these goods; "it was well worth while to incur a loss upon the first exportation, in order, by the glut, to stifle in the cratle those rising manufactures in the United States, which the war had forced into existence, contrary to the inatural course of things;" meaning, I suppose, by the "natural course of things," that course which would best promote the interests of the British nation.

It would be easy to multiply these instances, in which the want of a more stable system of domestic industry has placed us at the mercy of forcign legislation, or forcign traders. Such, for example, was the immense importation of East-India cotton into Great Britain, in 1818, in order to prostrate the price of the American product; and when, owing to this measure, cotton suddenly fell seven and a half cents on the pound, and declined, in a little more than two years, from thirty-two to sixteen cents, and in the three subsequent years ranged still lower. Such was the act of

$$
\text { Q4 } 5 \text { S. A. }
$$


Parliament, in 1S:4, reducing the duty on imported wool from sixpence sterling to one penny a pound, and afterwards to a half-penny, for the cleclared purpose, as the debates in Parliament show, of enabling the British manufacturer to undersell, in our own market, the native fabrics which were then springing up. And such, to add no other examples, is the wellknown practice of many British proprietors, at this time, in consequence of the adrantage of operating on a large scale, of manufacturing beyond the amount of orders they have received, and to export the surplus at a price which keeps down foreign competition. "The profits," sars Dr. Ure, when speaking, in his 'Philosophy of Manufactures,' of this practice; "the profits on the greater proportion indemnify them for the losses on the smaller." Is it not to be apprehended, that we shall soon witness another appalling display of the effects of this policy on our woollen manufactures? When, in 1842, the discriminating duties shall cease, and foreign woollens be receired, subject to so slight impost, is it not likely that we shall see another attempt, by glutting our marliets, to stifle those rising manufactures, in which such immense amounts of industry, capital, and skill, have been embarked, by the encouragement held out, too. from our own government ?

Such, then, are some of the reasons which seem to dictate to nations, and especially to a nation situated like ours, the policy of cultivating the useful arts. I need not repeat, I trust, that they are not presented as arguments for such an undue or exclusive encouragement, as would be likely to prejudice, if such a thing be possible, the interests of commerce and agriculture. "For myself," to borrow the words of General Washington, in his letter, in 1789, to the 'Delaware Society for promoting Domestic Manufactures,' "haring an

* It is proper to mention, here, that different views, from those adopted in this Chapter, are held by many persons ; and we advise our readers to examine both sides of this important question. for themselves. 
equal regard for the prosperity of the farming, trading, and manufacturing, interests, I cannot conceire that the extension of the latter (so far as it may afford employment to a great number of hands, which would be otherwise, in a manner, iclle) can be detrimental to the farmer. On the contrary, the concurrence of virtuous indiriduals, and the combinations of conomical societics, to rely as much as possible on the resources of our own country, may be productive of great national adrantages, by establishing the labits of industry and economy. The objects of your institution are therefore highly commendable, and you will permit me to add, gentlemen, that I propose to demonstrate the sincerity of my opinion on this subject, by the uniformity of my practice in giving a decided preference to the produce and fabrics of America, whensocrer it may be done without involving an unreasonable cxpense, or rery great inconvenience." In pursuance of this determination, when le appenied before Congress, in 1790, to deliver his speech, at the opening of the session, he was arrayed in a complete suit of American broadcloth, from the woollen manufactory established a short time previous, under the patronage of Colonel Jeremiah Wadsworth, at Hartford, in Connecticut, and which is beliered to have been the first establishment of the lind in America.

In regard to the influence of the Useful Arts on $\mathrm{Na}$ tional Prosperity, hislory spealis but one language. If we trace the progress of modern civilization, from its cradle, in the south of Europe, to its home, in the Island of Great Britain, or in the United States, we shall find that the state of the useful arts, at any period, and in almost any country, will form a true index to its general condition. It was these arts, borrowed through the Crusades from the East, or reanimated, after a long slumber, at home, that built up the free cities, and sent forth from them an awakening influence on all classes, creating new and higher tastes, even among the boors of the hamlet: and inciting them to corresponding ef- 
forts, in order to gratify them. It was by transplanting these arts from Italy to Flanders, that the Earl of the latter country first gave it an upward impulse, and laid the foundation for the supremacy which it so long enjoyed in industry and wealth, and in the freedom of its middle and working classes. And when England, pausing in the midst of her foreign wars, set herself to derelope her native resources, and commenced that career, in which she has ascended from one to another height of power, and wealth, and cirilization, what was the grand, the distinguishing, characteristic of her policy ? You will find the germ of it, if I mistalie not, as far back as the years 1336 and 1337 , when "Edward the Third, in the midst of his efforts to subdue Scotland, and preparations for subduing France, u'as not inattentive," to use the language of $\mathrm{UcPherson}$, in his 'Annals of Commerce,' ": to the more rational project of establishing the woollen manufactures in his dominions," and "foreign clothmakers, to induce them to more, were promised the King's protection, to live in any part of his dominions, together with fianchises (as the act of Parliament runs) to their full sotisfaction."

Then commenced the policy, which has ever since characterized England: the policy of awakening the dormant energies of her people, and turning to account all the resources of her territory, and all the discoreries of science; the policy of planting within her borders all the arts that are, by way of eminence, useful; that enrich, strengthen, gladden; the policr of giving employment, and the most productive employment, to a whole population, old and young, male and female; of enlisting in their aid the powers of Nature, and the inventions of genius; in one word, of rearing manufactures to stimulate agriculture and quicken commerce. And to what point has she arisen, under the auspices of this policy, aided, doubtless, by other causes. "Sir," sars one of our countrymen, a southern statesman, speaking on this subject, "I have weighed erery sylla- 
ble that I utter; I express a deliberate conviction, founded upon a patient inquiry, and a comparison as complete as my limited knowledge has cnabled me to make it, between the past and present condition of mankind, and between the great nation of which I am speaking, and those that surround her. Sir, there is a gulf between them; that narrow channel separates worlds: it is an ocean more than thrce thousand miles wide.

"I appeal to any one who has been abroad, wheth er going from England to any part of the Continent be not descending immensely in the scale of civilization. I know, sir, that that word is an ambiguous one; I know, that in some of the graces of polished society, in some of the arts of an elegant imagination; that in the exact sciences, and in mere learning and general intellectual cultivation, some nations have excelled, perhaps many equalled, England. But in that civilization which it is the grand end of modern political economy to promote, which at once springs out of, and leads to, the accumulation of capital, and the distribution of wealth and comfort among all classes of the community, with an immense aggregate of national power and resources, -in such a civilization, there is nothing recorded in the annals of mankind, that does not sink into the shades of the deepest eclipse, by the side of England.

"I say mothing of her recent achierements on the land and the sea; of her fleets, her armies, her subsidized allies. Look at the Thames, crowded with shipping; visit her arsenals, her docks, her canals, her railways, her factories, her mines, her warehouses, her coads, and bridges. Go through the streets of that wonderful metropolis, - the bank, the emporium, and the exchange, of the whole world; converse with those merchants who conduct and control, as fur as it is possible to control, the commerce of all nations; with those manufacturers who fill every market with their unrivalled products; go into that bank, where is the repos- 
itory of the precious metals for all Europe ; consider its notes, as well as the bills of private bankers, at a premium every where, more valuable than specie, symbols not merely of gold but of what is far more precious than gold, yea, than fine gold, of perfect good faith, of nublemished integrity, of sagacious enterprise, of steady, persevering industry, of boundless wealth, of business coextensive with the earth, and of all these things possessed, exercised, enjoyed, protected, under a system of liberty chastened by the law which maintains it, and of law softened and mitigated by the spirit of liberty which it breathes throughout.

"Sir," continues the eloquent gentleman from whom I quote, "I know, as well as any one, what compensations there are for all this opulence and power; (for it is the condition of our being, that we buy our blessings at a price;) I know that there are disturbing causes, which have hitherto marred, in some degree, the effect of this high and mighty civilization; but the hand of reform has been already applied to them, and every thing promises the most auspicious results. I have it on the most unquestionable authority, because from an unwilling witness, that, within the memory of man, never were the laboring classes of England so universally employed, or so comfortably situated, as at the beginning of the present year."

In view of this brilliant, but, as I believe, not overcharged picture of England's power and wealth, I could hardly help whispering, if I had access to the author's ear, that she has not reached so proud a preeminence by an exclusire devotion to agriculture, the favorite policy of the gentleman's own State; and that, while she has been coining her millions out of the manufacture of cotton, South Carolina has hardly compassed equal profits, though doubtless great ones, by raising it.

It would be easy to multiply these historical proofs,

* Speech of Hon. I. S. Legare, in Congress, 1837. 
by a reference to other countries, and even to our own, where the tide of prosperity never rolled on in such majestic wares, as during those periods (especially the last twelve or fifteen years) when the useful arts were most cultivated. But I must hasten to other views of the subject, and especially to some notice of the objections which are commonly preferred against any special effort to encourage these arts in the United States.

1. It is objected, in the first place, that it infringes on one great principle of productive industry, namely, in the division of labor. "No one," says Mr. M'Culloch, "thinks of performing every thing for himself, nor of making at home what it would cost him more to make than to buy. The tailor, as Dr. Snith has remarked, does not attempt to make his own shoes, but buys them of a shoemaker; the shoemaker, on his part, does not attempt to make his own clothes, but employs a tailor; and the farmer makes neither the one nor the other, but obtains them in exchange for his corn and his cattle. Each individual finds it for his advantage to employ himself in some particular business, and to cxchange a part of his peculiar produce, for such parts of the produce of others, as he may have occasion for. And it is not very easy," he adds, "to see how that conduct, which is universally admitted to be wise and proper in individuals, should be foolish and absurd in the case of a state; that is, of the total numbers of individuals inhabiting a particular tract of country."

Applying this principle to this country, it is thought to be unwise for a people, having such rast tracts of fertile and unoccupied territory, to divert from its tillage any portion of their industry, in order to fabricate articles which can as well be procured from abroad, and for manufacturing which, other nations have superior facilities. 'To this argument there would not be so obvious a reply, provided these other nations would consent to receive our agricultural products, in 
exchange for their manufactures; or, in other words, if there were between nations, as there is between individuals of the same nation, perfect freedom of trade. But this is far from being the case. While England wishes us to buy her cloths and hardware, she positively refuses, most of the time, to take, in exchange, omr corn, cattle, or lumber. "In such a position of things," said Hamilton, fifty years ago, and the remark has lost none of its force since; "in such a position of things, the United States cannot exchange with Europe on equal terms ; and the want of reciprocity would make them the victims of a system which should induce them to confine their views to agriculture, and refrain from manufactures. A constant and increasing necessity, on their part, for the commodities of Europe, and only a partial and occasional demand for their own, in return, could not but expose them to a state of imporerishment, compared with the opulence to which their political and natural advantages authorize them to aspire.". If the shoemaker should tell the farmer that he could no longer take his cattle and his corn for shoes; or could only take them occasionally, when he was unable to produce sufficient for himself, the farmer must necessarily reply, then, sir, I can no longer take your shoes. I must look out for some other individual, who will take the only articles of produce I have to give, or I must turn shoemaker myself. While Great Britain refuses to talie in exchange for her goods the produce of the labor of two thirds of the people of the United States, and the latter can obtain equiralents for that produce in no other part of the world, it ill becomes her to complain that these two thirds should attempt to manufacture for themselres.

2. But it is said, again, that industiy, if left to itself, will naturally find its own way to the most useful and profitable employment; and that to attempt, therefore, to hasten its morements, by special efforts, or by the agency of gorernment, is to do violence to the interests of the country. Those who advance this argument 
can hardly have appreciated the "strong influence of habit, and the spirit of imitation, which affects communities no less than individuals; the fear of want of success in untried enterprises; the intrinsic difficulties, incident to first essays towards competition with those who have previously attained to perfection in the business to be attempted; the combinations by those engaged in a particular branch of business, in one country, to frustrate, by temporary sacrifices, the first efforts to introduce it into another; the bounties, premiums, and other artificial encouragements, with which foreign nations second the exertions of their own citizens, in the branches in which they are to be rivalled." The force of habit and education is such, even in our bustling country, that there lives in my neighliborhood a gentleman of wealth and intelligence, but who belongs, in years, almost to another age, who questions altogether the utility of steam-boats, and who has never yet been persuaded to put his foot on board of one: and I have heard of an old planter, who died not many years since, in Maryland, who, having becn educated when there were few or no manufactories in America, continued, to the very last, to ship his tobacco to a factor in England, as before the Revolution, and to receive thence supplies of the most trifling articles for his family use, such as tea, sugar, coffec, pepper, mustard, and all farming utensils, and articles of clothing, packed up and forwarded as they liad been at the period of the first settlements in the State. The other considerations which have been suggested admit of similar illustration.

3. It has been objected, again, that manufactures can be built up, in a country like ours, only at the expense of commerce and agriculture. This opinion is the result of an old prejudice, by which these three great branches of industry are regarded as rival and even hostile interests, - a prejudice which the uniform experience of civilized nations ought, before this day, to have corrected. If we look over the world, we shall 
find that the most active and lucrative commerce, and the most improved and productive systems of tillage, have prevailed in the very countries which have been most distinguished for their arts and manufactures. Look at Lombardy and Flanders, of former times. Look at England and Scotland, at this moment. Look even at this Country, and tell me, in what parts of it there is the busiest commerce, the most active and intelligent culture of the soil. To build up commerce, you must furnish it with commodities to exchange; and the greater their variety, as well as their abundance, the more active the exchanges you will set in motion.

To stimulate, to the utmost, the energies of the husbandman, you must, on the one hand, furnish him with a ready market for his products, and, on the other, kindle in his mind new desires for the conveniences and luxuries of life. All this has been done by the useful arts, in other countries, and is now in the way of being done here. Even should foreign trade be somewhat contracted, it would only be the result of substituting for it a more extensive and profitable trade at home. The operations of this trade, being less imposing than those which belong to commerce with distant countries, and no full or accurate survey being annually taken of them by the authority of gorernment, wc are but little aware of their vast and paramount importance. The products of our domestic manufactures amount annually to little less than four hundred millions of dollars, - while all our imports from abroad are estimated at less than a quarter of that sum; and the imports of such articles as we can make in the United States at much less. Now, the domestic exchanges, or commerce, to which these four hundred millions of dollars worth of manufactures gives rise, the demand which it creates for the products of agriculture, the employment which is thus afforded for our coasting res sels, our canals, and steam-boats, constitute, together, an amount of industry, compared with which our whole foreign trade, and that portion of our agriculture en- 
gaged in producing for exportation, forms but an inconsiderable item.

And yet let it not be supposed that these advantages, cxempt as they are from the fluctuations inseparable from forcign trade, and investing us with a real as well as a nominal independence, have abridged essentially our intercourse with forcign nations. The truth is, they have not abridged it at all. Our imports, as the Reports of the Treasury Department show, have never been so great, on an arerage, as during the last fiftcen years, when our domestic arts have been most thriving. And this increase is the effect, not merely of an increasing population, but also, and in good part, of the addition which those arts have made to our wealth. Without these arts, what ability would New England, for instance, have, to buy, not merely the flour of Rochester, and the pork of Cincinnati, and the cotton of Alabama, (let not the Alabanian despise lis Eastern customer, for that customer adds not less than ten per cent. to the value of his staple,) not merely to buy these, but what ability would she have to purchase the silks of France, and the cutlery of England, and the teas of China? It is a fact, that two thirds of our whole population,those inhabiting the Eastern, Middle, and Western, States north of the Ohio,-have almost no foreign marliet for the products of their agricultural labor. Of the annual exports of the United States, more than three fourths are furnished from the plantation States, and consist of cotton, rice, and tobacco. In what way, then, could the other and much more numerous portions of our people provide themselves with foreign conveniences, and luxuries, but by first fabricating articles, or raising products, which can be sold at home, and with the proceeds of which they can present themselves as buyers in the furthest marts of Europe and of Asia?

And this system not only gives the means, it also enlarges, in the same proportion, the desire of purchasing; enlarges the circle of our tastes, and, in place 
of one foreign commodity, superseded by a correspon ding one of domeştic manufacture, it probably introduces two others, that are new. This is a topic pregnant with interest and instruction; and it demands a much ampler discussion, than can be afforded to it here. Whoever has had occasion to visit one of ous manufacturing towns, and to observe its ricinity, must lave seen beautiful exemplifications of the truth to which I have adverted. He will have seen how industry is quickened by the presence of gainful employment, as well as how it is aided and lightened by the discoveries of science. He will have seen the products of the neighboring husbandry increased fourfold, and not unfrequently tenfold. He will have seen an air of thrift, and even elegance, thrown over the whole population, exhibited in their habitations, dress, and manners, which betokens improved taste, as well as enlarged means.

I was very forcibly struck with all this, not long since, in visiting a town some forty or fifty miles westward from Albany. The situation is truly sequestered, being several miles from any great route of travel or transport, and in the midst of a sandy and sterile soil. A few years ago, however, the attention of the inhabitants was directed to the dressing of skins, and the manufacture of glores. This business gives employment not only to the male adults, who could be spared from farming, but also to the females and children; and, with the added blessings of temperance, education, and general morality, has been the means of making one of the most opulent, respectable, and happy neighborhoods, which it has been my fortune to witness. As I rode through the town, now rapidly increasing in population and wealth, every house and cottage prettily painted and furnished, a fine new church erecting, which would be no dishonor to our cities, a large academy, offering to all the inhabitants the means of a thorough though cheap education, the people all occupied, and all rejoicing in the consciousness of present 
prosperity, and in the hope of a bright and happy future, I could not but think what would have been the amount of trade, what the state of tillage, and what, above all, the condition of the people, had they confined themselves, after the example of some of their neighbors, exclusirely to agriculture.

4. My limits will permit me to notice but one other objection. It is, that the cultivation of the arts, especially the establishment of large manufactories, tends to demoralize and degrade a population; that, if they add to a nation's wealth, it is at the cxpense of that which is unspeakably more important,-_their virtue. Having given some attention to this subjesct, I should gladly spread the results before the reader, at greater length than my space will allow. I do not doubt that the factory operatives of England have been, to a fearful extent, depraved and ignorant; but I believe the same remark applies with equal, if not greater, truth, to her peasantry. The debased condition of the latter, it is true, is less obvious; because they are scattered over the country, and are rarely visited by the tourist, while lie beholds the corruption of the manufacturing classes collected into conspicuous focal points. But Colquhoun, one of the most accurate statistical writers of Great Britain, who had no partiality for manufacturing industry, has ascertained, that, as a class, operative mechanics, and especially manufacturers, are more orderly and better provided for, than the agricultural class; the criminal offences charged being as forty to one liundred, and the number of paupers as one to two, in favor of the manufacturing districts.

The same opinion is expressed, in an emphatic manner, and substantiated by a great variety of facts, in Dr. Ure's late work on the Philosophy of Manufactures, which was written immediately after an extended and careful inspection of the factory districts, both of England and Scotland. The truth is, the fearful amount of vice and suffering, among all the lower orders of England, is to be attributed to causes very different from 
the one here assigned; and might rather be said to exist in spite of manufactures, than on account of them. In the mean time, the jealousy which has unhappily subsisted between the landed and trading interests has instigated one party to seize upon this too palpable and melancholy fact, and to construe it to suit their own convenience. But whoever would determine the proper and legitimate influence of these arts, and especially as prosecuted by the modern system of factory labor, should risit the Manchester of our own Country,-Lowell. He will there find, if I am not deccired, a practical and conclusire refutation of the objection before us.

One of the most interesting and important questions connected with this subject, and one which I intended to have discussed at some length, must be omitted in this place. It is, by what means the growth and cultiration of these arts among a people can be best promoted; whether by the patronage and fostering care of the government, or by means simply of private enterprise. This question has been long and much agitated; the boolis of the political economists being on one side, and the almost invariable practice of civilized nations on the other. Reasons might be assigned for at least suspecting, that the far-famed speculations of Smith, McCulloch, and their distinguished followers, in defence of what they have invidiously termed free trade, are not altogether untainted by fallacy; and that the charge, especially, which they so often reiterate against the protecting policy, that it is essentially a monopoly, taxing one class for the benefit of another, is unfounded in fact. Reasons might be assigned for the opinion, that these speculations contemplate a state of things which nowhere exists, and that conclusions, drawn under such circumstances, and not according with the judgement or experience of practical men, should be received with much caution. But it may be well, that such discussions should be waived. However cogent may be the arguments in faror of a pro- 
tecting policy, unless they are likely to prevail with the people of our country, and to secure the firm and consistent administration of such a policy, they may well be spared. Frequent and great changes in the course of the government, on such a question, are much more injurious than entire neglect: and after the legislation of 1833 , by which not only an end is to be put to discriminating duties, in 1842 , but the power of all future regislatures to lay duties for the protection of domestic industry, or the countervailing of foreign restrictions, is negatived, and in view, too, of the sudden and capricious vicissitudes through which our protecting system has so often been compelled to pass, it may be wise, that the question should rest for a season.

But, if the career of industry, which we have commenced so auspiciously, and prosecuted so nobly, which has enabled us to compete with England, on her own favorite ground, and even to supersede her, in the making of coarse cottons, in the markets of her own Indies; if this career is still to be on the ascendant, it will need, to use the words already quoted, of Washington, the concurrence of virtuous individuals, and the combinations of economical socicties, to rely, as much as possible, on the resources of our own country. It will need, that the patriotic determination to prefer American fabrics should become more general and cordial; that our dealers, instead of being compelled to give to domestic goods a British mark, in order to secure a sale, should find that an American stamp is one of the highest recommendations. It will need, that we require, in the products of our looms and workshops, not so much cheapness as excellence; that we encourage the highest order of workmanship, and show that we can appreciate that perfection, towards which all arts ought to aspire. It will be necessary, that we spread among our people juster views of the influence of manufactures; that we contribute, by means of exhibitions and premiums, to awaken emulation, and develope inventive genius; and that we train those, who are to follow these 
pursuits, in the theory as well as in the practice of thent art. And above all, will it be necessary, that our people become still more preeminent than they now are, for intelligence and morality. One of the greatest advantages which, it is admitted, we enjoy, as a manufacturing people, is in this superiority; in the greater sobriety and mental activity of our workmen. This superiority we must not only maintain, but, above all, when our arts and manufactures are about to lose the protection of the government, we must be careful to advance it. We must remember, that it is mind, enlightened, refined, awakened, virtuous, mind, which must win the prize; and that, in the race of industry, as in every other, it is righteor'sness which exalteth a nation, while sin must at length - rove the curse of any people.*

See Appendix, XII. 


\section{APPENDIX.}

\section{PAGE 11.}

NATURE AND OBJECTS OF TECHNOLOGY.

TiIE arts considered generally, in their theory and practice, as connected with moral, political, and physical, science, form the subject of Technology, which now ranks as one of the sciences.

Technology is variously divided; by some writers into higher and lower; by others, into universal and particular.

Higher technology, according to one class of authorities, relates to such arts only, as require a higher degree of knowledge and skill in those who practise them. Such are watchmaking, shipbuilding, \&c. According to others, higher technology treats of the connexion of the arts and trades with the political condition of a nation, their influence on civilization, \&c. \& c.

Universal technology comprehends the principles which apply to all the arts; particular technology teaches the rationale and practical operations of particular arts. Particular technology is subdivided into, 1. The knowledge of raw materials; 2. Instruments and machines ; 3. Processes, manipulations, \&c.; 4. Manufactured articles, as to quality, \&c. 


\section{Page 11.}

CLASSIFICATION OF THE ARTS.

THE arts are classified, sometimes according to the operating powers, or agents, as into mechanical and chenical arts; sometimes, according to the natural derivation of the raw materials, as into animal, vegetable, \&c.; sometimes, according to the principal operations employed in them, as spinning, wearing; and sometimes, according to the relation of the products. One or another of these classifications will be found most conrenient, according to the special object we have in view. Being more or less arbitrary, they are necessarily imperfect. Beckmann, long eminent as Professor of Technology in the University of Göttingen, founds his dirision, (as does also Hermbstadt; a German writer of authority, ) on the last two principles mentioned above; that is, on operations and products. Poppe, Professor at Frankfort on the Maine, proposes a threefold division, 1. Mechanical arts; 2. Chemical, (wet;) 3. Chemical, (dry;) subdividing each into such arts as serve for, 1. Food; 2. Clothing; 3. Dwellings; 4. Comfort; 5. Pleasure. This arrangement was proposed, in order to aroid separating, unnaturally, those things which are nearly related.

I annex, for the satisfaction of the reader, a full classification, proposed by Dr. Ure, in his 'Philosophy of Manufactures.'

Manufactures are divisible into two great classes, according as they change the external form, or the internal constitution of their raw materials. Hence the distinction of mechanical and chemical arts. Each class may be subdivided into three families, according as it operates on mineral, vegetable, or animal, substances; thus presenting to the student three orders of manu- 
factures, which possess many interesting natural affinities.

Iron will afford the means of illustrating these relations. The ore of the metal is detected, and valued by chemical research; but it is dug and brought to the market, by mechanical ageney. The chemist conducts the process of smelting it into cast iron, as well as the conversion of the crude metal into malleable iron and steel, aided by the ministry of the engineer. For the purposes of art, iron is deprived of its metallic state, and acquires many new forms and qualities, by new combinations of its elementary particles. Its various oxides, sulphurets, salts, \&c., therefore, belong to chemical manufactures. The mechanical group comprehends the operations of the foundry, the forge, the rolling-mill, the slitting-mill, the flatting-mill, \&e.

\section{Mechanical Arts.}

The general classification of the mechanical manufactures may be made either in the order of their respective subjects, as these are arranged, by the natural historian, in the mincral, vegetable, and animal, kingdoms, or according to the nature of the mechanical and plyysical actions cxercised on these subjects. On the former plan, analogous arts would often be necessarily disjoined, in consequence of the disjoined origin of their materials, howerer similar their principles and processes might be. Thus, the woollen and cotton manufactures, though closely allied, would need to be separately considered, under the two distinct departments of the aninsal and regetable world.

The true philosophical principle of classifying the mechanical manufactures, is to arrange them in the order of the general properties of matter, which it is their object to modify. 'The several properties, on which mechanical and physical forces are made to act, in order to change the forms of bodies, for the uses of life, are the following:

I. Divisibility; II. Impenetrability, or Repulsive 
ness; III. Permeability, or Porosity; IV. Cohesweness; V. Ductility; VI. Malleability; VII. Inertia; VIII. Gravitation; IX. Elasticity; X. Softness; XI. Tenacity; XII. Fusibility; XIII. Crystallizability.

I. Dirisibilitr.-To this head, may be referred the following processes of art: 1. Pulverizing dry substances; 2. Triturating solid substances with liquids into a pasty consistence; 3. Boring; 4. Sawing; 5 . Rasping and chipping; 6. Tearing; 7. Abrading surfaces; \&. Splitting; 9. Planing; 10. Turning surfaces; 11. Shearing surfaces; 12. Granulating and shotcasting; 13. Distilling; 14. Subliming; 15. Exploding, or blasting, for mining purposes; 16 . Comminution of earths and soils.

1. Pulverization.-This operation is performed by various machines, according to the nature of the substance to be pulverized; such as corn-mills, flour-mills, drug-mills, manganese, chrome ore, and other mills for pulverizing mineral substances; dye-mills, stamp-mills, and other crushing machinery, \&c.

2. Trituration.-To this head belong color, or paint mills, flint, and other pottery mills, and comminuting processes; certain drug-mills; patio, and other amalgamation works, \&c.

3. Boring.-Here, the action of the cutter and drill is employed to form cylindrical carities for steam-engines, hydraulic-presses. pump-barrels; cannon, gun barrels; mine and Artesian-well boring. \&c.

4. Sawing.-Sawing comprehends every species of mill for cutting off' flat plates of timber, stone, metal, \&c.; such as saw-mills, of every kind, marble-mills, stone-cutting works, \&c.

5. Rasping and chipping.-Under these titles would fall masonry; or stone-hewing, the mechanical part of statuary ; rasping-mills for logwood, beet root, and machines for chipping the teeth of wheel patterns, \&c.

6. Tearing.-To this head may be referred papermaking, as well as flax-heckling, for tearing off its parenchymatous matter, threshing-machines, \&c. 
7. Abrasion of surfaces.-This process will comprehend all filing and polishing operations, such as grinding and polishing of metals, of glass, marble, \&c. Mirror and lens making belong to this class, as well as cutlery-grinding of every kind.

8. Splitting.-Here would be considered the art of splitting skins for cards and parchment; splitting timber for laths, whalebone, and other fibrous substances, \&c.

9. Planing.-Planing-machines, now so beneficially used in the working of metals for machinery of every kind, as well as for flooring, and other planks of wood, fall under this division, as well as the key-groove cutting machines, and many others.

10. Turning.-Every species of turning-lathe, in which a cutting edge is applied to surfaces in a state of rapid revolution, belongs to this process.

11. Shearing.-This process includes that beautiful branch of manufacture, by which woollen cloth, after being woven, is finished, with a soft, smooth surface. It is performed on the principle of shaving, by moving a slightly inclined, or nearly horizontal blade, close to the downy surface. As mowing machines operate in a similar way, they may be considered under this head.

12. Gramulating, and shot-casting.-In these processes, the property of divisibility is acted on by the solvent power of heat, which, skilfully made use of, saves the labor of grinding a fusible solid. The melted mass being nearly roid of cohesion, is separable, like water, into a shower of drops, which congeal in the course of their descent from the top of the shot-towers into the water-cistern at their base. The refiner of gold and silver, and the alloyer in general, granulate their melted metal, by pouring it on a bundle of moist twigs, or by trituration in a cold mortar.

13. Distilling.-Were, again, the force of caloric divides matter, whether solid or liquid, into separate substances, in the order of their expansiveness, by that physical agent. All the varieties of stills belong to this 
head, all the mechanical processes of the rectifier and compounder of alcohol, the manufacturers of coal gas, and pyroligneous acid, \&c.

14. Subliming.-The same physical influence is here employed, to divide and comminute, by separating the more volatile parts of bodies, which, in the aeriform state of repulsireness among their particles being suddenly cooled, precipitate in an impalpable powder.

15. Exploding, or blasting.-The property of divisibility is in this case acted upon, and made effectire, by the sudden generation of elastic fiuid, in such force, as to overcome the cohesion of the solid mass. Under this head might perhaps be considered the simple action of ignition, in effecting the disintegration of rocks for mining purposes.

16. Comminuting, or disintegrating earths and soils.-Tillage, with the spade, pickaxe, plough, har row, \&c.

To till the ground, or break the stubborn glebe with the furrow, is merely a division of its parts, to render the earthy substances friable, in order that the roots of plants may insinuate themselves more easily into it ; that the rains and dews may penetrate more readily to these roots; that any excess of water may more freely exhale; and lastly, that the air of the atmosphere may get access to the regetable mould of the soil, and convert it into soluble regetable food, on principles dereloped by chemistry. The proper comminution of the soil, by the plough and the harrow, is serviceable, also, in destroying weeds, in bringing up to the surface fresh layers of earth, incorporating with it manure and other improvers, and in giving a slope to the ground favorable to its drainage. The importance of the pulverizing process is so well known, that tillage and agriculture have been long used as synonymous terms. All its processes act on the divisibility of the soil in three ways: 1. By the spade; 2. By the pickaxe and hoe; 3. By the plough, with its wedge-shaped share, which cuts obliquely through the clod, and turns it over to one side 
Spade-tillage suits best for a soil which is uniform in toxture, deep, compact, level, and not very stony or moist. That of the pickaxe, or mattock, is most proper for land that is stony, dry, difficult to penetrate, and uneven, or sloping in its surface. 'The plough, though a less perfect pulverizing agent, is more expeditious, economical, and generally applicable to grounds, excepting to steep declivities. 'The best form of ploughshare, for dividing the soil, is an interesting problem in mechanical philosophy.

II. Impenetrability.-This property gives rise to works for separating, by compression, the liquid from the solid parts of bodies, in virtue of the impenetrability of matter. Uncler this class are comprehended oilmills, sugar-mills, beet-root-presses, cocoanut-lard-mills, all of which operate either by the flat pressure of a hydraulic or screw press, or by the pressure of surfaces rolling on each other; the object being to extract incompressible liquid matter from the interstitial pores of a solid. Die-presses for coining, and transferring engravings from hard steel to soft steel or copper, may be arranged either under impenetrability or condensability.

III. Permeability.-This property admits of one or more matters to pass through or impregnate the interstices of solids. Filtering apparatus, for sugar-refiners, for purifying oils, and many other liquids, by means of bibulous paper, sand, stones, with or without external pressure, as well as dyeing, calico-printing, letter-press, copper-plate, and lithographic, printing, belong to this head.

IV., V., VI. Cohesion, Ductility, Malleability or LAMiNabiLITY.-C'lhese are kindred properties, and are the foundations of kindred works, such as wire-drawing, and tubc-drawing apparatus, rolling-mills, flatting-mills, tilting-mills, laminating-mills, gold and silver leaf-beating, \&c.

VII., VIII. Inertia, Gravitation.-In reference to these properties, the raising, lowering, and removing, 
weights, come to be considered. These effects are produced by cranes, capstans, windlasses, gins for raising coals and other minerals; pulleys, wheels and axles; inclined planes for joining different canal lerels ; pumps, for lifting water ; dredging machines ; carriages of every kind. The equilibrium of architecture, and of shipbuilding, may be treated here.

IX., X., XI. Eldsticitr, Softress, AND TexaclTr.-These three properties are combined in the constitution of tortile fibres, used for making webs of various kinds, and give rise to the arts of spinning, knitting, and weaving, mineral, regetable, and animal, filaments; the principal of which are the manufactures of cotton, wool, flax, and silk. Rope-maling and wire-working belong also to this head. Under tortility must likewise be considered the processes of fulling, felting, and the manufacture of hats.

XII. Fusıinitr.-To this property belong foundries of the different metals, and the mechanical part of glassmaking, as well as casting figures in plaster, wax, \&c.

XIII. Crystallizability. - This property includes the various physical principles of the manufactures of saline substances, such as salt-works, nitre-works, alumworks, \&c.

The sixth of the abore divisions comprehends the mechanical arts most interesting to man. Here he has exercised his best talents, in producing raiment of every variety for his comfort and decoration ; and here, accordingly, he has orgarized systems of industry, no less remarkable for their magnitude than for their perfection. In certain parts of the clothing manufactures, moreover, automatic machinery has been so extensively substituted for the labors of intelligence, that the superintendence of young persons has come to supersede the costly toil of adults, to such an extent, that the vast multitudes of children thus employed have, of late years, attracted the earnest consideration of the public, and have, in consequence, led the legislature to frame a code of factory laws for their protection. 


\section{Chemical Manufachures.}

Those arts which involve the operation of chemical affinities, and consequently, a change in the constitution of their subject matter, may be distributed into three groups, according to the lingdom of Nature to which they belong:-the mineral, the regetable, and the animal.

Class I. The chemical manufactures employed on mineral, or, more accurately speaking, inorganic, matter, may be arranged conveniently under four heads: i. Those which operate on metallic bodies; ii. On earthy and stony substances; iii. On combustibles; iv. On saline substances.

Class II. The chemical manufactures which modify vegetable substances may be distributed according to the chemical analogies of these substances, as starch, sugar, oils, essences, \&c.

Class III. The chemical manufactures which modify animal substances may likewise be distributed according to the chemical analogies of their respective objects: as gelatine, or glue, albumen, skin, horn, \&c.

Class I. Order i. Arts and manufactures of metallic substances: 1. Extraction, purification, alloying of the precious metals, gold, silver, \&c., and their different chemical preparations. 2. The arts of smelting copper, and making its alloys, its saline and other preparations. 3. The arts of smelting iron, and making its alloys, its saline and other prepartions. 4. The arts of smelting lead, \&c. 5. The arts of smelting tin, \&c 6. The arts of smelting mercury, \&c. 7. The arts of snelting zine, \&cc. S. 'The arts of smelting bismuth, \&c. 9. The arts of smelting antimony, \&e. 10. The arts of smelting cobalt, \&c. 11." The arts of smelting nickel, \&c. 12. The arts of smelting manganese, \&c. 13. The arts of smelting arsenic, \&c. 14. The arts of smelting chromium, \&c. 15. The arts of extracting the other metals, cadmium, bismuth, rhodium, \&c.

Class I. Order ii. Arts and manufactures of earthy 
and stony substances: 1 . Those which operate on calcareous substances; such as limestones, gypsum, fluorspar, \&c. Mortars. 2. Those which operate on argillaceous earth, or clay; as the manufactures of pottery, porcelain, \&c. 3. Those which operate on silicious matter. Manufacture of glass.

Class I. Order iii. Arts and manufactures of combustible substances: 1. Sulphur. Manufacture of sulphuric acid. 2. Coal. Manufacture of coal gas, and its various products. 3. Amber, petroleum, bitumen, asphaltum.

Class I. Order iv. Arts and manufactures of mineral saline substances: 1 . Rock or sea salt; salt-works of various kinds; manufacture of muriatic acid, and of chlorine. Art of bleaching. 2. Alum, its manufacture. 3. Natron, or soda, its manufacture. 4. Potash, its manufacture. 5. Sal-ammoniac, its manufacture. 6. Nitre, its manufacture; that of gunpowder, nitric acid, \&c. 7. Borax, its manufacture. 8. Sulphate of magnesia, its manufacture.

Class II. The chemical manufactures of vegetable substances. 1. The art of extracting and refining sugar. 2. The art of extracting and purifying starch. 3. The art of making artificial gum. 4. Extraction and purification of fixed oils, drying and unctuous oils, such as linseed oil, castor oil, nut oil, \&c., oil of olives, of almonds, of the palm, of the cocoa-nut, \&c. Manufacture of oil soaps. 5. Extraction and purification of volatile oils, such as oil of turpentine, citron, anise, cinnamon, lavender, \&c. Art of the perfumer. 6. Art of purifying and bleaching wax. 7 . Extraction and purification of resinous bodies, such as common rosin, lac, mastic, \&c. Manufacture of varnishes and sealing-wax. 8. Extraction of caoutchouc; caoutchoucine. Manufacture of water-proof cloth. 9. Preparation of extracts for the apothecary ; extract of nut-galls. Manufacture of ink. 10. Extraction of the coloring matter of plants, as of madder, safflower, archil, logwood, weld, indigo, \&c. Arts of dyeing and calico-printing 11. Art of ferment- 
ing vegetable juices and extracts into wine, beer, \&c. Breweries, distilleries, $\mathcal{E c}$. 12. Art of fermenting vegetable juices and extracts into vinegar. 13. Art of fermenting dough into bread. Baking. 14. Decomposition of wood by fire in close ressels. Pyroxilic acid, spirit, and naphtha. 1j. Preparation of composts by the putrid decomposition of vegetable substances. Agriculture as a chemical art.

Class III. The chemical manufactures of animal substances are, 1. The art of extracting and purifying gelatine, or the manufacture of glue, size, isinglass, \&c. 2. The art of extracting butter from milk. Manufacture of cheeses. 3. The art of converting skin into leather, or tanning. 4. The art of the tallow-chandler. Purification of spermaceti. 5. The manufacture of tallow and other soaps. 6. Preparation of animal pigments, - carmine from cochineal. 7. The art of curing animal food. \&. Decomposition of animal substances by fire. Manufacture of sal-ammoniac, and of Prussian blue.

The preceding table presents merely the more gener al objects and subdivisions.

\section{PAGE 12.}

CONXEXION OF TIIE USEFUL AND FINE ARTS.

Tyrs connexion is in some cases very intimate. For cxample, silks, porcelain, calicoes, $\mathcal{E}$ c., derive much of their value from the designs with which they are embellished; and hence the necessity of combining the cultivation of the Arts of Design with the fabrication of these articles. So in building and engineering, Drawing is an indispensable prerequisite. It has been found, too, that in many cases, such as architecture, the nearer we approach to abstract beauty of form, the more perfectly we attain that which is useful, convenient, or economical. 
The following extract from Ure's 'Philosophy of Manufactures' will show how fully this connexion is appreciated by the French, and by what means they hare attained the superiority which distinguishes them in certain departments of industry.

The modes in which taste is cultivated at Lyons, in connexion with the silk manufacture, deserve particular study and imitation. Among the weavers of the place, the children, and every body connected with devising patterns, much attention is deroted to every thing in any way connected with the beautiful, either in figure or color. Weavers may be seen, in their holyday leisure, gathering flowers, and grouping them in the most engaging combinations. They are continually suggesting new designs to their employers; and are thus the fruitful source of elegant patterns.

There is hardly any considerable house in Lyons, in which there is not a partner who owes his place in it to his success as an artist. The town of Lyons is so con. scious of the value of such studies, that it contributes twenty thousand francs per annum to the government establishment of the School of Arts, which takes charge of every youth who shows an aptitude for drawing, or imitative design of any kind, applicable to manufactures. Hence all the eminent painters, sculptors, even botanists and florists, of Lyons, become eventually associated with the staple trade, and derote to it their happiest conceptions. In the principal school, that of St. Peter's, there are about one hundred and eighty students, every one of whom receives from the town a gratuitous education in art for five years; comprehending delineations in anatomy, botany, architecture, and loompattern drawing. A botanical garden is attached to the school. The government allows three thousand one hundred francs a year to the school at Lyons. The school supplies the scholars with every thing but the materials, and allows them to reap the benefit of their works. Their professor of painting is a man of distinguished talent, well known to connoisseurs. 
The French manufacturer justly considers that his pattern is the principal element of his success in trade; for the mere handiwork of weaving is a simple affair, with the improved Jacquard loom. He therefore visits the school, and picks out the boy who promises, by taste and invention, to suit his purpose the best. He invites him to his home, boards him, and gives him a small salary, to be gradually advanced. One gentleman told Dr. Bowring that he had three such youths in his employment; to the youngest of whom he gave one thousand franes, or forty pounds, [or one hundred and eighty-four dollars,] per annum. After three or four years, if the young artist's success be remarkable, he may liave his salary raised to double or treble that sum; and when his reputation is once established, he is sure of the offer of a partnership. Such is the general history of many of the schoolboys of Lyons. Eren the French weaver, who earns only fifteen or twenty pence a day, prides himself upon his knowledge of design; he will turn over several luundred patterns in his possession, and descant on their relative merits, seldom erring far in predicting the success of any new style. By this disposition, the minds of the silk-weavers in France become elevated and refined, instead of being stultified in gin-shops, as those of the English too frequently are. In flower patterns, the French designs are remarkably free from incongruities, being copied from Nature, with scientific precision. They supply taste to the whole world, in proportion to the extent of their exportations, which amount to one hundred and ten millions ont of one hundred and forty. In the Jyons school, collections of silk fabrics may be studied, extending over a period of four thonsand years, with explanations of the modes in which every pattern was produced, from the rude silk of the Egyptian mummies to the figured webs of the last year.

There are also weaving-schools, containing from sixty to eighty scholars. In these, a pattern being exhibited, they are required to exercise their invention, $26^{*}$ 
immediately, as to the best means of producing the design on a piece of silk goods. The master removes such difficulties as are occasionally encountered, and leads them on to the successful accomplishment of the task.

Within a few years, a large legacy has been left by Gencral Martin, for the purpose of establishing another institution, similar to the school of St. Peter.

Their superiority in art is turned to good account, in many other French manufactures. Notwithstanding the double price of the raw material in France, their fancy articles in iron and steel are exported in large quantities. Their bronze figures hare made their way into all parts of the world, along-side of their silk goods; both being equally productions of fine taste, and therefore yielding profitable returns.

\section{Pages 24 AXd 260.}

THE IMPORTAXCE OF SCIETCE TO THE MECHANIC.

[Extracts from an Address delivered December 9, 1835, at the opening of the first course of Lectures before the Mechanics' Literary and Benerolent Society of Poughkeepsie, New York, by A. РотTER.]

I NEED hardly remind this assembly, that the conmencement of such an enterprise is an event of some public importance. Though composed, for the most part, of meehanics, and to be conducted with a special riew to their improrement, it by no means follows that this association is interesting or important only to them. In contributing to their welfare, it must contribute, in the same proportion, to the welfare of all. For, be it remembered, that the manufacturers, mechanics, and artisans, of this place, form its most numerous, and, I may add, its most useful and influential class. As the country supplies the raw materials of human subsistener, 
and is occupied principally by an agricultural population; so it is in towns and cities that these materials are worked up into artieles of use and luxury, by mechanics and artisans, who, with their families, constitute its principal inhabitants. They are the young mechanics and apprentices of a town, therefore, whose influence is to be most powerfully felt, a few years hence, on its industry and enterprise; at its local and general elections; in the support of its seliools and churches, and on all occasions of public interest or emergency. If the town is to be improved, enlightened, elerated, who can do it, so effectually, as its most numerous and active citizens? and if it is to decline in morals, intelligence, and prosperity, beliere me, that it is among this class that the leprosy will first break out, and its foul taint be most widely and fatally diffused. Tell me, of any town, the intellectual and moral condition of its mechanics and operatives, and I will tell you what the condition of the town itself is. Tell me the character of its apprentices, and I will tell you what its condition ere long must be.

In view of these facts, I must profess my amazement at the apathy which so generally prevails respecting the intellectual and moral welfare of mechanics; and $m y$ still greater amazement at the contempt (worthy only of a dark age) with which some are disposed to look down on this most useful, and in cities, most numerous and powerful, class. Who can observe the workings of the social system, or peruse the records of the past, without feeling that theirs is a commanding infuence? What class, during the last seren centuries, occupies a more prominent place, in the history of civilization and of constitutional liberty? Where, anidst the dense darkness of the middle ages, first arose a taste for the comforts and refinements of life? Who first taught the feudal lord to encourage industry, instead of idleness; to substitute the improrement of his estate, and the embellishment of his castle, and the cultivation of personal refinement, in place of a coarse 
and prodigal hospitality? Who first supplied commodities for modern commerce, thus opening friendly intercourse between distant, dissimilar, and hitherto hostile, nations, and making the inprovements and discoreries of one the common property of all? And, above all, who first rekindled the long-extinguished spirit of civil liberty ? or, rather, let me say, who, for the first time, lit up that glorious spirit, which alone deserres the name of civil liberty, - a spirit which demanded written guarantees for indiridual rights, and taught that the state, instead of being what ancient republicans considered it, - a stupendous idol, to whose honor and aggrandizement the freedom and happiness of individuals were to be profusely sacrificed, was but an agent, or servant, appointed for the benefit of all, and responsible to all, alike, for its faithful stewardship? To these questions, History returns one and the same answer. It was from the free cities of Europe, founded, sustained, and enriched, by mechanics and tradesmen, that these blessings took their rise. It was these mechanics and tradesmen, who first conceired a taste for the arts and comforts of peace, who communicated this taste to the higher classes, and supplied commerce with its rich freights of wealth and utility. It was they, who first taught the lesson, not yet fully learned in Europe, of systematic and successful resistance to arbitrary power. Enterprizing and intelligent, knowing what was due to their industry and skill, and feeling that royalty itself looked for protection against the insolence of haughty and restless barons to their prowess and wealth, they claimed to be represented in the councils of the state. Thus arose the tiers etat, or third estate of the realm, which has for so many ages held the balance of power in Europe between the monarch and his nobles, and which, as the commons, or middling class, has been infusing more and more of freedom into the constitution of erery civilized people.

In this land, abore all others, it becomes us to make grateful and respectful mention of the services which 
mechanics have rendered to the cause of liberty. Their enterprise, be it remembercd, was among the causes which first excited the jealousy of the mother country towards her American colonies. It was by her oppressive and unnatural efforts to strangle that enterprise, that she contributed to weaken the ties of affection which bound them to her, and awoke on these shores a cry for independence. In the fearless remonstrances which were laid at the feet of royalty; in the negotiations which were opened; in the measures of retaliation which were concerted and put in execution; in the firm and enlightened policy which saw distinctly its object, and moved right onward to its attainment, who were more active or influential than the mechanics? And when, at length, the dic was cast, and the tidings from Lexington and Bunker Hill proclaimed that there was no hope, but in arms and in the God of battles, who stood forth, conspicuous, in the ficld, in the cabinet, and at forcign courts? In the army of the Revolution, I can recall no name, Washington's only excepted, which occupies a prouder place in the menory and affections of a grateful people, than that of Nathaniel Greene, the blaclismith. In the deliberations of Congress, and in the negotiations with foreign powers, I see no worthier representatives of the cool, sagacious, inflexible, upright, and far-reaching statesman, than Benjamin Franklin, the printer, and Roger Sherman, the shocmaker. I need not add the names of others, scarccly less honored. If we would know what mechanics were, at the era of the revolution; and what, in point of influence, they must ever be, in a country like ours, let this suffice :-Of the committce of five, appointed to draw up the Declaration of Independence, two were mechanics.* Of the brave men who led our armies, he, whom Hamilton, while he honored Washington as 'the first man of the country,' did not hesitate to style even 'the first soldier of the Revolution,' $\dagger$

* Benjamin Franklin and Roger Sherman.

t Nathaniel Greene. This fact is stated by Mr. Verplanck, in his 
was a mechanic. He who was the first choice of his country as her representative at imperial courts, and who, sent to baffle the arts of practised diplomatists, and face the menaces of exasperated power, did it all, and did it triumphantly-was a mechanic.* And, finally, he, who in congress and in conventions, by the mere force of intellect and knowledge, without any gifts of eloquence or external show, could still command the confidence and sway the opinions of the wisest; the man, who, to use the language of Jefierson, "never said a foolish thing in his life," and whom another colleague described as "a slow-spoken and almost tongue-tied man, but with a head as clear as light," he, also was a mechanic.t

I shall not be suspected, I trust, of recurring to these facts for purposes of flattery. I recur to them, that I may show young men what may be expected of those who have such models. I recur to them, that I may exhibit, to all who hear me, the true position, both political and moral, in which mechanics stand; and the deep interest which it becomes us all to feel in their welfare and improvement. And, above all, I recur to them, to prove that manual labor and study are not, as they are generally thought to be, incompatible; that it is perfectly practicable for a young man to be cultivating the highest talents, nursing the noblest purposes, drinking deeply from the purest springs of knowledge, while he still pursues, with diligence and zeal, his daily task in the forge, or at the work-bench. $\downarrow$ It is time to do away that unworthy prejudice, which has so long tended to estrange from each other the laboring man

Address before the New-York Mechanics' Institute, in 1833, on the authority of the late Col. Marinus Willett.

* Benjamin Franklin.

+ Roger Shermar.

¥ For an interesting example, in the case of the 'literary Black smith,' see 'Importance of Useful Education and Practical Knowl edge,' \&c., by Edward Ererett, forming the nineteenth volume of 'The School Library.' 
and the student; which serves to perpetuate that distinction between workingmen and gentlemen, which, in a country like ours, where there are no hereditary prerogatives, and where every man must be, at last, the artificer of his own fortune, is, I do not hesitate to say, of all distinetions, the most absurd and pernicious. However it originates; whether, as formerly, in a disposition to stigmatize all labor; or whether, as more recently, in a wish to exalt manual labor at the expense of that which is intellectual, it merits only execration. I give but utterance to the spirit of our institutions, and to the views of all grood and wise men, when I say, that in this land we are, or at least ought to be, all workingmen and all gentlemen. If there is any disgrace in being a workingman, in winning one's way to respectability and usefulness by means of effort and industry, let it attach to him who toils with his brain, as well as to him who works with his hands. And if there is any honor in it, let it not be reserved for him alone who wields the axe or the haminer; but let him, who adds to this the faithful use of his mental and moral powers; and him, too, who, though not a mechanic, nor in the ordinary sense, a laborer, still spares no toil, if he can but restore his client to his rights, or his patients to health; and him, who, while the mechanic is stretched upon his couch, in profound and refreshing slumbers, has to lieep anxious and wasting vigils, preparing for his place in the desk, or in the discharge of official duty,-let him, too, receive his share of honor, at the hands of the Republic. In this country, where so few are born to opulence, and none to station, labor of some kind is the inheritance of all; and whoever pursues that labor, in a liberal and enlightened spirit; striving to cultivate his talents, and refine his taste; ready for every good word and work, and never content while he may win for himself a brighter name, and a larger sphere of action; he is, in the truest and highest sense, a gentleman,-and, if he lives, will one day take his place beside the proudest of the land. 
But how can young men, situated as the mechanic and apprentice are, still malie great advances in useful knowledge? and why should they do it?

First, then, as to the manner in which it may be done. You will perceive, here, that I suppose the young mechanic to continue his accustomed occupations, and that, too, with no remission of industry or zeal. He is, in this respect, to do all that the most scrupulous could ask ; and yet he shall have time enough and means enough, to make great attainments in useful knowledge.

He shall have time enough. You have not failed to discover, before this, that a mian's achievements do not depend upon the time allowed him. They depend, rather, on his energy and spirit. 'To a listless, lethargic, idle man, you might give ages, and he would effect nothing; whereas a man, full of fire, and bent on some great end, seems to have the art of converting his minutes into hours. Husbanding every moment, with a miser's care, he accomplishes, in those little fragments of leisure, which most men think nothing of wasting, works that might seem to have required years. And perhaps they did require years, for minutes, multiplied, swell at last into years ; and many a one, whose apology it is, that he lost only a moment here, and a moment there, will at length find, when he reaches the age of fifty or sixty, that these little moments have expanded into years, long years, which stand a melancholy blank in the history of his life. It is related of the celebra ted Madame Campan, that she composed one or more of those works, which have been so popular, during the brief intervals which were accustomed to elapse between the moment of her obeying the summons to dinner and that of sitting down at table. Lord Brougham, whose labors present such a miracle to the scholar of these degenerate days; who, in addition to his cares and labors in the courts and in parliament, sufficient of themselves to overwhelm ordinary men, finds time to master all the discoveries of modern science; to take place 
himself in the very front rank of writers and inquirers; nay, to write books on natural theology; who can be seen at one hour, probing the abuses in the public charities of the country; at the next, investigating the state of popular education, and giving to that education new impuise; and, perhaps, before the day closes, bestowing a last revision on some work clesigned for the instruction or entertaimment of the common people; this man tells us, as the secret of his labors, that he has work cut out for every moment, and that he nerer postpones for an hour what can be done now. And another name, * associated with, or rather, under Providence, the source and strength of, one of the greatest religious movements recorded in history, a name which will ever be quoted as an example of energy and moral power, - can hardly be recalled, without thinking of that favorite motto of his,-always in haste, but never in a hurry.

Here, then, is the way in which you can make time for the pursuit of knowledge. It is by gathering up the fragments, that nothing be lost ; by hoarding them with a frugal care, or rather by spending them with a provident liberality, in laying up stores of useful science, which, at some future day, will repay you a hundredfold. Consider, for a moment, what these fragments amount to, in a year. It will be admitted, I presume, that, after meeting all the claims of your business, your family, your health, and your religion, you can still save, out of every day, in "odd ends" of time, nearly, if not quite, two hours, which is about one eighth of all the hours not spent in sleep. Thus, one eighth of the whole of life may be devoted to intellectual improrement; amounting (should a man live to the age of three score) to almost eight entire years. And is that all? Far from it. These brief intervals for study, recurring each day and several times a day, will, if improved, supply constant materials for interesting 
thought, during your hours of labor; so that not only may knowledge be acquired, while you are poring over books; but that knowledge can be digested and incorporated with the very substance of the mind, while you. are at work; nay, can actually be amplified and enriched by the new applications and illustrations which will be suggested by your pursuits, or by intercourse with others.

And to this, be it observed, the present state of the arts is eminently conducive. That division of labor, which is often adverted to, as one of the distinguishing features of modern industry, and which has found its way into every kind of mechanical labor, is not more favorable to the production and perfecting of material fabrics, than it is, when properly improved, to the cultivation and elevation of the human mind. It is often objected to such division, that, by simplifying labor, and superseding, in consequence, much of the thought and care formerly necessary, it tends to degrade the artisan into a mere machine. And so it does, if the artisan chooses to be degraded; chooses to spend the leisure, thus given him, in a state of mere mental vacancy. But why should he not consider it as a precious gift from heaven; as so much time rescued from toil, and designed for intellectual and moral improvement? To the reflecting and philanthropic mind, this is the highest end of all those grand inventions, devised by modern genius, to abridge, or supersede, human labor. They are not intended, by Providence, simply to pour wealth into the coffers of the few, nor even to augment the merely physical enjoyments of the many. Their aim, rather and above all, is, to redeem a large portion of that time which has hitherto been given to exhausting labor; but which, henceforth, can and should be devoted to elevating the intellectual, moral, and religjous condition of the workman.

Viewing the subject in this light, I think I do not exaggerate, when I say, that a mechanic, in these days, may, in effect, devote nearly one quarter of his time to 
mental improvement; or, which is the same thing, he may, in the course of an ordinary life, save, for this best and most important of all purposes, the entire space of twelre or fifteen years, which, as usually spent, is worse than wasted. And what facilities does he not enjoy, for the profitable employment of those years. Good books have become so abundant and cheap, that a man of very limited means can still possess himself of a rast fund of knowledge; in addition to which, public libraries are now so richly furnished, and are conducted on such liberal principles, that there is hardly any thing uscful in science, or elegant in literature, to which the youthful student may not have access, - I liad almost said, without money and without price. And this knowledge has, in modern works, been studiously adapted to the unlearned; is in many instances illustrated for the special benefit of the mechanic and the laboring man; and is rendered equally attractive and simple, by means of ancelotes, engravings, and maps. In addition to all this, the mechanic is invited to lectures, which, though they may not be sufficient to instruct him fully on any subject, are yet most useful in awakening a spirit of inquiry; in spreading before him an outline of the ground over which he ought to travel; and in supplying him with hints, for the direction of his route. And all these, be it remembered, are means. and appliances offered only to the modern inquirer. In the days of Franklin and Rittenhouse, and those other self-made men to whom I have referred, books were scarce; public lectures unlinown; and public iibraries as barren as they were rare. Is it too much, then, to ask of the young men of our day, that, enjoying as they do, more of leisure and immeasurably greater facilities for improvement, they should at least endeavor to emulate such bright examples?

But, in the second place, why should the mechanic and laborer acquire this knowledge? Such a question may seem strange and superfluous at this day; and yet I fear that even now, and notwithstanding, all we hear 
of the diffusion of useful knowledge, it is often asked. Many persons seem, I had almost said, alarmed, when we speak of educating more highly the laboring classes; and are constantly telling us, in the famous words of Pope, that a "little learning is a dangerous thing," and that the smattering which we can give our young men will only fill them with self-conceit, and make them despise their business. 'To all this, I say, in reply, that a little learning is not what we propose to give them; we mean to give them a great deal. Yes, I say it deliberately, a greal deal, as measured by any standard, known to the author of the celebrated and much abused maxim, to which I have just referred. It must be remembered, that, in the time of Pope, the term "learning," included little, if any thing, except a knowledge of ancient languages and literature, and an acquaintance with history and poetry. What in the true sense constitutes knowledge, - that knowledge which is emphatically power,- which reveals to a man the constitution of the external world, and of his own frame, and of civil societr, and gives him power with respect to them all, that knowledge was, in Pope's time, most of it, undiscovered. Where, for example, in those days, was chemistry, with all the power which it gires us in bleaching, dyeing, tanning, sugar-refining, \&c. \&c. Where was the philosophy of steam, of electricity, and - galvanism, of the true functions of our muscular and nerrous organization, of botany and geology, with all the control which these gire us, orer the operations of Nature, and the workings of our own system. These things have not only been discorered, but they have been explained and simplified, till the highest and most prolific elements of science are brought down to the understanding of a child, and the humblest man may now possess himself of knowledge, transcending any thing ever dreamed of in the philosophy eren of a Newton or a Boyle. What we are able to teach the practical man may be little as compared with the omniscience of the Deity, or as compared with the science 
of him who devotes all his hours to study; but, as compared with any knowledge, susceptible of direct and productive application to the pursuits of a mechanic, which was possessed even by Pope himself, or which he could have acquired, though he had drunk so decply of the 'Picrian spring,' as to drink it out, we are not afraid to say, that what we propose to tench is great.

But, waiving this point, and admitting that the knowledge which cin' be acquired by these young men is in every sense little, we deny that there is any danger eren in a little learning. On the contrary, we maintain that a man is a safer citizen and a more useful neighbor, knowing something, be that something cver so small, than knowing nothing; and that just as you increase his stock of information, provided it be innocently employed, you in the same proportion render lim a better and a happier man. Pope, it is true, assures us, that shallow draughts intoxicate the brain, meaning, I suppose, in the language of the modern objection, that they inspire vanity, and fill the mind with a disgust for business. But I imagine, that they, whose brains are so constituted, that they would be intoxicated by shallow draughts, would hardly be sobered again, by foilowing the poct's direction, and "drinking deeply." A vain mind will be rain of its learning, whether it be much or little, just as it will be vain of any other possession. It should be considered, too, that a man's acquirements will never inspire vanity, except when they scrve to elevate him above his associates. If we proposed to instruct only a fer mechanies, to institute, in this respect, a distinction between them, we might, perhaps, awaken their pride. But our wish is to place all, in this respect, on the same level; to make knowledge perfectly universal, to lave it considered among the necessaries of life; so that a young man shall no more thisk of growing old without it, than without clothes or food, and shall as soon boast, that he has raiment or a roof to cover him, as that he has that which is but the raiment and the shelter of his nobler part. 
And with respect to their business, is it true, that the knowledge, which we exhort young mechanics to acquire, will disqualify them for it: or make it the object of their contempt? The simple purpose of that knowledge is, to awaken, inform, and invigorate, the mental faculties; and those faculties are the very means by which they are to transact business, and do all their ordinary duties. Does walking, in which you use precisely the same bones, and tendons, and muscles, as in running, disqualify you for running? Or does eating food, by which you apply to the several parts of your system a healthy stimulus and nourishment, incapacitate those parts from performing their appropriate functions? As little, then, will studies, which tend to enlighten and strengthen the inind, serve to incapacitate that mind for the discharge of its accustomed and proper rocation.

While adrerting to this objection, however, I cannot deny, that an error prevails among young men themselves, which lends it some color. When they first conceive the desire for knowledge, they are too ready to imagine that their usual pursuits afford no adequate opportunity for indulging it; and that, even were it otherwise, still there is not to be found, in such pursuits, the requisite scope for the application of learning, or the exercise of talent. Hence, the disposition, so generally erinced by young men who become attached to study, to abandon agricultural and mechanical employments, and to embrace what are usually termed the learned professions. This disposition I would by no means condemn, indiscriminately. There are cases, doubtless, in which a solemn sense of duty prompts the step; and the Church of Christ, or the bar, or the medical faculty, gain by it a rich accession of talent and zeal. But a mechanic or famer, no less than other men, has occasion for the exercise of the most gifted and cultivated powers. He is not merely a mechanic who is to supply the wants of his customers, and accumulate wealth. He is a parent, who is to train up his 
children to excellence, and who needs, for this task, the most varied and thorough kmowledge. $\mathrm{He}$ is a citi$z e n$, having important civil duties, all of which require knowledge, and in the discharge of which, he, of all men, may exercise, if lue have talent, a commanding and most salutary influence. He is, abore all, a man, having afiections, to be chastened and refined; a taste, to be cultivated; a mental and moral vision, to be enlarged; and a soul, to be fitted, by the exercise of holy thought, for honor and immortality.

And eren as mechanics, will not your business afford you room for applying your knowledge, and exercising your abilities? The results, at which you aim, in the mechanic arts, are brought about, not by your muscular strength so much as by your knowledge and skill. The real and effective agents, by which you work, are the powers of Nature, her affinities, her attractions, her all-absorbing energies of heat and gravity. Your office is confined to a proper disposition and wise control of these powers. And in that high office, exalted enough, methinks, to satisfy the most aspiring mind, how much might science aid you? Is it not, in truth, by her guidance alone, that you can be conducted to an adequate acquaintance with the principles and processes of your business? Experience, we are aware can teach you much; and much, too, you can learn from the instructions and example of the master-workmen in your trade. But still these are not adequate to give you that complete, srstematic, and thorough, know]edge, which is essential to your highest success. Iou would scarcely be satisfied with a physician, who knew nothing of the human body, but what he had learned from the conversation of his master, and by ex. perimenting on his patients. You require hins to have regularly studied the principles of his art; to have added to his own experience, and that of his immediate instrueter, that immense mass of experience which is treasured up in books. Shall it be deemed unreasonable, then, that we ask a similar course from you? In- 
deed, does not your interest, no less than consistency, demand, that, in connexion with those labors of the shop, in which you train your eye to observe, and your hand to guide, the processes of your art, you study also the principles of that art,-principles which must always control such processes, and disregarding which, they must inevitably fail. Yes, let it not be forgotten, that complete success in the mechanic arts can be secured only by knowledge; and that the knowledge, which is alone equal to your wants, is that linowledge which combines, with individual experience, the collective and generalized experience of all who have labored and observed in the same sphere.

How, for example, without that knowledge, can yon provide for the unexpected emergencies, which await every mechanic in the prosecution of his business From the state of your instruments and materials, or from the demands of your employers, will arise frecquent difficulties, which you have never yet experienced; for which no directions can be found in those guides called 'Assistants,' 'Companions,' \&c., and the provision for which, therefore, must be found, if found at all, in the resources of your own mind. But to what, I ask, will his resources amount, who knows nothing of first principles; who has never been accustomed to reflect on the operations in which he is engaged; and who, if he undertakes now, for the first time, to do it, will be almost certain to stumble?

Consider, too, that, if ignorant of the natural laws which govern your processes, you are not prepared to appreciate the inventions and alleged improvements which multiply, with such astonishing rapidity, in every branch of manufactures; and which you are constantly rrged to adopt. Some of them are doubtless of great value, while many more are destined no less certainly to follow their predecessors, in a brief though noisy career, to the land of forgetfulness. Now, who can hope to discriminate between the meritorious and the worthless, - between the inferior and the superior,- 
but he who has qualified himself to look beyond the promises of interested projectors, and the certificates of incompetent or inconsiderate witnesses, and to test the principles involved by the unalterable laws of the Creator?

Consider, also, that an artisan or manufacturer must have a knowledge of the theory and principles of his business, if he would himself become its improver and benefactor; if he would be remembered as the honored inventor of some cheaper, simpler, or more certain, instrument, or process. That thousands upon thousands of such instruments and processes are still undiscovered, and that they lie within the reach of every enterprising and competent artisan, is certain ; but it is equally certain, that he alone is competent to the high task of thus adding to the resources of his race, who has knowledgc. Rarely, very rarely, indeed, does the uninstructed and unreflecting mechanic compass any great and lasting improvement.

Common sense, as well as the history of the arts, would teach us, that, when such men attempt to innovate, it will generally be in quest of some impracticable. end, like perpetual motion; or by means totally inadequate to the object proposed; or for the mere purpose of reinventing, in inferior forms, instruments which are already in existence? And even when they do prosecute an attainable and important end, with skill and apparent success, how often are they arrested and delayed, if not defeated, from bcing unable to solve the incidentai or collateral questions, which start up in the progress of their work. Even Fulton, with all his knowledge and skill, is said to have becn delayed, several months, in the completion of his great experiment, for want of the requisite knowledge of the theory of resisting fluids. Whittemore's card-machine, and Perkins's nail-engine, were both long delayed, one of them for years, and were the source (as we are informed*) of

- See Judge Story's Discourse before the Mechanics' Insti:ule of Boston, 1831. 
infinite vexation to their authors, simply from the want of an adequate acquaintance with the principles of mechanics. Indeed, I ask, where and when any great inrention was perfected, without the aid of knowledge, and of profound thought? These creations of human genius are not struck off, as is generally supposed, at a single heat, or at random. They are not the offspring of some happy accident, nor the almost inspired guess of ignorant, unreflecting minds. No: these may gire the first hint; but it is the province of knowledge and thought to seize that hint, and carry it out to its results ; to disengage it from the mass of surrounding error, and to clear away the difficulties and doubts which always beset unexplored paths. Who will tell me, that James Watt, or Sir Humphrey Dary, or Sir Richard Arkwright, or Reuben Whitney, or Robert Fulton, projected and invented without knowledge, without science? Who will tell me, that your own Brewster, * uneducated though he was, ever brought his instruments to perfection, without intense and long-continued study; without retiring from the din of business and the distractions of society, and burying himself in the solitude of his chamber? Who does not know how glad he was to call in the aid of books; how much he had derived from the society and instructions of able friends; and how constantly he was driven, for the want of acquired science, to task the powers of his own prolific and original mind? Who erer heard him depreciate a liberal acquaintance with science and literature; and who does not sympathize in the conviction felt, I am told, so deeply, by his friends and by himself, that he wanted but the power, which science would have given him, to have added a long and erer-memorable list to those inventions, which now stand associated with his cherished memory?

* The late Gilbert Brewster, of Ponghkeepsie, a man of equal ingennity and worth; who, by his invention of the Eclipse Speeder, and other improvements in cotton machinery, rendered important service to the manufacturing industry of his country. 
In addition, however, to these practical advantages, which would acerue to the artisan, from a knowledge of the principles of his art, there are others, of a moral and intellectual character, which are entitled to at least a passing notice. The habit of studying the theory, as well as the practice, of an art, cannot but have the happiest influence in enlarging and liberalizing the mind. It leads the artisan to regard his occupation as something more than mechanical drudgery; as a liberal and intellectual pursuit, fitted to exercise the powers of his mind, and to raise his thoughts from the humble workmanship of man to that vaster mechanism, which bespeaks the wisdom and power of the Almighty. It affords unfailing topics for reflection and eonversation, during his hours of labor, and provides resources, of an intellectual charaeter, on which he can draw, in seasons of leisure, and at the adrance of old age. It seems, indeed, high time that the years which have hitherto been employed by the apprentice, in learning the mere handicraft of his art, should be employed, in part at least, in studying its principles, and in tracing the operation of those principles, throughout the works of Nature. It is more than time, that a higher moral and intellectual taste should be cultivated among the artisans of every country; and that hours, now wasted in dissipation, or frittered away in frivolous reading and conversation, should be devoted to the acquisition of knowledge, and the cultivation of virtue. In an age like this, when every species of manual labor is rendered more and more precarious by the changes which are perpetually taking place in the arts, it is the obvious interest of the laboring man to prepare himself, by reading and reflection, either to embrace a new employment, or to conform himself to sudden and unexpected vieissitudes. Independent, however, of interest, there are other and higher considerations, which address him as an intelligent and immortal being, and which urge him to embrace the opportunities of improvement, which have been rouchsafed him, by a kind Providence, even in his ordinary avocations. 
I have thus dwelt, on the benefits to be derived by mechanics from liberal and scientific studies. All my remarks are but a commentary on the celebrated maxim of Lord Bacon, that Krowledge is Power; and let me add, that, for the human race, there is no other power. Inferior animals are guided in their labors by a blind but unerring instinct; and hence, though destitute of knowledge, they build up works of surpassing beauty and utility. But man comes into being, almost utterly destitute of instinctire skill. Nearly all his capability is the slow growth of effort, of prudence, availing itself of past error, of study, exploring the nature and properties of the material and immaterial objects around him. In books is stored away the fruit of the experience and study of those who hare gone before us; and it is in that storehouse that you are to gather power for the discharge of the high trusts, which have been committed to your hands. Left to your own unaided researches, you would learn little of the world on which we all enter, strangers; and you would fall an easy prey to its thousand dangers and deceptions. But when, with your own observations, you combine the accumulated wisdom of ages; and when this wisdom has become your own, by patient reading and reflection, you will, indeed, have power. You will have power orer the refractory substances on which you are called to labor, and will cause them to bend to your will with an almost magical celerity. You will have power eren orer future events, for you will be prepared to anticipate their nature, to prepare for their approach, and to employ them as harmless contributors to your advancement. Fou will have power, too, orer the minds with which you associate, since you will know the motives that sway, and the prejudices that pervert, and the high aspirations that warm, them ; aspirations, which, though now stifled by worldly pursuits, are yet susceptible of being roused into vigorous and beneficent exercise. And above all, you may, by a proper improrement of the means with which you are intrusted, secure that no- 
blest of all power,-power over yourselves. By habits of thought and application, you can gain the command of your intellectual forces, and can direct them, all discuplined and ready for action, to any required point. Any may I not hope, that, by the due examination. of your own hearts, and of the moral relations in which you stand, you will, with the aid of God's blessing, be animated to the pursuit of that yet higher dominion over appetite and passion, which constitutes the perfection of our being, and for which there is rescrved a crown of eternal and unfading brightness.

\section{PAGE 121 .}

PROGRESS OF ENGLISH AND AMERICAN AGRICULTURE.

Improvement slow.-Considering, says Mr. McCulloch, the wonderful facilities of communication that exist in Great Britain, and the universal diffusion of information, by means of the press, the slowness with which agricultural improvements make their way is not a little surprising. Mr. Harte mentions, that, when he was a youth, he heard Jethro 'T'ull declare, that, though he had introduced turnips into the field in King William's reign, with little trouble or expense, and great success, the practice did not travel beyond the hedges of his own estate till after the peace of Utrecht.-(Essays, ii., page 223.) It might, one should think, be reasonably enough supposed. that improved practices would now be much more rapidly diffused; but experience shows that this is not really the case. "What is well known and systematically practised, in one county, is frequently unknown, or utterly disregarded, in the adjacent districts; and what is to every umprejurliced observer evidently erroneous, and injurious to the land, is, in some quarters, persisted in, most pertinaciously, though a journey of not many miles would open to the view the beneficial 
effects of a contrary practice." * In a large portion of England there is no regular alternation of corn and green crops; and in many counties, the drill husbandry has hardly obtained any footing.

Notwithstanding, too, that the best-cultivated lands in Northumberland, Norfolk, and the Lothians, are all ploughed by two horses, nothing is more common, as already stated, than to sec, in the vicinity of the metropolis, and throughout most parts of the south and west of England, three, four, and still more frequently, fire, horses, yoked in line to a plough, even where the soil is light and sandy! And, as a driver is always necessary when there are more than two horses, at least double the labor is expended on ploughing, where this barbarous practice is followed, that is required where it is abandoned.

There is a much greater aversion to precipitate changes, and a more resolute adherence to whaterer has been long practised, among farmers, than among any other class of persons. "Improrements, which effect material changes in established customs, have, under all circumstances and in all countries, ever been slowly and reluctantly admitted. It requires no little effort to quit the common routine of practice, and still more to relinquish long-maintained opinions.

:The general circumstances affecting agriculture are, moreover, little favorable to great, and, more especially, sudden, alterations. The farmer is not so much within reach of information, as the merchant and manufacturer; he has not, like those who reside in towns, the means of ready intercourse, and constant communication, with others engaged in the same occupation. $\mathrm{He}$ lives retired; his acquaintance is limited, and but little ralued; and, unless in the habit of reading, he is little likely to acquire any other knowledge of his art, than what is traditionary, what is transmitted from father to son, and limited, in its application, to his own immediate neighborhood."

* Grainger and Kennedy, on Tillage. 
Agriculture, and all sorts of industrious pursuits, were kept in a peculiarly backward state, in England, till after the accession of Henry the Seventh, A. D. 1485. This arose, partly from the destructire contests that grew out of the wild efforts of the Norman monarchs to conquer France, and the civil wars by which they were succeeded ; and partly from the abuses produced by the feudal system, and the enslaved and depressed state of the cultivators of the soil. In IIenry's reign, the foundations were lide of an order of things more farorable to the growth of opulence, and the progress of improvement.

Turnips, clover, and potatoes, were all introduced into England in the seventecnth century.

Blythe's 'Improver Improved,' published in 1649, is the first systematic work, in which there are any traces of the alternate system of husbandry, or of the introduction of clover, turnips, \&c., between culmiferous crops. The practice did not, however, make much progress during the seventeenth century; and though it forms, as it were, the very foundation of good furming, there are extensive districts in which it is still very imperfectly understood, and but little followed.

'The famous Jethro 'i'ull was the first, or among the first, who introduced the drill husbandry; and his work on horse-hoeing husbandry, published in 1731, did a vast deal to recommend the practice; though, from his undervaluing the influence of manure, it was, in other respects, prejudicial.

Stock husbandry has been more improved, since 1750 , than tillage husbandry. As soon as Bakewell's system of breeding began to be linown, it was taken up and followed by spirited and jurlicious farmers, in all parts of the country. Of these, Mr. Culley, of Northumberland, was one of the most conspicuous. He published his 'Observations on Live Stock' in 1786 ; and in it, the just principles for improving the breeds of do mestic animals were, for the first time, fully elucidated This has had a wonderful influence in increasing the supply of butchers' meat. Indeed, the principal im- 
provement in arable lusbandry, - the general introduction and superior management of green crops,-may be, in no inconsiderable degree, ascribed to the anxiety of farmers to procure an abundant and suitable supply of food for their stock. The superior attention paid to stock farming may probably be, to some cxtent, at least, accounted for, from the circumstance of tithe pressing with comparative lightness on pasture land, while it falls with its full weight on arable land, and operates powerfully to prevent the outlay of capital upon it. Butt, howerer it may be accounted for, there can be no doubt of the fact, that stock husbandry is now more advanced than tillage husbandry; and that, in all that belongs to the breeding and rearing of cattle, horses, sheep, and pigs, the English are, at present, superior to the Scotch, and to every other people.

But, though surpassed by its kindred branch, the progress of arable husbandry in England, since 1760, and of the improrements connected therewith, has, notwithstanding, been great.

Of the recent improvements, one of the most important has been the introduction of bone-dust as a manure. In many places, but particularly in Lincolnshire, this has occasioned a vast increase of produce; and has enabled many extensive tracts to be brought into a high state of cultivation. There has been, in fact, almost every where, throughout the country, but especially in the northern counties, a progressive improrement in agriculture, effected, partly by the better drainage of the land, partly by the adoption of better rotations, partly by the enforcement of greater economy in the management of the details, and partly by other causes. No doubt, there is still, in many counties, very great room for further improvements; but there has been, eren in the most backward, considerable adrances made since the peace.

In proof of the extraordinary change that has taken place, we may mention, that, in the wolds of Lincolnshire, the crops of turnips are said to have become from 
five to ten times heavier, within the last few years, from the application of bone manure to their culture; at the same time that there has been a proportional increase in the productiveness of the crops! Similar improvements, and, in some instances, quite as great, have been made in other parts of the country. It is gratifying, too, to know, that the capacities of improvement are far from being any where exhausted. But what has been effected shows what might be done, were the productive energies of the more backward districts better developed by the extension of the improved practices of Norfolk, Northumberland, Lincoln, \&e., to other counties. The granting of leases of a reasonable length, and containing proper conditions as to management, and the abolition or commutation of tithes for a fixed, invariable payment, would be the most likely means to bring about so desirable a result. It is impossible, indeed, to say to what extent, under such circumstances, improvement might be carried. See .McCulloch's Statistics of Great Britain.

The following account of the present state of agriculture in England was recently given by the Hon. Danicl Webster, in a speceh delivered at a public meeting in Boston, Massachusetts.

Mr. Webster began with stating, that he regarded agriculture as the leading interest of society; and as having, in all its relations, a direct and intimate bearing upon liuman comfort and the national prosperity.

The primary elements, which enter into the consid eration of the agriculture of a country, are four ; climate, soil, price of land, and price of labor.

The climate of England differs essentially from that of this country. England is on the western side of the eastern, and we on the eastern side of the western, con tunent. 'The climate of each country is materially affected by its respective situation in relation to the ocean. The winds which prevail most, both in this country and in England, are from the west; it is known that the wind blows, in our latitudes, from some point west to 2S* 
some point east, on ain average of years, nearly or quite three days out of four. These facts are familiar. The consequences resulting from them are, that our Winters are colder and our Summers much hotter, than in England. Our latitude is about that of Oporto, yet the temperature is very different. On these accounts, therefore, the maturing of the crops in England, and the power of using thesc crops, creates a material difference between its agriculture and ours. It may be supposed, that our climate must resemble that of China, in the same latitudes; and this fact may have an essential bearing upon that branch of agriculture which it is proposed to introduce among us,- - the production of silk.

The second point of difference, between the two countries, lies in the soil. The soil of England is mainly argillaceous; a soft and nnctuous loam upon a substratum of clay. This may be considered as the predominant characteristic, in the parts which he visited. The soil in some of the southern counties of England is thinner; some of it is what we should call stony; much of it is a free gravelly soil, with some small part which, with us, would be called sandy. Through a great extent of country, this soil rests on a deep bed of chalk. Ours is a granite soil. There is granite in Great Britain; but this species of soil prevails in Scotland, a part of the country which more resembles our own. We may have lands as good as any in England. Our alluvial soils on Connecticut river, and in some other parts of the country, are equal to any lands; but these have not, ordinarily, a wide extent of clay subsoil. The soil of Massachusetts is harder, more granitic, less abounding in clay, and altogether more stony, than the soil of England. The surface of Massachusetts is more uneven, more broken with mountain ridges, more diversified with hill and dale, and more abundant in streams of water, than that of England.

The price of land in that country, another important element in agricultural calculations, differs greatly from the price of land with us. It is three times as high as in Massachusetts, at least. 
On the other hand, the price of agricultural labor is much higher in Massachusetts, than in England. In different parts of England, the price of labor is considcrably various; but it may be set down as twice as dear with us here.

These are the general remarks, which have suggested themselves in regard to the state of things abroad. Now, have we any thing to learn from them? Is there any thing in the condition of England, applicable to ours; or, in regard to which, the agriculture of England may be of use to Massachusetts and other countries?

The subject of agriculture in England has strongly attracted the attention and inquiries of men of science. They have studied particularly the nature of the soil. More than twenty years ago, Sir Humphrey Davy undertook to treat the subject of the application of chemical knowledge to agriculture, in the analysis of soils and manures. The same attention has been continued to the subject; and the extraordinary discoveries and advances in chemical scicnee, since his time, are likely to operate greatly to the advantage of agriculture. 'The best results may be expected from them. These inquiries are now prosecuted in France, with great enthusiasm and success. We may lope for like beneficial results here, from the application of science to the same objects.

But, although the circumstances of climate and situation and nature of the soil form permanent distinetions, which cannot be changed, yet there are other differences, resulting from different nodes of culture, and different forms of applying labor; and it is to these differences that our attention sliould be particularly directed. Here, there is much to learn. English cultivation is more scientific, more systematic, and more exact, a great deal, than ours. 'This is partly the result if necessity. $\Lambda$ rast population is to be supported, on comparatively a small surface. Lands are dear, rents are high, and hands, as well as moutlis, are numerous. Careful and skilful cultivation is the natural result of 
this state of things. An English farmer looks not merely to the present year's crop. He considers what will be the condition of the land, when that crop is off; and what it will be fit for, the next year. He studies to use his land, so as not to abuse it. On the contrary, his aim is to get crop after crop, and still the land shall be growing better and better. If he would content himself with raising from the soil a large crop this year, and then leaving it neglected and exhausted, he would starve. It is upon this fundamental idea, of constant production without exhaustion, that the system of English cultivation, and indeed of all good cultivation, is founded. England is not original in this. Flanders, and perhaps Italy, have been her teachers. This system is carried out in practice, by a well-considered rotation of crops. The form, or manner, of this rotation, in a given case, is determined very much by the value of the soil, and partly by the local demand for particular products. But some rotation, some succession, some rariation in the annual productions of the same land, is essential. No tenant could obtain a lease, or, if he should, could pay his rent and maintain his family, who should wholly disregard this. White crops are not to follow one another. White crops are wheat, barler, rye, oats, \&c. Our maize, or Indian corn, must be considered a white crop: although, from the quantity of stalk and leaf which it produces, and which are such excellent food for cattle, it is less exhausting than some other white crops; or, to speak more properly, it makes greater returns to the land. Green crops are turnips, potatoes, beets, retches, or tares, (which are usually eaten while growing, by cattle and sheep, or cut for green food,) and clorer. Buck or beech wheat, and winter oats, thought to be a rery useful product, are regarded also as green crops, when caten on the land ; and so, indeed, nay any crop be considered, which is used in this way. But the turnip is the great green crop of England. Its cultivation has wrought such changes, in fifty years, that it may be said to have revolutionized En rich arriculture. 
Before that time, when lands became exhausted, by the repetition of grain crops, they werc left, as it was temed, fallow; that is, were not cultivated at all, but abandoned, to recruit themselves as they might. This occurred as often as every fourth year, so that one quarter of the arable land was always out of cultivation, and yielded nothing. Turnips are now substituted in the place of these naked fallows; and now, land in turnips is considered as fallow. What is the philosophy of this? The raising of crops, even of any', the most farorable crop, does not in itself enrich, but, in some degree, exhausts the land. The exhaustion of the land, however, as experience and observation have fully demonstrated, takes place mainly when the seeds of a plant are allowed to perfect themselves. The turnip is a bicnnial plant. It does not perfect its seed before it is consumed. There is another circumstance, in respect to the turnip plant, which deserves consideration.

Plants, it is well understood, derive a large portion of their nutriment from the air. The leaves of plants are their lungs. The leares of turnips expose a wide surface to the atmosphere, and derive, therefore, much of their subsistence and nutriment from these sources. The broad leaves of the turnips likewise shade the ground, preserre its moisture, and prevent, in some measure, its exhaustion by the sun and air.

The turnips have a further and ultimate use. Meat and clothing come from animals. The more animals are sustained upon a farm, the more meat and the more clothing. These things bear, of course, a proportion to the number of bullocks, sheep, swine, and poultry, which are maintained. The great inquiry, then, is, what kind of crops will least exhaust the land in their cultivation, and furnish, at the same time, support to the greatest number of animals ?

A very large amount of land, in England, is cultivated in turnips. Fields of turnips of three, four, and even five, hundred acres, are sometimes seen, though the common ficlds are much less; and it may be ab- 
served, nere, that in the richest and best-cultivated parts of England, enclosures of ten, fifteen, twenty, or thirty, acres, seemed more common. Since the introduction of the turnip culture, bullocks and sheep have trebled in number. Turnips, for the reasons given, are not great exhausters of the soil ; and they furnish abundant food for animals. Let us suppose, that one bushel of oats or barley may be raised at the same cost as ten bushels of turnips, and will go as far in support of stock. The great difference in the two crops is to be found in the farmer's barn-yard. Here is the test of their comparative value. This is the secret of the great advantages which follow from their cultivation. 'The value of manure, in agriculture, is well appreciated. M'Queen states the extraordinary fact, that the value of the animal manure, annually applied to the crops in England, at current prices, surpasses in value the whole amount of its foreign commerce. There is no doubt that it greatly exceeds it. 'The turnip crop returns a vast amount of nutritive matter to the soil. The farmer, then, from his green crops, and by a regular system of rotation, finds green feed for his cattle and wheat for the market.

Among the lighter English soils, is that of the county of Norfolk; a county, however, which he had not the pleasure to visit. Its soil, he understood, is light, a little inclined to sand, or light loam. Such soils are not unfarorable to roots. Here is the place of the remarkable cultivation and distinguished improvements of that eminent cultivator, Mr. Coke, now Earl of Leicester.* In these lands, he understood, a common rotation is turnips, barley, clover, wheat. These lands resemble much of the land in our county of Plymouth; and the sandy lands to be found in the vicinity of the Connecticut and Merrimack rivers. The cultivation of green crops in New England deserves attention. There is no incapacity in our soil; and there

* He has increased the rental of his farms, by his improvements, from twenty-five to two hundred thousand dollars a year. 
are 110 circumstances unfavorable to their production. What would be the best kind of suceulent vegetables to be cultivated, whether turnips or carrots, he was not prepared to say. But no attempts, within his knowledge, have been made among us of a systematic agriculture; and until we enter upon some regular rotation of crops, and our husbandry becomes more systematic, no distinguished success ean be looked for. $\Lambda$ s to our soil, as had been remarked, there is no inherent incapacity for the production of any of the common crops. We could raise wheat in Massachusetts. The average crop in England is twenty-six bushels to the acre. From his own farm, and it was comparatively a thin and poor soil, he had obtained, this Summer, seventy-six bushels of wheat upon three acres of land. It is not, therefore, any want of capability in the soil; but the improvement and success of our husbandry must depend upon a succession of crops adapted to the circumstances of our soil, climate, and peculiar condition.

In England, a large portion of the turnip crop is consumed on the land where it grows. The sheep are fed out of doors all Winter; and he saw many large flocks, thousands and millions of sheep, which were never housed. This was matter of surprise, especially considering the wetness of the climate; and these sheep were often exposed in fields where a dry spot could not be found for them to lie down upon. Sheep were often folded in England by wattled fences, or hurdles, temporarily erected in different parts of the field, and removed from place to place, as the portions of the crop were consumed. In some cases, they were folded, and the turnips dug and carried to them. In such case, they were always fed upon lands which were intended the next year to be, as far as practicable, brought under cultivation. He had seen many laborers in fields, employed in drawing the turnips, splitting them, and seattering them over the land, for the use of the sheep, which was considered better, often, than to leave the sheep to dig for themselves. These laborers would be 
so employed all Winter; and if the ground should become frozen, the turnips are taken up with a bar. Together with the turnips, it is thought important that the sheep should have a small quantity of other food. Chopped hay, sometimes a little oil cake, or oats, is given. This is called trough food, as it is eaten in troughs, standing about in the field. In so moist a climate as that of England, some land is so wet, that, in the farmer's phrase, it will not carry sheep; that is, it is quite too wet for sheep to lie out upon it. In such cases, the turnips must be carried, that is, removed from the field, and fed out elsewhere. The last season was uncommonly wet, and for that reason, perhaps, he could not so well judge; but it appeared to him, it would be an improvement in English liusbandry to furnish for sheep, oftener than is done, not only a tolerably dry ground to lie on, but some sort of shelter against the cold rains of Winter. The turnips, doubtless, are more completely consumed when dug, split, and fed out. The Swedish turnip, he had little doubt, was best suited to cold climates. It was scarcely injured by being frozen in the ground in the Winter, as it would thaw again, and be still good in Spring. In Scotland, in the Lothians, where cultivation is equal to that in any part of England, it is more the practice, than further south, to house turnips, or draw them, and cover them from frost.

One of the things which now attracted much attention among the agriculturists in England, was the subject of tile draining. This most efficient and successful mode of draining is getting into very extensive use. Much of the soil of England, as he had already stated, rested on a clayey and retentive subsoil. Excessive wetness is prejudicial and destructive to the crops. Marginal drains, or drains on the outside of the fields, do not produce the desired results. These tile drains have effected most important improvements. The tile itself is made of clay, baked like bricks, about one foot in length, four inches in width, three fourths of an inch in 
thickness, and stands from six to cight inches in height, bcing hemispherical, or like the half of a cylinder, with its sides elongated. It resembles the Dutch tiles sometimes seen on the roofs of the old loouses in Albany and New York. A ditch is sunk eighteen or twenty inches in depth, and these drains are multiplied over a field, sometimes at a distance of only seven yards apart. The ditch, or drain, being dug, these tiles are laid down, with the hollow side at bottom, on the smooth clay, or any other firm subsoil, the sides placed near to each other, some little straw thrown over the joints to prevent the admission of dirt, and the whole covered up. This is not so expensive a mode of draining as might be supposed. The ditch, or drain, need only be narrow, and tiles are of much cheaper transportation than stone would be. But the result is so important, as well to justify the expense. It is estimated, that this thorough draining adds often twenty per cent. to the production of the wheat crop. A beautiful example came under his obscrvation in Nottinghamshire, not long before he left England. A gentleman was showing him his grounds for next year's crop of wheat. On one side of the lane, where the land had been drained, the wheat was already up, and growing luxuriantly; on the other, where the land was subject to no other disadrantage than that it had not been drained, it was still too wet to be sowed at all. It may be thought singular enough, but it was doubtless true, that on stiff, clayey lands, thorough draining is as useful in dry, hot Summers, as in cold and wet Summers; for such land, if a wet Winter or Spring be suddenly followed by hot and dry weather, is apt to become hard and baked, so that the roots of plants cannot enter it. Thorough draining, by giving an opportunity to the water on the surface to be constantly escaping, corrects this evil. Draining can never be needed to so great an extent in Massachusetts, as in England and Scotland, from the different nature of the soil ; but we have yet quantities of low meadow lands, producing wild, harsh, sour grass- 
es, or producing nothing, which, there is little doubt, might be rendered most profitable hay fields, by being well drained. When we understand better the importance of concentrating labor, instead of scattering it, when we shall come to estimate, duly, the superior profit of 'a little farm, well tilled,' orer a great farm, half cultivated and half manured, overrun with weeds, and scourged with exhausting crops, we shall then fill our barns, and double the Winter feed for our cattle and sheep, by the products of these waste meadows.

There is in England another mode of improvement, most important, instances of which he had seen, and one which he regarded as the most beautiful agricultural improrement which had ever come within his observation. He meant irrigation, or the making of what is called water meadows. He had first seen them in Wiltshire, and was much struck with them, not having before understood, firom reading or conversation, exactly what they were. But he had afterwards an opportunity of examining a most signal and successful example of this mode of improvement on the estates of the Duke of Portland, in the north of England, on the borders of Sherwood forest. Indeed, it was part of the old forest. Sherwood forest, at least in its present state, is not like the pine forests of Maine, the heary hard-rood forests of the unredeemed lands of New Hampshire and Vermont, or the still heavier timbered lands of the West. It embraces a large extent of country, with various soils, some of them thin and light, with beautiful and venerable oaks, of unknown age, much open ground between them and underneath their wide-spread branches, and this covered with heather, lichens, and fern. As a scene to the eye, and to the memory by its long existence and its associations, it is beautiful and interesting. But in many parts the soil is far enough from being rich. Upon the borders of this forest are the water meadows of which he was speaking. A little river ran through the forest in this part, at the bottom of a valley, with sides moderately 
sloping, and of considerable extent, between the river at the bottom and the common level of the surrounding country above. 'This little river, before reaching the place, ran through a small town, and gathered, doubtless, some refuse matter in its course. From this river the water was taken, at the upper end of the valley, conducted along the edge, or bank, in a canal or earrier, and from this carrier, at proper times, suffered to flow out, very gently, spreading over and irrigating the whole surface, trickling and shining, when he saw it, (and it was then November,) among the light green of the new-springing grass, and collected below in another canal, from which it was again let out, to flow in like manner over land lying still further down towards the bottom of the valley. Ten years ago, this land, for production, was worth little or nothing. He was told that some of it had been let for no more than a shilling an acre. It has not been manured, and yet is now most extensively productive. It is not flooded; the water does not stand upon it; it flows gently over it, and is applied several times in a year, to each part,-say in Mareh, May, July, and October. In November, when he saw it, the farmers were taking off the third crop of hay cut this season, and that crop was certainly not less than two tons to the acre. 'This last crop) was mostly used as green food for cattle. When he spolie of the quantity of tons, he meant tons of dried hay. After this crop was off, sheep were to be put on it, to have lambs at Christmas, so as to come into market in March, a time of year when they command a high price. Upon taking off the sheep in March, the land would be watered, the process of watering lasting two or three days, or perhaps eight or ten days, according to eircumstances, and repeated after the taking ofl of each successive crop. Although this water has, no doubt, considerable sediment in it, yet the general fact shows how important water is to the growth of plants, and how far even it may supply the place of other sourees of sustenance. Now, we in Massachusetts have a.more un- 
even surface, more valleys with sloping sides, by many times more streams, and such a climate that our farms suffer much oftener from drought than farms in England. May we not learn something useful, therefore, from the examples of irrigation in that country?

With respect to implenients of husbandry, Mr. Webster was of opinion that the English, on the whole, had no advantage over us. Their wagons and carts were no better; their ploughs, he thought, were not better any where, and in some counties far inferior, because unnecessarily heavy. The subsoil plough, for which we have little use, was esteemed a useful invention; and the mole plough, which he had seen in operation, and the use of which was to make an under-ground drain, without disturbing the surface, was an ingenious contrivance, likely to be useful in clay soils, free from stone and gravel, but which could be little used in Massachusetts. In general, he thought the English utensils of husbandry were unnecessarily cumbrous and heary. The ploughs, especially, required a great strength of draught. But as drill-husbandry was extensively practised in England, and very little with us, the various implements, or machines, for drill-sowing, in that country, quite surpass all we have. He did not remember to have seen the horse-rake used in England, although he had seen in operation implements for spreading hay, from the swarth, to dry, or rather, perhaps, for turning it, drawn by horses.

The raising of sheep, in England, is an immense interest. England probably clips fifty millions of fleeces this year, lambs under a year old not being shorn. The average yield may be six or seven pounds to a fleece. There are two principal classes of sheep in England, the long-wooled and the short-wooled. Among these are many varieties, but this is the general division, or classification. The Leicester and the South Down belong respectively to these several families. The common clip of the former may be estimated from seven to eight pounds; and of the latter, from three to three and 
a half or four. Mr. Webster mentioned these particulars only as estimates; and much more accurate information might doubtless be obtained from many writers.

The Lcicester sheep were like the short-horned cat tle. They must be kept well; they should always be fat; and, pressed by good keeping to early maturity, they are found very profitable. 'Feed well' was the maxim of the great Roman farmer, Cato ; and that short sentence comprises much of all that belongs to the profitable economy of live stock. The South Downs are a good breed, both for wool and mutton. They crop the grass that grows on the thin soils, over beds of chalk, in Wiltshire, Hampshire, and Dorsetshire. They ought not to scorn the pastures of New England.

When one looks, said Mr. Webster, to the condition of England, he must see of what immense importance is every, even the smallest, degree of improvement in its agricultural productions. Suppose, that by some new discovery, or some improved mode of culture, only one per cent. could be added to the annual results of English cultivation; this, of itself, would materially affect the comfortable subsistence of millions of human beings. It was often said that England was a garden. This was a strong metaphor. There was poor land, and some poor cultivation, in England. All people are not equally industrious, careful, and skilful. But, on the whole, England was a prodigy of agricultural wealth.

\section{AMERICAN AGRICULTURE.}

The system of husbandry prevailing in our country is much inferior to that in England and Scotland. The produce of virgin soils at the West is not only no proper measure of the character of our culture, but it lias doubtless contributed to keep it in a depressed state. Instead of having recourse to better tillage, and a more enlightened plan of cropping, the farmer who finds his profits declining abandons his farm, and establishes himself in a new country. In this way our soils, in the eastern 
part of the Union, have been gradually deteriorating, while those of England and Scotland have been improving. The same process is now going on in the Western States; and, unless the work of exhausting the soil is arrested, successive emigrations must take place, till our farming population reach the shores of the Pacific. The a verage produce of an acre of land in the eastern counties of New York, or in Massachusetts, is about one third less than it is in England. In many parts of Scotland, a country, which, forty years since, was little more than unbroken heath, the arerage annual produce is greater than in England. These countries owe their superiority in this respect, therefore, not to any natural adrantages of soil or climate, but to a larger outlay of capital in manuming and draining, and to a more judicious system of rotation in crops. The proprietors of land, too, have not been infected with so great a dread of "book-farming," as has prevailed with us.

The history of the last few years, however, is full of encouragement. The old plan of fallowing is nearly abandoned. Our farmers are beginning to discover the value of manure. Fifteen years since, nothing was more common, in Winter, than to see farmers who resided on the Mohawk drawing the manure which had been accumulating, perhaps for years, and emptying it, through holes in the ice, into the river. It is now preserved, and applied to the fields. The use of plaster, too, has done much to ameliorate the soil, and some progress has been made (though much too little) towards a proper system of rotation and root culture. Wherever the spirit of improvement has been actire, the results have been astonishing. The annual produce of Dutchess county, on the Hudson, has doubled, perhaps trebled, within twenty years. The price of land has adranced in a still greater ratio. Instances are adduced from various parts of the country, all showing that nothing is wanting but good liusbandry, to make any of our soils fertile and profitable. For more detailed remarks on this important subject, I would refer to 
The Farmer's Companion,' by the late Judge Buel, which constitutes the sixteenth volume of 'TuE School Lizizany.' Of this work Professor Dean, in his Sketch of the Life of Judge Buel, thus speaks: 'This is "the last and most perfect of his works, containing, within a small compass, the embodied results of his agricultural experience, $-\mathrm{a}$ rich legacy, to which the great extent of our farming interest cannot remain insensible." "I deem it really the most fortunate circumstance in his life, that he should have been permitted, so immediately previous to his departure, to furnish just this volume, for just this purpose; and I shall confidently expect, that the coming generation will be better farmers, better citizens, and better men, from having had the formation of their young minds influenced, to some extent, by the lessons of experience and practical wisdom derived from the last, best, most mature, production of this excellent man."

\section{PAGES 188 AND 948.}

IIPROVEMENT IN FOOD, CLOTHING, AND LODGING.

There is no better way of testing the real influence of improvements in the arts and sciences, than by considering how they have affected the great bulk of the people. While all classes have been vastly benefited, there can be no doubt, that they who labor with their hands have been the greatest gainers. These improvements have enabled multitudes of them to employ their talents in the most productive manner, and in that way, to advance themselves to the highest stations of wealth and influence. In this country, it is proverbial, that the rich and distinguished of the present generation are descended from those, who, two generations since, were poor, and without a name. It is not so generally known, that, to a great extent, the same fact may be alleged of Great Britain. "I believe," says Mr. Rickards, "it 
may be safely added, that every one of the great fortunes and immense establishments, existing in the manufacturing districts, may be traced to the minute savings of common operatives, who, from the smallest of small beginnings, have, by prudence, skill, and unremitting perseverance and industry, raised themselves, with unexampled rapidity, to a pinnacle of wealth and importance, which, but for its existence, could scarcely be believed. This, then, is a state of society, with its institutions, essentially popular in its origin."

It is our object, however, in this place, to show what the mass of the people have gained, in respect to physical comfort. For this purpose we shall compare their past condition with their present, in respect to food, clothing, and lodging; making the comparison in regard to England, Scotland, and the United States.

\section{Exgland.}

1. In the Reign of Elizabeth.

[A. D. 1568-1603.] "The bread, throughout the land," says Harrison, who wrote in the reign of Elizabeth, "is made of such graine, as the soil yielded; neverthelesse, the gentilitic commonlie provide themselves sufficientlie of wheat for their owne tables, whilest their household and poore neighbours, in some shires, are inforced to content themselves with rie or barleie; yea, and in time of dearth, manie with bread made either of bran, peason, or otes, or of all together, and some acorns among; of which scourge the poorest doe soonest tast, sith they are least able to provide themselves of better. I will not saie that this extremitie is oft so well to be seene in time of plentie, as of dearth; but, if I should, I coulde easilie bring my triall." $-D e$ scription of England.

Sir F. M. Eden, whose elaborate researches have thrown much light on this subject, truly states, that the substantiality of diet, for which the sixteenth century is renowned, was confined chiefly to the tables of per 
sons of rank. "A maid of honor, perhaps, breakfasted on roast beef; but the ploughman, in these good old times, as they are called, could, I fear, only banquet on the strength of water gruel." - State of the Poor.

"It was not," says Hume, "till the end of the reign of Henry the Eighth, that any salads, carrots, turnips, or other edible roots, were produced in England; the little of these regetables that was used, was imported from Holland and Flanders. Queen Catharine, when she wanted a salad, was obliged to despatch a messenger thither, on purpose."

With the execption of the potato, most of these regetables seem to have been introduced into England from the south of Europe. The artichoke, which is perhaps the oldest, eame from the Levant, by way of Italy, and was introduced into England in the rcign of Henry the Eighth. Asparagus and celery came from Italy, through France, and were introduced about the close of the sixteenth century. The cauliflower was brought from Italy, where it was obtained from the island of Cyprus, and was imported into England about the close of the seventeenth century. The beet and radish eame at a later period, from France. (See Beckmann.)

"Many esculent plants," says Wade, in his 'History of the Middle and Working Classes,' "which are now cultivated in the fields, and, in a scarcity of corn, are found to be admirable substitutes even for bread, were in the beginning of the sixteenth century either little known, or exclusively confined to the tables of the rich. Potatoes, at present, are a general article of diet; in King James's reign, they were considered as a great delicaey. They are noticed among the articles provided for the Queen's houschold; the quantity, however, is small, and the price two shillings the pound. In 1619, two cauliflowers cost two shillings, and sixteen artichokes, three shillings and four pence,-prices which sufficiently prove their rarity. Tea and sugar, which now form regular artieles of cottage economy, were still 
greater rarities. The former article was not imported, in any considerable quantities, till after the establishment of a new East-India Company, with liberty to trade to China and Japan, in 163\%. No notice is ti.ken of tea, in the book of rates, annexed to the act, passed in 1660, for granting Charles the Second a sub sidy of tonnage and poundage upon all merchandisc exported and imported; but in a subsequent act, passed in the same session, tea, coffee, and chocolate, are subjected to the excise. It is singular, howerer, that the duty was imposed on the liquor prepared from these articles, in lieu of the articles themselres; from which it may be inferred, that none of these bererages were made by private families, but they were purchased, ready prepared, from the compounders.

"The high price of butchers" meat, in the reign of James the First, (the necessary consequence of agricultural improvement,) is a strong proof that flesh meat constituted an inconsiderable portion of the diet of laborers, at the beginning of the seventeenth century. About this period, beef was three pence and three farthings, and mutton three pence and three eighths of a penny, the pound. At this time, the wages allowed by justices in a midland county, to laborers in husbandry, were from six pence to ten pence the day, without meat, and to women haymakers, four pence the day, without meat. In these ratings, the magistrates calculated that half the day's earnings were equivalent to diet for one day, which is a much less proportion than would be requisite at present. The price of corn was rather higher than in the middle of the following century. The arerage price of middling wheat, from 1606 to 1625 , was one pound fourteen shillings and one penny, the quarter; whereas the arerage price, for the twenty years ending in 1745 , was one pound nine shillings and ten pence.

"In regard to clothing, Moryson, who lired in this reign, and travelled extensively over Europe, speaking, in his 'Itinerary,' of England, tells us, 'Husbandmen 
weare garments of course cloth, made at home, and their wives weare gownes of the same cloth, kirtles of some light stuffe, with linnen aprons, and cover their heads with a linnen coyfe and a felt hat, and in general their linnen is course, and made at home."

Dr. Howell, as quoted by Hume, states that Queen Elizabeth herself never wore any other than cloth hose, until the third year of her reign, when she was presented with a pair of black silk linit stockings, by her silk woman.

'The luxury of a linen shirt was confined to the higher classes, says McCulloch. The cloth used by the bulk of the people was mostly of home manufacture; and, compared with what they now malic use of, was at once costly, coarse, and comfortless. All classes, from the peer to the peasant, were miversally without many articles, the daily enjoyment of which is now deemed essential, even by the poorest individuals. Tea and coffee were then wholly, and sugar almost wholiy unlinown.

In regard to lodgings, it appears, that in this reign, the dwelling of an English peasant was little superior, in comfort and cleanliness, to what we observe in the elay-built horels of the Irish. The dwellings of the common people, according to Erasmus, had not yet attained the convenience of a chimney to let out the smoke, and the flooring of their huts was nothing but the bare ground; their beds consisted of straw, among which was an ancient accumulation of filth and refuse, with a hard block of wood for a pillow. And such, in general, was the situation of the laboring classes, throughont Europe. 'The following passage is from 'Holingshed's Chronicle,' chapter x :

"Neither do I speak this in reproach of any man, God is my judge; but to show that I do rejoice rather to see how God has blessed us with his good gifts, and to behold how that, in a time wherein all things are grown to most excessive prices, we do yet find the means to attain and achieve such furniture, as hereto- 
fore has been impossible; there are old men yet dwelling in the village where I remain, which have noted three things to be marvellously altered in England within their sound remembrance. One is, the multitude of chimneys lately erected: whereas, in their young days, there were not above two or three, if so many, in most uplandish towns of the realm, (the religious houses and manor places of their lords always excepted, and, peradventure, some great personage:) but each made his fire against a reredosse, in the hall where he dined and dressed his meat. The second is the great amendment of lodging; for, said they, our fathers, and we ourselves, have lain full oft upon straw pallettes, covered only with a sheet under coverlets, made of dagswaine or hopharlots, (I use their own terms,) and a good round $\log$ under their head, instead of a bolster. If it were so, that the father, or the goodman of the house, had a matrass or flock-bed, and thereto a sack of chaff to rest his head upon, he thought himself to be as well lodged as the lord of the town: so well were they contented. Pillows, they said, were thought meet only for women in childbed: as for servants, if they had any sheet above them, it was well : for seldom had they any under their bodies, to keep them from the pricking straws, that ran oft through the canvass, and rased their hardened hides. The third thing they tell of is the exchange of treene platters (so called, I suppose, from tree or wood) into pewter, and wooden spoons into silver or tin. For so common were all sorts of treene ressels in old time, that a man should hardly find four pieces of pewter (of which one was, peradventure, a salt) in a good farmer's house."

Again, in chapter sixteen: "In times past, men were contented to dwell in houses builded of sallow, willow, \&c., so that the use of the oak was, in a manner, dedicated wholly unto churches, religious houses, princes' palaces, navigation, \&c. ; but now, sallow, \&c., are rejected, and nothing but oak any where regarded; and yet see the change; for, when our houses were builded 
of wiliow, then had we oaken men; but now, that our huuses are come to be malle of oak, our men are not only become willow, but a great many altogether of straw, which is a sore alteration. In these, the courage of the owner was a sufficient defence to keep the house in safety; but now, the assurance of the timber must defend the men from robbing. Now have we many chimneys ; and yet our tender lines complain of rheums, catarrhs, and poses; then had we none but reredosses, and our heads did never ache. For, as the smoke, in those days, was supposed to be a sufficient hardening for the timber of the house, so it was reputed a far better medicine to keep the good-man and his family from the quack or pose, wherewith, as then, very few were acquainted."

Again, in ehapter eighteen : "Our pewterers, in time past, employed the use of pewter only upon dishes and pots, and a few other trifles for service; whereas, now they are grown into such exquisite cunning, that they can, in manner, imitate by infusion, any form or fashion of cup, dish, salt, or bowl, or goblet, which is made by goldsmith's craft, though they be never so curious, and very artificially forged. In some places beyond the sea, a garnish of good flat English pewter (I say flat, because dishes and platters, in my time, began to be made deep, and like basins, and are, indeed, more convenient, both for sauce, and keeping the meat warm) is almost esteemed so precious, as the like number of ressels that are made of fine silver."

\section{In the Reign of George the Second.}

Food.-The author of 'Tracts on the Corn Laws,' who is regarded by Mr. McCulloch as high authority, estimates that, in 1760, not much more than half the population of England and Wales fed on wheat; that nearly one sixth of the whole subsisted on rye, and the remainder on barley and oats. MeCulloch is quite sure that, at present, there are not twenty thousand in the whole country who use rye; that the use of barley and oats is entirely discontinued; that wheat is now the all 
but universal bread-corn of England; and that even the inferior kinds of wheat are now rejected, except by the very lowest and poorest classes. He also calculates that the quantity of butchers' meat consumed in london, at this time, is twice as great, compared with the population, as it was in 1740 or 1750 . The author of 'The Doctor,' who is very partial to the olden time, speaking of the garden of a substantial yeoman, in Yorkshire, says, "A hundred years ago, potatoes had hardly yet found their way into these remote parts; and in a sheltered spot under the crag, open to the south, were six beehives, which made the family perfectly independent of West-India produce. 'Tea was in these days as little known as potatoes, and for all other things, honey supplied the place of sugar."

Clothing.-The improvements which in this respect have been made, within even half a century, are very remarkable. The unparelleled abundance and cheapness of cotton goods, caused by the wonderful progress made in the cotton manufacture, have been, in this respect, of rast importance. "It is impossible," says Mr. Baines, "to estimate the advantage, to the bulk of the people, from the wonderful cheapness of cotton goods. The wife of a laboring man may buy, at a retail shop, a neat and good print, as low as four pence per yard: so that, allowing seven yards for the dress, the whole material shall only cost two shillings and four pence. Common plain calico may be bought for two pence and a half per yard. Elegant cotton prints, for ladies' dresses, sell at from ten pence to one shilling and four pence per yard; and printed muslins, at from one shilling to four shillings, the higher priced having beautiful patterns, in brilliant and permanent colors. Thus, the humblest classes have now the means of as great neatness, and even gayety of dress, as the micidle and upper classes of the last age A country wake, in the nineteenth century, may display as much finery as a drawing room of the eighteenth; and the peasant's cottage may, at this day, 
with good management, have as handsome furniture for beds, windows, and tables, as the house of a substantial tradesman, sixty years since."-History of the Cotton Manufaciure.

'The price of most other articles of clothing has also been considerably reduced, though not in the same degree as cottons, at the same time that their fabric has been improved and beautified.

Improvements in Lodgings. - Since the middle of the last century, an cxtraordinary change for the better has taken place in the habitations of all classes. Any one must be struck with this, who compares the houses in the old streets and lanes, in any of our towns, with those built within the last fifty years. The latter are, in all respects, superior. They are constructed on a larger scale; the apartments are more spacious and lofty; they are better rentilated, and are supplied with water to an extent of which our ancestors had no idea. It is, in fact, to the better construction of houses, the greater width of streets, and, above all, to the abundant supply of water, and the effective system of underdraining that now exists, that the entire freedom of our great towns from epidemical discases, and the astonishing improvement in the health of the inhabitants, are mainly to be ascribed.-McCulloch's Statistics of Great Britain.

\section{Scotraxd.}

The above statements apply only to the changes that have taken place in the condition of the people of England and Wales; but the change that has taken place in Scotland, since the beginning and middle of last century, has been still more striking and extraordinary. "At the periods referred to," says Mr. McCulloch, " no manufactures, with the exception of that of linen, had been introduced into Scotland. Its agriculture was in the most wretched state imaginable; and the inhabitants were miserably supplied, even in the best years, with food, and were every now and then exposed to all 
the horrors of famine. The details already laid before the reader have shown the extreme prevalence of outrage and disorder in England, in the sixteenth century ; but Scotland was a prey to the same sort of disorders, so late as the end of the seventeenth, and the beginning of the eighteenth, centuries. In one of the discourses of the Scotch patriot, Fletcher of Saltoun, written in 1698 , we find the following statement:

" : There are, at this day, in Scotland, (besides a great many poor families, very meanly provided for by the church boxes, with others, who, by living on bad food, fall into various diseases,) two hundred thousand people begging from door to door. These are not only no way advantageous, but a very grierous burden to so poor a country. And though the number of them be, perhaps, double to what it was formerly; by reason of this present great distress, yet, in all times, there have been about one hundred thousand of those ragabonds, who have lived without any regard or subjection, either to the laws of the land, or even those of God and Nature. No magistrate could ever discover, or be informed, which way one in a hundred of those wretches died, or that ever they were baptized. Many murders hare been discovered among them; and they are not only a most unspeakable oppression to poor tenants, (who, if they give not bread, or some kind of provision, to perhaps forty such villains in one day, are sure to be insulted by them,) but they rob many poor people, who live in houses distant from any neighborhood. In years of plenty, many thousands of them meet together in the mountains, where they feast and riot for many dars; and at country weddings, markets, burials, and other the like public occasions, they are to be seen, both men and women, perpetually drunk, cursing, blaspheming, and fighting together.':

We suspect there must be some exaggeration in this striking paragraph; for, as Scotland did not, at the period referred to, contain more than a million of inhabitants, it is difficult to suppose, notwithstanding the 
peculiar distress by which she was then visited, that two hundred thousand persons, or a fifth part of the entire population, could be given up to the mendicancy and disorders described above. But the intelligence and good faith of Fletcher are unquestionable; and there can not be the shadow of a doubt, that the disorders to which he refers were of long standing, and upon the most gigantic scale, and that he did not believe he had in any degree overstated them. Indeed, so impressed was he by the idleness and crime then so prevalent, and by the enormities he had witnessed, that, to introduce good order and industry, he clid not scruple to reconimend the establishment of a system of predial slavery, to which the vagabonds in question and their children should be subjected! The nature of the proposed remedy show's what the disease must have been.

The establishment of schools, and of a more vigorous and impartial system of government, happily succeeded in repressing these disorders. But the people of Scotland continued, till a comparatively recent period, without manufactures or trade, and were involved in the extreme of misery and destitution. The following authentic paragraph, extracted from the statistical account of the parish of Meigle, in Strathmore, contributed by the late Rev. Dr. Playfair, of St. Andrew's, may be considered as applying to the whole surrounding district :

"Since the year 1745, a fortunate epoch for Scotland, in general, improvements have been carried on with great ardor and success. At that time, the state of the country was rude, beyond conception. The most fertile tracts were waste, or indifferently cultivated. The education, manners, dress, furniture, and tables, of the gentry were not so liberal, decent, and sumptuous, as those of ordinary farmers are, at present. The common people, clothed in the coarsest garb, and starving on the meanest fare, lived in despicable huts, with their cattle. 
"The half-ploughed fields yielded scanty crops, and manufactures scarcely existed. Almost every improvement in agriculture is of laie date; for no ground was then fallowed; no peas, grass, turnips, nor potatoes, were then raised; no cattle were fattened; and little grain was exported. Oats and barley were alternately sown; and, during seven months of the year, the best soil was ravaged by flocks of sheep, a certain number of which was annually sold and carried off, to be fed on richer pastures.

:The inactivity and indolence of farmers were astonishing. When seed-time was finished, the plough and harrow were laid aside till after Autumn; and the sole employment of the farmer and his servants consisted in weeding the corn-fields, and in digging and carrying home peat, turf, and heath, for Winter fuel. The produce of the farm was barely sufficient to enable the tenant to pay a trifling rent and servants' wages, and to procure for his family a scanty subsistence."

In the Highlands, the situation of the inhabitants was, if possible, worse. The writer of the statistical account of the united parishes of Lochgoilhead and Kilmorish, in Argyleshire, referring to the state of the people about 1760, observes,-

"Indolence was almost the only comfort they enjoyed. There was scarcely any variety of wretchedness, with which they were not obliged to struggle, or rather, to which they were not obliged to submit. They often felt what it was to want food. 'The scanty crops they raised were consumed by their cattle, in Winter and Spring; for a great part of the year they lived wholly on miik, and even that, by the end of the Spring and the beginning of Summer, was very scarce. To such an extremity were they frequently reduced, that they were obliged to bleed their cattle, in order to subsist some time on the blood, (boiled;) and even the inhabitants of the glens and ralleys repaired in crowds to the shore, at the distance of three or four miles, to pick up the scanty provision which the shell-fish afford- 
ed them. They were miserably ill-clothed, and the huts in which they lived were dirty and mean, beyond description. How different from their present situation! They now enjoy the nccessarics, and many of the comforts, of life, in abundance; even those who are supported by the charity of the parish fcel no real want." Thic southern counties presented the same picture of sloth, poverty, and wretchedness. The late Rev. Mr. Smith, in his 'A gricultural Survey of Wigtown and Kirlicudbright,' published in 1810 , gives, on authority of persons "now living," the following details, with respect to the state of husbandry, and the condition of the people, towards the middle of the last century :

"Estates appear to have been broken down into very small farms; or, where these were large, they were held in common, by two, three, or cren four, different tenants, who divided the labor and produce in a proportion corresponding to their rent. These, when in tillagc, were sometimes run-rigg, when each had his proportion allotted; sometimes, the whole was ploughed, sowed, and reaped, in common, and the producc divided in the field, barn, or barn-yard. Houses or sheds, for the whole cattle of the farm, never entered into their conception. Their cows were indecd not uncomfortably lodged; rery often under the same roof with themselves, and sometimes without any intervening wall or partition. Their houses werc commonly wretched, dirty hovels, built with stones and mud; thatched with fern and turf; without chimneys; filled with smoke; black with soot; having low doors, and small holes for windows, with wooden shutters, or, in place of these, often stopped with turf, straw, or fragments of old clothes.

"The principal object of tillage was to afford straw for the Winter support of the few cattle which the pasture (if such it could be called) maintained in Summer. As they always orerstoclicel, this was a difficult task; and the poor starvel animals, before the return of Spring, were reducerl to the greatest extremities. 
Through mere weakness, often they could not rise of themselves. It was a constant practice to gather to. gether neighbors to lift the cows or horses, or to draw them out of the bogs and quagmires into which they werre tempted by the first appearances of regetation.

"Nothing, but the frugal, penurious manner in which the peasantry then lived, could have enabled them to subsist and pay any rent whatever. Their clothing was of the coarsest materials; their furniture and gardening utensils were often made by themselres; their food, always the produce of their farms, was little expensive, consisting chiefly of oat-meal, regetables, and the produce of the dairy; if a little animal food was occasionally added, it was generally the refuse of the flock, unfit to be brought to market."

The situation even of the Lothians was but little better. So late as $\mathbf{1 7 5 7}$, neither turnips, potatoes, clover, nor cultivated herbage of any sort, had been introduced into that district. The condition of the occupiers and of the peasantry was also exceedingly depressed. It is stated by Mr. Robertson, that, so late as 1765 , mendicity in the Lothians was so very prevalent, that hardly a day passed, in which farm-houses were not visited by beggars, and hardly a week, without some of them getting a night's lodging in the barn.-' Rural Recollections.'

Such was the abject state of Scotland, about the middle of the last century! And we are bold to say, that the contrast between the savages, by whom Kentucky was formerly occupied, and its present civilized inhabitants, is hardly greater than the contrast between the farmers and laborers of Scotland, in 17\%0, and those of the present day. The existing Scotch farmers are distinguished by their superior intelligence and skill in agriculture, the excellence of their stock and implements, and their genteel, comfortable style of living. The laborers, too, are universally well fed, and well clothed ; their cottages are generally comfortable and well furnished; and they are all in the enjoyment of luxuries, 
that formerly were never tasted, even by the most extensive proprietors.

The demand 'for butchers' meat, in Scotland, has increased, in the most extraordinary manner. So late as 1763 , the slaughter of bullocks, for the supply of the public markets, was a thing wholly unknown, even in Glasgow, though the city had then a population of nearly thirty thousand! Previously to 1775 , or perhaps later, it was customary in Edinburgh, Glasgow, and the principal Scotch towns, for families to purchase, in November, what would now be reckoned a small, miserable, half-fed cow or ox, the salted carcass of 'which was the only butchers' meat they tasted throughout the year. In the smaller towns and country districts this practice prevailed, till the present century; but it is now almost every where abandoned. The consumption of butchers' meat in Glasgow, as compared with the population, does not at present differ materially from that of the metropolis. We do not indeed believe that the command of the people of any country over food and all sorts of conveniences, ever increased, in any cqual period, half so rapidly as that of the pcople of Scotland has done, since 1770.Mc Culloch's Statistics.

\section{I. United States.}

An aged friend states, that fifty-five years ago, in Connecticut, a substantial farmer used tea very rarely, in his family, coffee never; that wheaten bread was brought on the table only on the most remarkable occasions; that there were no carpets or umbrellas; that almost the entire raiment worn was of domestic manufacture, being coarse linen or woollen; that there were no wheel-carriages used, except that now and then a very considerable person rode in a one-horse chaise, of two wheels, and rudc construction; that all travelling was on foot or horseback ; that there was no stagecoach or public conveyance for passengers; that the principal food was beans, pork, and Indian bread; 
that hardly any sugar was used, except that made fron the maple tree of the woods, nor any molasses, except what they extracted from cornstalks; that hardly any cooking utensils were used, except a frying-pan and iron pot; and that they ate almost invariably off of wooden trenchers, and drank tea, in most cases, out of wooden cups.

Any person acquainted with the habits of this class of people, now, will see at once, that the change, which, within half a century, has taken place in their condition, is immense. Wooden bowls and cups have giren place to cheap, cleanly, and oftentimes to elegant, earthen-ware and porcelain; the inmates of the family are clothed with materials gathered from all quarters of the world, and wrought into warm, delicate fabrics in the looms of England, France, and America; wheaten bread is considered an indispensable article of daily consumption; fresh meat is used almost daily; and sugar in abundance; the potato, and other garden regetables, are cultivated unirersally, and form a grateful and cheap addition to the meal, throughout the year; tea and coffee are regarded as indispensable; few families are without umbrellas and carpets; and every farmer must have his pleasure ragon.

A newspaper of Albany, bearing date in $179 \%$, is now before me ; and, among many other adrertisements, indicating the state of society at that time, I find cotton thread is adrertised by one person as a new article, and peculiarly valuable, because it had been spun in Rhode Island, by water. It is to be presumed, that, at this time, there was no cotton factory in the State of New York; and that spinning by water had just commenced in our Country.

iv. Notices of the Mode of Limixg in Exgland, preriots to the time of Queex Elizabeth.

To enable the reader to extend the comparison be tween the past and present state of the arts in England, some further notices are added. 


\section{England, in the Reign of Henry the Seventh.}

The household book of the Duke of Northumberland, edited by Bishop Percy, may give us some notion of the mode of life in the noblest and most opulent families of England, at the beginning of the sixteenth century.

The number of persons in the establishment was about two hundred and twenty, of whom something over fifty were strangers or guests, daily provided for.

The average expense of meat, drink, and fire, for each person, was reckoned at two penee and a halfpenny per day, which Hume supposes would be equivalent to about fourteen pence in his time. These items formed two thirds of the whole expense of the establishment.

The frugality, with which the houselıold was managed, appears from the fact, that no servant could be absent a day, without having his mess struck off; the number of pieces which must be cut from every quarter of beef, mutton, pork, or veal, and even from fish, are determined, and must be entered or accounted for, by the different clerks appointed for that purpose; no capons or other poultry were allowed, except "for my lord's own mess," nor were plovers to be bought even for that purpose, except "in Christmas and principal feasts; and my lord to be served therewith, and none other, and to be bought for a penny a piece, or a penny half penny, at most."

The luxuries enjoyed may be inferred from the fact, that the family had fresh meat only from midsummer to Michaelmas, (September twenty-ninth), living all the rest of the year on salted meat, with few or no vegetables; that no sheets were used; that only forty shillings are allowed for washing throughout the whole year, most of which seems to have been expended on the linen belonging to the chapel; that only seventy ells of linen, at eight pence a yard, are annually allowed for this great family, this linen being made into eight tablecloths for my lord's table, and one table-cloth for the 
knights, the servants having none; that only ninetyone dozen of candles and eighty chaldrons of coals were allowed for the establishment through the year; and that after Lady-day no fires were permitted in the rooms, except "half-fires, in my lord's and lady's, and Lord Piercy's, and the nursery." He seems to have had but two cooks for this household; to have occupied three country seats, having furniture only for one. "No mention," Hume says, "is any where made of plate; but only of the hiring of pewter ressels. The servants seem all to have bought their own clothes from their wages." See Hume, Vol. iii. Note (G.)

\section{England, in the Reign of Edward the Third, (1365.)}

The following view of the condition of the English people, in this reign, is extracted from a tract on the 'Rights of Industry,' published in the 'Workingman's Companion.'

In the reign of Edward the Third, Colchester, in Essex, was considered the tenth city in England, in point of population. It then paid a poll-tax for two thousand nine hundred ând fifty-five lay-persons. In 1311 , about half a century before, the number of inhabitant housekeepers was three hundred and ninety; and the whole household furniture, utensils, clothes, money, cattle, corn, and every other property found in the town, was valued at $£ 518.16 s .0 \frac{3}{4} d$. This valuation took place on occasion of a subsidy or tax to the crown, to carry on a war against France; and the particulars, which are preserved in the Rolls of Parliament, exhibit, with great minuteness, the classes of persons then inhabiting that town, and the sort of property which each respectively possessed. The trades exercised in Colchester were the following:-baker, barber, blacksmith, bowyer, brewer, butcher, carpenter, carter, cobbler, cook, dyer, fisherman, fuller, furrier, girdler, glass-seller, glover, linendraper, mercer and spice-seller, miller, mustard and vinegar seller, old-clothes-seller, saddler, tailor, tanner, tyler, weaver, woodcutter, and woolcomber. 
If you look at a small town, of the present day, where such a variety of occupations are carried on, you will find that each tradesman has a considerable stock of commodities, abundance of furniture and utensils, clothes in plenty, some plate, books, and many articles of convenience and luxury, to which the most wealthy dealers and mechanics of Colchester, of the fourteenth century, were utter strangers. That many places, at that time, were much poorer than Colchester, there can be no doubt; for here we see the division of labor was pretty extensive, and that is always a proof that production is going forward, however imperfectly. We see, too, that the tradesmen were connected with manufactures, in the ordinary use of the term; or there would not have been the dyer, the glover, the linendraper, the tanner, the weaver, and the woolcomber. There must have been a demand for articles of forcign commerce, too, in this town, or we should not have had the spice-seller. Yet, with all these various occupations, indicating considerable profitable industry, when compared with earlier stages in the history of this country, the whole stock of the town was ralued at little more than five hundred pounds. Nor let it be supposed that this smallness of capital can be accounted for, by the difference in the standard of money; for $£ 518$, of the time of Edward the Third, would amount only to $\& 1450$, of our present money.* We may indeed satisfy ourselves of the small extent of the capital of individuals at that day, by referring to the inventory of the articles upon which the tax we have mentioned was laid at Colchester.

The whole stock of a carpenter's tools was valued at one shilling. They altogether consisted of two broalaxes, an adze, a square, and a navegor, or spokeshave. Rough work must the carpenter have been able to perform with these humble instruments; but, then, let it be remembered, that there was little capital

- Eden's Table of the Convertible Value of British Money, in his History of the Poor. 
to pay him for finer work, and that very little fine work was consequently required. The three hundred and ninety housekeepers of Colchester then lived in mud huts, with a rough door and no chimney. Harrison, speaking of the manners of a century later than the period we are describing, says, "There were very few chimneys, even in capital towns: the fire was laid to the wall, and the smoke issued out at the roof, or door, or window. The houses were wattled, and plastered orer with clay; and all the furniture and utensils were of wood. The people slept on straw pallets, with a $\log$ of woad for a pillow." When this old historian wrote, he mentions the erection of chimneys as a modern luxury. We had improved little upon our AngloSaxon ancestors in the article of chimneys. In their time, Alcuin, an abbot who had ten thousand vassals, writes to the Emperor at Rome, that he preferred liring in his smoky house, to risiting the palaces of Italy. This was in the ninth century. Fire hundred years had made little difference in the chimneys of Colchester. The nobility had hangings against the walls, to keep out the wind, which crept in through the crevices which the builder's bungling art had left; the middle orders had no hangings. Shakspeare alludes to this rough building of houses, even in his time :

"Imperial Crsar, dead, and turned to clay,
Might stop a hole, to keep the wind away."

Even the nobility went without glass to their windows, in the fourteenth and fifteenth centuries. "Of old time," says Harrison, "our countrie-houses, instead of glasse, did use much lattice, and that made either of wicker, or fine rifts of oak, in checkerwise." When glass was introduced, it was for a long time so scarce, that at Alnwick Castle, in 1567 , the glass was ordered to be taken out of the windows, and laid up in safety, when the lord was absent.

The mercer's stock-in-trade, at Colchester, was much upon a level with the carpenter's tools. It was somewhat various, but very limited in quantity. The 
whole comprised a piece of woollen cloth, some silk and fine linen, flannel, silk purses, gloves, girdles, leather purses, and needle-work; and it was altogether valued at $£ 3 ;-$ or $£ 9$, of our present money. 'There appears to have been another dealer in cloth and linen in the town, whose store was equally scanty. We were not much improved in the use of linen, a century later. We learn from the Earl of Northumberland's household book, whose family was large enough to consume one hundred and sixty gallons of mustard, during the Winter, with their salt meat, that only seventy ells of linen were allowed for a year's consumption. In the fourteenth century, none but the clergy and nobility yore white linen. $\Lambda$ s industry increased, and the cleanliness of the middle classes increased with it, the use of white linen became more general. But, even at the end of the next century, when printing was invented, the paper-makers had the greatest difficulty in procuring rags for their manufacture; and so careful were the people of every class to preserve their linen, that night-clothes were never worn. Linen was so dear, that Shakspeare makes Falstaff's shirts eight shillings an ell. The more sumptuous articles of a mercer's stock were treasured in rich fumilies, from generation to generation; and even the wives of the nobility did not disdain to mention in their wills a particular article of clothing, which they left to the use of a daughter or a friend. The solitary old coat of a baker came into the Colchester valuation; nor is this to be wondered at, when we find that even the soldiers at the battle of Bannockburn, about this time, were described by an old rlyymer as "well near all naked."

The household-furniture found in use amongst the families of Colchester consisted, in the more wealthy, of an occasional bed, a brass pot, a brass cup, a gridiron, and a rug or two, and perhaps a towel. Of chairs and tables we hear nothing. We learn from the Chronicles of Brantôme, a French historian of these days, that even the nobility sat upon chests, in which they kept 
their clothes and linen. Harrison, whose testimony we have already given to the porerty of these times, affirms, that if a man, in seven years after marriage, could purchase a flock-bed, and a sack of chaff to rest his head upon, he thought himself as well lodged as the lord of the town, "who peradrenture lay seldom on a bed entirely of feathers.' An old tenure in England, before these times, binds the rassal to find straw eren for the king's bed. The beds of flock, the few articles of furniture, the absence of chairs and tables, would have been of less consequence to the comfort and health of the people, if they had been clean; but cleanliness never exists without a certain possession of domestic conveniences. The people of England, in the days of which we are speaking, were not famed for their attention to this particular. Thomas à Becliet was reputed extravagantly nice, because he had his parlor strowed every day with clean straw. As late as the reign of Henry the Eighth, Erasmus, a celebrated scholar of Holland, who visited England, complains that the nastiness of the people was the cause of the frequent plagues that destroyed them; and he says, 'their floors are commonly of clay, strowed with rushes, under which lie, unmolested, a collection of beer, grease, fragments, bones, spittle, excrements of dogs and cats, and of every thing that is nauseous.' 'The elder Scaliger, another scholar who came to England, abuses the people for giving him no convenience to wash his hands. Glass vessels were scarce, and pottery was almost wholly unknown. The Earl of Northumberland, whom we have mentioned, breakfasted on trenchers and dined on pewter. While such universal slovenliness prevailed, as Erasmus has described, it is not likely that much attention was generally paid to the cultivation of the mind. Before the invention of printing, at the time of the valuation of Colchester, books in manuscript, from their extreme costliness, could be purchased only by princes. The royal library of Paris, in 1378 , consisted of nine hundred and nine volumes; 
an extraordinary number. The same library now comprises upwards of four hundred thousand volumes. But it may fairly be assumed, that where one book could be obtained, in the fourteenth century, by persons of the working classes, four hundred thousand may be as easily obtained now. Here, then, was a privation, which existed five hundred years ago, which debarred our ancestors from more profit and pleastre, than the want of beds, and chairs, and linen; and probably, if this privation had continued, and men, therefore, had not cultivated their understandings, they would not have learnt to give any really profitable direction to their labor, and we should still have been as scantily supplied with furniture and clothes, as the good people of Colchester, of whom you have been reading.

Now, let us compare the Colchester of the nineteenth century, with the Colchester of the fourteenth, in a few particulars.

In the reign of Edward the Third, Colchester numbered three hundred and fifty-nine houscs of mud, without chimneys, and with latticed windows. In the reign of William the Fourth, it has six hundred and twelve houses, each at a rent above ten pounds. The houses below ten pounds are not mentioned in the return from which we derive this information. Houses of ten pounds a ycar and upwards are, as you know, commonly built of brick, and slated or tiled; secured against wind and weather; with glazed windows and with chimneys; and generally well rentilated. The worst of these houses are supplied, as fixtures, with a great number of conveniences, such as grates, and cupboards, and fastenings. 'To many of such houses, gardens are attached, wherein are raised vegetables and fruits, that lings could not command two centuries ago. Houses such as these are composed of several rooms, - not of one room only, where the people are compelled to eat and sleep, and perform every office, pcrhaps in company with pigs and cattle,-but of a kitchen and often a parlor, and several bedrooms. 'These rooms are furnish- 
ed with tables, and chairs, and beds, and cooking-utensils. There is ordinarily, too, something for ornament and something for instruction,-a piece or two of china, silver spoons, books, and not unfrequently a watch or clock. The useful pottery is abundant, and of really elegant forms and colors; drinking-vessels of glass are not uncommon. The inhabitants are not scantily supplied with clothes. The females are decently dressed, having a constant change of linen, and gowns of various patterns and degrees of fineness. Some, even of the humbler classes, are not.thought to exceed the proper appearance of their station if they wear silk. The men have decent working habits, strong shoes and hats, and a respectable suit for Sundays, of cloth often as good as is worn by the highest in the land. Every one is clean; for no house, above the few hovels which still deform the land, is without soap and bowls for washing, and it is the business of the females to take care that the linen of the family is constantly washed. The children almost universally receive instruction in some public establishment; and when the labor of the day is over, the father thinks the time unprofitably spent, unless he burns a candle, to cnable him to read a book or the newspaper. The food which is ordinarily consumed is of the best quality. Wheaten bread is no longer confined to the rich; animal food is not necessarily salted, and salt meat is used principally as a variety; regetables of many sorts are plenteous, in every market, and these, by a succession of care, are brought to higher perfection than in the countries of more genial climate, from which we have imported them; the productions, too, of distant regions, such as spices, and coffee, and tea, are universally consumed, almost by the humblest in the land. Fuel, also, of the best quality, is abundant, and comparatively cheap.

If we look at the public conveniences of a modern English town, we shall find the same striking contrast. Water is brought not only into every street, but into svery house; the dust and dirt of a family is regularly 
removed, without bustle or unpleasantness; the streets are paved, and lighted at night; roads, in the highest state of cxcellence, connect the town with the whole kingdom, so that a man can travel a hundred miles more readily, now, than he could ten miles, in the old time; and canal and sea navigation transport the weightiest goods, with the greatest facility, from each district to the other, and from each town to the other, so that all are enabled to apply their industry to what is most profitable for each and all. Every man, therefore, may satisfy his wants, according to his means, at the least possible expense of the transport of commodities. Every tradesman has a stock ready to meet the domand; and thus the stock of a very moderately wealthy tradesman, of the Colchester of the present day, is worth more than all the stock of all the different trades that were carried on in the same place in the fourteenth century. To effect these public conveniences, millions of capital have been invested. which sums have afforded profitable labor to millions of workmen. Look at the iron trade, which has so large a share in all public works. In the year 1788 , sixty thousand tons of cast iron were manufactured. In the year 1823, the amount of the produce of cast iron was six hundred thousand tons. A large portion of this enormous increase has been applied to the internal improvement of the country, in water-pipes, gas-pipes, bridges, rail-roads.

But to allow us to form a tolerable estimate of the increased production and accumulation of this country, we must take a few general points of comparison, which may enable us to estimate the astonishing ertent of this production and accumulation, more accurately, eren. than from the individual case we have exhibited.

And first, of the population of the country, for an increase of population always show's an increase of pro duction, since without increased production, the amount of population must remain stationary, with diminished production, it must become less, and if there were no production. and therefore no accumulation, population 
would be altogether extinguished. Mr. Turner, the historian of the Anglo-Saxons, has estimated, from ' Domesday Book,' that the population of England at the time of the Norman Conquest somewhat exceeded two millions. It has been estimated, by Mr. Chalmers, that in 1377 , the population did not exceed $2,350,000$ souls. There was an increase, therefore, of only the third of a million, in three centuries and a half. From 1377 to 1821 , a period of four centuries and a half, the population of England had increased to nearly twelve millions, or five times the amount of the population of $137 \%$. The increased production of the country must have gone forward in the same proportion, to say nothing of the much greater comparative increase of production demanded by the change for the better in the habits of every class of the consumers. We have no materials for comparing the general production of five hundred years ago with the general production of the present day; yet every man may compare, in his own mind, the state in which he himself lives, and the state in which the people of Colchester lived, at the time we have described. To assist this comparison, we will furnish a few particulars of the present home consumption of the kingdom, in the great staple articles of her commerce and manufactures. We only take those articles which can be accurately estimated.

Of wheat, fifteen million quarters are annually consumed in Great Britian. This is about a quarter of wheat to each individual.* of malt, twenty-five million bushels are annually used in breweries and distilleries in the United Kingdom; and there are forty-six thousand acres under cultivation with hops. Of the quantity of potatoes and other regetables consumed, we have no accounts. Of meat, about one million two hundred and fifty thousand head of cattle, sheep, and pigs, are sold during the year, in Smithfield market alone, which is probably about a tenth of the consump-

* This calculation does not include Ireland, as the subsequent estimates do. 
tion of the whole kingdom. The quantity of tea consumed in the United Kingdom is about thirty million pounds annually. Of sugar, nearly four million hundred-weights, or about five hundred million pounds, every year, which is a consumption of twenty pounds for every individual, reckoning the population at twentyfive millions; and of coffee, about twenty million pounds are ammually consumed. Of soap, one hundred anil tourteen million pounds are consumed; and of candles, about a hundred and seventeen million pounds. Of sea-borne coals alone there are about three million chaldrons consumed, in England and Wales; and it is estimated that, adding the coals of the great coal fields of South Wales, of Yorkshire, Lancashire, and the midland counties, each person of the population consumes a chaldron throughout the kingdom. Of clothing, we annually manufacture about two hundred million pounds of cotton wool, which produce twelve hundred million yards of calico and various other cotton fabrics, and of these we export about a third; so that eight hundred million yards remain for home consumption, being about thirty-two yards, annually, for each person. The woollen manufacture consumes about thirty million pounds of wool. Of hides and slins, about fifty millions are annually tanned and dressed. Of paper, abont fifty million pounds are yearly manufactured, which is about two million reams, of fire hundred sheets to the ream.

To earry on the commeree of this country with foreign nations, and between distant parts of the United Kinglom, there are twenty thousand ships, in constant employ, belonging to our own merchants. To carry on the commerce with ourselves, the total length of our turnpike roads is twenty-five thousand miles, and three thousand miles of canals. To produce food for the inhabitants of the country, we have forty miltion acres under cultivation. To elothe them, we have millions of spindles, worked by steam, instead of a few thousands: turned by hand, as they were a century ago. The fixed 
capital of the country insured in fire-offices, that insurance being far short of its real amount, is above five hundred million pounds sterling. The fixed capital uninsured, or not represented by this species of insurance, is perhaps as much. The capital expended in improvement in land is, we should conceive, equal to the capital which is represented by houses, and furniture, and shipping, and stocks of goods. The public capital of the country expended in roads, canals, docks, liarbors, and buildings, is equal to at least half the private capital. All this capital is the accumulated labor of two thousand years, when the civilization of the country first began. The greater portion of it is the aecumulated labor of the last four hundred years, when labor and capital, through the partial abolition of slavery, first began to work together with freedom, and therefore with energy and skill. We might show you the objects to which this succession of labor, working with accumulation, has been applied, and the instruments with which these two great powers have worked."

It may not be uninteresting to have some further notices of the condition of the English people in the fourteenth century. Baker, in his Chronicle, (page 128,) tells us, that in the "parliament holden in thirty-serenth of Edward the Third, certain sumptuary laws were ordained, both for apparel and diet; appointing every degree of men the stuffe and habits they should wear, prohibiting the wearing of gold, silver, silks, and rich furs, to all but eminent persons. The laborer and husbandman is appointed but one meal a day, and what meats he should eat."

While these restrictions were laid on the common people, what were the habits of their superiors? Famines occurred almost every year, and yet we read, in Mathew Paris, (see Henry, rol. iv. page 511,) that, at the installation of Ralph, Abbot of St. Augustine, Canterbury, six thousand guests were entertained at a dinner consisting of three thousand dishes ; that "it would require a long treatise to describe the astonishing splen- 
dor and festivity with which the nuptials of Richard, Earl of Cornwall, were celebrated at London. To give the reader some idea of it, in few words, above thirty thousand dishes were served up at the marriagedinner ;" and the writer states, that, at another marriagefeast, made on occasion of the marriage, at York, of a daughter of the King of England, "the Archibishop of York made the King of England a present of sixty fat oxen, which made only one article of provision for the feast, and were all consumed at that entertainment."

Chancer, in the 'Parson's 'Tale,' complains that " pride of the table appercth full ofte; for certes riche men be called to festes, and pore folks ben put away and rebuked. And also in excess of divers metes and drinkes; and namely such maner bake metes, and dish metes brenning of wild fire peynted and castelled with paper and samblable waste, so that it is abusion to think."

In regard to dress, Mathew Paris states, that, at the marriage above referred to, of a daughter of Henry the Third of England, the King was attended by one thousand knights, uniformly dressed in silk robes; "and the next day, these knights appeared in new dresses, no less splendid and expensive."

Of the elergy, Chaucer says, -

"They hie on horse willeth to ride
In glitterande golde of grete arai,
Peynted and portrid all in pride,
No common knight maye go so gaie ;
Chaunge of clothing every daie,
With golden girdels great and small."

Henry, rol. iv. page 508, thus describes the dress of an English beat of the fourteentl century: "He wore long pointed shoes, fastened to his knees by gold or silver chains ; hose of one color on one leg, and of another color on the other; short breeches, which did not reach to the middle of his thighs, and disclosed the shape of all the parts included in them; a coat, one half white and the other half black or bluc; a long 
beard; a silk hood, buttoned under his chin, embroid ered with grotesque figures of animals, dancing men, \&c., and sometimes ornamented with gold, silver, and precious stones. This dress, which was the very top of the mode in the reign of Edward the Third, appeared so ridiculous to the Scots, (who probably could not afford to be such egregious fops,) that they made the following satirical verses upon it:

"Longbierds hirtiless,
Peynted whoods witles,
Gay cotes gracieles,
Maketh England thriftieles."

The dress of the gay and fashionable ladies, who frequented the public diversions of those times, was not more decent or becoming. It is fhus described by Knyghton, A. D. 1348:

"These tournaments are attended by many ladies of the first rank and greatest beauty, but not always of the most untainted reputation. These ladies are dressed in party-colored tunics, one half being of one color and the other half of another; their lirripipes, or tippets, are very short; their caps remarkably little, and wrapt about their heads with cords; their girdles and pouches are ornamented with gold and silver; and they wore short swords, called daggers, before them; they are mounted on the finest horses with the richest furniture. Thus equipped, they ride from place to place, in quest of tournaments, by which they dissipate their fortunes, and sometimes ruin their reputations."

The head-dresses of the ladies underwent many changes in the course of this period. They were sometinies enormously high, rising almost three feet above the head, in the shape of sugar-loares, with streamers of fine silk flowing from the top of them to the ground. Upon the whole, I am fully persuaded, that we have no good reason to pay any compliments to our ancestors of this period, at the expense of our contemporaries, either for the frugality, elegance, or decency, of their dress. The common people in Wales (where the 
arts had made little progress) were very imperfectly clothed in this period. The Welshmen in the army of Edward the Second were known, in their flight from the battle of Bannockburn, by the meanness of their dress.

"Sir Maurice also, the Barclay,

Fra the great battle hed his way ;

With a great rout of Walishmen,

Where'er they yied men might them ken;

For they well near all naked were,

Or linen clothies had but mare."

\section{Miscellaneous Notices.}

To illustrate the mode of transport for persons and goods, and the style of living, which prevailed in the time of Henry the Fourth, we may read Shalispeare, who is true to the circumstances of the times. From the discourse of the two carriers in the inn-yard at Rochester, we find that they were on horseback, with panniers; that "the one had a gammon of bacon and two cases of ginger, to be delivered as far as Charing-cross ;" that "the turkeys in the pannier of the other were quite starved;" and that travellers of different quality and rank were in the labit of travelling in companies, for mutual protection.

From other sources we learn, that, at this period, and for some time after, barley and beans formed the staple food of the people; that, though wheat might be bought for six shillings and eight pence a quarter, just after harvest, yet, owing to the improvidence of the consumers, and the want of corn-merchants, it became so scarce before the next harvest, that it was not unusual to pay eighty shillings the quarter; that even convents, which we have been accustomed to associate with well-fed monks, who rioted in abundance, could afford their inmates, for long periods, nothing better than oatmeal and beans, and these with the greatest dificulty. We learn, that the corn was usually ground at home, in a quern, or handmill, and that, even a century ago, it was found impossible, on a certain occasion, to procure a 
loaf of wheaten bread at any shop in one of the largest towns of the north of England, (Carlisle.)

So with meat. The great proportion of the people had but little, eren in England; in France, none, the French peasantry living on apples, water, and ryebread. The gentry; during the long Winters, had rarely any thing better than salted meat and fish; there being no provision, in the system of farming then practised, for stall-feeding, and of course nothing, in fact, to answer to the magnificent ideas which we have been accustomed to form of the roast beef of Old England. The roast beef of $\mathrm{C}_{\mathrm{LD}}$ England was, in truth, a chine of salted beef boiled. This was the principal standing dish on the table of $\mathrm{my}$ lord and lady, morning, noon, and night; it being surmounted by a loaf of bread, two manchets, a quart of beer, and a quart of wine. Coffee, which was not introduced into England till the serenteenth century, was regarded with so much aversion by many good people, as to have been formally denounced, and that, too, in good set terms, from the pulpit. Many sermons seem to have been aimed, about this time, at coffee and tobacco, as equally pernicious and offensive. The following is an extract from one of them : : They cannot wait till the smoke of the infernal regions surrounds them, but encompass themselves with smoke of their own accord, and drink poison, which God made black, that it might bear the deril's color."

Another passage, from the letters of a cardinal, ( $\mathrm{Da}$ miani, ) written about the eleventh century, will show what, in the estimation of the eminences of that day, was luxury. Writing to the Lady Blanche, once a petty Princess, who had entered a convent, and warning her of the great danger of setting her heart on luxurious living, he proceeds to tell her a story, which he had heard from a person of veracity. "The Doge of Venice had married a lady of Constantinople, whose luxury," says he, "surpassed all imagination. She would not even wash in common water, but had the cruelty to compel her servants to collect rain-water for 
her!" Her chamber was perfumed with aromatics, so nany in number, that Damiani is quite ashamed to mention them, and no one would believe him if he did. But, what was most monstrous, this wicked creature would not eat with her fingers, but absolutely had her food cut into pieces, rather small, by her attendants, and then,-_" she conveyed them to her mouth with certain golden two-pronged forks."

The ladies of that day do not seem to have confined their extravagance to the use of rain-water and forks; in another respect, they proroked the displensure of their ecclesiastical superiors; and, in the hope that the indignant remonstrance of good Bishop Pilkington, one of the polemics of the time, may not be lost upon the fair of our own day, we quote one of his reproofs. It is directed against "five-fingered ruffers, with their sables about their necks, corked slippers, trimmed buskins, and warm mittens." "These tender Parnels," he says, "must have one gown for the day, another for the night; one long, another short; one for Winter, another for Summer; one furred through, another but faced; one for the work-day, another for the holyday; one of this color, another of that; one of cloth, another of silk or damask. Change of apparel, one afore clinner, another after; one of Spanish fashion, another of Turkey; and, to be brief, never content with enough, but always devising new fashions and strange. Yea, a ruffian will have more in his ruff and his hose than he should spend in a year: he which ought to go in a russet coat spends as much on apparel, for him and his wife, as his father would have kept a good house with." 


\section{PAGE 189.}

MANUFACTURE OF AMERICAN IRON.

The following remarks of Nicholas Biddle, Esq., on the manufacture of American iron, will be read with interest.

I need not say that the two substances, which have most contributed to the comfort and eivilization of the world, are coal and iron. The naturalists have asserted, that the chief ingredient of the richest precious stones is carbon; and that, after all, a diamond and a coal are the same thing. The comparison disparages the coal, since certainly, for every purpose of human comfort or enjoyment, the coal outweighs all the gems that ever glistened at all the coronations of all the sovereigns of the earth. As to iron, is it not far more valuable than all the miscalled precious metals? The best friend of man ; his companion in every stage of his civilization, from the rough ploughshare to the complicated steamship. These elements of wealth, the coal and the iron ores, were scattered profusely over this country, but some inexplicable mystery kept them asunder. The coal, in its ficrcest intensity, could make no impression upon these impenetrable masses, and the adjoining hills which contained them frowned on each other, as upon neighbors who could never be united. At length, by one of those happy inspirations which confound all reasonings, the whole obstacle was removed, in a way so simple, that every body wonders it was never dreamed of till now. When these ores and coal were put together in a furnace, the fire was kept up by a stream of cold air. To this process the ores refused to yield. At last, a projector tried what impression he could make by a stream of hot air, and the ores instantly gave up their treasures, like the traveller in the fable, who only wrapped himself the closer at the cold wind, but could not resist the sunshine. And this, after all, is the great 
mystery, - the substitution of what is called the hot blast for the cold blast.

Let us see the changes which this simple discovery is destined to make. As long as the iron ores and the coal of the anthracite region were incapable of fusion, the ores were entirely useless, and the coul nearly unavailable for manufactures, while, as the disappearance of the timber made cliarcoal very expensive, the iron of Eastern Pennsylvania was comparatively small in quantity and high in price, and the defective communications with the interior made its transportation very costly. The result was, that, with all the materials of supplying iron in our own hands, the country has been obliged to pay cnormous sums to Europeans for this necessary. In two years, alone, 1836-7, the importations of iron and steel amounted to upwards of twentyfour millions of dollars. 'The importations for the last five years have been about forty-nine millions of dollars. It is especially mortifying to sce, that, even in Pennsylvania, there has been introduced, within the last seven years, exclusive of hardware and cutlery, nearly eighty thousand tons of iron; and that, of these, there were about forty-nine thousand tons of rail-road iron, costing probably three millions and a half of dollars. Nay, at this very day, in visiting your mines, we see, at the furthest depths of these subterranean passages, the very coal and iron brought to the mouth of the mines on tracks of British iron, manufactured in Britain, and sent to us from a distance of three thousand miles. This dependence is deplorable. It onght to cease for erer ; and let us hope, that, with the new power this day acquired, we shall rescue ourselves, hereafter, from such a costly humiliation. We owe it to ourselves, not thus to throw away the bounties of Providence, which, in these very materials, have blessed us with profusion wholly unknown clsewhere.

The United States contain, according to the best estimates, not less than eighty thousand square miles of coal, which is about sixteen times as much as the coal 
measures of all Europe. $A$ single one of these gigantic masses runs about nine hundred miles from Pennsylvania to Alabama, and must itself embrace fifty thousand square miles, equal to the whole surface of England proper. Confining ourselves to Pennsylvania alone, out of fifty-four counties of the State, no less than thirty have coal and iron in them. Out of the forty-four thousand square miles, which form the area of Pennsylvania, there are ten thousand miles of coal and iron, while all Great Britain and Ireland have only two thousand ; so that Pennsylvania has five times as much coal and iron as the country to which we annually pay eight or ten millions of dollars for iron.

Again, the anthracite coal fields of Pennsylvania are six or eight times as large as those of South Wales. Of these great masses, it may be said, confidently, that the coal and the iron are at least as rich in quality, and as abundant in quantity, as those of Great Britain, with this most material distinction in their favor, that they lie above the water level, and are easily accessible, while many of the mines of England are a thousand or fifteen hundred feet below the surface.

With these resources, you have abundant employment, if you could only supply the present wants of the country, for which we are now dependent upon foreigners. But the sphere of demand is every day widening, for the consumption of iron. The time has come, when nothing but iron roads will satisfy the impatience of travellers, and the competition of trade. The time is approaching, when iron ships will supplant these heavy, short-lived, and inflammable, structures of wood We shall not long be content to cover our houses with strips of wood, under the name of shingles, prepared for the first spark, if we can have low-priced iron; in which event, too, the present pavements of our towns would be superseded by footways of iron.

The only difficulty which is suggested is the high price of labor in this country. Allow me to say, that I consider this a misapprehension. The high rate of 
wages is always put forward as the obstacle to any effort to make for ourselves what we import; but I do not believe that it ever made any serious obstacle in practice. I believe, on the contrary, that in any comparison between the price of labor in England and the United States, if we consider, not the nominal price paid to the laborer, but the amount of work actually done for a given sum of money, and if we regard the English poor rates, which are only a disguised addition to the rate of wages, we shall arrive at the conclusion, that labor is yet very little, if at all, higher in the United States than in England. I know that one of the most respectable and intelligent farmers among us, an Englishman, who, after farming in his own country, finished his career a farmer in my neighborhood, declared, that, although lie scemed to pay a higher rate of wages, yet, on the whole, the labor of his farm was done twenty per cent. cheaper in Philadelphia county, than it had been done in England. Since my arrival here, I have had occasion to compare the rates of wages given in our collieries with those of England, and, although they are nominally somewhat ligher, the difference would not materially affect large operations.

Having, then, the material and the labor, it remains to ask, if you have the industry to follow out this new career. Need I ask that question, in such an active community as this? Nay, you would not belong to this American nation, if you had a particle of sloth in you. Our manners, and habits, and customs, have been often described, but I venture to say, that no description will approach the truth, unless it begins and ends with the declaration, that the Americans are the hardest working people on the face of the earth. Other nations labor in order to live; the Americans seem to live only to labor. To exist, and not to toil, is incomprehensible. They cheerfully acquiesce in the doom of Providence, and, instead of repining at being condemned to labor, they would deem the heaviest curse to be repose. Every man seems born with some steam-engine 
within him, driving him into an incessant and restless activity of body and mind. All the amusements which require time; the luxurious indulgences which consume it; the absurdity of quiet; the unnatural condition of rest; all these he scorns, as unworthy of men whose destiny it is to create, and to build up, and to found, works, and cities, and states. Here is a whole nation, with few rich men, and no idle men; every head and every hand busy, with a thousand projects, and only one holyday, - the Fourth of July,-working from morning till night, with the most intense industry. Yet it is not merely a sordid spirit which impels then; for what they earn thus hardly, they spend with a recklessness quite as characteristic. They work, not to accumulate, but because they must work, or die of apathy. Such a temperament is inseparable from many follies, and leads to many rices; but, after all, it is the true instinct to achieve great things, and whenever it becomes concentrated on some favorite object, wo to the rival whose path it crosses!

My hope, therefore, is, that when the country shall see what marrellous results will repay its industry, in their new career, it will enter upon it with its characteristic eneroy. If coal and iron have made Great Britain what she is; if they have given to her the power of four hundred millions of men, and impelled the manufactories which made us, like the rest of the world, her debtors: why should not we, with at least equal advantages, make them the instruments of our own indepen dence?

To begin that great work, no time would be more proper than the present. Nations seem subject to the same laws as individuals, and they must go through the same diseases which afflict infancy; the same passions which mislead youth; the same infirmities which distress old age. It is, therefore, a subject rather of regret than surprise, that the last few years have been years of great national extravagance. We have bought far too much from foreign nations, and have indulged 
with a childish excess, in all the luxurious follies of the old world. Look only where this has led us. During the last ten years, we have imported about one hundred and eighteen millions of clolkars of silks, and more than forty-one millions of dollars of wines and spirits, making an aggregate of more than one hundred and fifty-nine millions, for articles of the merest luxury. If we had been able to barter for these the grain and the iron which are within our reach, we might have made our industry some apology for our extravagance. But, during the same time, the productions of our farms were rigorously excluded from Great Britain, and we imported more than eiglity-four millions of dollars of iron. Here, then, are

Payments for silks, of . . . \$ \$118,000,000 Wincs and spirits, of . . . . 41,000,000

And for iron, . . . . . . . 84,000,000

Making a sum, for necessarics and

luxurics, of . . . . . . \$243,000,000

paid, in fact, for things which we should have supplied, ourselves, or have dispensed with altogether. And having done all this, we wonder that we are so much in debt! Fortunately, too, if young nations have the errors, they have the elastic spirit and resources, of youth ; and if we only cease the cxtravagant importation of luxuries, and cultivate our own resources, we shall soon recover from these temporary embarrassments.

To no part of the Union will such a clange be more beneficial than to our own Pennsylvania. With the zeal characteristic of our American temperanent, she has gone too suddenly into great public improvements, beyond the immediate wants of the State. The necessity, too, of winning over to any general system the aid of particular portions of the State, has induced her to commence too many works at one time; and, unfortunately, she has too often harl, as counsellors, the two most expensive advisers in all great enterprises, ignorance and parsimony; the one directing blindly, the 
other executing badly. I think it may be said, withe out reflecting harshly on errors, of which we must now all bear our share, that all the works executed for the developement of our Pennsylrania resources ought to have been made for two thirds of what they have actually cost ; and that our debt, instead of thirty-two millions, ought not, at this day, to have exceeded twentytwo millions. But there it is, and we have nothing to do but to pay it; pay it, cheerfully and honestly; by ordinary revenue, if we can, by taxes, if we must. After all, it is not worth while to despond over it. We owe thirty-two millions of dollars. Why, Great Britain and Ireland are not three times as large as Pennsylvania, and they owe four thousand millions of dollars. They pay it with coal and iron. Why may not we? If Pennsylvania, now that she will soon cease to require laborers on her public works, were to apply herself to the resources of coal and iron, which she possesses above all her sister States, she will have her rail-roads and canals covered with these heavy burdens, increasing tenfold the income from her public works, and a fresh tide of prosperity will set into the State, which will enable her citizens to carry her triumphantly through all her troubles. That she must and shall be so upheld, we all feel, since no reproach or degradation can come upon our Commonwealth, without involving all of us in a common shame.

\section{PAGE 216.}

ENGRAVING BY GALVAYIC ELECTRICITY.

Is common copper-plate engraving, the lines which are to be copied by the ink on paper are cut into the surface of the metal. This circumstance renders necessary a peculiar mode of printing off the sheets, much slower and more expensive than printing with raised 
types, and so unlike it, that the two kinds can never be combined in the same impression. 'There are many cases in which such a combination is highly desirable, especially in the figures and drawings to illustrate such a work as this. To supply the place of them, much coarser engravings on wood, or metallic castings from such engravings, are used as substitutes. Recently, a method has been discovered of producing raised lines on the copper-plate, by a very ingenious application of galvanic electricity.

The first publication on this subject appears to liave been in a letter from Professor Jacobi, of St. Petersburgh, to Mr. Faraday, of London, dated in June, 1839, and published in the London Philosophical Magazine, for September of that year. In the course of the same month, (September,) a pamphlet was published by Mr. 'Thomas Spencer, of Liverpool, in which he states that he had made the discovery as carly as September, 18:37, and had been engaged in a series of experiments to bring it to a useful state of improvement. Whether or not we concede to Mr. Spencer the right which he claims, and apparently with justice, of priority of discovery, it is evident that he had, at the time of publication, advanced much further in producing useful practical results than Professor Jacobi. Another paper by Mr. Spencer, giving some results of his further experience, is published in the London Athenæum, for April, 1840. We have not secn Mr. Spencer's original pamphlet; but an extended cxtract, containing apparently nearly the whole of it, is contained in the London Mechanics' Magazine, for October, 1839. From this, and from Mr. Spencer's second paper, we have prepared the following abstract.

To render the operation intelligible to those who are not familiar with the chemical effects of galvanism, it is necessary to premise a short explanation. All the metallic salts are made up of an oxide of the metal as its base, united with an acid. If the acid is withdrawn, by a stronger affinity, the metallic oxide is deposited; 
or, if both the acid and the oxygen are withdrawn, the metal is deposited in a pure state. The metallic salts, as well as the other salts, are all capable of being thus decomposed by galvanic electricity; and the metal is deposited upon the surface of the wire, or plate, which forms the medium of communication of the galvanic circuit. Thus, if a solution of sulphate of copper is brought under galvanic influence, all that part of the wire which is immersed in the solution will be coated over with a film of pure copper; or, if a metallic plate be soldered to the wire, and immersed in the solution, the whole plate will be thus coated. In this case, it matters not whether the conducting metal be the same with that of the base of the salt in solution, or not.

A very simple apparatus is sufficient to excite the galvanic action for the purpose of engraving. That used by Mr. Spencer is a little more complicated. It is as follows. Take an oblong ressel, or trough, of convenient size, of earthenware or wood. Into this fit a smaller vessel, of similar form, but so much more shallow, as to allow a sufficient space for the copper plate and the solution in which it is placed, between the two vessels. The bottom of the inner vessel must be composed of some porous substance, suitable for the transmission of the galvanic action. Mr. Spencer at first used plaster of Paris; but, in his late communication, he recommends brown paper, as rendering the deposition of copper more rapid and more firm than any thing else that he had tried; "not the brown paper usually sold by the stationers, but a thicker sort, manufactured by the papermakers to enclose their parcels." This paper he fastens to the bottom of the vessel by melted pitch, or the common resinous cement used by philosophical-instrument makers. It will be perceived, that we have, by this arrangement, a galvanic apparatus with two cells, differing from the common apparatus only in providing for a horizontal position of the plates in the cells, and at the same time preserving their parallelism; the porous bottom of the interior vessel operating as a partition be- 
tween the cells. In the outer cell is placed the plate to be engraved, immersed in a saturated solution of sulphate of copper; and in the inner, a plate of zinc, of equal size, immersed in a solution of common salt, or of some acid. As it is not desirable that the action should be very rapid, Mr. Spencer prefers the salt. The communication is completed by means of a wire, soldered on the back of each plate, and brought over the edge of the cells. The contact of the wires should be made very perfect, by brightening them, and confining them iogether with a binding serew. The plates are placed horizontally, the copper with the engraved surface upwards, about five eightlis or three fourtlis of an inch, and the zinc one eighth of an inch, distant fiom the brown-paper partition. For copying medals, and for sinall engravings, a very simple apparatus may be made by taking a common glass jar for an outer cell, and suspending in it rertically a large glass tube, a lampglass, for example, with a paper or plaster of Paris bottom for a partition.** Mr. Spencer attaches considerable importance to the horizontal position of the plates. Mr. Taylor, of London, in a paper in the Philosophical Magazine, for March, 1840, recommends a rertical position, as possessing some positive advantages, besides being much more convenient. Any ressel divided into two parts by a proper partition would then answer all the purposes of a sufficient apparatus. But Mr. Spencer replies, that the vertical position has been found, by expericnee, to be a disadvantage. The deposition of metal at the lower end will greatly exceed that at the top, consequently rendering the plates very much thicker at one end than the other; which is to be aroided.

To render this process available for the purpose of engraving, the following method is pursued. 'Talie a plate of copper, such as is used by an engraver, solcler a piece of copper wire to the back part of it, and then give it a coating of wax. Mr. Spencer, at one time

* A piece of bladder tied over tha lower end of the tube is said to make an excellent partition. 
recommended a cement for this purpose; but in his later paper he says he finds that common beeswax, melted by heating the plate, entirely prevents deposition on those parts to which it is applied; while every thing else that he had tried allowed a partial deposition to take place. On the coating of wax write or draw, with a pencil or point, the design to be copied; the wax must then be cut through, with a steel point or graver, taking special care that the copper is thoroughly exposed in every line. The shape of the graving tool should be such, that the lines made are not V-shaped, but as nearly as possible with parallel sides. The plate should next be immersed in diluted nitric acid,-say three parts water to one part acid. It will at once be seen whether it is strong enough, by the green color of the solution, and the bubbles of nitrous gas evolved from the copper. Let the plate remain in it long enough for the exposed lines to become slightly corroded, that the wax, which gets into the pores of the copper during the heating process, may be thoroughly remored. The plate must then be washed in water, and, thus prepared, is placed in the solution of sulphate of copper in the trough described above, and a plate of zinc, of equal size, is placed in the other cell, and the metallic communication completed by means of the wires. The apparatus is then left for several days. If it can be kept at a temperature of eighty or ninety degrees, the process is accelerated. This, Mr. Spencer says, is much better than quickening it by the addition of the salt or acid used to excite the positive cell.

As the wax defends the plate, except in the lines from which it has been removed, it is obvious, that the precipitated copper, instead of being spread over the whole plate, as in the former case, is deposited only in those lines. Unless these lines be perfectly clean, the deposited copper will not adhere with any force, but is easily detached when the wax is removed. Another cause of imperfect adhesion, pointed out by Mr. Spencer, is the presence of a minute portion of some other 
metal, such as lead, which, by being precipitated before the copper, forms a thin film, which prevents the adhesion of the subsequently-deposited copper. 'The surface of the copper in the lines will be found to be more or less rough, according to the quickness of the action. To remedy this, rub the surface with a piece of smooth flag or pumice stone, with water. 'Then heat the plate, and wash off the wax-ground with spirits of turpentine and a brush. The plate is now ready to be printed from at an ordinary press.

The length of time necessary to complete the process must depend on the degree of eleration. To obtain the thickness of an eighth or tenth of an inch will require eight or ten days, at the ordinary temperature. For common printing, a much less height than this will answer. Crystals of sulphate of copper should be added, from time to time, to the cupreous solution ; but, should the deposition require to be thick, and long continued, it will be necessary to take out the cupreous solution once or twice, during the operation, and add an entirely fresh one.

Another method of obtaining an engraved copperplate, with raised lines, is to cut the lines in a plate of soft metal, as lead, or type-metal, and place this plate in the coppery solution, in the galvanic circuit. The copper will be deposited on the whole surface, filling the lines, and thus producing corresponding elevations in its own surface. If lead or type-metal is used for this purpose, the copper is easily separated from it when the process is completed, by applying the heat of a spirit lamp. In other cases, a too strong adhesion may be prevented by lieating the plate, before it is inmersed in the solution, and covering it with wax, and then wiping off the wax as cleanly as possible. Enough will remain to prevent a permanent cliemical union of the two metals, but not enough to prevent the deposition of the copper.

Copper plates, engraved in the common manner, that is, with depressed lines, may easily be copied by the 
galvanic process, and the number of copies multiplied, to any desirable extent. Procure an equal sized piece of sheet lead, (clean and bright, as it comes from the roller,) lay it on the engraved side of the plate, and put both under a very powerful press; when taken out, the lead will have every line in relief that had been sunk in the copper. A wood-engraving may be operated on in the same manner. The lead plate should be encased in a box, before being placed in the galvanic apparatus.

It will readily occur to a man of inventive turn of mind, that the method of precipitating metals, by means of galranic electricity, must be applicable to a great variety of purposes in the arts. The various processes, of coating metallic surfaces with the finer metals, as silvering, gilding, $\mathbb{E} c$., would seem to be capable of great improrement in this way, although we are not aware that any attempts have as yet been made with it. Iron, in machinery where it is particularly exposed, may, by the same process, be corered with a coating of copper, so as to preserve it from rusting. But our concern, at present, is chiefly with the difierent modes of copying. Mr. Spencer has applied it to copying medals, with entire success, having produced perfect copies in copper, exhibiting all the lines, and especially the letters, of the original, with great distinctness and sharpness, as if struck by a die. We have seen some beautiful copies of medals procured by this process, by Mr. Dixon, whose transfer process we hare already mentioned on page 228 of this Volume.

There are two methods of doing this. In the first, the medal to be copied is placed in the solution of sulphate of copper, in the galvanic circuit. Copper is deposited upon its surface, forming a perfect facsimile, reversed, thus constituting a mould, in which, by a repetition of the process, an exact counterpart to the original is produced. In this operation means must be taken to prevent the adhesion of the precipitated copper. This may be done, as has been before intimated, 
by a deposition, in the first place, of a slight film of lead, or other metal. Or it may be effected, more conveniently, by heating the medal, and rubbing a small portion of wax over it. This is then wiped off, a sufficient quantity always remaining to prevent adhesion.

The other method is still more expeditious. Two pieces of clean, milled, sheet lead are taken, and the medal, being placed between them, the whole is subjected to pressure in a screw press, and a complete mould of both sides, is thus formed in the lead, showing the most delicate lines, perfect, (in reverse.) Twenty or even a hundred of these may be so formed on a sheet of lead, and the copper deposited by the galvanic process, with the greatest facility. Those portions of the surface of the lead which are between the moulds may be covered with wax, to protect them from the copper, or the whole sheet may be covered with the deposition, and the medals afterwards cut out.

Neither of these operations will form but one side of the medal. Mr. Spencer has succeeded in copying entire medals, so as to make a perfect facsimile of the original. But the process is more complicated and delicate; and as he is making improvements in it, he has not described it. Copies of the most ancient and rare coins and medals may, by these means, be multiplied at will, so that we may say of this process, as has been said of Mr. Dixon's method of copying ancient prints and manuscripts, that the value from scarceness seems to be almost annihilated by it.

Mr. Spencer has succeeded, also, to some extent, in procuring a deposition of copper on moulds of clay, or plaster of Paris; and it seems not improbable that we shall ere long be able to copy the entire liuman bust in copper, upon the clay model of the sculptor. The art is at present in its carliest infancy; and it cannot be doubted that great and important improvements will be made in it.

Mr. Spencer concludes his last paper, as follows: $33^{*}$ 
"I am now occupied in some experiments, which may terminate in still greater improvements in the economical use of this principle. While I write I have before me a small, electro-magnetic, rotary machine, in rapid motion. In connexion with it, there is a helix, or coil, of corered copper wire, consisting of two lengths, each four hundred feet, the thicker one transmitting the primary current, the smaller one the induced current. In connexion with one end of the primary wire, I have placed a copper plate to be copied. To the opposite end of the same wire I have connected a spiral coil of copper wire, which is immersed in a porous cell, containing diluted sulpluric acid, with a few drops of nitric acid, the plate to be copied being immersed in sulphate of copper. The electric action, excited by this arrangement, being sufficient to revolre the magnetic machine, while at the same time it is depositing pure copper on the plate to be copied, in one cell, and producing sulphate of copper, by the dissolution of the copper wire, in the other. To each end of the smaller wire transmitting the induced current, I hare also attached a similar arrangement; namely, a plate to be copied, and a piece of spiral wire, in a pair of separate cells. This arrangement is also depositing copper on the plate to be copied. My object in this was, to take advantage of the increased amount of electric action always acquired by transmitting the current through spiral coils, and also to arail myself of the induced current which is always eliminated in an opposite direction to the primary. This latter current is generated at absolutely no expenditure of material. For the mere purpose of depositing copper, I might have used the helix without the rotary magnet; but my object was to ascertain the practicability of employing the electricity, generated by the process, for other uses. From this experiment, I can give my opinion, without hesitation, that, should electro-magnetic machines be brought into practical use, of which I entertain no doubt, the same battery that excites them into action, on the one 
hand, will, on the other, copy engravings, ad infinetum. For, after all we have heard lately of voltaic batteries of intense power, sustaining ones, slow but equable, are the only apparatus that can be depended on for an indefinite length of time. I lave not yet made experiments with the helix, in sufficient number, to justify me in stating, for the present, the increase of deposition that may be derived from its use. I intend trying a number of statical experiments, with coils of different thickness, and also coils of flat copper rolled up in the form of a riband, covered with silk. The results of these may form the subject of another communication."

\section{Page 240.}

ANCIENT RATE OF TRAVELLING.

LET us here take a slight retrospective glance at the road-communication of Britain.

In 1678 , the first coach was started from Edinburgh to Glasgow, a distance of forty-four miles, which distance was accomplished, to and from, in six days.* At the present period, four hours and a half is all the time required to travel, by coach, from one city to the other.

In 1706, the conveyance from London to York was by a stagecoach, which was advertised to perform "the whole journey in four days." $\uparrow$ This is now accomplished in twenty-four hours.

* In 16\%S, Mr. William Hume, merchant, of Edinburgh, contracted witl the magistrates of Glasgow, that he "should have in readiness a sufficient strong coach, to run between Edinburgh and Glasgrow, to be drawn by six able horses, to leave Glasgow ilk Monday morning, and return ilk Saturday night, God willing."

+ Every Monday, Wednesday, and Friday, (if Cod permit,) it sets forth, "at five in the morning, and returns from York to Stamford in two days; and from Stamford by IIuntington to London, in two days more, and the like stages on their return." 
In 1712, we find, by an advertisement* in the Newcastle Courant, that the stagecoach conveyed passengers between London and Edinburgh, by means of "eighty able horses," in thirteen days without any stoppages. But according to McCulloch's Dictionary, there was only one coach in the year 1763, which set out once a month, taking from ten to twelve days to perform the journey. Other routes were equally tedious. $\dagger$

"In 1760," says a writer in Pinnock's "Guide to Knowledge,' "w when it was necessary for a journey to be taken from Brighton to the metropolis, (a distance, then, of about sixty miles,) the travellers, after breakfasting, dining, and supping, on the road, were, by great exertion, able to get as far as East-Grinstead, (about thirty miles,) where they stayed all night; and by persevering, in the same nianuer, the following day, were enabled to reach London, at night, making the extraordinary journey of sixty miles in two days. These were the 'good old times.' Things are now strangely alkered, and we are extravagant enough to perform the same journey (now reduced to fifty-two miles) in fire hours, and sometimes less."-See Gordon, on Locomotion.

The first stagecoach established in America was in 1784, between Boston and New York. The journey between the two cities was accomplished in four days.

* "Edinburgh, Perwick, Newcastle, Durham, York, and London, stagecoach begins on Monday, the thirteenth of October, 1712 . All that desire to pass from Edinburgh to London, or from London to Edinburgh, or any place on that road, let them repair to Mr. John Baillie's, at the Coach and Horses, at the Head of Canongate, Edinburgh, every other Satnrday, or to the Black Swan, in Holborn, Loudon, every other Monday; at both which places, they may be received into a stagecoach, which performs the whole jonrney in thirteen dars, without any stoppages, (if God permit,) haring eighty able horses to perform the whole stage. Each passenger paying four pounds ten shillings for the whole journey, allowing eacil passenger twenty ponnds weight, and all above to pay six pence a pound. The coach sets out at six o'clock in the morning. Performed by Hen. Harrison, Robert Yorke, Richd. Speight, Richard Croft."

iे "A new, fast coach, hung on steel springs, with furr horses and two postillions, sets ont from the Greshound Inn, Market-place, Bath, and the George Inn, Drury Lane, London, every Monday, Wednesdas. 


\section{Page $\cong 41$.}

INFLUENCE OF IMPROVEMENTS ON HUMAN WELFARE.

"IT is a favorite phrase," says an eloquent countryman of ours, "of those who boast of what is called the 'march of intellect,' that things are thus changed, [he refers to the growing distaste for war,] because the 'schoolmaster is abroad.' But I tell you that something far more effective than the schoolmaster, - a mightier than Solomon,-is abroad. It is the steamengine, in its twofold eapacity of a means of production and the means of transport; the most powerful instrument, by far, of pacification and commerce, and therefore of improvement and happiness, that the world has ever seen: which, while it increases capital, and multiplies, beyond all imagination, the products of industry, brings the most distant people into contact with one another; breaks down the barriers which exclusive legislation would oppose to the freedom of mercantile exchanges ; effaces all peculiarities of national character; and promises, at no distant period, to make the whole Christian world, at least, one great family."

And again, speaking of the cultivation of cotton, he says, and says truly, "Whoever shall write the political history of that invaluable plant, will liave a more important work to perform than has ever fallen to the lot of a biographer of statesmen or philosophers. I will venture to say, without going more into details, that the single circumstance of bringing the wonderfully cheap fabrics produced by modern machinery within the reach of even the humblest of the laboring classes, of substituting decent and comfortable raiment for the few scanty and filthy rags, the squalid exterior, which makes poverty not only more painful, but at once more

and Friday, at seven o'clock in the morning, and arrives at the above inns on the following days, at four in the evening. The coach stops all night at Andover, going and coming." -Weuspaper, 1765. 
humiliating and degrading, to its victim, and more dis. gustful to others, than it ought to be, will signally contribute to elevate the condition of the poor in the social scale; to raise their self-esteem, and to increase the sympathy of others for them; in a word, to make them feel themselves men, entitled to a place among men ; not pariahs and outcasts, whose contact is contamination. A people well clad and well housed will be sure to provide themselves with all the other comforts of life; and it is the diffusion of these comforts, and the growing taste for them, among all classes ; it is the desire of riches, as it is commonly called; that is gradually putting an end to the destructive and bloody game of war, and reserving all the resources hitherto wasted by it, for enterprises of industry and commerce, prosecuted with the fiery spirit which once vented itself in scenes of peril and carnage."

"And how is the face of Europe changing by means of such enterprises? I have travelled in parts of the Continent which the spirit of gain, with its usual concomitants, industry and improvement, has invaded since the peace, at an interval of fifteen years; and been struck with the revolution that is going on. There is a singularly beautiful, though rather barren, tract of country, between Liege and Spa, where, in 1819, my attention had been principally attracted by the striking features of a mountainous region, with here and there a ruin of the feudal past, and here and there the hovel of some poor hind,- - the very haunt of the 'wild-boar of the Ardennes' in the good old times of the House of Burgundy. I returned to it, in 1835, and saw it covered with mills and factories, begrimmed with the smoke and soot of steam-engines; its romantic beauty deformed, its silvan solitudes disturbed and desecrated by the sounds of active industry and the busy hum of men. I asked, what had brought about so great a change, and found the author of it,-a man having a more numerous band of retainers and dependents than any baron bold of the fourteenth century, and in every 
respect more important than many of the sovereign princes on the other side of the Rhine, - was an English manufacturer, who had established himself there some twenty years ago, without much capital, and had effected all this by his industry and enterprise." Speech of H. S. Legare, in Congress, 1837.

\section{PAGE 251.}

ANCIENT AND MODERN PHILOSOPHY COMPARED.

Tre end which the great Lord Bacon proposed to himself was the multiplying of human enjoyments and the mitigating of human sufferings. The ancient philosophy disdained to be useful, and was content to be stationary. It dealt largely in theories of moral perfection, which were so sublime, that they never could be more than theories; in attempts to solve insoluble enigmas, in exhortations to the attainment of unattainable frames of mind. It could not condescend to the humble office of ministering to the comfort of human beings. All the schools regarded that office as degrading, some censured it as immoral. Once, indeed, Posidonius, a distinguished writer of the age of Cicero and Cæsar, so far forgot himself, as to enumerate among the humbler blessings which mankind owed to philosophy, the discovery of the principle of the areh, and the introduction of the use of metals. This culogy was considered as an aftront, and was taken up with proper spirit. Sencea vehemently disclaims these insulting compliments. Philosophy, according to him, has nothing to do with teaching men to rear arched roofs over their heads." "The true philosopher loes not care whether he has an arched roof, or any roof. Philosophy has nothing to do with teaching men the uses of metals. She teaches us to be independent of all ma- 
terial substances, of all mechanical contrivances." $\mathrm{He}$ labors to clear Democritus from the disgraceful imputation of having made the first arch, and Anacharsis from the charge of havigg contrived the potters' wheel. 'The business of these philosophers was to declain in praise of poverty, with two millions sterling out at usury; to meditate epigrammatic conceits about the evils of luxu$\mathrm{ry}$, in gardens which moved the envy of sovereigns; to rant about liberty, while fawning on the insolent and pampered freedman of a tyrant ; to celebrate the divine beauty of virtue with the same pen which had just before written a defence of the murder of a mother by a son. From the cant of this philosophy, a philosophy meanly proud of its own unprofitableness, it is delightful to turn to the lessons of the great English teacher. The philosophy which he taught was essentially new. Its object was the good of mankind, in the sense in which the mass of mankind always have understood, and always will understand, the word good. The aim of the Platonic philosophy was to exalt man into a god. The aim of the Baconian philosophy was to provide man with what he requires, while he continues to be a man. Tlie aim of the Platonic philosophy was to raise us far above vulgar wants. The aim of the Baconian philosophy was to supply our vulgar wants. The former aim ivas noble; but the latter was attainable. Ask the follower of Bacon, what the new philosophy, as it was called in the time of Charles the Second, has effected for mankind, and his answer is ready. It has lengthened life; it has mitigated pain; it has extinguished diseases ; it has increased the fertility of the soil ; it has given new securities to the mariner; it has furnished new arms to the warrior; it has spanned great rivers and estuaries with bridges, of form unknown to our fathers; it has guided the thunderbolt innocuously from heaven to earth; it has lighted up the night with the splendor of the day; it has extended the range of the human vision; it has multiplied the power of the human muscles; it has accelerated motion; it has annihilated 
distance; it has facilitated intercourse, correspondence, all friendly offices, all despatch of business; - it has enabled man to descend to the depths of the sea; to soar into the air, to penetrate securely into the noxious recesses of the earth, to traverse the land on cars which whirl along without horses, and the occan in ships which sail against the wind. 'These are but a part of its fruits, and of its first fruit. For it is a philosophy which never rests, which has never attained, which is never perfect. Its law is progress. $\Lambda$ point, which was yesterday invisible, is its goal to-day, and will be its starting-post to-morrow.-Edinburgh Revicw.

\section{Page 299 .}

TECHNOLOGICAL INSTRUCTION.

Among the most effectual means of developing manufacturing skill and enterprise in a country are, legislative protection, associations for the encouragement of the arts, public exhibitions and repositories, and technological instruction. It was our intention to have entered into some details, with respect to each of these, but our linits forbid. Omitting, therefore, any further reference to the first three, which are beginning to be appreciated among us, we pass to the fourth, which has hitherto receired scarcely any attention in the United States, but is perhaps superior in importance, at this time, to either of the others.

By technological instruction, we mean the systematic instruction of the young in the theory and cconomy of the useful arts. To some extent, this instruction ought to be made general, and should therefore be introduced into our elenientary sehools and colleges. What is more particularly wanted, however, is special instruction for those who are intended for industrious pursuits. Of these, there are, of course, two classes * 
one, having some capital and the means of taking a thorough course of instruction, and who contemplate becoming proprietors or superintendents of manufactories, or engineers; the other contemplate beginning as operatives, and advancing, by degrees, to a higher station. For both of these, a more thorough preparatory training is necessary, as it respects the science of their business.

It is necessary, on the simple principle that knowledge is power. Under the strong stimulus of circumstances, our people contrive to acquire vast dexterity in whatever they undertake. It is none the less certain, however, that with more thorough and systematic training, this dexterity might be increased and made more general, at the same time that it would be applied with more steadiness and forecast. Our enterprise is now somewhat too impulsive. Undertakings of great promise, and involving great expense, terminate disastrously, because not commenced with sufficient deliberation; or because intrusted, for their execution, to incompetent agents and operatives. The effect of a well-digested system of technological instruction, if it become extensive, would be to provide a ready stock of ability and skill, which miglit at any time be made available for such undertakings. More capital, too, would be invested in the arts and in manufactures, if the capitalists could find agents, and had more confidence in their ability.

Another effect of such instruction would be, to elevate the character and sentiments of the pupils, and thus inspire them with the desire of excelling in their respective pursuits.

A young country, like ours, especially if its industry is not protected by the gorernment, can build up its own arts only by superior native skill. It must have artisans, superintendents, \&c., of its own, seeking employment, who are able to fabricate the best articles at the cheapest rate. This is peculiarly necessary among us, at this time. In respect to geographical position, facilities for obtaining the raw materials, freedom from 
taxation, and general activity and intelligence among the people, we are more advantageously situated for manufacturing than the countries of Europe. But they have more capital, more science, and cheaper labor; and they are now busily engaged in acquiring more skill. This may be regarded as the distinguishing feature of European industry, especially of continental industry, at this time. Tired of dependence on England for all the articles needed in home consumption, France and Germany are now laboring to develope their own arts, through the medium of education. Though they have judiciously regulated their tarift for this purpose, and Prussia, in order to insure success, has abandoned lier policy of free trade, as it respects England, and resorted to an admirable system of protecting duties, yet they seem to rely greatly on the superior skill which they are aiming to develope by instruction.

For this purpose, professorships of technology have been established in the universities, in connexion with repositories or museums for instruments, products, materials, \&c. ; and text-books, and other instruction connected with the arts, have been introduced into the gymnasia and inferior schools.

In addition to these, institutions specially devoted to the training of those intended for industrious pursuits are rising in all parts of Germany, Austria, and France. Some of them, like the school of arts and manufactures at Paris, the institute of arts at Berlin, and the polytechnic institute at Viemna, teach the elementary learning of all the arts, in connexion with other branches, useful for those who are not intended for the learned professions. 'Ihe following branches are usually taught, in addition to the languages, which may be omitted: namely, chemistry and its applications, physics and their applications, elementary and higher mathematics and their applications, mechanics and their applications, civil and hydraulic architecture, drawing, modelling, \&.c. 'These institutions are designed, of course, for those intended for engineers, su- 
perintendents, \&c. They are supported, for the most part, by government.

There are also agricultural, or rural, schools, in Switzerland, Ireland, \&c., which are usually designed for the poor, who will devote themselves to agriculture. The instruction is confined to the inferior branches, and is connected with manual labor in the field. The celebrated institution of Fellenberg, at Hoffwyl, is of a higher character.

Special schools of arts, mines, and manufactures, are also established, which give ample courses of instruction in elementary learning, with a particular reference, however, to some one art or class of arts. Of this nature, is the polytechnic school of Paris, which educates those who are intended for military service, civil engineering, \&c. ; the school of roads, bridges, and mines, in France, the school of mines, in Saxony, the industrial school of Lyons, in France, connected more especially with the silk manufacture, \&c. \&c. \&c.

Theoretical instruction is combined, more or less, in these schools, with practice. The student goes through the manipulations in chemistry, modelling, drawing, \&c., and also (in Germany, not in France) in the particular art of trade for which he is destined. Much difficulty has been experienced, however, in conducting the latter branch of instruction. Experience, in Germany, seems to have taught, that, in the case of some arts, (such as masonry, carpentry, joinery, \&c.,) the manual and theoretical parts cannot be combined, and hence young men, intended for these, are, in some schools, required to have scrved an apprenticeship at their trade before entering. In other arts, (such as dyeing, glass-cutting, carving, engraving, machine-making, \&c. \&c.) a certain portion of time is given to practice, either in workshops belonging to the establishments, in large manufactories in the vicinity, or in smaller shops, occupied by mechanics, in the town, who, in consideration of being allowed to attend lectures, \&c., will teach the pupils for a few hours, weekly, the use of 
tools, the operations, \&c. Of these three methods, the last is probably the best, as involving less expense, and yielding more real instruction, than the first, and securing a greater variety of practice and instruction, than the second.

The only institution of this kind, known to us, in the United States, is the Rensselaer Institule at 'Troy, New York, founded, and for many years sustained, by the late Stephen Van Rensselaer, of Albany.

NOTE ON THE COTTON MANUFACTURE.

Since the preceding pages were in type, we have received a highly interesting work by Mr. James Montgomery, superintendent of the York Factories, in Saco, Maine, and published in Glasgow, Scotland, on the Cotton Manufacture of the United States, contrasted and compared with that of Great Britain. We have not room, in the short space allowed for this Note, for cren a summary of the very important facts presented in this volume. We might otherwise have drawn from it many striking illustrations of the principle which it has been our object to enforce,- the comnexion of science and intelligence with improvement in the arts,especially in reference to the condition of the manufactures in this Country, and the prospects which await them on the expiration of legislative protection. The comparative expense of manufacturing cotton in this Country and Great Britain is exhibited in detail, with a description of the machinery and processes that are peculiar to either country, and their cost in each. From this comparison, it appears that nothing but a high degree of skill can hereafter enable our manufacturers to compete, successfully, with their more experienced rivals abroad. The cost of buildings and machinery, and the expense of working the cotton, is considerably less there than here. 'This, however, is somewhat more $31^{*}$ 
than counterbalanced by the diminished cost of the raw material to the American manufacturer. But it may well be doubted, whether this difference will be sufficient to protect any manufactories, but such as are managed with that high degree of skill which adequate knowledge alone can impart. The immense amount of the interests involved renders this a question of vast consequence to our whole community, and the accumulation of facts here presented has a very important bearing upon it. It were foreign to our purpose, even if we had room, to speak of the value of the details in this volume, to the manufacturer himself, in conducting his operations, although we conceive it must be of great advantage to him, by enabling him to compare his own processes and their results, with those of others, both in our own Country and Great Britain.

Mr. Montgomery says, that the preliminary processes of assorting and preparing the cotton, and the picking and spinning, are better done,- - that is, with more care, and with better machinery, and therefore more perfectly,-in Great Britain, than in America; but that the weaving is quite as well done here, as there. If this observation is well founded, there must be ample scope among us for the exercise of ingenuity and skill, until the improvement in one department shall be at least equal to that in the other; and until a reduction shall be effected of the cost of manufacturing, which is now nineteen per cent. greater here than it is in Great Britain. 


\section{G L O S S A R Y}

WORDS AND PHR.ISES NOT EASIIY TO LE UNDERSTOOD

HY THE YOUNG READER.

[Hany names $\mathrm{N}^{*}$ persons and places, terms of art, Sc., which ocur in this Volune, will be found explained in one of the passages where they occur. For thesc, see IxDEx.]

lisusion, abuse, impropriety.

Ad infinitum, to infinity.

$A d=c$, or .Addice, a tool of the axe kind, used by coopers and carpenters

for cutting thin chips from timber, having its blade thin and arching, and its edge at right angles with the handle.

Arriform, having the form or nature of air.

- Agincourt, a village in France, celebrated for a battle, fought October

25,1415 , between the French and English, in which the latter, commanded by King Henry V., were victorious, though the French army was seven times more numerous than the English, and the latter, destitute of alsnost every thing, and reduced by sickness, had, before the battle, requested peace on disadvantageous terms. The French lost twenty-four thousand men, the English sixteen hundred. - Ilbumen, a substance found in living bodies, which congulates, or becones hard, by heat. White of egg is an exansple.

Alchymists, the professors of .Alchymy, an art which originated in Arabia, in the fourth century, and was afterwards much cultivated in Europe. It had for its object the transmutation or change of other metals into gold, and the power of curing all diseases, and renewing and prolonging life. This was to be cffected, as they supposed, by a substance of which they were in search, and which they called the clixir of lif $c$, or, the philosopher's stonc. Though engaged in what is now known to have been a visionary object, they rendered great service to science, and particularly to chenustry; inany really valuable discoveries having been made by them, while in the fruitless pursuit of the imaginary "philosopher's stone."

. Alcuin, (Flaccus Alcuinus, or Albinus,) an English seholar, the most learned and polished man of his time. He was horn A. D. 732, and died A. D. 804. Ile was Abbot of Canterbury, but in 782, on the invitation of Charlemagne, (or Charles the Great.) he went to France, where he became the instructer and confidential adviser of that monarch, and continued to be so till A. D. 801 . He est .blished various schools, and labored to diffuse through Europe a knowledge of the sciences. He left numerous works in theology and philosophy, which were published in 1617, and again, in a more complete edition, in $17 \% \%$. The Acadenies of Tours, Paris, and many others, were either founded, enlarged, enriched, or instructed, by him, or through his influence with Charlemagne.

alkili, (plural alkalics,) a substance that lias the property of combining with, and neutralizing the properties of, acids, producing salts by the combination. Alkalies cliange most of the vegetable blues 
and purples to green, red to purple, and yellow to brown. Caustic alkali, an alkali deprived of all impurities, being thereby rendered more caustic and riolent in its operation. This term is usually applied to pure potash. Fixed alkali, an alkali that emits no characteristic smell, and cannot be rolatilized or eraporated without great difficulty. Potash and soda are called the fixed alkalies. Soda is also called a fossil, or mineral alkali, and potash, the regetuble alkali. Volatile alkali, an elastic, transparent, colorless, and consequently invisible gas, known by the name of ammonia, or ammonical gas.

.9mmonia, see the preceding article.

. Inacharsis, a Scythian philosopher, who flourished about B. C. 582 He was brother to the King, Saulus, and went to Athens, on an em bassy, in the time of Solon, by whom he was much esteemed. He was admitted by the Athenians to the honor of citizenship, being the only stranger upon whom that honor was ever conferred. On his return to scythia, he attempted to change the customs of his country, and introduce the civilization and worship of Greece; but he was slain by the king, before he was enabled to put his design in execution. He was esteemed one of the seven wise men of Greece.

.Inderson, (James, LL.D.,) a celebrated Scotch agriculturist and author, who was born near Edinburgh, A.D. 1739, and died Oct. 15, 1803. At an early age, perceiving the importance of a scientific acquaintance with agriculture, he entered upon the study of chemistry, and pursued, at the same time, several other branches of useful knowledge. He published many valuable works on agri culture and other subjects, among which, was a 'Correspondence with General Washington.'

Inglo-Saxon, an appellation giren to the language spoken by the English Saxons, or inhabitants of England in the latter part of the fifth century, (A. D.450, and after.) The name England is derived from the Angles, a tribe who settled there about A.D. 440. They formerly inhabited ancient Germany, as did also the Saxons, who came orer to England about the same time.

Anthracile, one of the most raluable kinds of mineral coal. It is rery abundant in the United States.

Appert's process, a method of preserving articles of food from decay, brought into notice by M. Appert, in a mork published by order of the French Minister of the Interior, and entitled, 'The Art of preserving all Kinds of Animal and Vegetable Substances for severa] Years.'

Arai, or araie, array, pomp, splendor, show.

Irchil, (or archilla, called also rocella, and orsielle,) a whitish moss, which grows upon rocks in the Canary and Cape de Verde Islands, and yields an extremely beautiful and rich purple tincture. When prepared for dyeing, it is called litmus, or lacmus.

Archimedes, the most celebrated among the ancient geometricians, born at Syracuse, in Sicily, about two hundred and eighty-seren years before the birth of our Saviour. He was the inventor of sereral of the most important mechanical powers, such as the compound pulley, the endless screw, \&c.; and is reported to have said, he would more the world, if he could find a fulcrum, or point, without it, on which he could stand and place his lever. He is also said to have constructed lenses or burning glasses, of such great 
power, that he set on fire with them the shifs of the Roman flect, which was besieging Syracise. Hiero, King of Syracuse, suspecting that an artist liad added some common metal to a crown, which he had directed to be made of pure gold, requested Archimedes to ascertain the fact. He discovered the method of solving the ques tion, while he was in the bath, as mentioned in this volume, page 67 Aristollc, a distinguished Greeian philosopher. born three liundred and eighty-four years brfore Christ, at Stagira, in Macedonia; whenee lie is sometimes called 'the Stagirite.'

Arliacrigh, (Sir Richard,) inventor of the spinning-jenny, who was born Dec. 23,1732 , and died in 1792. For a further account of him, see the second' volume of " P'ursuit of Knowledgre under Difticulties,' forming Vol. xv. of 'TuE Schoul Library,' Larger Series.

Artesian $x c l l$, a cylindrical perforation, bored vertically into the earth, through one or more of the geological strata, till it passes into a porous gravelly bed, containing water under sufficient incumbent pressure to force it to the surface, or to a height convenient for the operation of a pump. For a full notice of such wells, see Bigelow's ' Useful Arts,' Vol, ii., forming the twelfth volume of the Larger Series of 'The Schoul Library.'

The Athenian hero, (on page 217,) see Thenistocles.

.Iugustine, or Austin, St., see St. Augustinc.

- Automatic, mechanieal, not voluntary, not depending on the will.

.4zote, see Nitrogen.

Bubbage, (Charles,) a distinguished English writer and mathematician, Protessor of Mathematics in the University of Cambridge, author of the 'Economy of Machinery and Manufactures,' and other valuable works.

Bacon, (Francis, Lord Verulam,) Lord High Chancellor of England, was born $\Lambda$. D. 1561, and died $\Lambda$. D. i626. He was a profiound scholar in the whole circle of the sciences, and is to be regrarded as one of the most remarkable men of any age. He adrocated, with great eloquence and learning, the reforming of philosophy, by founding it on the observation of Nature, though he is not, perhaps, to be regarded as the first who made this great step towards the advasteement of science.

Bucon, (Roger, an English monk of the thirteenth century, distinguished for his discoveries in chemistry and natural philosophy. For an account of him, see the second volume of 'Pursuit of Knowledge under Difficulties,' being volume xv. of 'Tur. Scroul LIBRARY,' Larger Series.

Baler's 'Chronicle of the Kings of England,' a work written by Sir Richard Baker, who was born in the county of Kent, in England, about A. D. 156׳, and died Feb. 18, 1644-i).

Bnlicicell, (Robert,) an English grazier, who was born at Dishley, in Leicestershire, A. D. I726, and died in 1795. 1le obtained great celebrity by his strenuons efforts to improve the breed of cattle; in effecting which object, he travelled over England, Ireland, and Holland.

Bannorliburn, battle of, a sanguinary engagement, which took place near the village of Bannockburn, in Scotland, on the River Bannock, between the linglish and Scottish armies, June 24, 13/4, in which the English were defeated. The contending armies were commanded by the Sovereigns of England and Scotland, Edward II. 
and Robert Bruce; and the issue of the battle decided the question of the liberty of Scotland.

Barille, the ashes of certain marine plants.

Barlic, barley.

Batoon, or batten, (called also a lay,) that part of a weaving loom, in which the reed is placed, and which, moving backwards and forwards, presses the crossing threads, or weft, close together, after each passage of the shuttle through the warp.

Battering-rum, an ancient military engine, consisting of a long and heavy wooden beam with an iron end shaped like a ram's head, suspended from a frame of timber, and employed for battering down walls.

Beaters, in a cotton-cleaning machine, are projections on a revolving cylinder, by which the cotton is struck with great velocity and force as it passes into the machine, and is thus loosened and pre. pared for carding.

Becket, Thomas $\dot{o}$, a celebrated Roman Catholic prelate, who was born in London, A. D. 1119, was made Archbishop of Canterbury, in 1162 , and was killed, December 22, 1170. He was a haughty and imperious prelate, yet after his death he was canonized, or called a saint, and many miracles were said to have been wrought at his tomb.

Beclimann, (John Anthony,) an ingenious and learned scholar, a native of Hloye, in Hanover, who in 1767 became Professor of Physic in the University of Gottingen, where he died in 1811 . He wrote many works; one of which, a 'History of Discoveries and Inventions,' has been translated into English.

Bcrgmann, (Torbern Olof,) a Swedish natural philosopher, physician, and chemist, who was born March 9, 1735, and died in 1784 , exhausted by his exertions in the cause of science. Ile was Professor of Mathematics and Natural Philosophy, and also of Chemistry, at the University of Upsal, and was a nember of most of the learned Societies of Europe. He made many discoveries in science, and published many learned works.

Bcril, or bevel, an instrument composed of two straight edges or blades, comnected at one end as a centre, and movable, so as to form any desired angle.

Bin, a box or place parted off for the reception of corn, bread, or any other article in bulk.

Bismuth, a brittle metal, of a reddish white color, very fusible, reọuiring but little heat to melt it.

Bitartrate, a compound, having two proportions of tartaric acid.

Black, (Dr. Joseph,) a very celebrated modern chemist, who was born of British parents, at Bordeaux, in France, A. D. 1723, and died in Edinburgh, November 26, 1799, in the seventy-first year of his age.

Black drop, a preparation of opium and acetic acid, or vinegar.

Blast, the introduction of air, either hot or cold, into a furnace, to promote combustion.

Bloom, the blue color upon plums and grapes newly gathered.

Boors, uncivilized peasants.

Bossut, (Charles,) an eminent French mathematician, who was born at Lyons, in 1730, and died in 1814. He was author of several valuable works on Mathematics.

Bowing, a process in the preparation of furs for making hats. It is 
performed with a bow made of a pole seven or eight feet in length, to which are fixed two bridges some what like those of a violin, and over which is stretehed a catgut. The bow is held horizontally among the fur, when the string is stretched and sprung; the elasticity of the string scatters the fur, and by repeated strokes opens and separates the filaments, till it is all in a fit condition for felting, or making into felt, the substance of which the bodies of hats are generally composed.

Boylc, (Robert.) a celebrated natural philosopher, who was born at lismore, in Ireland, January 26,1627 , and died at I.ondon in 1691 . For a further notice of him, see ' Pursuit of Knowledge under Difficulties,' Vol. ii., forming the filteenth volume of the Larger Series of 'TuE Sc nool LiBRary.'

Bramah, (Joseph,) a very ingenious English engineer and mechanician, who was born in Yorkshire, April 13,1749, and died near London, December 9, 1314. He distinguished himself by his inventions, particularly by his locks, and his hydraulic press, and for his improvements in fire engines.

Bruntome, (so called, from an Abbey which he possessed, but whose real nane was Pierre de Bourdeilles,) a French courtier of the reigns of Charles IX, and Henry III., who was born A. D. 15\%7, and died in 1614. He wrote several works; and his memoirs of his eontemporaries form fifteen volumes.

Brassiea, the generic name for the cabbage, and plants of that family. Brennirg, burning. Brenning of wild-fire, lighly-seasomed.

Briarean, having many hands; from Briareus, a labled giant, who is said to have had one hundred hands and fifty heads.

Broccoli, a species of cabbage.

Brunell, (M. J.,) a skilful and enterprising English engineer, who projected, and is still (1840) superintending, the construction of a tunnel or passage under the River Tlames, from one side to the other.

Burleigh, (IVilliam Cecil,) Lord, a celebrated English statesman, who was born in 1520 , and died in 1593 . He was characterized as "the oldest, the gravest, and the greatest statesman in Christendom." Ile was Secretary of State to Queen Elizabeth.

Buslied, adorned, lecorated, prepared, made ready.

Cadmium, a metal of a light whitish color, resembling tin, but some. what harder and more tenacious. It was discovered in 1817 , by Professor Stromeyer.

Casur, (Caius Julius,) a very distinguished Roman general, emperor, statesman, and historian, who was born B. C. 100 . He is said to have been victorious in five hundred battles, and wrote Commentaries on the wars in which he was engaged, on the spot where his battles were fought. He was assassinated at Rome, March 15, B. C. 44. Cresar was also the family name of the first five Roman emperors, and the surname given to the next seven; and became, subsequently, the cecond, and finally the third, title of dignity under the emperors

Calamine, carlsonate of zinc.

Cam, (from the French eame, a lift,) a wheel, the axis of which is not situated in its centre, and the object of which is to produce an eccentric, or alternate, motion, in any part exposed to its action.

Campan, Madame, (Jeanne Louise Henriette, a French lady, who was born at Paris, October 6, 1752, and died Mlarch 10, 1820. She was attached to the family of Marie Antoinette, wife of Louis XV1., 
King of France; and was afterwards principal of a school founded by the Emperor Napoleon, for the daughters of some of his officers. She wrote Memoirs of the Private Life of the Queen, with Recollections of Louis XIV., XV., and XVI., and other works.

Caoutchouc, elastic gum, or India rubber.

Caoutchoucine, a liquid obtained from caoutchouc, by distillation.

Capon, a kind of poultry.

Carbonote, a compound, or salt, containing carbonic acid. Carbonate of a mmonia, a compound of carbonic acid and ammonia.

Carbonic ucid, a gas composed of carbon and oxygen. It has lately been obtained in a solid form.

Cascous, resembling cheese.

Castelled, surrounded or adorned with turrets and battlements, like a castle.

Cato, (Marcus Porcius,) the Roman farner, called also the Censor, from his haviug exercised that office, was born at Tusculum, B. C. 232. He cultivated a small farm with his own hands, and died in an extreme old age, about B. C. 147. He composed many works, only one of which, a treatise on Husbandry, now remains.

Cementution, a chemical process, by which the character of a metal is changed, as iron into steel, copper into brass. Glass is also changed in to porcelain, by cementation.

Cenire-bit, an instrument turning on a centre, used by carpenters, cabinet-makers, \&c., for making circular lioles.

Certes, certainly.

Champagne, a particular kind of wine, originally made in Charnpagne, in France.

Chiptal, (Jean Antoine Claude, Count of Chanteloup, and Peer of France, a distinguished pliysician, chemist, and author, who was born A. D. 1756, and devoted himself to the study of medicine and the natural sciences. He wos author of many valuable works, on national industry, chemistry, the cultivation of the vine, chemistry applied to the arts and agriculture, \&c. \&c.

Charing-cross, a large open triangular space in London, fronting on some of the principal streets. A large marble cross formerly stood in the centre of it, which was erected by King Edward I., and destroyed by the Republicans in 1643. A statue of Charles I. on horseback, in brass, was erected upon the same spot, on the restoration of Cliarles 11 .

Charles II., King of England and Scotland, born in 1630, was the son of Cliarles I. He became King, May 29, 1660, and died February, 1685 . He was a licentious and immoral prince.

Chazecr, (Geoffrey,) one of the greatest, as well as most ancient of the English poets, born in London, A. D. 1328, and died October $21,140 \mathrm{i})$. He is considered the "father of English poetry."

Chaunge, change.

Chloride, a compound of chlorine and some other substance.

Chlorine, a simple substance, formerly called oxymuriatic acid. In its pure state, it is a gas, and, like oxygen, supports the combustion of some untlammable substances.

Chromate, a compound of chromic acid with some other substance.

Chrome, o1 Chromium, a brittle metal, of a yellowish white color.

Chromec actd, an acid of which chromium is the basis.

Cicero, (Marcus Tullius, the most distinguished writer and orator of Rome, who was born B. C. 106, and died December 7, B. C. 43. 
Citric acid, the acid obtained from the juice of lemons or lines.

Clepe, to call. Ciepci, called.

Cloaca maxima, a large subterranean passage or street, constructea under ground by the Romans, for the purpose of purifying their city, and dritining off the filth, Sc., from the houses and streets.

Cluch, a projecting tooth on a wheel or other piece of machinery, intended to connect two or more parts of a machine moved by the same power, so that one can be stopped while the other is in motion.

Cungulum, that which has the power of coagulating, or making hard. Cubalt, a brittle metal, of a reddish gray color, and weak mictallic Iustre.

Cocou-nut iard, the oil of the cocoa-nut, in a state of lard.

Culie, (Thomas William,) now Earl of Iseicester, a celebrated English a grriculturist, who was born about $\mathrm{A}$. D. 1748. He was made Earl of Leicester by Queen Victoria.

Commissarint, the body of otlicers providing provisions for an army.

Cop, the conical hall of thread wound on the spindle of a spinning frame, whence it is reeled, or transferred to boubins.

Cotcs, (old Scotch,) coats.

Confe, a coif or headdress, a lady's cap.

Ditie, day.

Dagswaine, a rough, coarse mantle.

Dumiuni, (Peter,) a cardinal of the Romish Church, who died A.D. 1073. Dutu, adinitted truths.

Duoy. (Sir Huinphrey,) one of the most distinguished cliemists of the agc, who was born in Cornwall, England, A. D. 17\%9, and died in 15\%). See 'Pursuit of Knowledge under Difficulties,' Vol. ii., forming the fifteenth volume of 'TnE Scrool Librass;' Larger Series.

Decolorant, a substance which cxtracts color.

Decaloration, an extraction of the color from any substance.

Decrees, French, decrees passed by the French government, in 180\%, prolnibiting the trading of neutral vessels to any port of Groat Britain, with whom France was then at war. See Orders in Council.

Democritus, a celebrated philosopher of Abdera, a city of 'Thrace, who was born about B. C. 470 , and died about B. C. 361 .

Disintegrating, separating into particles.

Dumfsiluy (or doomsday) book, a very ancient record, made A. D. 1081 to 1036 , containing a survey of nearly all the estates in England

Donued, put on, invested with.

Ductor, (Latin,) a guide, leader, or conveyor.

Eist. The countries in Asia, being east of Europe, are generally spoken of as the East, or Fistern or Oriental World.

Erlfystone lighthouse, a lighthouse built on some ridges of rocks in the English Channel, where the ocean swell is very tremendous. "ilue foundation of the lighthouse is one entire solid mass of stones to the height of thirty feet. These stones are engrafted into each other, and united by cvery incans of additional strength. 'The whole height is about eighty feet. The first lighthouse here was erected in 1(006, but it was destroyed by a storm in 170):3. Another was built in 1709, and wis destroyed in 1755. A third was erected in 1759, and withstood all the rage of the weather, till 13:30, when it was found necessary in rebuild it.

Elen, (Sir Frederic Morton,) an English statesman, and statistical 
writer, who died in London, November 11, 1809. He was ambassador to Berlin, Vienna, and Madrid, and author of several works.

Edvard II., King of England, son of Edward I., was born A. D. 1224, and died September 21, 13\%\%. He commanded the English army at the battle of Bannockburn.

Edccard $I I I$., King of England, son of the preceding, was born A. D. 1313, proclaimed King at the age of fourteen, and died June $21,13 \% \tau$

Electro-magnetic, pertaining to the science of electro-magnetism, which shows the connection of electricity and nugnetism.

Elements, Euclid's, see Euclid.

Elixir of life, see. Alchymsst.

Elizabcih, Queen of England, and one of its most celebrated Sorereigns, was daughter of Henry VIII. and born A. D. 1533. She was proclaimed Queen in 1555, and died Miarclı 24, 1603.

English. Money is calculated in pounds, (marked $\mathfrak{E}_{\text {., }}$ ) shillings, pence, and farthings. There are also guineas and cromns.

A pound contains 20 shillings, and is now worth aboul 4 dollars 87 cents.

" shilling " 12 pence, "6 "

" penny " 4 farthings, c: " "

"farthing is worth about - 0 - a d a

" guinea is worth about 5 dollars $;$ cents. A crown, about $i$ dollar 15 cents.

Epsom-salts, sulphate of magnesia. It was first procured from the springs of Epsom, in England, whence its name. It is now procured from sea water. Seé page 42.

Erusmus, (Desiderius,) a celebrated scholar, who was born in Rotterdam, October 28, I16 $\tau$, and died July $] 2,1536$.

Etruscan, belonging to Etruria, (now Tuscany,) a region of ancient Italy, on the Mediterranean, north of the Tiber. The iuhabitants were remarkable for their shill in the useful and elegant arts.

Euclid, a celebrated mathematician, who was born in Alexandria, in Egrpt, about B. C. $2=0$. He distinguished himself by his writings on Music and Geometry; and his 'Elements of Geometry' is in use at the present day.

Fac simile, an exact copy.

Fahrenhcit, (Gabriel Daniel,) a celebrated natural plilosopler, who was born at Dantzic, A.D. $16 £ 6$. He made great improvements in the thermometer; and his name is sometimes used for that instrument.

Falstuf, (sir John.) a celebrated character in Shakspeare's Drama of Henry IV.

Felspar, or Fcldspar, a constituent part of numerous rocks. Its lustre is shining, and its colors white, gray, rellowish, and reddish white. It decays readily, and forms soil, and also porcelain earth.

Fellenbcrg, (Emanuel de,) a celebrated and benerolent individnal, who established a school at Hofwyl, in Switzerland, for the instruction of young persons in the theory and practice of agriculture.

To Fclt, to unite without weaving; to make felt, or the substance of which the hodies of hats are generally composed.

Fesies, feasts.

Flosche, flesh.

Fletcher, (Andrew, a Scottish political writer and patriot, who mas born at Saltoun, Scotland, A. D. 16i33, and died in London, in 1716.

Flocculent, resembling locks of wool, down, or cotton.

Flock-bed, a bed filled with locks of wool, or pieces of cloth cut up very fine.

Fluor-syar, or fluate of lime, lime combined with fluoric acid, a beau 
tiful brittle mineral, of different colors, sometintes transparent, and generally occurring in a beautifully crystallizeo state. The most clegant is found at Derbyshire, in England, where it is wrought inte vases, candlesticks, and other ormanents; and is thence called Derbyshire spar.

Flyers, forked pieces of iron attached to the spindles of a spinning frame, the object of which is to receive the thread, twist it, and convey it to the bobbin on which it is wound.

Formule, plural of formula, a prescribed form.

Forteseue, (Sir John,) an eminent English Judge and writer on the law, who flourished in the reign of Henry VI. and Edward IV. He was made Chief Justice of the Court of King's Bench, A. D. $144:$, and wrote many valuable works. He died about A. D. 1465.

Fina, from.

Franc, a French silver coin, worth about eighteen and a half cents.

Franklin, (Benjamin,) a celebrated philosopher, patrint, and statesman, who was born January 17, 1706, in Boston, and died in Phil. adelphia, $\Lambda$ pril 17, 1790, at the age of eighty-tumr. His life will be given in one of the volumes of 'TuE Scuoul Library.'

Frce citics, cities enjoying an independent government, subjest to no person or state, and each forming an independent republic.

Frontal, belonging to, or at, the tront.

Fulcrum, the point of support on which a lever rests. See page 90 .

Fulton, (Robert,) an eminent engineer and mechanist, to whoin the world is indebted for the first successful application of steam-power to navigation. For his biography, see the fourth volume of 'THE Scinowr. Library,' Larger Séries.

Galen, (Claudius,) one of the most celebrated plysicians of ancient times, who was born at Pergamus, in Asia Minor, A. D. 131, and died about A. D. 200 . He is said to have written seven hundred and fifty works, only a part of which have been preserved.

Galileo (Galilei,) a celebrated astronomer, mathenutician, and natural philosopher, who was born at Florence, (or, as some say, at l'isa,) a city of Tuscany, in Italy, February 19,1564 , and died January 8 , 164:2, in the seventy-eighth year of his age. See "Pursuit of Knowledge under Difficulties,' forming volumes xiv. and $x v$. of 'TuE Scilool Librarr,' Larger Series.

Gulcanic, relating to Galcunism, a braneh of the science of electricity, first discovered by Galvani, a professor of Bologna, whence its name. The electricity is developed by a chemical action which takes place between certain bodies, such as plates of different metals, separated by moist pieces of cloth or an acid mixture. see Volta.

Finstric, relating to the stomach. Gastric juicc, the fluid which dissolves the food in the stomach.

Gcologist, nue skilled in geology, or the science which treats of the rocks and otler substances of which the earth is composed.

George (Augustus) II., King of Great Britaiu, son of George I. He was born $\mathrm{A}$. D. 1633, ascended the throne in 1727 , and died October $25,17(i 0$.

Girdel, a girdle.

Girdler, one who makes girdles.

Gin, a machine for raising great weights; also a nachine for cleans. ing cotton from the seed. See page 145.

Glitterande, glittering, shining, sparkling. 
Gluten, glue ; that part of the blood which gires firmness to its texture; also, a tenacious, ductile substance, procured from inost kinds of grain, as wheat, by repeated washings of the fiour in large quan. tities of water, which dissolves the fecula or starch, and leaves the gluten behind. It is the most nutritious part of regetables.

Gothic, a style of architecture principally used in churches, and which is sousetimes called the ecclesiastical style. Its principle seems to have oliginated in the imitation of groves and bowers of trees, under which the ancients performed their sacred rites. It is cliarac. terized by pointed arches, pinnacles and spires, clustered pillars, dc. See the first volume of Bigetow's 'Useful Arts,' forning the eleventh volume of ' The School Library.'

Gracieless, graceless, abandoned, wicked, without elegance.

Grcene, (Nathaniel,) one of the major-generals in the American army, during the Revolutionary War, and born in Warwick, Rhode Island, A. D. 174\%. He was the son of a blacksinith, and indebted to his own exertions for his education. His life is to be read in the history of the American Revolution. He was remarkable for personal courage, resolute frmness of mind, prudence, and judgement. He died at the age of forty-four, June 19, $17=6$.

Grete, great.

Grist, supply, quantity

Gucriclic, Otto, the most celebrated mathematician and philosopher of his time. He was born at Vlagdeburg, in Saxony, A. D. 160?, and died at Hamburg: when on a risit to that city, in $16 \leqslant 6$.

Guizot, (F.) a distunguished French statesman and writer. who was born at Nismes, October 4, 17:7. He studied law at Paris, and published several works before he attained his twenty-fith year. He engaged in public affairs, and in 1832 became a nember of the French cabinet, and afterwards prime minister.

Gymnasium, (plural gymnnasia,) a school for exercises, adapted to derelope the porrers of the body, and preserve them in perfection. The name is from the Greek rumos, (gymnos, naked,) and in the ancient gymnasia at Sparta, the young men engaged naked in the exercises, which consisted in leaping, running, wrestling, Nc.

Gypsum, or sulphate of lime, a mineral of great importance. One form of it is alabaster, employed, from its whiteness and beauty, for statuary and ornaments; another is pluster of Puris, employed for the fine plastering in the finishing of walls and ceilings, and of rreat use as a manure for land.

Hamnibul, a celebrated general of Carthage, in Africa, who was bern B. C. 243 , and died B. C. $1 \leqslant 3$.

Hurrison, (William,) an English historian, who died A. D. 1593. He was author of : An Historical Description of the lsland of Britaine, in Three Books,' prefixed to the 'Cluronicles ' of Holingshed.

Harte, (Walter.) an English divine. poet, and historian, who was born about A. D. 17 15, and died in 17\%. He published several works; annong them, 'Essays on Husbandry.'

Heather, heath, a beautiful low shrubby plant, admired on account of its lasting verdure, light foliage, and the elegance of jts flowers. It is of the genus Erica.

Heckling, or hatchelling, beating of flax, separating, tearing asunder. Hed, had, took, or went; also, the head.

IIenry, (Robert,) author of a History of England, in five volumes. He was born near Stirling, in Scotland, A. D: 1718. and died in 1790. 
Henry III., King of England, was born A. D. 1207, succeeded lis father, John, in 1216 , being only nine years old, and died in 1:25: I le was a weak prince, and unlit for his high station.

IIcnry $V$., King of Lingland, was born $A$. D. 13s8, and succeeded lis futher, lleury IV., in 1413 . He defeated the Frencl at the battle of A rincourt, (10hich see, and died in 1422.

IIcury VII., King of Enyland, born A. D. 145\%, and proclaimed King on the battle fieid of Busworth, where he had defeated the usurper, Hichard 111 , in 1455 . 11 is reigu was bencficial to his country, and he died inuch beloved, in 1509 .

IIcnry VIII., King of Lngland, was born in 1491, and suceceded his father, Henry VII, in 1509 . He was a well-educated prince, but his reign was arbitrary and tyrannical. He began the Reformation, in England. by throwing off the usurpations of the Church of Rome. He died January $23,1547$.

IIcrmbstelt, (Sigisinund Frederic.) a celebrated German chemist and writer, who was born at Erfurt, April 14, 1760.

IIcrinctically, chemically; a glass tube or other vessel is said to be sealed hermetically, when the neck is healed till it be ready to melt, and then twisted, so as to prevent the entrance of a particle of air.

Herschel, (Sir Williau,) an eminent astronomer, remarkable for his unwearied devotion to observations of the heavens, for the construction of large and powerful telescopes, and for his discovery. of the planet which has received his name. He was born in $1730^{\circ}$, and died in 102.3. His son, John F. W. Herschel, is also an able and distinguished astronomer.

IIcsiod, a celebrated poet, born at Ascra, un Bøotia, a province of Grece, about nine hundred years before Christ. He was the first who wrote a poem on agriculture, and is admired for the elegance of his diction, and the sweetness of his poetry.

Hic, ligh; to makc haste; to lasten.

IIrro, a king of Syracuse, the friend and patron of Archimedes. Ile died about B. C. 225 , in the ninety-fourth year of his age, universally regretted; and the Sicilians showed, by their lanentations, thit they had lost a common father and friend. See. Archimedes.

llirtiless, lieartless, spiritless, without courage.

Holingshed, (Raphael.) an Engrlish historian, who died about A. D. 150:2. His 'Chronicles,' first published in 1577, in two volumes, folio, luave been much celebrated.

Ilomer, a celebrated Greek paet, who is supposed to have flourished between cight lundred and one thousand years before Christ. But little satisfactory is known respecting him.

Hoslic, (Robert,) an eminent English philosopher and mathematician, who was born at Fresliwale.r, in the Isle of Wight, in 1635, and dicd in 170:2. Ilis writings are numerous and valuable.

IIopharlots, a rough, coarse cloth, like that of which are made the bags in which hops are packed.

Iforell, (Willian, LL.D.,) an English listorieal writer, who died in l6i-s. He was author of a 'History of the World,' and other works.

Inddert, (Joseph,) an eminent navigator and liydrographer, who was born A. D. I 741 , and died in IEl6. The loss of lis cables in a tempest during one of his vingages, led him to seek a remedy against similar accidents. and he invented a kind of rope whicle has since been used in the British navy.

Inume, (David,) a celebrated philosopher and historian, who was born $3.5^{*}$ 
at Edinburgh, in 1711, and died August 25, 17:6. He published 'Essays,' which are strongly tinctured with infidelity, and a 'History of England,' which luas been much celebrated, but is in many respects uniaithful, unfair, and partial; and leans towards principles utterly subrersice of all good government.

Huygens, (C'hristian,) a very celebrated Dutch mathenatician and astronomer, who was born at the Hague, in $160^{\circ}: 9$, and died in 16.55 .

Hydruulic, relating to the motion or force of water. Hydraulic press, a machine in whicls the force of water is ènplored, for the purpose of obtaining an immense pressure. For a description of this press, (also called the Hydrostatic press,) see page 64 .

$I l k$, each, erery.

Inquisition, a tribunal, or court, in some Roman Catholic countries, tor the suppression of heresies. It was at one time very powerful. It conducted all its investigations in secret, employing the inost cruel tortures to compel its victims to confess the crimes with which they were charged.

Iodine, a simple substance, of a grayish black color, and melallic lustre, having a violet-colored rapor. It is obtained from marine plants.

Irory black, or animal charcoal, the dust or shavings of irory burnt in close vessels and reduced to powder.

Jacquard, a peculiar and ingenious mechanism inrented by M. Jacquart, of Lyons, in France, to be adapted to a silk or muslin loom, for the purpose of superseding the enuployment of children for drawing the cords in weaving figured goods.

Japunned, varnished in a particular manner, called japanning.

Julius Casar, see Cosar.

Kumes, (Henry Home.) Lord, a celebrated Scotch nobleman and judge, who was born in $16 \% 6$, and died December $2 \%, 1 \%=2$. He was author of" nuan valuable works, among which were 'Essays on Criticism,' 'Art of Thinking,' The Gentlemen Farmer,' and other raluable agricultural papers.

$K c l p$, tise ashes of sea reed.

Kivderminster carpets, a particular kind of carpeting, first manufactured at Kidderminster, a market town of England.

hing post, the chief beasn under the roof of a house.

Kirtles, gowns, women's upper garments.

Knyghton, (Henry, an Fnglish historian. who flourished in the fifteenth century. He was anthor of a 'History of English Affairs,' an 'Account of the Deposition of Richard I1', Sc.

Lar, an inflammable gumuy substance produced by an insect called Coccus Lacca, and found on sereral trees in the East Indies. It is used in the manufacture of scaling max, rarnishes, Ac.

Laroisier, (Anthony Laurence,) a celebrated French chensist, who was born in 1743 . His philosophical researches were rery extensive and important to science. He was put to death as mentioned on page $11 \%$.

Lars of - Vuture, the laws or mode by which the Deity is pleased to act, in relation to the works of Nature.

Leicester, (Robert Dudley,) Earl of, the farorite of Queen Elizabeth, of England, was born in 1532, and died in September, 1505 .

Leicester, Eurl of, see Culie

Lichen, a species of moss.

Lirripipe, or Liripoop, a kind of hood, or covering for the head.

'ittell, little. 
Lond, land.

tougbierds, long beards.

Lamir dune, green or coarse manure, of which straw forms a part.

Mc.lelum roals, roads construeted of hard stones broken into small pieces and spread upon the ground, in time becoming perfectly solid. The mane is derived frum the introducer of the system.

.Hc Culluch, (John Robert,) one of the most talented British ivriters on political conomy, ac., who was born in Sentland about 17Es. He has within a few years been appointed Profe'ssor of Politicul Econ. omy at the London University.

-Maller, a dye stutt, which, by the use of different mordants, (or substanees used to fix the colors,) may be made to produce every shade of red, purple, and even black

Mugncsin, a kind of earth, light and white, with alkaline properties.

. Malic ucill, acid of apples.

Mancr, kind, sort.

- Manganesc, a brittle metal, of a dull whitish color, extremely difficult to melt, of great use in clemistry and the arts.

Manipulations, operations by hand.

Marchauntcs, merchants.

. Ware more. Bul murc, nothing more.

Mariner's compuss, an instrument for the guidance of mariners, in stceriug their course on the ocean. It was invented in the fourteentli century, previous to which time, the mariner's only guides were the heavenly bodics; and in cloudy weather he had nothing to direct lis course. Consequently he dared not venture far frem the land.

. Fuximum, the largest number or quantity, or highest point.

. Merl, a pirt or portion, a ineasure of food, or any thing else.

.Irtes, meats.

- Ifica, an elastic substance, which, when obtained in thin layers, is transparent, and used for lanterns, and sometimes for windows. It is often called isinglass.

- Mincrulized, converted into a mineral substance.

. Vinrrulogicul, relating to mineralogy.

Minimum, the smallest number or quantity, or lowest point.

Millus, less.

Alinutio, the smallest particulars.

Muryson, (Fines, an English writer, who was born A. D. 156G, and died about llit4. He published "An Itinerary, containing ten years' travels through the twelve dominions of Germany, SEc., and :A Ilistory of Ireland.'

Wuriute, a silt, containing muriatic or hydroehloric acid.

Murintic ucill, an acid composed of chlorine and hydrogen; called, also. lsydrochloric acid, and spirit of salt.

Murinte of "Immoniu, a salt composed of ammonia and muriatic acid.

.lurinte of limc, a salt componsed of muriatic acid and lime.

- Muses. There were nine deities, called Muses, in heathen mytholnuy, each of whom had the protection or patronage of some partic. ular franch of science or art: as Clio, of histury, Euterpe, of music, Thulia. of comedy, Jelponene, of tragedy, Terpsichore, of danciug, Erato, of lyric poctry, Polyhymnia, of eloquence and mimicry, Urania, of astronomy, and Calliope, of epic poetry 
They were represented as beautiful virgins, and were worshipped by the Greeks and Romans.

Niscent, grnwing, increasing, beginning to exist or grow.

Niutron, or Sodu, an alkali obtained from marine plants.

Nuture, Luzs of. See Lazrs.

Laregur, or Nafe-gar, an auger, a winuble, or instrument with which holes are bored in the naves of wheels. Sc.

- Vertor, (Sir Isaac,) an eninent English philosopher and mathematician, who was born on Christunas day, 1649, and died March 20, 172\%. He was mucli distmguished for his very important discovcries in optics and other branches of Natural Philosophy. See the first volume of 'Pursuit of Knowledge under Dithculties,' forming the fourteenth volunie of 'Thr. Scnome Librarr,' Larger Series.

- Vitrule, a salt, containing nitric acid.

Vitre, or sultpetrc, nitrate of potass, a salt used in malsing gunpowder.

Nitric ucid, an acid composed of oxygen and nitrogen.

Vilrogen, or azole, a simple substance, which exists in the atmosphere in the form of gas. It does not support respiration nor flame.

Nitruss, having the qualities of nitre. Nitrous gas, a compound of nitrugen and oxygen gases.

. Virmun Conquest. In the year 1066, William the First, Duke of Normandy, invaded England with his Norman followers, and obtained the English throne. This event is called the Norman Invasion, or Norman Conquest.

Orders in Council, (British,) orders passed in 180z, by the British gorernment in cabinet councils, subjecting to confiscation the vessels of neutrals trading to any port of France, with whom Great Britain was then at war. These orders were issued in retaliation for the French decrees, and between the two, neutral commerce suffered very considerably. See Decrees.

Orgunic, consisting of rarious parts cooperating with each other.

Orgunic remains, those animal and regetable substances found in or upon the earth in a mineralized state.

Ot $t$ s, oats.

Oxide, a compound (which is not acid) of a substance with oxygen; for example, oxide of iron, or rust of metals.

Oxidize, to combine oxygen with a body without producing acidity.

Oxyger, vital air, a simple and very important substance, which exists in the atmosphere, and supports the breathing of animals and the burning of combustibles.

Uxygenous, possessing or containing oxygen.

Oxymuriutic acid. See Chlorine.

Packing, any substance put round the piston in a pump or other tube, for the purpose of naking it water or air tight.

Prillette, a pallet, a poor or hard bed.

Popin. (Denys,) an eminent French natural philosopher, who was born in Blois, in France, about the middle of the seventeenth century. He is best known for his invention of the ressel mentioned on page 180 .

Parenchymutous, spongy.

Pariah, a low class among the Hindoos, or people of Hindoo-stan, or Hindostan. Any thing bad is thus termed by them.

Poris, (Matthew,) an eminent English historian, who wrote a Universal History, from the creation of the world to the year of his death A. D. 1259 . 
Parncl, a wanton, immodest girl.

Patent office, a public repository for the collection of newly-invented articles, and the issue of patent rights to inveutors, securing to them the privileges of their inventions.

l'erson, pease, food of peas.

Paintid, or peyn'cd, painted.

Percy, (Thomas, Bishop, an eminent prelate, who was born at Bridgenorth, England, in 1723, and died at Dromore, in Ireland, of which he was Bisliop, iu 1311. He was autlıor of 'Reliques of Ancient English Poetry,' and many other valuable works.

Pericles, a celebrated Grecian statesman, who was for forty years at the head of the $\Lambda$ thenian government. He was horn about five hundred years before Christ, and died in the seventieth year of lis arre. During his life, the arts and sciences were in their most flourishing condition in Greece, and this period of listory is frequently termed the Pcriclcun uge.

Pcrsıne, a man; generally a maı of dignity; a parson; a rector of a church. 'Pcrsoncs Talc,' 'Parson's 'Tale,' one of Chancer's Poems.

Pcter the IVild Boy, a youth found in the woods in llanover, in 1z26, and carried to England, by order of Queen Caroline. No care or pains could ever make him articulate a word.

Pctro'cum, a bituminous inflammable fluid mineral substance, resembling tar or pitch in its properties and uses.

Peynterl, painted.

Pharmaccutical, relating to the art of pharmacy, or preparation of medicines.

Philosopher's stone, see Alchymist.

Physico-mechnnico, relating to the laws of physics and mechanics.

Physics, natural philosophy.

Picrian, belonging to the Muses, who were also called l'ierides, from Mount Pierus, in Thessaly, which was sacred to them.

Pile cnerinc, an engine for driving piles, which are large wooden posts or tiubers, driven into the mud, to support bridges and other structures.

Pillingrton, (James,) Bishop, a learned English prelate, who was born at Rivington, in Lancashire, in 1520 , and died in 1575 . He was forced to flee from England, at the accession of Queen Mary, on account of his opposition to Popery; but when Elizabeth became Queen, be returned, and was soon after made Bishop of Durham.

Pinion, a suall wheel which plays into a larger; or a spindle, in the body of which are several notches, which eatch the teeth of a wheel that serves to turn it round.

Plaster of Paris, gypsum, or sulphate of lime; so called from the city of Paris, ir the vicinity of which it is abundant.

Plotinum, the heavie'st usetal yet known.

Plutonir, reliting to Plato, a celebrated Greek philosopher, who was born about B. C. 4?!), and died nn his eighty-second birthday. 1 is mame was given him, (from a Greek word, signifying broal,) on account of the breadth of his chest and forcherad.

Play of offinities, the clsemical action which takes place when compound substances are mixed, for the purpose of forming new compounds; in which ease all the substances are decomposed, and unite in a different inunner from that in which they were beforo mited.

Ploerr. a bird, the lapwing. 
Polytechnic, comprehending many arts.

Pope, (Alesander,) a celebrated English poet, who was born in Lon. don, May 22, liš, and died May $30,1 \% 44$.

Pore, or puure, poor.

Portrid, portrayed.

Puse, a cold; a stufing of the head; catarrh.

Posidonius, a plilosopher, who was born at Apamea, in Srria, about B. C. 103. He taught at Rome, where le had Cicero, and others of the most distinguished Romans for his scholars.

Potass, an alkali, composed of potassium and oxsgen.

Pntassium, a liglit and very inflammable inetal, discovered in potass, or potash, by Sir H. Davy.

Protcan, changing shape; so called from Proteus, a fabulous seadeity, who is said to have frequently changed his shape, to elude those who wished to consult bim.

Prussian blue, a strong and durable blue color, made from blood and other animal matters.

Pulp, a soft nuass.

Pyroligncous acid, an acid obtained from the smoke of wood.

Pyroxilic acid and spirit, a colorless volatile liquid, which is formed when wood is subjected to lieat. It is extensively used by hat makers.

Quurtz, an abundant rock, of which flint, rock crystal, carnelian, jas* per, sc., are specimens.

Quern, a handmill.

Quinine, a regetable alkali extracted from Peruvian bark. It is rery bitter, and is used as a medicine.

Ruleigh, or Raleglı, (Sir Walter:) an illustrious English navigator and historian, who was born in 155?. He discnvered Virginia, and rendered other eminent services to Queen Elizabeth; but in the reign of her successor, James $I$., he was persecuted, and finally beheaded, October $29,1618$.

The Reformation, that erent in the history of the Christian Church, when Protesiants separated from the Church of Rome.

Rerclosse, the raised back of a seat; a projection built out from the wall, against which to build a fire.

Residuum, the part which remains.

The Recolution, (American, the change in the constitution of govern ment, by which the United States became independent.

Rhodium, a brittle and extremely hard white metal, found in minutp quantities in the ore of platinum.

Rie, rse.

Rigg. a ridge.

Rillenhouse. (David,) a distinguished American Philosopher, who was born at Germantomn. Pennsylrania, April 8, 1732, and died June 26. 1796. For his Life, see the second volume of 'Lives of Eminent Indiriduals.' forming the fifth rolume of "TuE Scuool LI ERIRT; Larger Series.

Rabespicre. (Mlaximilian Isidore,) a revolutionary monster, who, in the French Revolution, was one of the leaders of the mob, and for a short time liad the supreme command in France, which he deluged in blood, but was himself executed in July, 1794.

Rosctle, an ornament in the shape of a rose.

Ruffie, to be in contention, to put into disorder or confusion. 
liuffer, a notorious rogue; a disorderly person; a disturber of peace and good order - also, a ruftle.

Safllower, the dried flowers of a plant called Carthanus Tinctorius. It is used in dyeing, and produces a bright red color.

Saie, say.

St. Iugustinc, or St. Austin, the first Roman Cacholic Archbishop of Canterbury. IIe was originally a monk, in a convent at Rome, and was sent to Britain by Pope Gregory, Bishop of Rome, A. D. 596 , with forty otler monks, to endeavor to bring the Bishops and Clergy of the British Church into subjection to the Church of Rome.

St. Murlin, a celebrated bishop, the first of France. Ho flourished in the fourth century, and died November 11, A. D. 400.

Sul, salt. Sal ammoniuc, a salt containing ammonia.

Salt, a vesscl to contain salt, a saltcellar.

Samblable, or scmbluble, like, resembling.

Suran, the French terin for a scientific man.

Scaliger, (Julius Casar, usually called the elder, a famous Italian pliysician and plilosopher and eninent Latin poet and critic, who was born 1. D. 1434, and died in 1558. His son, Joseph Justus Scaliger, (called the younger,) was also a great critic and learned scholar, being master of thirtecn languages.

Sclayne, slain.

Seutch, to whip, to bcat.

Scuborne, borne over the sea, brought by sea.

Sclilen, seldom.

Scmi, half: Scmi cylinder, a half cylinder.

Sencia, (Marcus Aunxus,) a learned rhetorician and philosopher of ancient Ronne, who flourished during the first half century after Christ. Ile was the tutor of the youthtil Emperor Nero. Being suspected, by that Prince, of being connceted with a conspiracy against his life, he was pint to deatl?, A. D. 66.

Seringupatum, (or Patana,) a fortified city of Hindostan. It was formerly nme of the richest cities of the kast, and supposed to have contained, in $178: 2$ to 1752, , one loundred and fifty thousand inhab. itants. There are extensive quarrics of granite in its vicinity.

Shalispeare, (William,) the most celebrated English poct and writer, who was born A. D. 1564, and died in 1616.

Share, the blade of a plough, or that part which cuts the ground.

Shell-lac, see Lnc.

Sherman, loger, one of the signers of the Declaration of American Independence, who was born at Newton, Massachusetts, April 19, 1721 , and dicd at Kew Haven, July 20, 1793. He began life as a shoemaker, and rose to many high and responsible offices.

Slinrt dung, rotted dung for manure.

Sidnry, (Sir l'hilip.) one of the most accomplished statesmen of the reien of Queen Elizabeth, and author of 'The Areadia, and several other poems. He was born A. D. 1554, and died from wounds reccived in battle, in $15 \approx 6$.

Silict, or silex, the earth of which quartz, flint, Sc., are composed.

Silicious, containing silex.

Sinclair, (Sir Juhn,) a distinguished statesman and agriculturist, whn was born in Caithness, Scotland, A. D. 1751. He was for maly years a member of Parliument, and author of many valuable orta. 
Sisyphus, a fabulous prinee of antiquity, said to have been condemned to roll up a hill a large stone, which no sooner reached the summit, than it fell baek into the plain, thus rendering his punishment eternal. The epithet is often applied to any very difficult and apparently interminable labor.

Sith, since.

Simuit, a powdered glass, of a blue color.

Smeaton, (Joln.) an eminent Fnglish mcchanic and engineer, who was born in Yorkshire, May 25, 1724 , and died September 8, 1792. He was the builder of the Eddystone lighthouse.

Smith, (Adam,) a celebrated Scottish writer on moral and political :conomy, who was born June $5,17: 23$, and died in $17 ! 0$.

Smithifid, a celebrated Square in London, in which is held the great. est cattle market in England. It is famous in history, as the place where the martyrs were burnt, in the religious persecutions of the sixteenth century.

Sinoke-juck, an instrument to turn a spit, and which is set in motion by the smoke or rarefied air ascending the climney.

Soda, or Natron, an alkali obtained from the ashes of marine plants.

Spenser, (Edmund,) a celebrated English poet, who was born in London, about A. D. 1553, and died at the age of forty-six. His great poem, called the 'Faerie Queene,' is full of beautiful sentiment and imagery, and exquisite descriptions of character.

Sphenoid, wedge shaped; the name of one of the bones of the skull. Sce cut on page 130 .

Spolie-shuxe, a sliave or knife uscd by wheelwrights and carpenters, for the purpose of shaving smooth the spokes of wheels, \&c.

Stippling, a mode of engraving by making dots or punctures in the copper, instead of cutting limes.

Stock, cattle, and other aniunals on a farm.

Sirilirs, combinations of workmen to abstain from work till they liave exacted higlier wages, or effected some other object.

Siultifiel. made foolish, deprived of understanding.

Sub, a Latin prefix, signifying under or below.

Sub-soil, the soil lying directly under the regetable soil which is on the surface.

Sulphates, Sulphats, Sulphites, salts formed by the combination of any base with sulphuric acid. See pp. 43,44 , notc. Sulphate of copper, blue vitriol; blue stone. Sulphate of iron, copperas; green vitriol. Salyhale of lime, gypsum, or plaster of Paris. Sulphate of magnesia, Epsom salts. Suiphate of polash, a chemical salt, composed of sulphuric acid and potash. Sulphute of suda, Glauber's salts. Sulphate of sinc, white vitriol.

Sulpliurcls, combinations of alkaline earths or metals with sulphur.

Sulpharic acid, nil of vitriol; vitriolic acid.

Sulphuret of potash, sulphur and potash fused together.

Sulphuruas ucid gras, a gas formed by burning sulphur in oxygen or common air, under a bell glass.

Siccdish turnip, or ruta baga, a variety of turnip, large, and of a yellowish color.

Swiche, or Swillic, such.

Tumboured, ornamented with a kind of needle-work.

Tunnin, a substance found in the bark of the oak, and almost all other trees. It is used for tanning hides, and as a dye-stuff, 
Turquins, a family who reigned in Rome, between five and six hundred years before Christ.

Themistucles, a celebrated Athenian general, who was horn about B. C. 514, and died about B. C. 44!). Jle was several years at the head of the Athenian republic, and contributed much to its security and the improvement of the capital. Being once laughed at, for his ignorance of some genteel accomplishments, he replied, "It is true, I never learned how to tune a harp, or play upon a lute; but I know how to raise a small and inconsiderable city to glory and greatness."

Theophrastus, a Greck philosoplser and moral writer, who was born at Leslos, B. C. 3\%1, and died about B. C. 286. He wrote numerous works, but few of which remain.

Togrrle-juint, an elbow or knee-joint, consisting of two bars, so con nected by a joint, that they may be brought into a straight line.

Tonies, medicines to strengthen the nerves, and give vigor to the systern.

Topical, limited, local.

Truction, the act of drawing a load; draught.

Treasury Depurtment, the Department having the care of the revenues of a country.

Trecne, (from tree,) wooden, made of wood.

Trigonometrical, pertaining to trigonometry, or the art of measuring triangles.

Tubal Cain, sec Genesis, iv. 22.

Tull, Jcthro, an English gentleman, inventor of the drill-plough, and the first writer who ever suceessfully attempted to reduce agriculthe to certain and uniform principles. He was born about A. D. 16 (is, and died January $3,1740$.

$T y / c r$, tiler, one who lay's tiles on houses.

Ulloa, (Dom Autonio de,) an able Spanish naval officer and mathematician, who was born at Seville, in 1716 , and died in 1795. He resided ten years in South America, was Governor of Louisiana, and published an aceount of his travels.

Ulmic aill, or humic acid, that peculiar substance or property in vegetable soil, which has been grenerally supposed to constitute the fuod or nourishment of plants. From reeent researches by an agricultural chemist, (Professor Liebig, of Germany,) it would appear, that, instead of heing directly the foud of plints, it is the source of the carbonic acid which serves to nourish them.

Ulysses, a celebrated ancient Grecian prince, of great valor, prudence, and sagacity. If mas King of the Jslands of Ithaca and Dulichium, in the Ionian Sea, and flourished about twelve huridred years before Christ.

The L'mited Kingrdom, Great Britain, composed of England, Scotland, and Ireland.

Ure, (Andrew, a distinguished English physician and writer, P'rofessor of" l'ractical Seience, author of " $\Lambda$ Dictionary of $A r t s$, Manufactures, and Mines,' and several other works.

Utupiun, imacrinary; from a work by Sir Thomas More, a celebrated Fuglish judge and chancellor, in which he describes the government, laws, dic., of an imaginary island, which he calls Utnpia, (frnm the Greck ierotros, outopos, no place,) giving political vicws much in advance of those of his age, and satirizing unany of tho vices and absurdities of Europe. 
Vetches, a family of plants similar to the pea.

Viaduct, a passage; a piece of masonry built across a stream or valley to support a road or railway.

Vice versa, the side being changed, or the question reversed.

Volta, (Alexander,) a celebrated experimental philosopher, who was born at Como, in Italy, in 1745, and died March 6 , 1826 . He contributed largely to the progress of science, and paid great attention to electricity. To his discovery or invention of the Voltuic pile or buttery, we are indebted for many important philosophical and chemical discoveries.

Walishmen, Welchmen.

Watt, J I $m c s$, a man remarkable for his acquisitions in science and natural philosophy, and for his improvements in the steam-engine. He was born in 1736 , and died in 1819 . For a biographical sketch of his life, see 'Pursuit of Knowledge under Difficulties,' vol. ii., forming volume $x v$. of ' The School Libraky.'

Wedgzood, (Josiah,) an eninent inprover of the manufacture of pottery, who was born in July, 1730, and died January 3, 1795. He invented the ware which is known by his name, and rendered many other services to science.

Weld, wold, yellow weed, or dyer's weed, a plant cultivated for its use in dycing yellow.

Whitney, Eli, an able and ingenious mechanician, who was born at Westborough, Missachusetts, in $\mathbf{1 7 6 5}$, and died in 1825. He was buried at New Haven, and over lis remains a beautiful monument has been erected to his memory. He was the inventor of the cotton-gin, a machine for separating the seeds from the downy fibre of the cotton, an operation previously performed slowly, and with great labor, by lıand. For a description of this nachine, see Bigelow's 'Useful Arts,' vol. i. page 111, being the eleventh volume of 'Tuf. School Library,' Larger Series. His Life will appear in a subsequent volume of this series.

Whittemore, (Amos,) the inventor of a machine for sticking cards, who died at West Cambridge, in 1823, aged sixty-nine.

Whoods, hoods, coverings for the head.

Wicler, work made of twigs or small sticks.

Willium IIT, Prince of Orange, born A. D. I650, and became King of England, in consequence of the deposition of James II., in 1689 . He died March 8, 1702.

William $I V$., King of Great Britain, was born August 21, 1765, and became King on the death of his brother, George IV., June 26, 1830. He died June 20, 1837 .

llipers, cams of a particular construction, intended to p:oduce two or more alternate movements for each revolution of the wheel.

Willrs, senseless, inconsiderate, wanting understanding.

IVollnston, (IVilliam Hyde,) a celebrated chemist and experimental philosopher, who was born A.D. 1766, and died December $22,1823$. Ile became one of the most eminent chemists and experimentalists of modern times; and invented the camera lucida, and several other valuable instruments.

Yied, went, did go.

Young, (Arthur,) a celebrated Fnglish agricultural writer, who was born September 7, 1741, and died February 20, 1820. 


\section{N D E X.}

A.

Abrasion of surfaces, 297.

Abutments, of the arch, 128.

Acceleration, uniform, of motion, 57. Laws regulating, $58,59$.

Accident, sometimes originates important inventions, 33.

Acetate of zinc, 43.

Acctous fermentation, 174.

Achromatic glass, 206. Compared with human eye, 206, 207.

Acid, humic, or uluic, 109.

Acid, sulphuric, process of manufacturing, 40.

Action and reaction, principle of, 5.1, 10.4. Euables the hird to fly, 54 .

Aeriform bodies, gravity of, acts as a moving force, 68 .

Ationities, chemical, applied to the art of dyeing, 162 .

Aftinity, definition of, 40, 103. Distinguished from cohesion, 40. Operation of, seen in soIntions, 41,103 . Action of, opposed by cohesion, 4l. Chemical combinations caused by, 41. Different degrees of, 42, 43. Application of the laws of, to the useful arts, 47, 104. Aftuity, chcmical, definition of, 40. Examples of, 40. Laws of, $41-47$. The foundation of all chemical science, 47 .

Aftinity, elective, $-13,103$. Double, example of, 43 . Lse of, in the arts, 4.1. Defined, 43, 103. Single, $43,103$.

Agents, employed in the arts, 40. Agents, chemical, obey the laws of chemical affinity, 40 ; action of, 47,104 .

Agents, mechanical, mode of action, 47, 104. Name of, 47. Enumeration of, 48, 104. Gravity of air, 68 .

Agriculture, importance of, $10 \mathrm{~s}$. Attention to, in different countries, 10s. Principles of, derived from chemistry and mechanics, 108. Application of other sciences to, 108. Errors in, aroided by scientific information, 117. Chinese, 118. Advantage of inachines in, 118 , 119. Scientific knowledge jmportant to the farmer, 116-121. Improvers of British, 117. Jgnorance of, cause of fanines, 120 ; of miserable condition of peasantry in Spain and Portugal, 120. P'rogress of, in Lingland, 121. Relative importance of, compared with commerce and manufactures, 262. Furnishes employment to a part only of population, 262. Arts and manufactures not hostile to the interests of, $2 \& 6$. Slow advance of, in Tugland, 325. Recent iuprovements in, 328 . Webster's account of itspresent state in England, 329. Applieation of chemistry to, 331 . Rotation of crops, 332. Tile draining, 33\%. Irrigation, 33s, 339. American agriculture, 341 ; inferiority of, to English and Scotch, 341 ; improrement in, 342 . 
Agriculture, chemical, 108-118. Advantages of, 116 ; illustrated by Lavoisier, 117, 118.

Agriculture, mechanical, improvensent in, 119 . Among the Greeks, 119.

Air, weight of, 68 ; application of, as a moving force, $6 \mathrm{~S}$; in the pump, 69 ; barometer, 70 ; windmills, $70, \pi 1$; flight of birds, 71. Elasticity of, 71 Action in the fire-engine, 71 , 72,105 ; in the air-gun, 72 , 105 ; in bleaching, 159 . Assists decomposition, 186 .

Air-gun, 72 .

Alchymists, jgnorant of the laws of Nature, 31.

Alcohol, combines with water, 40 ; greater aftinity for it than for camphor, 43. Dangers and evils from use of, $177-179$.

Alexander Selkirk, 10.

Alloys, use of, 194. Most common, 194.

Alsace, dyc-works in, 164.

Amalgamation of ores, 193.

Imerica, first stagecoach established in, 392.

Imericans, activity of, 379,380 .

Ancients, ignorant of the laws of Vature, 248.

Animal force, 54-56.

Animal manures, 113.

Animals, strength of, constitutes the animate forces, 54 ; causes influencing, 54 ; rules for employing, 55. Relative ralue of, 55 .

Animate forces, 5 $5-50$.

Anuealing, glass, 204.

Antiseptics, properties of, $15 i$. Examples of, 187.

Appert's process for preserving fruit. 186.

Aquedncts, ancient, 65.

Arch, unknown to the earlier architecture, 12S. First found among the Rorman, 123. An Etrascan invention, 123. Principle of, 128 . Strength of, and resistance to pressure, 129. Parts of human frame on principle of, 129-131; the foot, 129 ; the skull, 129-131.

Archimedean screw, Smith's, 246.

Archimedes, invented method of ascertaining specific gravities, 67. Boast of, 93 .

Architect, knowledge of geometry needed by, 123; of chemistry, 125. Seeks permanence in his works, 125. Should understand the principles of mechanical philosophy, 127.

Architecture, gives evidence of the prorressive powers of the nijod, 121. Of insects and quadrnpeds, 121. Of Nature, 122, 129-131, 132-134; founded on principles slowly discorered and employed by man, 122, 128. Applications of geometry to, 122-124; of chemistry, 121-126. Dependence of, on mechanical philosophr, 12\%. Gravitation a principle of, 127. The arch, 12S-131. In Egrpt, 125, 134, 135. The column, 131. Of trees, 134. Machines employed in, 134. In II provement in, the rcsult of inprovement in mechanical science, 135, 136. Of dwellinghouses much inproved, 136 , $13 \%$.

Arkwright, Richard, his obligations to science, 33,34 . Il is water-spinning-frame, 143,144 ; his invention of, disputed, 143 ; improved that of Wyatt, 143.

Armstrong, General, on manures, 114.

Arnott, Dr., on the relatire resistance of friction, in sliding and rolling motion, 234 .

Art, signification of the term, 11 . Its dependence on science, 21 ; connexion with science, 34,35 . Leading feature of modern in- 
provements in, 248. Comparison of ancient and modern, 245,249 . Modern, the offspring of scienec, 249 .

Articholic, introduction of, in England, 3.15.

Artisan, advantages of scientific information $t o, 22-34,37$; of moral aud intellectual cultivation, $35,36$.

Arts, distinction between the fine and uscful, 11. Study of, interesting and important to all, 13 ; its great advantage in the pursuit of almost every science and branch of knowledge, 14 ; of mathematical science, 14, 15 ; of political cconomy, 16 ; of listory, poetry, \&c., 16,17 . Spurious quality of substances euployed in, 27. Rapid progress of, and constant improvements in, 29, 35. Qualificalions necessary to an inventor in, 31, 32. Iuprovements iu, preceded by discoreries in science, 3.1, 35. Evils arising from neglecting the application of science to, 36 . Hependent on science, 36,37 . Substitute intelligence in place of brute force, 39. Agents employed in, 40. Importance in, of chemical combinations, 11 . Machincry cniployed in, 57-100, 105. Lnumeration of several of, 107. Agriculture one of the first of, 10s. Of working metals, 189-199; interest and inportance of, 199: not unknown in carly ages, 190 ; crmmeriltion of, 190; mining, 191, 192; dressing ores, 192; reducing, 193 ; working up metals, 194199. Of glasis-makimw, 199207. Of pottery and porcelain, 207-213. Of copying, 21:230 ; casting, 214: enuraving, 215, 216 ; puluhing, 218; drawing, 219, 220; stamping. 221 ; printing, $221-230 . \quad \mathrm{O}_{13}$ $36^{*}$ the progress of the, $246-260$ On the coumexion between the useful and fine, 303-306; in French maunfictures, $30 \cdot 1-306$. School of, at Lyons, 30t-306. Physical comfort of the people iucreased by the progress of, 341-3\%3. Schools of, iumportance of, 399. It l'aris, \&c. 399. Mnde of instruction in, 100. Troy Institute, 101.

Arts, cliemical, 294; those employed on metallic substances, 301 ; earthy, 302 ; coubustible, 302 ; saline, 302 ; on vegetable, 302 ; animal, 303.

Irts, domestic, great improvo ments iu, 1ST, iss.

Arts, fune, $11,303-306$.

Arts, liberal, their object, 19. Enuncration of, 19, 20. Usefut, in the highest sense, 20. Founded on science, 20.

Arts, mechanic, susceptible of unlimited improvement, 101.

Arts, mechanical, classification of, 295-300.

Arts, useful, connexion between them, and the physical scicnces, $11,12,18$; importance of this conmexion, 12; evils arising from a disregard of $i t, 12$. Effects produced in, by the powers of Nature, 39 . Importance of double clective alimity in, 44. Application of iaws of affinity to, 47. Eflects of the application of science to, 249258. Increased respectabilityof, 251. Ignorance of, among the Greclis, 256. Improvenients in, tend to economy, 256 . Tarilities for cultivating and inproving in Anericil, 25?, 260. influence of, on national welfire, 260, 279. Afford cmployment, 262. Finulate mind, 265. Motives for cultivation of. in Inited states, 265-275; contributes to national independener, 274. An index of 
civilization, 279. Cultivation of, in England, 2s0-292. Objections against the encouragement of, in the Lnited States, considered, 2\$3-290. Effect of the cultiration of, on morals, 289. By what means their cultivation best promoted, 290 . Classification of, 294.

Asparagus, first in England, 345. Assaying, ores, 193.

Atmosphere, pressure of, 68. Office of, to plants, 109.

\section{B.}

Babbage, Mr., quoted, 97, 99, $219,220,22 \tau$.

Pacon, Lord, anecdote of, 18. On the twofold office of man, 39. Ilis Novum Organum, 251 . On application of science to art, 252. Object of his philosophy, 395-397.

Baines, Mr., on the spinuingframe, 143. Referred to, 149 . On cotton manufacture, 151 . Cheapuess of cotton goods, 350 .

Baker's Chronicle, $3 \% 0$.

Bakewell, on husbandry, $32 \pi$.

Baking, 151 .

Barometer, princıple and use, $\boldsymbol{\tau} 0$. Beckman, on introduction of regetables in England, 345.

Beer, statistics of, 121 .

Bees, cells of, 124 .

Bell, Sir Charles, remarks of, on structure of human body, 122 . Referred to, 133.

Bellows, hydrostatic, 63.

Bergmann, first referred dyeing to chemical affinities, 162 .

Biddle, Nicholas, on manufacture of American iron, 376-38?.

Bigelow, 'Technology, 3, 201,208. Bird, support of, in the air, 54 .

Birds, feathers and wings of, 71 . Black, Dr., indebtedness of Watt to, 33.

Blacksmith, the literary, 310 .

Bleaching, of paper-rags, 154, 155,161 In general, 158-
161. By air and light, 159 By chlorine, 159. By sulphurous acid gas, 160. Of was, 160. Theory of, 160.

Blythe, 'Improver Improved,' $32 \pi$.

Body, human, wonderful structure of, 122, 129-131, 132 .

Boiling, food, 179,150 .

Bologna phials, 204.

Bone-dust, as a manure, 113,328 .

Bone-mills, 113.

Bones of the foot, 129. Of the skull, 130 ; parietal, 130 ; temporal, 130 ; sphenoid, 131 . In form of hollow crlinder, 132.

Books, facilities for obtaining, 315 .

Boring, 296.

Bowing, of furs, 139.

Bramah, lydrostatic-press, 64, 105.

Brantome's Chronicles, 363.

Bread, vinous fermentation in, $17 \%$. Mode of raising, 173.

Brewster, Dr., on the eye, 207.

Brewster, Gilbert, indebted to science, 322. Inventor of the eclipse speeder, 322.

Bricks, 20s.

British orders, injurious to American commerce, 276 .

Bronze, 194

Brougham, Lord, on importance of science in cookery, 27. Discourse on adrantages of science, 30, 34. On American manufactures, $27 \%$. His economy of time, 313.

Bruce, Joln, biscuit-machine, 172 .

Brunell, origin of invention of, 102

Drussels carpets, 139.

Buel, Judge, on root culture, 115

'Farıer's Companion,' 343.

Buhl-work, how done, 218.

Bull's ere, 203.

Busts, plaster, 214.

Butter, making of, 153,184 .

C.

Calico-machine, five-colored, 40 
Calico printing, art of, 164. Principles studied by French manufitcturers, 164. Process, 165. Four modes, 166 ; by hand, $16 \mathrm{fi}$; by the Perrotine, 166 ; - ly the eylinder, 167.

Calomel, how obtaned, 44.

Cinteron, Sir Evan, 252, 253.

Campan, Madime, her economy of time, 312.

Canal, advantiges of, compared with riil-roid, $237,238$.

Carding, process of, 148 .

Carpets, Brussels and Turliey, lıaw made, 139. Kirlderminster, 140.

Carriages, wheel, as a means of transportation, 232-235. L'se of springs in, 235.

Case, in printing-oflice, 22.2.

Calsk, pressure of water in, 63 , 64.

Cast-iron, 195.

Casts, copies unultiplied by, 213 , 214.

Cauliflower, first in England, 3.15.

Celery, brought into England, 345 .

Cementation, of iron, 195.

Cements, composition and action of, 126.

Centre of gravity, 52, 53.

Centrifugal force, a law of mation, 50. Examples of, 50. Viluable application of, $\overline{5}$.

('liaptal, on fullowing, 111, 112.

Claise, printer's, 2:21.

Chaneer, on pride of the table, 371. On the elergy, 371.

Clusese, how made, 152. Great care requisite to malie good. 182 ; Sir Joln Sinclair's remarkis on, 152.

Clemicul affinities, sce Affuity.

Chemical agents, t0-4T. Sicc Agents.

Chemical agriculture, 10S-11S.

Chennical arts, 2y.1, 301-303.

Chemical manuficture, see Minuficture.

Chemical manufactures, 40, 301.

Chemieal philosophy, iuportunce of, to cookery, 27 ; to agriculture, 109.

Clieunical processes in manufacturing closh, 158-165; in bleaching, 158-161; in dyeing, 161, 164. In the domestic arts, $171-157$.

Chenical science, see Seience.

Chemist, farmer a, 116.

Chemistry, importance of, to agriculture, 109, 116-118. Dependenca of architecture on, 122. Applieations of, to architecture, 12.1-126 ; in counteracting llceay, 125; in cements, 126. Application of, to dyeing, 162-164.

Chloride of lime, in bleaching rigs, $15 \bar{j}$; cotton, \&e., 160.

Chlorine, used as it hleaching agent, 159 ; its action, 160.

Chlorine gas, in bleaching, 154.

Chronicle, llollingshed's, on progress of luxury in England, 137, 255,347 .

Churning, attended by chemical clinnges, 183. A delicate process, 154.

Civilization, the work of industry, 247. Stite of the useful arts, an index of, 279. Iligh state of, in Finglind, 281, $28 \%$.

Clity, contracts by heat, 77. As i) manure, 112. Various kinds used in pottery and percelin, 208. Process of preparing, 208 , 209 ; shaping, 209,210 ; burning, 210 ; glazing, 211.

Cloth, mannficture of, 138. Preparation of the fibres, 138. $1 \mathrm{~V}$ eaving, $\mathrm{F}$ rions linds of, 13 ?. 1)ressing, 1+u, 1.11. Machinery used in manufacturing, 141145. Manuficture of cotton, 145-152. Chernical processes employed in inanufacturing, 158. Conifort of mankind increased by improvements in manufacture of, $163,169$.

Clawes, Messrs., rapid operation of their power-presses, 225. 
Coal, value of, 376. Abundance of, in America, $377,378$.

Coffee, introduction of, in England, 374.

Cohesion, distinction hetween it, and affinity, 40, 41. Lessened by lieat, \&c., 41 . Mechanical works founded on, 299.

Coke, Mr., his land cultivation, 334.

Colchester, condition of, in the fourteenth and nineteenth centuries compared, 360-367.

Colquhoun, on comparative morality of manufacturing and agricultural classes, 289.

Column, principles regulating the use of, 131. Advantages of the hollow cylinder form, 131, 132.

Commerce, effect of, on mational progress, 230. Fluctuations of, 272. Independence of foreign, 274. Where most flourishing, 285, 286.

Comminuting soils, 298.

Commons, or middling class, orjgin of, 308 .

Comparative expense of mannfacture of cotton in United States and Great Britian, 401.

Composition, chemical, results from active affinity, 44 . Examples of, 44 .

Compositor, work of a, 223 .

Compound motion, instances and laws of, 51,52 .

Compounds, chemical, laws of, and instances of, 42-47. Remarkable characteristic of, 45 .

Converance, water, relative advantage of, and land-conveyanec, 237, 235. Steam-boat, $213,214$.

Cookery, art of, connected with the principles of chemical philosophy, 27.

Copper-plates, 225. Copied by means of galvanic electricity, $387,388$.

Copying, art of, 213-230; by casting, 213,214 . Chief labor of, in forming the pattern, 217. By punching, 218; drawing. 219 ; wire-drawing, 219 ; tubedrawing, 219; jron-rolling, 220; stamping, 221 ; printing, 221226 ; transfer, 223,229 . In* fluence of, on welfare of humall race, 227.

Cornwall, mines of described, $191,192$.

Corrosive sublimate, a product of mercury and chlorine, 45.

Cotton, manufacture of, 145-152 ; ginning, 145. American seaisland, and upland, 145, 146 . Increased cultivation of, since the invention of Whitney's cotton-gin, 146. Statistics of, 146,169 . Processes preparatory to carding, 147. Carding, 148. Drawing and plying, 148. Roving, 148. Spinning, 149. Weaving, 150. Various transformations of, 151. Export of, 271. Effect of cultivation of, on progress of society, 393, 394. Montgomery's comparison of American and British manufacture, 401.

Cotton-mill, finest example of antomatic industry, 40.

Cradle, in agriculture, 119.

Crean, constituents of, 183 .

Creation, works of, formed on mathematical principles, 71 .

Crops, green, 111. Rotition of, 112, 332, 335. White, 332. Green, 332 .

Crystallizability, 300.

Culinary processes, 179-181; boiling, 179, 180 ; baking, 151 .

Culley, his 'Observations on Live Stock,' 327.

Culture, benefits of, to the artisan, 35, 36. Root, 115.

Cylinder, hollow, adrantage of, in the form of a column, 131133. Bones of the human frame formed on the principle of, 132 . Employed in Nature, 133.

Cylinders, for drying paper, 158 
D.

Damiani, Cardinal, strictures of, on lusury, 374.

Dams, how undermined, 65.

Dary, Sir llumphrey, "Principles of Agriculturil Chemistry,' 25. Safety lamp, 34. On manures, 113. On electricity applied to plants, 115. Improver of agriculture, 117. Application of chemistry to agriculture, 331 .

Dead water, 236.

Dean, Professor, on Buel's ' Farmer's Companion,' 343.

Decay, carres of, 124,125 ; $\mathrm{ar}-$ chitect must guard agatiost, 125. Intidotes igitinst, 125,126 . In wond, 126. legetable and animal substances liable to, 1 S5. Causes of, 185 ; moisture, 185 ; air, 186 ; heat, 187. 'l'emperature most fivorable to, 157. Arresled at freezing point, 157. Prevented by antiseptics, 187.

Deckel, 1.56.

Defoe, origin of his romance of Robinson Crusoe, 10.

Description of England, Iarrison s, 344 .

Diagnnal of a parallelogram, 51.

Digester, Papin's, 180.

Distillation, proeess of, $17 \%$.

Distilling, 297.

Divisibility, processes referrible to, $296-299$.

Division of labor, 25\%, 253.

Dixon, Joseph, discoverer of metiod of copying by transfer, 225 ; process described, 229 ; account of his discuvery, 229 ; specinens, 229. Copies of medals by, $3 \mathrm{Ss}$.

'Doctor,' quotation fiom, 350

Jolfing-cylinder, 143 .

Dothing-plate, 145.

Dollond, inventor of the achromatic glass, 206.

Donkin's pressure apparatus, 158.

Double-specder, description and use of, 149, 149.

Draining, of soils, 110,111
Draining, tile, how effected, 337. Benefits of, 337 .

Drains, sce Draining.

Drill, agricultural implement, 119.

1) ry-rot, 126.

Dupont's copying by transfer, 228.

Dyeing, a chemical proccss, 162. Dependson atiinities, 162. Use of mordants in, 163 .

\section{E.}

Eastern islands, want of iron among people of, 198 .

Economy, an effect of improvements in the arts, 25\%. Of materials, $257,25 \mathrm{~s}$.

Eden, Sir F. M., on diet in England, $34 t$. Ilis " History of the l'oor,' 361 .

Edward HH., condition of the English people during the reign of, $360-365$; of the city of Colchester, 360-365. Dress in the reign of, 371,372 .

Egypt, architecture in, 123, 134, i35. I'yramids of, 135.

Egyptians, unacquainted with the arch, 1:25; with the arts of building, 134, 135; with the use of weaver's shuttle, 142.

Elasticity, of air, 71. P'rocesses founded on, 200 .

Flectricity, assists vegetation, 115. $A$ destroying agent, 125.

Electricity, galwanic, engraving by, 35:-353. Common copperplates copied by, 357, 358 . I'recipitating metals by, applicable to various purposes in the arts, 388 ; to copying medals, $3 s s$.

Elephant, effective force of, $\mathbf{5 5}$.

Elixir of life, pursuit of, consequence of ignorance, 31 .

Elizabeth, reign of, state of the arts during, 254, 255. Dornestic accommodations, comforts, \&c., of the people duri:ng, 254,255 , $344-349$. England in the reign of 3t4-349. Ilose worn by, 
347 Clothing, lodgings, \& e., of the penple, $3+7-349$.

Embossing, process of, 226 .

Enery, in polishing glass, 205.

Employment, prodactive, dependence of national welfare, on. 262. In arts and manufictures, 263. Varieties of, 269.

Engine, beating, in paper-making,

155. Fire, how worked, 71 . Steam, sec Steam-engine. Stuff, 154.

England, hasbandry in, 10 s.

progress of laxury in, 254, 255.

Civilization in, a consequence of caltivation of the useful arts, 250-252. Prosperity of, 251. Moral condition of operatives in, 289 ; of peasantry, 289. Account of present state of agriculture in, 329-3+1. Climate and soil compared with those of United States, 329, 330 ; price of land and labor, 330,331 Agriculiural wealth of, $3+1$. Description of, in the reign of Elizabeth, 344-349; food, 344346 ; clothing, 347 ; lodgings, $347-349$. Mode of living, in the reign of Henry VII., 359 ; Edward III., $360-365,370$. Dress in, in the fourteenth century, 3il. Cotton manufacture in, compared with United States, 401.

Eugravers' plates, metlood of forming, 215 .

Fngraving, varieties of, 21.5. WVood, 215. Line, 215. Mecluanical, 215. IIezzotinto, 215 . Chemical, 215. Etching, 215, 216. Galvanic, 216. On steel, Perkins's inrention for maltiplying copies of, 22\%. By galvanic electricity, 3\$2-3\$s. Process of, described, 3\$5-3\$s.

Epsom salt, 42.

Equilibriam, unstable, 53.

Erasmus, on mode of living in England, 364.

Ericson's propeller, 246 .
Etching, process of, 215, 216

Evaporation, of sea-water, salts resulting from, 42 .

Everett, Edward, work of, referred to, 310 .

Exchanges, domestic promote national prosperity, 273,274 .

Exchanges, commercial, 2sł-286. Doinestic, $2 \$ 6$.

Expense of manufacturing cotton in America and Great Britain compared, 401.

Exploding, or blasting, 298.

Exports of United States, 272, 273.

Fve, luman, formation of, $20 \%$.

F.

Factories, heating by steam, is.

Fallowing, lands, 111,333 .

Famines, caused by ignorance and imperfection of liasbandry, 120.

Farmier, the, importance of scientific knowledge to, 24-26. A chenist, 116. Iniprored condition of, 120 .

'Farmer's Companion,' quoted, 115. Remarks on, 343 .

Feldspar, material of Chinese purcelain, 212.

Fellenberg, institution of, at Hofwyl, 400 .

Fermentation, processes dependent on, 1il. Arts connected with, 1i1. Different kinds of, 172. Vinous, instances of, $1 \div 2$, 173. Acetous, 174 .

Fibres, on twisting, weaving, Sic., 13s-140. Of flax, cotton, wool, fur, rags 139.

Fine arts, 11.

Fire-engine, how worked, 71.

Fletcher, statement of, respecting mendicancy in Scotland, 352.

Flint, constituent of glass, 200, 201.

Fluids, action of gravity through, 60. Flowing through orifices, pipes, canals, \&c., 62. Slight cohesion of, 63 . On the pressure of, 64,65 ; its equality, 63,64 . 
Level of, 65 ; a consequence of equal pressure and gravity, 65 . Specific gravity of, 67.

Fly-wheel, application of inertia, 50. Power of, 97. Use of, 98. Food, on preparing, 170, 171, 179,155 . Application of heat to, 179-181. On preserving, 155-157. Improvement of, in quantity and quality, 1S8. In England, in the reign of Elizabeth, $344-346$.

Foot, formed on the principle of the arch, 129.

Force, advantage of changing the direction of, 93 ; in steanboats, 94 .

Force, animal, 5-1-56, 104, 231. Should be employed, when possible, in preference to human, 56,231 .

Force, centrifugal, 50,51 .

Force, human, compared with animal, 56, 231. Most expensive of all forces, 56 ; least convenient, 56. Exercised without intelligence, degrades man, 56 . In the Fast, 232.

Forces, or prime movers, $4 \pi, 4 \$$, 68. Two, acting on a body in motion, 51. Employed to produce motion, 54. Regulated by machinery, 97. Of variable intensity, $9 \%$.

Forces, animate, 54,104 . Iaws regulating, 54, 55, 104.

Forces, inanimate, $56,57,71,75$, 104.

Form, in printing, 224.

Fourdrinier, Messrs., tlıeir paper machine, 157.

Franklin, Benjamin, 309, 310.

Free citics of Europe, the useful arts in, 279. Impulse given by, to civilization and liberty, 308 .

Free trade, 290, 291.

French decrees, effect on American commerce, 276 .

Friction, 232, 233. Expedients for lessening, 233 ; rolling motion, 233.
Frit, 202.

Frost, caused by evaporation, and radiativi, 116.

Fruit, preservation of, $136 ; A \mathrm{p}$ pert's process for, 186.

Fulling cloth, 140. Known to the Greeks and Romans, 141 .

Fulling-mill, 140.

Fulton, his want of scientific knowledge, 321 .

Fur, bowing of, 139.

Furnaces, defects in construction. of, 86 . Ilints for improvements in, 86,87 . llot-blast, 87 .

Fusibility, 300.

G.

Galileo, 33. Hlis application of science to art, 3.1. Discoverics of, 59, 131. Charged with Atheism, 133. On limit to size in works of art, 133.

Galley, printer's, 223.

Galvinism, 383, 384.

Gangues, of metals, 191 .

Gas, carbonic acid, necessary tc plants, 109. How generated, 110,111 . A principle of decay. 121.

Gas, chlorine, used in bleaching paper-rags, 154.

Gas, sulphurous acid, 160.

Gauze, how woven, 139.

Geometry, applied to architecture, 122-124.

fin, rolling, 145 .

Gin, saw, 145 .

Glass, 200-206. Important uses of, 200. Windows, a modem invention, 201. Milking, 201 ; blowing, 202 ; casting, 203 : moulding, 204 ; annealing, 204; grinding and cutting, 205 ; coloring and staining: $205,206$.

Glauher's salt, 42 .

Glazing pottery, process of, 211 Clinese, 211. Of stone ware, 211. l.ead, 212.

Gold, purity, test of, 67 .

Gordon, Mr., on applications of 
steam, 83-85. On steam-boat conveyance, 243 .

Governor, a regulating machine, 98.

Grain, waste of, 121.

Grainger, on Tillage, 326.

Granite, method of splitting, near Seringapatam, 27.

Granulating, 297.

Grape, yields best wine, 173, 174.

Grape-vines, furnished with electric conductors, I 15.

Gravitation, universality of law of, 13. A principle of architecture, 127. Machinery fousded on law of, 300 .

Gravity, substances acter on by, 57 ; its effect on solid bodies, 57,105 ; on projectiles, 57. Accelerating force of, 58. Acts through fluids, 60 ; examples, 60-71, 105; water-wheels, 60, 61,105 ; pipes, canals, \&c., 62,105 . Action modified by pressure of fluids, 63. One cause of the level of fluids, 65. Of aeriform bodies, $6 \mathrm{~s}$. Action of, on water, 105 ; on air, 105.

Gravity, centre of, 52. Necessity of supporting, 53. Importance of determining position of, 53 .

Gravity, specific, mode of ascertaining, 66 . Of solids 66 ; ftuids, 67. Water the standard of, 66. Advantage over air, 66 . Mode of ascertaining invented by Archimedes, 67. A test of the purity of substances, 67 .

Great Britain, slow advance of agricultural inprovements in, 325 . Increased production and accumulation of, 367-370. Statistics of population in, 367 , 368 ; of articles of consumption, \&c., 368, 369 ; of commerce, \&c., 369. Road-communication of, 391. Comparative rate of travelling in, at different periods, 391, 392. Expense of manufacturing cotton compared with the United States, 401.

Greelis, ignorance of mechanic powers, 72 ; of the useful arts, 256. Agricultural implements used by, 119. Spinning and weaving among, 141 .

Greene, Nathaniel, the blacksmith, 309.

Griffitls, Mr., on roads in Ireland, 243.

Grindstones, singular action of centrifugal force on, 50

Guinard, M., improvement of, in objectglasses, 207.

Guizot, on combination of theory with practice, 250 .

Gun, air, 72 .

Gunnery, art of, indebted to men of science, 57 .

\section{I.}

Half-stufi, 154.

Hamilton, on commercial exchanges, 284.

Hammer, tilt, velocity of, 97 .

Hand, excellence and powers of, $83,89$.

Hargreaves, Richard, introduced the spinning-jenny, 142 .

Harrison, on bread in Elizabeth's reign, 344 . On poverty in reign of Edward III., 362, 364.

Harte, Mr., 'Essays' of, referred to, 325 .

IIeat, as a mechanical agent, 75 , 105 ; expands bodies, 75,105 ; remarkable instance of its use, 75. Substances contracted by, 77. Effects of expansive power of, 78 ; sometimes injurious, 78. Effect of, on pendulums, 78; causes irregularity in clocks, 78. Changes form of bodies, 78-31, 105. Changes water to vapor, 78. An almost universal fuser, 85. Importance of, 85. Production and application of, one of the most in1portant arts, 85 ; still very imperfect, 86 ; defects in, 86,87 
On practical eeonony of, 86 . Iints on generating and usung, $86,87,105$. Service of, to plants, 115, 116. A cause of decay, $125,187$.

IIenry IV., mode of living in the reign of, $373-375$.

Henry VII., mode of living in the reign of, 359 .

IIerschel, his Discourse on study of natural philosophy, 27, 28.

Hiero, ling of Syracuse, 67.

Highlands of Scotland, miserable condition of people of, in eighteenth eentury, 354-357. Benefit of opening good roads in, 241. See Scotland.

Iistory, its neglect of state and progress of the arts, 247.

- Iistory of the Middle and IVorking Classes,' in Eugland, VVade's, 345, 346.

Ilofwyl, Fellenberg's institution at, 400 .

Ilolingshed's 'Chronicle,' on the progress of luxury in England, 137, 255, 547-349.

Home-market, adrantages of, $273,286$.

Ilorse, force exerted by, 55. Best method of einploying strength of, 55 .

Horse-power, 231.

IIot-blast, in furnaces, 87. In fusing iron, 376.

Ilot-pressed paper, $15 \%$.

Houses, improvement in, 351.

IIuman force, see Force.

Humate, 109.

IIume, on raising and use of vegetables in England, 345 .

IIumen, 110.

IInsbandry, in England, 327. Drill, introduced in England, by Tull, 327. Stock, improvement in, 327. Arable, progress of, 328. Iinplements of, 340 .

IIydrostatic bellows, principle of, 63.

Hydrostatic press, forco of, 64 ; explained, 64 .
IIy lrostatic pressure, 63,64 .

\section{I}

Ice preserves food, 187.

Ignorance, dangers of, 22 , \&c., 30,45 . Cause of failure or delay in attempted inventions or inprovements, $31,32,33$, 321,322 . Of scientific principles, 73, 74 .

Impenetrability, 299.

Implements of agriculture, 118 , 119. Improvements in, 118121. Used by the Grecks, 119. Plough, 119 ; harrow, 119 ; drill, 119 ; cradle, 119. Inventions in, 120. I'roduction increased fivefold by means of, 120.

Inclined plane, 91. Ineludes tho screw, and wedge, 91.

India muslin, 141.

Inertia, 48-50. Gradually overcome in the ease of rail-road cars, 49. Machinery, fonnded on principle of, 299,300 .

Instruction, technological, 397. I'rofessorships of, in Germany and France, 399.

Instruments, levelling, 66. l'se of, 66 .

Intellect, supremacy of, 249 .

Inventors, in the arts, qualifications for becoming, 31, 32. Names of most distinguished, 33. Generally men of science, 33, 34. Borrow hints from the works of Nature, 102.

Ireland, benefit to parts of, from improved roads, $242,243$.

Iron, value of, 189,190 . Art of working introduced into Britain by Julius Cæsar, 190. I'rocess of working ; cast ; wrought ; puddling and rolling; pigs ; case-hardening; cementation of; tempering, 195. Conversion of, into a knife-blade, 195-199. Demand for, in the Eastern islands, 198. Manufacture of, 295.

S. A. 
Iron, Aınerican, Mr. Ijiddle on manufacture of, 376-382. Application of hot-blast to fusion of, 376. Importation of, 377 , 381. Means for manufacturing in our own country, 378, 379.

Iron, cast, how converted into wrought, 96, 195.

Iron-rolling, 220.

Iron-trade, increase of, 367 .

Irrigation, 338, 339.

Italy, regetables introduced into England from, 345.

'Itinerary of England,'Moryson's, 346.

Ivory-black, 161.

$\mathrm{J}$.

Jacobi, Professor, on galvanic engraving, 383.

James I., price of provisions in reign of, 346 ; clothing worn, 347.

İ.

Kempton, Mr., on cotton manufacture in America, 271.

Kennedy, on tillage, 326 .

Kidderminster carpets, 140.

Knowledge, agency of, on luman power and happiness, 247. Characterizes modern art, 248. Increased regard paid to, 249. A necessary of life, $31 \%$. Important assistant in business, 318-322. Moral and intellec'tual advantages of, 323. Power conferred by, 324 .

L.

Labor, must be adapted to climate and position, 267. Division of, 257,283 ; favors the cultivation of the mind, 314. Price of, in United States and England, 379.

Lace, mode of weaving, 139.

Lactometer, 67.

Land conveyance, 237, 238.

Lathe, turning, 99.
La Vendée, Iavoisier's farm in, $117,118$.

Lavoisier, 117, 118. His arrest and fate, 117 .

Law of definite proportions, 46 .

Laws of affinity, 41-47.

Laws of motion, 48-54, 104, 248.

Laws of Nature, 13, 14, 21, 22, $23,31,248$.

Lead, sulphate of, how produced, 43, 44. Why so called, 44.

Lead, sugar of, its composition, 43. Results of mixing with white vitriol, 43. Employed in adultcrating wine, 175 .

Legare, Ion. H. S., speech of, $281,282,393-395$.

Leicester, Earl of, 334.

Level of fluids, 65. Principle of fountains, \&c., 65. Of levelling instruments, 66 . Sce Fluids.

Level, water, construction and figure of, 66 .

Levelling instruments, 65,66 .

Lever, the, examples of, 89,95 . Of three kinds, 89,90 . Figures of, 90. Action of, on reloci ty, 95 .

Liberal arts, 19, 20.

Light, effect of, on plants, 115.

Lime, constituent part of plants, $110,113$.

Line, chloride of, used for bleaching, 155,160 .

Line engraring, 215 .

Linen, scarcity of, in reign of Elizabeth, 317 ; of Henry ViI., $359,363$.

Liquids, their solvent property, 41,103 . Increased by heat, 41. Point of saturation in, 42 . When saturated with one substance, capable of combining with a second and third, 42 .

Lithography, process of, 216.

Locomotion, advantages of different kinds of, 230-232. Relative value of steam, as a means of, 231, 232. Wheel carriages, 
232-235. Vessels, 235, 236. Roads, 237, Sc.

London Quarterly Review, 221224.

Lothians, the, state of the people in, 356 .

Lowell, manufuctorics at, $26 \%$, 290.

Lyons, silk manuficture of, 304306. School of arts at, 30.4 .

\section{MI.}

McCulloch's 'Statistics of the British Empire,' $143,149,329$, 357. On division of labor, 283 ; on slow advance of agricultural improvements in England, 325. On clothing, food, \&c., in reign of Elizabeth, 347. On manufactures and agriculture in Scotland, 351.

Machine, calico, 40 .

Machine, new printiug, 225 .

Machinery, employed in the arts, S7-102. All composed of the three simple machines, 92,105 . U'ses of, 92-100, 105, 106 ; divides resistance, 92 ; changes direction, 93 ; changes velocity, $9.1,106$; renders motion uniform, 27, 106; accumulates force, 9S, 106 ; saves power, 98, 106 ; secures exactness in work, 99, 106 ; increases efficiency of luman strength, 99 ; of inamimate forces of Nature, 93. Further advantages of, 100 ; examples, 100 . lieasons for the invention and employment of, 105. Used in manu. fucturing cloth, Ec., 111-145. Economy of, $25 \%$. Substitution of, for luuman labor, 270 ; advantage of this, 27 .

Machines, construction of, 89 . 'Those employed in architecture, 134 ; at first very rude, 13.6. Improvenent in, 135. Advantages from the linowledge and use of, 136. Used in the manuficture of eloth, \&c.,
11-145. Those used in papermaking, 153-155; in calicoprintiıg, 165-165; in maling ship-biseuit, 171; in working iron, 197.

Machines, simple, enumeration and deseription of, 89-92, 105. Rerluced to three clisses, 92 . Applical to accumulate force, 98. Of unlimited application, 101.

Siagnitude, limit to, in works of art, 133 ; of Nature, 134.

Malt, 173.

Man, his physical inferiority to other animals, 9 ; Robinson Crusoe, 9; Ross Cox, 10. Ilis intellectual power, 10; effects of, as coöperating with the laws and powers of Viature, 11. Superior to the animals by means of the arts, 36. Agent of powers of Nature, 39, 100. Twofold office of, in regard to Nature, 39. Superiority of, to animals, 88 . llaml of, 83. 1 tool-maling animal, 89. iequires the aid of machiner 5 , 99. 11 onderful frame of, 102. Progressivo powers of his inind, shown in architecture, 122. Clothing of, 135. IIappiness and virtue of, affected by pliysical comforts, 253. Importance of study and knowledge to, 324 .

IIanual labor, not incompatiblo with study, 310 .

Mannfictories, in the United Fitates, stitisties of, 263,264 . At I.owell, 263. Division of labor in, 265. Show the closo connexion between science and industry, 266.

Minuficture, of seythes, 97. Of boxes, 99. of cloth, paper, Sc., 187-1\%0. Of India nuslin, 1.11, 1.12. Of corion, 1.15 $-152,401$. Of paper, 152-153. Of uetils, 189-199. Of glass, 199-206. Of pottery and porcelain, 207-21:3. 
Manufacture, chemical, depends on affinities, 40. Mlechanical, automatic, 10 .

Manufactares, occupation afforded by, 263. American, 27\%, 278, 285. Encouragement of, not prejudicial to intercsts of commerce and agriculture, 278 , 255, 256. Advantage of, to England, 280-282. Classification of, 294. Freach, silk, 304 -306 .

Manufactures, chemical, classification of, 301-303. Those emploved on mineral substances, 301 ; on regetable, 301,302 ; on animal, 301,303 . Of metallic substances, 301 ; earthy, 302 ; combustible, 302 ; saline, 302.

Mannre, application of, to different soils, 25. Different kinds of, 112. Tarieties of mineral, 112 ; their use, 112, 113 . Animal, kinds and nse of, 113. Vegetable, 113 ; Sir H. Dary on, 113; General Armstrong, 114. Most common, 114. Bonedust, 113, 328.

Manuscript copies of books, 227, 225 .

Maps, colored, by metal types, 226.

Marseilles quilts, mode of wearing, 140 .

Martin, General, his legacy to found a School of Arts, 306 .

Material history of man, interest of a, 247.

Wathematical sciences, connexion with the useful arts, 1t, 15 .

Iatrices, of metals, 191. Monlds, $21 \%$.

Iatter, inert, 43.

Meat, butchers', high price of, in reign of James $\mathrm{I}, 346$. Increased demand for, in Scotland, 357. Little used in reign of Heary IV., 374.

Mechanical agents, 47, 48, 68 , 104.
Mechanical agricultuıe, 119.

Mechanical manufacture, 10 .

Mechanical philosophy, deposdence of architecture on, 127 . Principles of, 12\%.

Mechanical powers, ignorance of the Greeks and Romans respecting, 72 . Principles not generally understood, 73 ; instances of this, 73, 74. Enumeration of, 89,105 ; examples of, lever, 89 ; wheel and axle, 89,90 ; inclined plane, screw, and wedge, 91 ; pulley and rope, 91. Reduced to three classes, 9?.

Mechanics, on the influence of, in the community, 30\%. Benefits conferred on society by, 308. Services of, to the cause of liberty, 309. Means of, for obtaining useful lnowledge, 312 ; time, 314 ; facilities, as books, lectures, \&c., 315. Adrantages of learning, to, 31631S. Usefulness and happiness of, proportionate to knowledge, 31\%. Knowledge, of essential serrice to, in business, 318,319 ; in providing aguinst emergencies, 320; enabling to judge of inrentions \&c., 320 ; to inrent and improre, 321 ; moral and intellectual adrantages of knowledge to, 323 .

Ilechanic's Literary and Benerolent Society, Address before, 306-325.

Mechanism, traces of, in the works of God, 101, 102.

Medals, process of stamping, 221. Copied by means of galvanic electricity, $3 \unlhd s, 3 \S 9$.

Meigle, account of the parish of, $353,354$.

Mendicancy, in Scotland, 352, 356.

IIetals, arts of working, 159-199. Value and usefulness of, 189. Processes of working, 190. Found combined with other 
substances, 190. Working of pure, 194. Casting, 194. Üsed for engraver's plates, 215 .

Mexico, architecture of, 134. Temple at, 135.

Mezzotinto, 215.

Milk, an the management of, 1S I -15.5. Il ow made into checse, 182 ; butter, 183.

Mills, wind, 71 .

Mills, cattle, used in Rome, 72.

Mlills, saw, 94 .

Millstones, curious process in France, 28.

Mind, power of, seen in the opcratious of a large factory, 266.

Mineral manures, 112, 113.

Mines, of Cornwall, description of, $191,192$.

Mines, coal and iron, in United States, 37\%, 37S.

Mining, art and processes of, 191, 192.

Moisture promotes decomposition, 185.

Montgolfier, Messrs., their mode of bleaching paper-rags, 154 .

IIontgomery's comparison of $\mathrm{A}$ merican and British cotton manufacture, 401.

Moody, Paul, a distinguished machinist, 150. Ilis warping nuchine, 150 .

Mordants, derivation of the name, 163. Ofice of, 163 . Vlode of using, 163, 164.

Moryson, his 'Itinerary of England,' 346.

Motion, laws of, 45-54, 104, 245; inertia, 48 ; centrifugal force, 50 ; degree aud direction of force applied, 51 ; when a body is acted upon by two forces, 52; principle of action and reaction, 54 . Fores enuployed, to produce, 54. Gravity as a noving force, 5\%. Uniform acceleration of, 57, 5S. Produced by gravity, 58. Uniformity of, result of machinery, 97. Roll- ing and sliding, 233. 'Through water, $235-237$. On rail-roads, 239.

Motion, compound, instances and laws of, 51, 52 .

Moulds, paper, 156.

Mountains, height of, indicated by the barometer, 70 .

Moving power, 152, 231, 232.

Mule, machine used in spinning, 149. Sclf-acting, 149 .

Iusic-printing, 225.

Muslin, India, manufacture of, 141.

\section{N.}

National prosperity, see Prosperity.

Natural philosophy, Herschel's Discourse on the study of, 27 , 28.

Nature, architecture of, 122,128 -133 . Furnishes ideas to man, $124,128$.

Naturc, laws of, the foundation of the principles on which the useful arts depend, 13, I4. Absolute and immutable, 21. Discovered and made known by science, 21. A knowledge of, essential to the artisan, 22, 23. Forbid the inventor in the arts to attempt inpossibilities, 31 , 248.

New England, manufictories in, 264 ,

New Zealani, houses in, 136.

Nimmo, Mr., on roads in Ireland, 242 .

Nomenclature, chenical, principles of, 43,44 .

Nortlyumberland, Duke of, his estahlishment, in sixtcentli century, 359, 363.

Nottinghamshirc, tile draining in, 337.

'Novam Orgaum,' of Bacou. 251.

O.

Oil has no affinity for water, 40 
Oils, essential, how procured,17\%. Uses of, 17\%.

Oleometer, 67 .

Operatives, English, moral condition of, $2 \subseteq 9$.

Ores, dressing, \&c., 192. Reducing, 193. Smelting, 193, 196. Assaying, 193.

Ox, used for farm labor, 55.

Oxides, metallic, nsed in coloring glass, 205 ; for glazing pottery, 211 ; of lead, in glass-making, 207.

\section{P.}

Paper, improvement in the manufacture of, 152, 153. Process of making, 153-15S. Sizing of, 155, 15\%. Moulds, 156 . Water-mark in, 156. Forming sheets of, 156,15\%. Hot-pressed, 157. Manufactured by machinery, $15 \%$; advantages of this mode, 15\%, 153.

Papin's digester, 180.

Parallelogram, diagonal of, described by a moring body when acted upon by tro forces, at right angles, $\delta 1$.

Parietal bones, 130.

Paris, Matthew, extravagant entertainments mentioned by, 370 , 371. On dress, 371.

Paris, plaster of, 210 .

'Parson's Tale,' Chaucer's, quoted, $37 \mathrm{I}$.

Patterns used in arts of copying, 21:-21s. Labor of making these, $21 \%$.

Pendulum, 95.

Pennsylrania, coal and iron in, $37 \%, 378$. Importance of working these, 381,382 .

I'erkins, Mr., invention of, for multiplying copies of engravings, 227.

Permeability, 299.

Perrot, M., inventor of the Perrotine, 166.

Perrotine, description of, 166 . Extensirely used, 167 .
Persians, arch anknown to, 128.

Peru, architecture in, 134.

Philosopher's stone, attempt to discover, arose from ignorance of natural laws, 31.

Philosophy, ancient and modern compared, 395-397. Ancient schools of, 395,396 . Of $\mathrm{Ba}$ con, 396.

Philosophy, mechanical, 127.

'Philosophy of manufactures,' Dr. Ure s, quotation from, 29.

Physical sciences, their connexion with the useful arts, 12, 13.

$\mathrm{Pi}$, term nsed by printers, 223 .

Piers, of an arch, 128.

Pigs, of iron, 195, 196.

Pilkington, Bishop, reproof of extravagance in dress, 375 .

Pinion, of a clock, 219.

Pinion-wire, 219.

Pipes, leaden, how made, 220.

Pitkin, his 'Statistics of the United States,' referred to, 146 .

Plane, inclined, 91.

Planing, 297.

Plants, food of, 109-115. Office of the roots of, 109, 113. Need stimulants, as light, heat, electricity, 115. Effect of light on, 115 ; of heat, 115.

Plaster of Paris, moulds of, used in making pottery, 210 ; in taking busts, 214 .

Plates, engravers', method of forming, 215 .

Plates, stereotype, how made, $21 \%$

Playfair, Dr., on the parish of IIeigle, in Strathmore, 353.

Plonghs, among the Greeks, 119. Improved, 119. Steam, 119.

Plumb-line, 57.

Plush, mode of weaving, 139.

Point of saturation, 42 .

Political economy, 16.

Pompeii, glass windows at, 201. Porcelain, clars used for, 208. Chinese, made of feldspar, 212; superiority of, 212. Philadelphia, 212. 
Posidonius, 395.

Potass, constituent principle of plants, $110,113$.

Pottery, manuficture of, 207-213. Sluaping, 209. Burning, 210. Glazing, 211. Coloring or painting, 212. Connexion of the art witl chemical science, 212. Progress of the art, 212, 213.

Powder, used in stone quarries, 135.

lower, gained by velocity, 93 . Relative value of horse, 231 ; steam, 231. Ratio of, so velocity, 237, 235; to ascent, 239.

Power, moving, in a modern fuctory, 152. Finployed in transportation, 231, 232. See Transportation.

Power, physieal, conuparative regard for, in former and present times, 249. Relative value of, and intellect, 249.

Power-presses, sec Presses.

Press, liydrostatic, 64.

Press, printing, great improvements in, 224.

Press-man, work of a, 224.

Presses, power, \&c., how worked, 225. Cireat amount of work performed by, 225. Messis. Clowes's, 225.

l'ressure, Iydrostatic, 63,64 .

Pressure of the atmosphere, 68 .

Prime movers; 4\%, 45 .

Printers' types, metil of, 194.

Printing, 99. Improrement in the art of, 221. London Quarterly Review on, 222-224. Process of, described, 2:2-2:4. Rapid improvement in art of, 225. From eavities, cxamples of, 225,226 . Of colored maps, 226. Bencfits bestowed by the art of, 227 .

Printing of calico, 164-16\%.

Printing-press, grent improvements in, 221.

Projectiles, effect of gravity on, 57.
Propeller, Captain Ericson's, 246.

Property, effect of, on national wellire, 261. Dependence of, on industry, 261 .

Proportional numbers, 46.

Proportions, definite, 46.

Prosperity, national, inflaence of cultivatien of the usefnl arts on, 261, 279-252. Productive cmployment essential to, 262.

Pulley and rope, 91. Same principle with the lever, 92.

Pulp, in paper-making, $154,155$.

Pulverization, 296.

Pump, common, principle of, 68 , $69,73$.

Punching, opcration of, 218. Instances, 2 IS.

Pyramids, of Egypt, 135. Or South America, 135.

Pyrometer, use of, 76,105 . Construction of, 77 . Invented by Wedgewood, 77.

Q.

Quarterly Revicw, London, 224

Queen Catharine, 345.

Quilts, . Iarscilles, 140.

R.

Radiation, occasion of frost, 116. Rags, paper, preparation of, 152, 153. IIode of reducing to pulp, 154, 155. Grinding, 154 Bleaching, 154, 155. Beating, 155. Economy of, 257.

Rail-roads, advantages of, 235 ; when level, 239. Ricent improvements in, 244, 215.

Rasping and chipping, 296.

liennet, $19 \mathrm{I}$.

Rensselaer Institute, 401.

Resistance, overcome by machinery, 92. Can be overcome only by greater force, 93.

Review, London Quarterly, on printing, $222-224$.

Revolution, American, stato of the army during, 275 .

Rivers, as meana of conveyance, 238. 
Roads, rail, 238, 240, 244-246. McAdam, 239. Among the ancicnts, 240 ; the Romans, 240 ; in England in time of Elizabeth, 240. Influence on the happiness and welfare of a people, 241 , \&c.; in Highlands of Scotland, 2-11; in Ireland, 243.

Roberts, self-acting mule of, 119 . Rolling-gin, description of, 145. Romans, absence of mechanic inventions among, 72. Spinning and weaving among, $14 \mathrm{I}$.

Rotation of crops, 112, 332, 335. Roving, 148.

Roving-frame, 148.

Rupert's drops, 20.4.

S.

Saggars, 210.

St. Martin, abbey of, 75 .

Sal-ammoniac, production of, 258.

Salt, common, obtained by evaporation, 42.

Salt, Glauber's, 42.

Salt, Epsom, 42.

Sand, as a manure, 112.

Saturation, point of, 42 ; importance of knowing, 42 .

Şawing, 296.

Saw-rin, described, 145. Invented by Whitney, 145. Effect of, on production of cotton, 146.

Sew-mill, 94 . Figure of, 94.

School of Arts, at Lyons, 304. At Paris, and other cities, 399.

Scloools, rural, of Switzerland and Ireland, 400 .

Science, discovers and applies the laws of Nature, 21. Importance of acquaintance with, to practical men, $24,26,25,30,31-34$, 318-324. Brougham on advantages of, 30, 3. . Progress of, 35,316 . Efrects of the application of, to the useful arts, 249-25S. Probable future discoveries of, 259. And industry, connexion between, 266.

Science, chemical, founded on laws of affinity, 47, 103.
Science, mechanical,improvement in, 13t-137. Effect of this on society, 136. Application of, to inanufacture of cloth, \&c., 138-158, 166, 167.

Scotland, mendicancy in, 352 . Miserable condition of, in the seventeenth and eighteenih centuries, 352-357 ; recent improvements, 356,357 .

Scotland, Highlands of, benefits of opening good roads, 241,242 . Scouring and cleansing wool, 161. Screw, principle of, 91. Figure of, 91 .

Scutching-machine, 147.

Scythes, manufacture of, 97.

Seneca, philosophy of, 395.

Seringapatam, grauite quarries near, $2 \%$.

Sharpe's self-acting mule, 149.

Shearing, 297.

Sheep, feed, \&c. of, 335, 336. Raising of, in England, 340 . Leicester and South Down, 340,341 .

Sherman, Roger, 309, 310.

Sherwood forest, 338 .

Ship-biscuit, process of making, $171,172$.

Shot-casting, 297.

Silica, or silicious earths, in making glass, 201 ; pottery, 208.

Sinclair, Sir John, on making cheese, 192.

Sizing, for paper, 155.

Skull, constructed on the principle of the arch, 129-131. Bones forming the, 130. See Bones. Slip, cement for pottery, 210.

Snieaton, 102.

Snelting ores, 193, 196.

Smith's Archimedean screw, 246. Smitl, Rev. Mr., acconnt of condition of Scotch in last century, $355,356$.

Soap, manufacture of, 26 .

Society, progress of, influenced by intercourse and transportation, 230, 240-243. Affected by improvements in the arts, 
$252-256,260,288,290$. Effect of cultivation of cotton on, 393-395.

Soda, a bleaching agent, 160 .

Soil, importance of water to the, 110 ; of carbonic acid gats, 111 ; and how procured, 111. On manuring, 112-114; season for this, 114. l'roductiveness of, greatly increased by culture, 117,118 . I ight, 334.

Soils, treatment and mixture of, depends on chemical principles, $25,26,109$. Means of improving, 109.

Solders, 194.

Solids, subject to action of gravity, 57, 104. Effect of gravity on, 57, 105. Specific gravity of, 66 .

Solution, power of, limited, 41 .

Solutions, show the operation of affinity, 41, 103. Principle of, $41,103$.

Solvents, liquids are, 41, 103. Water a solvent, 124 .

South America, pyramids of, 135. Weaving among the Indians of, $1+2$, nolc.

Specific gravity, 66,67 .

spencer, Thomas, on engraving by galranic electricity, $3 s 3$; his apparatus, 384,385 . Copying medals, 38s. Depositions of copper, on clay and plaster, 359 . Further experiments of, 390 .

Sphenoid bone, 131.

Spinning, among the Greeks and Romans, 141. With the spinning-wheel, 142 ; spinning-jenny, 1.12 ; spinning-frame, 143 , 144; of cotton, 142-144, 149 .

Spinning-frame, Arkwright's, 143, 144,149 .

Spinning-jenny, 142.

Spinning-whecl, 96, 1.12.

Splitting, 297.

Springs, in carriages, use of, 235. Stamping, copying by means of, 221. Medals, 221 .

Stamping-mill, for metals, 192.
Statistics, of beer, 121. Of cotton, in America, 146,169 ; in Great Britain, 169. Of manufactories in the United States, 263, 264. Of Great Britain, $36 \tau-3 \tau 0$; population, 368 ; grains and other articles of food and consumption, 368, 369; commeree, agriculture, manufactures, 369.

'Statistics of the British Eimpire,' McCulloch's, 143, 149, 329, 319-35:, 357.

Steam, how produced, 78 . In heating factories, 78 . Immense expansion of water to form, 79

As a mechanical agent, $79-84$; in the steam-engine, 80-84. Nimmerous applications of, $83-$ S5.

Steam-boat conveyance, bencfits of, $2-13$.

Steam-engine, value of, 393. Low-pressure, 80. Figure of Watt's, S1. lligh-pressure, 82, 83 ; superior advantages of, 83 . Figure of, 8.t. Advantage of, ill transportation, 231, 232.

Stcam-loom, inereasing powers of, 29 .

Steall-navigation, recent improvements in, 244.

Steam-plouglıs, 119.

Steam-power, advantage over horse-power, 231, 232.

Stcam-ships, royal mail, 244.

Steel, how made, 195, 195 .

Stereotype plates, how made, 217.

Stippling, 215.

Story, Judge, on advantages of science to a mechanic, 30,32 . Quoted, 321.

Study, manual labor no: incompatible with, 310 .

Stuff-chest, 155.

Stuff-engine, 15.1.

Subliming, 298 .

Suction pump, 69.

Sugar made fronı linen rags, 288.

Sugar of lead, 143, 175. 
Sugar-refining, new process of, 34.

Snlphate of lead, sce Lead.

Switzerland, rural schools of, 400 .

T.

'Tea, use of in England, 346 .

Tearing, 296.

Teasel, bur of, 141.

Technology, Bigelow's, 3, 201, 208. Science of, 293. Divisions of, 293.

Telescope, improvements in, 206, 207.

Telescope, tubes for, 219, 220.

Telford, Mr., on opening roads and canals, $241,242$.

Temperature, measured by thermometer, 76,105 ; by pyrometer, $76,7 \pi, 105$.

Tempering steel, 195.

Temporal bones, 130 .

'Theory and practice, 250 ; Gnizot on, 250.

Thermoneter, $76,105$.

Tile draining, 336, 337 .

Tiles, 208.

Tillage, Grainger and Kennedy on, 326 .

Tilt-hammer, 97.

Time, on husbanding, 312, 313.

Tortility, 300 .

'Transfer, copying by, 22S. Dixon's and Dupont's, 223. Wethod described, 229 .

Transferring, 212.

Iransportation, facilities for, pronote improrement and enjoyments of men, 230, 241. Moving power employed in, 231 , 232 ; human force ; horsepower ; wind and stcam, 231, 232. Vehicles used in, 232-237. Improred facilities for, 240 ; and benefits of these, 241-246.

Travelling, comparative rates of, in Great Britain, at different periods, 391, 392.

Trees, arclitecture of, $15-1$.

Triblet, 219.

Trituration, 296.
Tubal-Cain, a worker of metals, 189.

Tube-drawing, process of, 219 , 220 .

Tubes for telescopes, 219, 220.

Tull, Jethro, on turnip.;, 325. Introduced drill husbandry in England, 327.

Turkey carpets, 139, 140.

Turning, 297.

Turnips, cultivation of, 325, 333; influence of this on English agriculture, 332. Advantages of cultivating, 333. Consumption of, by shcep, 335 . Sredish, 336.

Types, making, 217. How supplied with ink, 224.

\section{$\mathbf{L}^{\top}$.}

Ulloa, on wearing among the South-American Indians, 142.

United States, natural advantages of, 268 ; varieties of soil and climate, 268 ; rivers, lakes, canals, Eic., 26s. These resources should be turned to account, 269. Peculiar advantages to, of substituting machinery for human force, 271. Expense of labor in, 271 . Water-power in, 271. Objections against encotragement of the useful arts in, considered, 2s3-290. Climate and soil of, compared with Lngland, 329, 330; price of land and labor, 330,331 . Improvement in food, clothing, \&c., 35т,35s. Coal and iron mines. 37\%, 378. Price of labor, 379 .

Ure, Dr., 'Philosophy of Manufactures,' 29. On mechanical and chemical manufacture, 40 . On spinning, 144. On heating factories, 7S. On moving power of a modern factory, 152. On use of the Perrotine, 166,167 ; on calico-printing cylinder, $16 ;$; on manufacturing districts of England and Scotland, 263, 259 
His classitication of the arts, 294-303. On silk manufacture of Lyons, 30-4-306.

Useful arts, see Arts.

V.

Valley Forge, 275.

Vegetable manures, $113,114$.

Fegetables, history of, 345 . $\mathrm{Ar}$ tichoke, asparagus, celery, cauliflower, 315.

Velicles, used in transportation, 232-237. Wheel carriares, 232 -235. Vessels, 236 .

Velocity, 50. Of moving bodies, 57-59. Increases power with loss of time, 93. Change of, by machinery, 94,95 . Nodes of increasing, $96,97$.

Velvet, how woren, 139.

Verplanek, G. C., 309.

Vessels, on motion of, in water, 236. Best form of, 236. Steam, $243,244$.

Vinegar, how made, 17t.

Vinous fermentation, 172, 173.

\section{IV.}

Viagon, centre of gravity illustrated by, 53.

Viar, of 1S12, effects of, on commerce in Lnited States, 273.

VIarp, in weaving, 139.

Washington, state of his army, 275. On extension and encouragement of manufacturing illterests, $278,291$.

Watch, balance-wheel of, 94 . Figure of, 95. Wheels of, 96.

Water, combines with alcohol, 40. Dissolves sugar, 41. Of what composed, $44,4 j$; same ingredients always in same proportions, 4j. Action on wheels, 60-62. Supply of, in a city, 62. Pressure of, 63,64 . linployed as the standard of specific gravity, 66. How raised in the pump, 69. How forced out, in the fire-engine, 71. Freezing of, 77, 78. Great expansion of, in steaur, 79. Use to soil and plants, 110. Powerful solvent, 124. Resistance of, to vessels, \&c., 236, 237; in a canal, 237 ; increases as the square of the velocity, $23 \mathrm{~S}$.

Water conveyance, 237, 238, $243,244$.

Water-level, construction and figure of, 66 .

Water-mark, in paper, 156.

Water-meadows, 338, 339.

Water-power, in United States, 271.

Water-wheels, varieties of, 60 , 61,62 .

Watt, James, 53. Figure and iiIustration of his steam-engine, S1. Origin of his flexible water-main, 102. A man of science, 322.

Wiax, bleaching of, 160 .

Wreaving, process of, 139, 140 , 150. Various kinds of, 139, 140. Among Greeks and Romans, 141 .

Webster, Danicl, on agriculture in England, 329-341.

ViVedge, principle of, 91 . Figuro of, 91. Examples of, 91 .

IVedgewood, prrometer invented by, 7 . Minufuctory of, 209. limprovements in the art of pottery, 213.

Veiglit, in a clock, 5 .

Wesley, John, 3 I 3.

THeat, 188.

Theel, overshot, 60 ; water acts on, by weight, 60 . Undershot, water acts on, by" impulse, $6 \mathrm{I}$. Breast, 61, 62. 'Toothed, and rack, 94. Balance, in a watch, 9.6, 95.

Wheel and axle, examples of, 89, 90. Principle of, 90, 95, 96. Representations of, 90 , 95, 96. Power of, 95, 96.

Wheel carriages, 232-235.

Wheel, fly, power, 97. Use, 98. Wheels, diminish resistance of friction, 233 ; in proportion 10 
their size, 234. Why dishel, Wire-drawing, 219.

235. Broad and narrow, 235. Wood-engraving, 215.

Water, varieties of, $60,61,62$. Woof, weft, or filling, 189 .

White vitriol, 13.

Whitney, Eli, 145, 146.

Wilks, J., his pulp-rollers, $15 \mathrm{~S}$.

Willett, Col. M., 310.

Willow, the, 14\%.

Wiltshire, meadows in, 338.

Windmills, $i 1$.

Window-glass, how made, 203.

Windows, glass, a modern invention, 201. Found at l'ompeii, 201. Painted, 206.

Wine, best, obtained from the grape, 173, 174. Adulteration of, 175,176 .

Wool, scouring and cleansing, 161. Dyeing, 162.

'Workingman's Companion,' 360

Workingmen, who are, 311.

Wort, 173 .

Wrought iron, 96, 195.

Wyatt, John, his patent for spinning-frame, 143.

Y.

Yolk, in wool, 161.

$Z$.

Zine, acetate of, 43.

THE E.YD. 









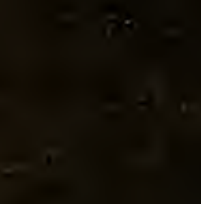

$=$

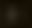

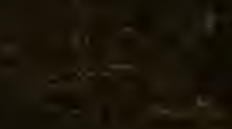

a

$=$

3
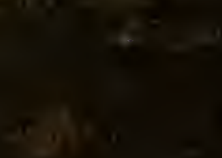

$$
\text { in }
$$
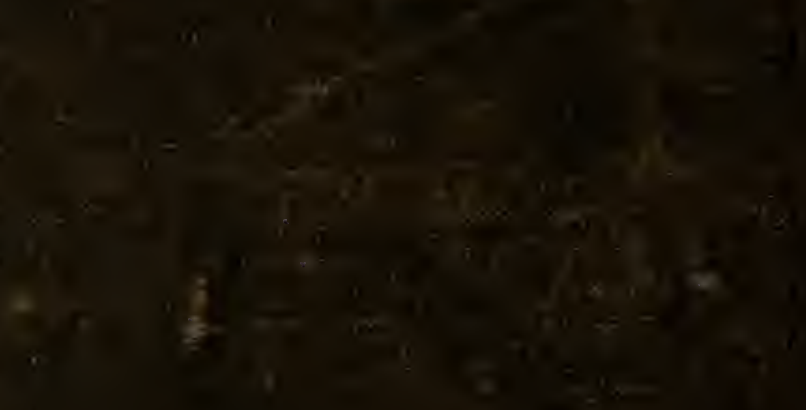